\title{
Geometry and deformation mechanisms of the Central Iberian Zone and the Iberian Central System
}

Autor:

Juvenal Andrés Cabrera
Supervisores:

Dra. Puy Ayarza

Dr. Ramon Carbonell

Tesis presentada para optar al grado de Doctor en Geología

$$
\text { por la }
$$

Universidad de Salamanca

Departamento de Geología 
Juvenal Andrés Cabrera : Geometry and deformation mechanisms of the Central Iberian Zone and the Iberian Central System (2020)

(C) This work is licensed under a Creative Commons Attribution 4.0 International License. To view a copy of this license, visit http://creativecommons.org/licenses/by/4.0/. 
Dra. Puy Ayarza Arribas, Catedrática del Departamento de Geología de la Universidad de Salamanca y Dr. Ramon Carbonell Bertran, Profesor de Investigación del Consejo Superior de Investigaciones Científicas (CSIC),

Certifican que la presente tesis "Geometry and deformation mechanisms of the Central Iberian Zone and the Iberian Central System" presentada por Juvenal Andrés Cabrera ha sido realizada bajo su dirección en el Departamento de Geología de la Universidad de Salamanca y en el Instituto Geociencias Barcelona (Geo3BCN-CSIC). Por, y con ella, opta al Grado de Doctor en Geología por la Universidad de Salamanca.

Firmado:

Firmado: 
"Thanks to my solid academic training, today I can write hundreds of words on virtually any topic without possessing a shred of information, which is how I got a good job in journalism."

Dave Barry 


\section{Abstract}

\section{Geometry and deformation mechanisms of the Central Iberian Zone and the Iberian Central System}

by Juvenal Andrés Cabrera

The Iberian Central System is an intraplate mountain range located in the Central Iberian Zone. It divides the Iberian Inner Plateau in two sectors: the northern Duero Basin and the Tajo Basin to the S. The topography of the area is highly variable, with the Tajo Basin having an average altitude of $400 \mathrm{~m}$ while the Duero Basin presents a higher average elevation of $750-800 \mathrm{~m}$. The Iberian Central System is characterized by a thick-skin pop-up and pop-down configuration formed by the reactivation of Variscan structures during the Alpine Orogeny. The high topography is, most probably, the response of a tectonically thickened crust that should be also identified by i) the geometry of the Moho discontinuity, ii) an imbricated crustal architecture, and/or iii) the rheological properties of the lithosphere. Shedding some light about these features is the main target of the current investigation.

In this work, we present a lithospheric-scale model across this part of the Iberian Massif. We have used data from the CIMDEF project, which consists of 1 to 2 months of recordings of ambient noise and teleseismic events along an almost-linear array of 69 short-period seismic stations, which define a $\simeq 320 \mathrm{~km}$ long transect. We have applied different approaches of Seismic Interferometry techniques in an effort to achieve the best resolved images of the area. The processing of the datasets provides an approximation of the zero-offset reflection response of a single station to a vertical source sending (near) vertical seismic energy.

Results indeed reveal a clear thickening of the crust below the Iberian Central System resulting from an imbrication of the lower crust that probably affects the upper crust too. This implies that the geometry of the mountain range is similar to that of other Alpine cordilleras (e.g., the Pyrenees) and that, contrarily to previous models, buckling has played a minor role in deformation. In addition, the late Variscan evolution of NW Iberia, characterized by gravitational collapse, extension and melting, has left an imprint in the crustal structure of the Central Iberian Zone that has constrained its present characteristics. On the one side, the crust is highly re-mobilized and thinner in this area, as witnessed by the calculation of the Curie-Depth Point maps presented here. Furthermore, the orogen scale mid-crustal discontinuity characterizing the Iberian Massif is probably erased or redefined in Central Iberia. This allows shallow thrusts to continue in depth, cutting across the entire crust, connecting with the lower crustal imbrication and allowing the upper crust to partly underthrust and sink. This process is, most likely, responsible of the contrasting altitude observed in the mesetas to the $\mathrm{N}$ and $\mathrm{S}$ of the Iberian Central System.

Finally, the mantle in the Central Iberia Zone is not magnetic, as it is deeper than the $580^{\circ} \mathrm{C}$ isotherm. However, it displays some sparse reflectivity that is tentatively related to the, already identified to the $\mathrm{S}$ of the CIMDEF profile, Hales discontinuity. 


\title{
Geometry and deformation mechanisms of the Central Iberian Zone and the Iberian Central System
}

\author{
by Juvenal Andrés Cabrera
}

El Sistema Central Ibérico es una cordillera intraplaca ubicada en la Zona Centro Ibérica. Divide la meseta Ibérica en dos sectores: la Cuenca del Duero al N y la Cuenca del Tajo al S. La topografía de la zona es muy variable, teniendo la Cuenca del Tajo una altitud media en torno a $400 \mathrm{~m}$ mientras que la Cuenca del Duero presenta una elevación media más alta, de 750-800 m. El Sistema Central Ibérico se caracteriza por una configuración estructural en "pop-up" y "pop-dow" formada por una tectónica tipo "thick skinned" como consecuencia de la reactivación de estructuras Variscas durante la orogenia Alpina. La alta topografía es probablemente el reflejo de una corteza tectónicamente engrosada que también debería ser identificada por, i) la geometría de la discontinuidad cortezamanto, ii) una configuración cortical que exhiba estructuras imbricadas, y/o iii) como un resultado de las características reológicas de la litosfera. El principal objetivo de esta investigación es poder discriminar y entender cada una de estas contribuciones.

En este trabajo se presenta un modelo a escala litosférica de esta parte del Macizo Ibérico. Para ello, se han utilizado los datos del proyecto CIMDEF, que consiste en la adquisición de ruido sísmico ambiental y de terremotos distantes durante 1-2 meses, a lo largo de un perfil casi lineal. Estos datos sísmicos se han registrado en 69 estaciones de corto período dispuestas a lo largo de una transecta de $\simeq 320 \mathrm{~km}$ de longitud. La interpretación de los datos se ha realizado mediante la aplicación de diferentes técnicas de Interferometría Sísmica, lo que nos ha permitido lograr imágenes, más o menos detalladas, de la estructura bajo la cordillera. La aplicación de esta técnica supone una aproximación al proceso por el cual se genera la reflectividad bajo una estación sísmica, simulando las características por las que se registra energía sísmica procedente del interior de la Tierra cuando esta incide de forma (casi) vertical.

Los resultados revelan, tal y como se esperaba, un claro engrosamiento de la corteza bajo el Sistema Central Ibérico. Este es la consecuencia de una imbricación cortical que afecta a la parte inferior de la misma y probablemente a la superior. Esto implica que la geometría de la cordillera es asimétrica, similar a la de otras cadenas alpinas (por ejemplo, los Pirineos) y que, a diferencia de los modelos propuestos anteriormente, la deformación por buckling o flexura ha jugado un papel menor en la configuración de la misma. Además, la evolución tardi-Varisca del NO de Iberia, caracterizada por un colapso gravitacional, extensión y fusión cortical, ha condicionado la estructura cortical de la Zona Centro Ibérica, afectando a la posterior evolución de la misma y, por ello, a sus características actuales. Por un lado, la corteza está altamente removilizada y es más delgada en esta área, como lo demuestra el cálculo de la profundidad a la que se encuentra el Punto de Curie, presentado como parte de esta tesis. Además, la discontinuidad que separa la corteza superior de la inferior y que se identifica a lo largo de todo el Macizo Ibérico ha sido, probablemente, asimilada por los granitoides que se encuentran bajo el Sistema Ibérico Central. Esto permite que los cabalgamientos y fallas superficiales puedan continuar en profundidad, cortando toda la corteza y conectando con la imbricación observada en la corteza 
inferior. Este hecho permitiría que la corteza superior subduzca ligeramente de manera conjunta con la corteza inferior y se hunda bajo el Sistema Central Ibérico. Este proceso es, muy probablemente, responsable del contraste de altitud que se observa entre las mesetas al N y S del Sistema Central Ibérico.

Finalmente, el manto en la Zona Centro Ibérica no es magnético, ya que es más profundo que la isoterma $580^{\circ}$ C. Sin embargo, muestra una reflectividad escasa que se relaciona, tentativamente, con la discontinuidad de Hales ya identificada hacia S del perfil CIMDEF. 


\section{Agradecimientos}

Después de cuatro años (y pico) lo único que me queda para acabar es escribir estas líneas, quizá las más complicadas.

En primer lugar agradecer a mis directores de tesis, Ramon Carbonell y Puy Ayarza, la oportunidad que me brindaron, no solo de realizar el doctorado bajo su dirección, sino también, de volver a casa. La paciencia, confianza y apoyo que habéis mostrado durante estos años me permite estar escribiendo estas líneas. A Ramon, et vull agrair la confiança ("cega" si no recordo malament) des del principi, el teu perenne somriure i l'entusiasme que has mostrat amb cada petita victòria. A Puy, en realidad sin Puy no estaría aquí, su apoyo desde que nos conocimos allá por 2011. No puedo decirte más que gracias, de todo corazón. Gracias por introducirme y empujarme a seguir en esto de la investigación. Aunque ahora me haya "desviado" un poco no dudo en que volverás a "pincharme". La energía que transmites es contagiosa. Gracias también por la libertad que me habéis dado para explorar otros campos fuera del plan inicial y por buscar lo mejor para mí en cada momento. Nos hemos llevado unas cuantas hostias, pero al final nos ha quedado resultona.

Quiero agradecer a Martin Schimmel el haberme enseñado los intríngulis de la sísmica pasiva y haberme ayudado en la transición metodológica de esta tesis. Siempre has tenido la puerta abierta, me has aconsejado y animado a probar nuevos enfoques. Sin tu ayuda, y tu software, esta tesis no hubiese llegado a buen puerto. En esta misma línea quiero agradecer a Mario Ruiz su enorme contribución a esta tesis. Els mesos de camp que m'has dedicat, les hores de preparació de material i dades són impagables. Moltes gràcies, he disfrutat molt treballant amb tu!

A los integrantes, pasados y presentes, del despacho X, (como concepto), Ignació Marzán, David Martí y Juan Alcalde. Gracias por vuestro apoyo durante este viaje. Vuestra ayuda en papers, campo o simplemente charlando, han allanado el camino. Siempre que he ido a vuestro despacho, he salido con una sonrisa en la cara. Tot i que ara està una mica més lluny del despatx vull agrair també a Imma Palomeras la seva ajuda i dedicació.

A los Almejas gracias por los cafés, las charlas y los buenos momentos, aunque en los últimos tiempos haya "desaparecido" un poco.

Quiero agradecer al Ministerio de Educación, Cultura y Deporte la financiación de esta beca FPI. Así mismo, agradecer al ICTJA y CSIC por poner a mi disposición los medios necesarios para poder realizar esta tesis. Gracias a todo el personal y en especial a Marc, Jordi y administración (Chelo, Leo, Nuria, Xavi) que me han salvado en más de una ocasión.

Many thanks to Deyan Draganov for hosting me for three months at TU Delft. Thanks for your help and guiding in the processing of the earthquake data, and for being so kind and nice. Extended thanks to Kees Weemstra and Jan Thorbecke.

A mis amigos de Cornellá y de la Uni, muchas gracias por los buenos momento que me habéis brindado durante todos estos años, y los que quedan, por el apoyo y el cariño. Yo también os quiero, aunque seáis unos gañanes. 
Este agradecimiento nunca hará justicia a lo mucho que le debo a mi padres y hermana. Gracias por ayudarme en cada paso que he dado, por vuestra bondad y por haber estado siempre a mi lado, guiándome y enseñándome, aunque nunca haya sido buen alumno. Todo es más fácil cuando sé que os tengo cerca. Gràcies també a la meva "nova família", tot i que ja són molts anys, pel seu recolzament y per estimar-me tal i com sóc.

Finalmente, gracias a tí Helena. No hay palabras para describir lo afortunado que soy de tenerte a mi lado. Has sido, eres y serás lo que me mantiene en pie, me orienta y me endereza. Cambiaste mi vida y me has iluminando desde que te conocí. Sin tí no solo no habría tesis, sino que no habría camino que recorrer. Gràcies de tot cor Mongui! Gracias por traer a Quim, que llena cada día de alegría, a costa de horas de sueño, y por los que están por llegar... Junto a Rem, el perro más peludo y bonito del mundo mundial, no hay nada que no podamos conseguir. 


\section{Contents}

Abstract $\quad$ v

$\begin{array}{ll}\text { Agradecimientos } & \text { ix }\end{array}$

\begin{tabular}{lc} 
Contents & xi \\
\hline
\end{tabular}

$\begin{array}{ll}\text { List of Figures } & \text { Xv }\end{array}$

$\begin{array}{lc}\text { List of Tables } & \text { xix }\end{array}$

1 Introduction $\quad 1$

1.1 General Context . . . . . . . . . . . . . . . . . . . . . . . 2

1.2 Objectives and Outline . . . . . . . . . . . . . . . . . . 3

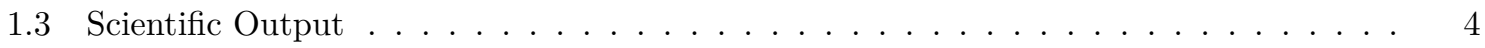

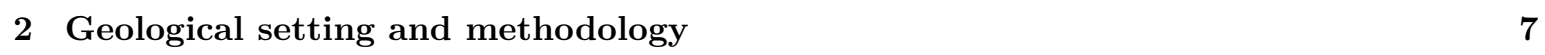

2.1 Geological Setting . . . . . . . . . . . . . . . . . . . . 8

2.1.1 Variscan Domain . . . . . . . . . . . . . . . 9

2.1 .2 Alpine Domain . . . . . . . . . . . . . . . . . . . 10

2.1 .3 The Iberian Central System . . . . . . . . . . . . . . . . . . . . 10

2.1.4 The Northern and Southern Mesetas . . . . . . . . . . . . . . . . . . 13

2.2 Geophysical Background . . . . . . . . . . . . . . . . . . . . . . 14

2.3 Geophysical Methods Applied in this Thesis . . . . . . . . . . . . . . . . . 15

2.3.1 Curie-Point Depth (CPD) Determination . . . . . . . . . . . . 15

Window Size . . . . . . . . . . . . . . . . . . 18

Fractal Exponent . . . . . . . . . . . . . . . . . . . . . 19

2.3 .2 Seismic Interferometry . . . . . . . . . . . . . . . . . 20

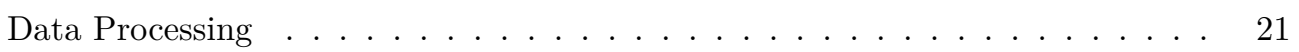

Correlation and Stacking Methods . . . . . . . . . . . . . . . . . . 22

Global Phase Seismic Interferometry . . . . . . . . . . . . . . . . . . 24

Ambient Noise Seismic Interferometry . . . . . . . . . . . . . . 28

3 Curie Point Depth of the Iberian Peninsula and Surrounding Margins 33

3.1 Introduction . . . . . . . . . . . . . . . . . . . . . . 35

3.1 .1 Magnetic Data . . . . . . . . . . . . . . . 36

3.2 Data and Methods . . . . . . . . . . . . . . . . . . . . . . 38 
3.2.1 Crustal Thickness Map . . . . . . . . . . . . . . . . 38

3.3 Results . . . . . . . . . . . . . . . . . . . . . . . . . 38

3.3.1 Comparison of Crustal Thickness with Curie-Point Depths . . . . . . . . . 41

3.3.2 Heat Flow Map . . . . . . . . . . . . . . . . . . . . . 42

3.3.3 Moho Temperature Map . . . . . . . . . . . . . . . . . . . . . . 44

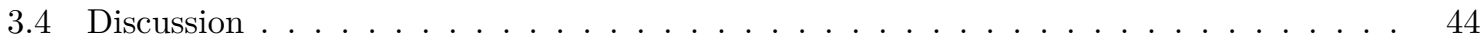

3.4.1 Betic-Rif Orogenic System/Gibraltar Arc . . . . . . . . . . . . . . . . 44

3.4 Western Mediterranean .................... 46

3.4 .3 Variscan Belt . . . . . . . . . . . . . . . . . . . . 49

3.4.4 Alpine Tectonics Domains and Atlantic Margin . . . . . . . . . . . . . . 50

3.5 Conclusions . . . . . . . . . . . . . . . . . . . . . . . . . 52

4 Global-Phase Seismic interferometry lithospheric image $\quad 53$

4.1 Introduction . . . . . . . . . . . . . . . . . . . . . . . . 54

4.2 The CIMDEF Experiment . . . . . . . . . . . . . . . . . . . . 55

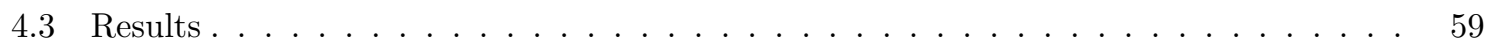

4.4 Discussion . . . . . . . . . . . . . . . . . . . . . . 62

4.4 .1 Upper Crust . . . . . . . . . . . . . . . . . . 62

4.4 Lower Crust . . . . . . . . . . . . . . . . . . 63

4.4 .3 Upper Mantle . . . . . . . . . . . . . . . . . . . . . 69

4.5 Conclusions . . . . . . . . . . . . . . . . . . . . . 69

4.A Data Selection and Processing . . . . . . . . . . . . . . . . . 71

4.B Delta Pulse Suppression . . . . . . . . . . . . . . . . . . . . . . 71

5 Ambient seismic noise lithospheric image of the Central Iberian Zone and the $\begin{array}{ll}\text { Iberian Central System } & 73\end{array}$

5.1 Introduction . . . . . . . . . . . . . . . . . . . . . . 74

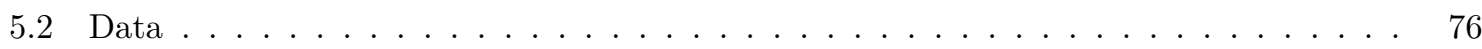

5.3 Results............................... 76

5.3 .1 Northern Segment . . . . . . . . . . . . . . . . 77

5.3 .2 Central Segment . . . . . . . . . . . . . . . . . . 77

5.3 .3 Southern Segment ........................... 78

5.4 Discussion . . . . . . . . . . . . . . . . . . . . . . 80

5.4 Crustal Features . . . . . . . . . . . . . . . 80

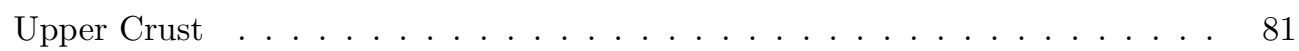

Lower Crust . . . . . . . . . . . . . . . . . . . . . . . 82

Crust-mantle Boundary ..................... . 84

Upper Mantle . . . . . . . . . . . . . . . . . . 86

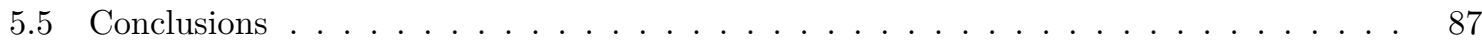

6 Discussion and Conclusions $\quad 89$ 
6.1 Crustal Extension and Melting in the CIZ: The Heritage of the Late Variscan Evolution 90

6.2 Alpine Lithospheric Structure of the Iberian Central System and its Foreland Basins . 91

6.3 Concluding Remarks . . . . . . . . . . . . . . . . . . . . . . 98

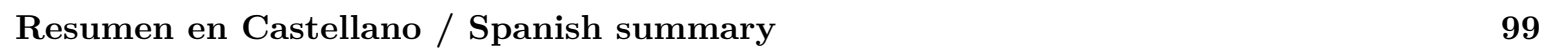

$\begin{array}{lr}\text { A Complementary publications } & 109\end{array}$

$\begin{array}{lr}\text { Bibliography } & 125\end{array}$ 



\section{List of Figures}

2.1 Simplified geological map of Iberia with major tectonic provinces and structures of the Iberian Massif. TM: Toledo Mountains, ICS: Iberian Central System, DB: Duero Basin, TB: Tajo Basin, CZ: Cantabrian Zone, WALZ: West Asturian Leonese Zone, GTMZ: GaliciaTrás-os-Montes, CIZ: Central Iberian Zone, OMZ: Ossa-Morena Zone, SPZ: South Portuguese Zone. Locations of Variscan granites and granitic zonation are taken from Simancas et al. (2013). White rectangle denotes location of Figure 2.2. . .

2.2 Simplified geological map of the ICS with the position of the stations deployed during the CIMDEF experiment. . . . . . . . . . . . . . . . . . .

2.3 Crustal structure of the ICS derived from gravity modelling (modified from de Vicente

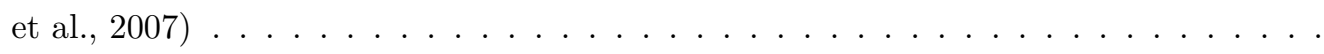

2.4 Map of previous controlled-source seismic experiments developed within the IM. The southern and northern ALCUDIA and ESCIN-2 models are used to aid in the interpretation of the CIMDEF dataset. . . . . . . . . . . . . . . . .

2.5 (a) Example of the change in the shape of the original amplitude spectrum (red line) after correction for different fractal exponents. Note the displacement of the peak from low to higher wavenumbers when increasing the exponent. In orange, the modeled spectrum using the calculated depth to the top and bottom is represented. (b) Example of a final corrected spectrum (black line) and the scaled spectrum (red dashed line) with the selected segments used to calculate $\mathrm{Z}_{\mathrm{t}}$ and $\mathrm{Z}_{\mathrm{c}} \ldots \ldots \ldots \ldots \ldots$

2.6 Distribution of the center of the window sizes used to calculate the CPD, including both $150 \times 150 \mathrm{~km} 2$ and $200 \times 200$, sizes. . . . . . . . . . . . 18

2.7 Map of the distribution of $\beta$ parameter used to calculate the CPD map. . . . . . . . . 20

2.8 Seismic Interferometry by autocorrelation applied to vertically arriving energy in a horizontally layered medium. Black arrows represent ray paths and black horizontal lines represent medium discontinuities. Parameter $t_{1}$ represents the two-way travel time between the station at the surface and the reflector $\mathrm{j}$ in the subsurface. The autocorrelation allows the retrieval of a seismogram composed of reflected energy released by a virtual source co-located at the position of the station. Each layer is heterogeneous, which is perceived by the arriving energy at times between strong arrivals. For sake of simplicity,we only show vertical-component results without reflector multiples. 
2.9 Diagram of the Earth with some of the seismic phases produced by an earthquake at 30 $\mathrm{km}$ depth and recorded by two seismic stations located at different epicentral distances $90^{\circ}$ and $150^{\circ}$. The first one records, among others, direct phases such as the direct $\mathrm{P}$ and $\mathrm{PP}$ waves with a high angle of incidence, whereas the second one records phases that travel through or are reflected at the core, such as PKIKP and PKiKP, which arrive at the station nearly vertical. . . . . . . . . . . . . . . . . 25

2.10 Workflow used to generate the stacked autocorrelations of ambient seismic noise. . . .

2.11 Power-spectral density plots of two earthquakes recorded by the CIMDEF array. They cover both ends of the used magnitudes, thus proving the existence of energy at the selected frequency band. . . . . . . . . . . . . . . . . .

2.12 Representative examples of the three approaches tested to eliminate the high-amplitude sidelobe created at $t=0$ with the resulting autocorrelation trace, and the signal extracted from the original trace. The final selected method was muting the delta pulse between 0-3 s as the deconvolution of each station wavelet, and the subtraction of the averaged wavelet did not provide consistent results throughout the profile. . . . . . .

2.13 Workflow used to generate the stacked autocorrelations of ambient seismic noise. . . .

2.14 Example of a daily autocorrelation section for a central station of the profile, showing the consistency of the retrieved reflections. On the right, the final stack is shown to compare the signal. Autocorrelations were computed using phase cross correlation within a frequency band between 1.5 to $4 \mathrm{~Hz}$. . . . . . . . . . . . . . .

2.15 Example of frequency bands tests, ranging from low frequencies (top) to higher frequencies (bottom). Coherent identified reflections are enclosed in colour bands. It is clear that, as frequency increases, more details are retrieved in the autocorrelations, while consistently capturing the main reflections. . . . . . . . . . . . . . .

3.1 Map of the total magnetic field anomalies of the Iberian Peninsula and North Africa used in this study with overlapped major tectonic areas. The data come from Getech Group Plc. Data gaps have been filled with the EMAG 2 data set (see text for merging details). . . . . . . . . . . . . . . . . . . . .

3.2 Moho map compiled from the data sets from Diaz et al. (2016), Carballo et al. (2015a), and Laske (2013). The bold lines represent geologic units as seen in Figure 3.1. . . . .

3.3 Map of the misfit between the observed amplitude spectrum and the modeled one using our CPD solutions. The Root-Mean-Square of the misfits is 0.27 . The bold lines represent geologic units as seen in Figure 3.1. . . . . . . . . . . . .

3.4 Curie-point depth (CPD) map of the Iberian Peninsula averaged from the CPD maps calculated with window sizes of $150 \times 150 \mathrm{~km}^{2}$ and $200 \times 200 \mathrm{~km}^{2}$. The map shows the thickness of the magnetic layer. The isolines correspond to contours of the CPD. The bold lines represent geologic units as seen in Figure 3.1. . . . . . . . . . . . . . 
3.5 Map showing the differences between the crustal thickness and the Curie point depth (CPD) (Figure 3.4). Negative values (red) correspond with CPD (Fig. 3.4) deeper than the Moho (black dashed line). Positive values (orange/green/blue) represent CPD above the Moho. The bold lines represent geologic units as seen in Figure 3.1 . . . . .

3.6 Surface heat flow has been calculated as a one layer problem when the Moho is deeper than Curie point depth (CPD) and as a two layers problem when CPD is deeper than the Moho. We assume that heat production $(\mathrm{A})$ and thermal conductivity $\left(k_{\mathrm{c}}\right.$ for the crust and $k_{\mathrm{m}}$ for the mantle) are constant. . . . . . . . . . . . . . . . .

3.7 Heat flow map of the Iberian Peninsula and surrounding areas derived from the CPD map presented in Figure 3.4. The bold lines represent geologic units as seen in Figure 3.1. The white lines represent heat flow trends measured by Fernández et al. (1998). .

3.8 Moho temperature map of the Iberian Peninsula and surrounding areas derived from the CPD map presented in Figure 3.4. The bold lines represent geologic units as seen in Figure 3.1. . . . . . . . . . . . . . . . . . . . . . .

3.9 (a) $S$ - wave velocity of the upper mantle as a function of degree of serpentinization. The red dots represent laboratory measurements by Christensen (1966); the grey dots are based on Vs velocities from Palomeras et al. (2017). (b) Degree of serpentinization of the upper mantle. The extent is derived from the Curie-point depth/crustal thickness offset, and the percentage is obtained from Figure 3.9a . . . . . . . . . . .

3.10 Curie-point depth map of the Iberian Peninsula overlain with outcropping Variscan granites (white polygons) and the Alboran Domain volcanism (dashed white polygons). The bold lines represent geologic units as seen in Figure $3.1 \ldots \ldots$. . . . . . . .

4.1 Colour-coded earthquakes $(M w \geq 5)$ used for the three deployments. There were 17 earthquakes (blue stars) used for the central deployment, 38 (purple stars) for the southern segment, and 26 (orange stars) for the northern part of the profile. Polar plots represent the back azimuth of selected earthquakes for each deployment. . . . . .

4.2 (a) Reflectivity profile retrieved by global-phase seismic interferometry. In the wiggle plot, the grey lobes indicate positive polarity. On top is the lateral extent of the geological areas crossed by the profile and the boundaries of the granitic magmatism. Coloured triangles represent the different acquisition stages (from $\mathrm{N}$ to $\mathrm{S}$ : third, first, and second deployments). (b) Interpretation of the lithospheric reflectivity profile. Solid lines represents coherent continuous stable features, and dashed lines indicate possible features. The blue line marks the boundary between the upper crust and the lower crust. The red line is the crust-mantle boundary. Scattered reflectivity within the upper mantle is marked by the dashed green lines. . . . . . . . . . . . . .

4.3 Zoom in of the reflectivity profile retrieved by global-phase seismic interferometry presented in 4.2. In the wiggle plot, the grey lobes indicate positive polarity. The blue line marks the boundary between the upper crust and the mid-lower crust. The red line is the crust-mantle boundary. . . . . . . . . . . . . . . . . . . 
4.4 Sketch of the proposed crustal geometry, overlapped with Moho results from gravity inversion and receiver function (RF). (a) Model where the South Central System Thrust (SCST) and the Tiétar River Fault (TRF) lie within the upper crust and only the lower crust imbricates; (b) model where the entire crust imbricates below the ICS. . . . . . .

4.A.1Comparison of the image of the central segment created with all the earthquakes (left) and only with those $M w \geq 6$ events (right) . . . . . . . . . . . .

4.B.2Approaches to eliminate the influence of the delta pulse at $t=0$. 1 ) deconvolution for each station of the wavelet, 2) subtraction of the average wavelet of all the station, 3 ) muting of the wavelet. . . . . . . . . . . . . . . . .

5.1 Topographic map of the ICS, DB and TB, to the $\mathrm{N}$ and $\mathrm{S}$ respectively, overlapped by the available seismic datasets in the area, and the situation of the recording stations deployed during the CIMDEF experiment (triangles) . . . . . . . . . . . . .

5.2 a) Reflectivity profile retrieved by autocorrelation of ambient seismic noise. In the wiggle plots, the grey lobes indicate negative polarity. Coloured triangles placed over a topographic section represent the different acquisition stages (from $\mathrm{N}$ to $\mathrm{S}$ : third, first, and second deployments). b) Interpretation of different reflectors, which are labelled between A-F. A marks the boundary between the upper crust and the lower crust. B represents the interpreted depth extension of granites below the ICS. C marks an intracrustal reflector within the lower crust. D is the crustmantle boundary. E represents a key $\mathrm{S}$ verging thrust affecting the southern end of the ICS. F marks the scattered reflectivity within the upper mantle. . . . . . . . . . . . . . . .

5.3 Sketch of the proposed crustal structure below the Iberian Central System, and the Duero and Tajo Basins. . . . . . . . . . . . . . . . . . . . .

6.1 Model for the lithospheric folding for continental lithosphere, modified after MuñozMartín et al., 2010. To the right, strength profile for a two layer continental crust. . .

6.2 Interpreted seismic sections created in this thesis. Top, lithospheric image result of applying GloPSI to the CIMDEF dataset. Bottom, reflectivity profile derived from autocorrelations of ambient seismic noise. Both images are presented together to compare the interpreted major boundaries, e.g., the upper-lower crust and crust-mantle

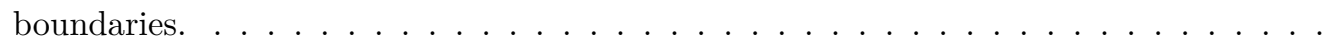

6.3 Comparison of the topography across three Alpine mountain belts within IB. The Pyrenees and the Cantabrian mountains are characterized by subduction of just the lower crust, while in the ICS the whole crust underthrusts. Only the latter shows lower topography on the underthrusting (southern) side than to the $\mathrm{N}$, evidencing differences in the way the whole crust responds to Alpine compression. . . . . . . . . . . .

6.4 Sketch of the proposed crustal structure below the Iberian Central System and the Duero and Tajo Basins, along with the continuation towards the northern ESCIN-2 profile (Pulgar et al., 1996), modified from Gallastegui et al., 2016, and the correlation of the crust-mantle boundary and the mid-crustal detachment. . . . . . . . . . . . 


\section{List of Tables}

2.1 Parameters used in the processing of earthquake recordings $\ldots \ldots \ldots 26$

2.2 Parameters used in the processing of ambient seismic noise $\ldots \ldots \ldots \ldots$

4.1 Selected earthquakes used to apply Seismic Interferometry. . . . . . . . . . . . . 57 



\section{List of Abbreviations}

$\begin{array}{ll}\text { DB } & \text { Duero Basin } \\ \text { CIZ } & \text { Central Iberian Zone } \\ \text { CZ } & \text { Cantabrian Zone } \\ \text { CPD } & \text { Curie-Point Depth } \\ \text { GTMZ } & \text { Galicia Tras-Os-Montes Zone } \\ \text { Hales } & \text { Hales discontinuity } \\ \text { HF } & \text { Heat Flow } \\ \text { IB } & \text { IBerian Peninsula } \\ \text { ICS } & \text { Iberian Central System } \\ \text { IM } & \text { Iberian Massif } \\ \text { Moho } & \text { Mohorovičić discontinuity } \\ \text { OMZ } & \text { Ossa-Morena Zone } \\ \text { SCST } & \text { Southern Central System Thrust } \\ \text { SI } & \text { Seismic Interferometry } \\ \text { SPZ } & \text { South Portuguese Zone } \\ \text { WALZ } & \text { West Asturian-Leonese Zone } \\ \text { TB } & \text { Tajo Basin } \\ \text { TRB } & \text { Tiétar River Basin } \\ \text { TRF } & \text { Tiétar River Fault } \\ & \end{array}$



Chapter 1

\section{Introduction}




\subsection{General Context}

The present configuration of the topography of the Iberian Peninsula is the result of its tectonic evolution, subsurface processes, and recent surface processes. The current elevation is the outcome of the Alpine orogeny that took place during the Cenozoic as the result of the convergence between the African and Eurasian plates. However, the response of the crust to the applied forces, is strongly influenced by its previous configuration, inherited from the Variscan orogeny and post-Variscan tectonics.

The lithospheric structure of the Iberian Peninsula (hereinafter IB) remains an interesting area of study within the Earth-Sciences. In its westernmost part, the Iberian Massif (IM) presents an almost complete outcropping section of the Varican orogeny, which resulted from the Devonian-Carboniferous collision between Gondwana, Laurentia and some peri-Gondwana terrains. Later on, the Alpine orogeny, occurred during the Cenozoic, reactivated Variscan structures and accordingly shaped the current topography of Iberia.

The lithosphere is the uppermost part of the Earth and it is composed by the crust and the upper mantle. The structure of this layer plays a crucial role in the current configuration of the topography of Iberia. The lithospheric structure of Iberia has been largely studied by different seismic techniques, e.g., controlled source seismic studies (Ayarza et al., 2004; Ayarza et al., 1998; Banda et al., 1981; Carbonell, 2004; Ehsan et al., 2014, 2015; Flecha et al., 2009; Julià and Mejía, 2004; Martínez Poyatos et al., 2012; Palomeras et al., 2009, 2011, 2014; Pulgar et al., 1996; Simancas et al., 2003; Suriñach and Vegas, 1988), receiver functions (Mancilla and Diaz, 2015), shear wave tomography (Palomeras et al., 2017), etc. Also, potential field modelling, e.g., (de Vicente et al., 2007; Torne et al., 2015) has been used to unravel the crustal structure of the lithosphere of the Iberian microplate. Most of these studies have focused mainly on the southern and northern parts of the IB. Among those studies, only the regional study of de Vicente et al. (2007) and the large-scale studies of Mancilla and Diaz (2015), Diaz et al. (2016), Palomeras et al. (2017) and Torne et al. (2015) cover the interior of Iberia.

The IM has been studied by active seismic experiments since the early 90s. First the ESCIN project sampled the northern part of the IM with five profiles, some of them onshore and some sampling offshore areas of the orogen. After that, the IBERSEIS project carried out between the 2000 and 2003, studied the southern portion of the IM with a Wide-Angle (WA) experiment as well as with Normal Incidence (NI) data. Finally, the ALCUDIA project (2007-2012), acquired WA a NI data starting in the northern part of the IBERSEIS transect and extending to the southern limit of the Iberian Central System. This configuration left a significant gap in the Central Iberian Zone, between the ALCUDIA profile and the ESCIN transects to the N, which has remained unsampled until now. The lack of detailed seismic data has hindered the complete comprehension of the current lithospheric structure of the IM and its evolution.

This thesis presents results from the recently completed CIMDEF project (2017-2019) that was designed to acquire natural and controlled source seismic data across the central segment of the IM, 
and represents a link between the northern and southern seismic datasets.

\subsection{Objectives and Outline}

The work presented in this thesis aims to provide constraints on the lithospheric structure of the Iberian Central System (ICS), located within the Central Iberian Zone (CIZ), and its relationship with its northern and southern foreland Duero and Tajo basins (DB, TB), respectively. The thickness of the crust and the structural configuration below the mountain range are key points to understand the topography of central IB. Furthermore, the configuration of the crust below its foreland basins gives insights on the evolution of the mesetas and their topography during the Variscan and Alpine orogenies. Overall, these are important parameters in order to explain the tectonothermal evolution of this part of the Iberian microplate and to infer how the features inherited from the Variscan orogeny affected the evolution of the crust during the Alpine orogeny. With this goal, several geophysical techniques have been used, each of them providing unique constraints on different physical properties and aspects of the lithosphere. The integration of potential field and seismic methods has proven to be powerful enough to constrain the central IB structure and geometry.

According to the above presented goals, this thesis is organized in five chapters. In chapter $2 \mathrm{a}$ summary of the geological and geodynamic setting is presented, explaining the current knowledge of the lithospheric structure of the ICS as well as the Cenozoic DB and TB. Furthermore, the methodologies used in this thesis are introduced and explained, aiming to give the appropriate background for the following chapters.

In chapter 3, I analyse the thermal structure of the IB by means of magnetic data inversion. Although the main objective of this thesis is the study of the ICS, this chapter evaluates the entire IB as the technique itself requires wide datasets to be reliable and less affected by edge effects during the processing. Nonetheless, this has allowed us to explore the thermal structure of IB and its surrounding margins and account for the long wavelengths magnetic/thermal anomalies. Within this study, a complete map of the $580^{\circ} \mathrm{C}$ isotherm for IB is created along with a heat flow (HF) map and a map of the temperature at Moho depth. All these results provide useful constraints to the crustal thickness of central IB.

The next two chapters are based on results obtained by means of seismic interferometry (SI) methods geared to image the lithosphere beneath the ICS and surrounding basins, using natural sources, as seismic ambient noise and earthquakes.

In chapter 4 we zoom into the ICS structure configuration as observed by passive seismic imaging methods. This chapter presents the dense CIMDEF passive seismic array that samples the ICS and its foreland basins. The profile crosses the central CIZ within the IM, and the Cenozoic DB and TB. The data acquisition and processing workflow has been previously explained in chapter 3 . The energy source used in this part of the experiment to generate the seismic profile is that of teleseismic earthquakes. The retrieved reflectivity profile shows two major crustal boundaries: the limit between 
the upper and the lower crust and the crust-mantle boundary. Furthermore, the dataset indicates that an imbrication of the crust below the ICS exists, giving constraints on the mechanisms that gave rise and support the mountain belt.

In chapter 5 the CIMDEF profile is revisited. However, this time the energy source used for the interpretations is the ambient noise wavefield, which produces an image similar to that of chapter 4 but better resolved. Both images are complementary and therefore, similarities are observed. For instance, the above indicated crustal scale boundaries are also retrieved within this dataset, although differences exist. A key aspect that in the former dataset explains these differences, is the use of higher frequencies in this profile $(1.5-4 \mathrm{~Hz})$ in the latter dataset, which gives a finer crustal structure as more details could be retrieved.

Whereas at the end of each chapter, discussion and conclusions are presented, chapter 6 summarizes the main conclusions and findings of this thesis, and gives an outlook for the future.

\subsection{Scientific Output}

As output of this thesis, three scientific articles have been published in peer-reviewed scientific journals indexed in the "Journal Citation Report" of the Institute for Scientific Information (ISI-JCR), and another one is ready for submission as an invited paper in the Gondwana Research journal. These papers form the core of the thesis. Furthermore, another paper was published during the development of this thesis. Although it is not directly related with the main topic it evidences the broad knowledge that has been acquired in the fields of geophysics, geology, data processing and interpretation while developing research to reach this Ph.D. degree. This latter contribution is also included in the annexes.

- Andrés, J., I. Marzán, P. Ayarza, D. Martí, I. Palomeras, M. Torné, S. Campbell, and R. Carbonell, 2018. Curie Point Depth of the Iberian Peninsula and surrounding margins. A thermal and tectonic perspective of its evolution, Journal of Geophysical Research: Solid Earth, $n / a-n / a$, doi: 10.1002/2017JB014994.

- Andrés, J., Draganov, D., Schimmel, M., Ayarza, P., Palomeras, I., Ruiz, M., and Carbonell, R., 2019. Lithospheric image of the Central Iberian Zone (Iberian Massif) using Global-Phase Seismic Interferometry, Solid Earth, https://doi.org/10.5194/se-2019-10\%.

- Andrés, J., Ayarza, P., Schimmel, M., Palomeras, I., Ruiz, M., and Carbonell, R.: What can seismic noise tell us about the Alpine reactivation of the Iberian Massif? An example in the Iberian Central System, Solid Earth Discuss., https://doi.org/10.5194/se-2020-94, in review, 2020.

- Andrés, J., Ayarza, P., Palomeras, I., Martí, D., Marzán, I., Carbonell, R., Poyatos, D.J.M., Yenes, M., Gonzalez-Lodeiro, F. Geometry of the crust in an intra-plate orogen: The Iberian Central System. In preparation to be submitted to Gondwana Research as an invited Focus paper.

Other research developed during the thesis but not related with the main topic: 
- Andrés, J., Alcalde, J., Ayarza, P., Saura, E., Marzán, I., Martí, D., Martínez Catalán, J. R., Carbonell, R., Pérez-Estaún, A., García-Lobón, J. L., and Rubio, F. M, 2016. Basement structure of the Hontomin CO2 storage site (Spain) determined by integration of microgravity and 3-D seismic data, Solid Earth, 7, 827841, https://doi.org/10.5194/se-7-827-2016. 

Chapter 2

Geological setting and methodology 
This chapter is divided in two main sections. The first one is devoted to give an introduction to the geological/geodynamic context of the Iberian Peninsula (IB), with a main focus on the Iberian Central System (ICS) and the Cenozoic Duero and Tajo basins (DB/TB). Furthermore, a review of the available geophysical knowledge of IB is presented to contextualize the resulting findings of this thesis. This information is relevant in chapters 3,4 and 5 as the results of the magnetic data inversion, and the application of Seismic Interferometry to different datasets are presented and the implications discussed.

In the second section I will give an overview of the methodologies used in this thesis, starting with the workflow used to calculate the Curie-Point Depth (CPD) which will be presented in chapter 3 . Later, I will introduce Seismic Interferometry (SI) and give an outline of the workflow and procedures applied to properly use this technique for seismic imaging, as explained in chapter 4 and 5 .

\subsection{Geological Setting}

The IB, in western Europe (Fig. 2.1), is geologically bounded by the Pyrenees and the Gulf of Biscay to the $\mathrm{N}$ and by Africa to the $\mathrm{S}$. From a tectonic point of view, it can be divided in, i) Variscan Iberian Massif (IM), outcropping at its western half, forming the main IB basement, ii) Alpine mountain chains, including the Pyrenees, and the Iberian and Betic cordilleras, iii) the western Mediterranean area that includes the Gibraltar Arc, the Algerian Basin, and the Valencia Trough and the Balearic Promontory; and iv) Atlantic domains, namely, the Gulf of Cadiz, the western Iberian Atlantic margin, and the Bay of Biscay.

The geological framework of the ICS is marked by the footprint of two orogenies that affected the area, namely, the Variscan orogeny and the Alpine orogeny. The former, took place during the Late Paleozoic times by the collision between Laurussia and Gondwana (Matte, 2001), which closed the Rheic Ocean and amalgamated these continents along with other minor terranes like Armorica (Franke, 2000; Matte, 2001) to define the Pangea supercontinent. These terrains constitute the basement of the IB, and are composed by Upper Proterozoic to Carboniferous rocks deformed and intruded by granites.

Later, the Permian-Triassic extensional period led to the desegregation of Pangea (Van Wees et al., 1998; Ziegler, 1990) which formed new plate boundaries. As a result, during the Cenozoic, IB was a microplate enclosed between the African and Eurasian plates. The relative movement of the African plate in a NNW direction, compressed the Iberian plate (between 65 and 2.5 million years) and led to the inversion of previously generated intraplate basins, and the formation of the Pyrenean-Basque-Cantabrian range, the southern Betic range and the intraplate ICS and Iberian chains. 


\subsubsection{Variscan Domain}

The Variscan orogen is the result of the collision of different continental blocks (Gondwana, Laurussia and peri-Godwanan terranes) during the end of the Paleozoic (Franke, 2000; Matte, 2001). This collision also closed the Rheic Ocean that separated the continents. Accordingly, the basement of the IB is composed by rocks formed during the Upper Proterozoic until Carboniferous times, deformed and intruded by granites as a consequence of the Variscan orogeny.

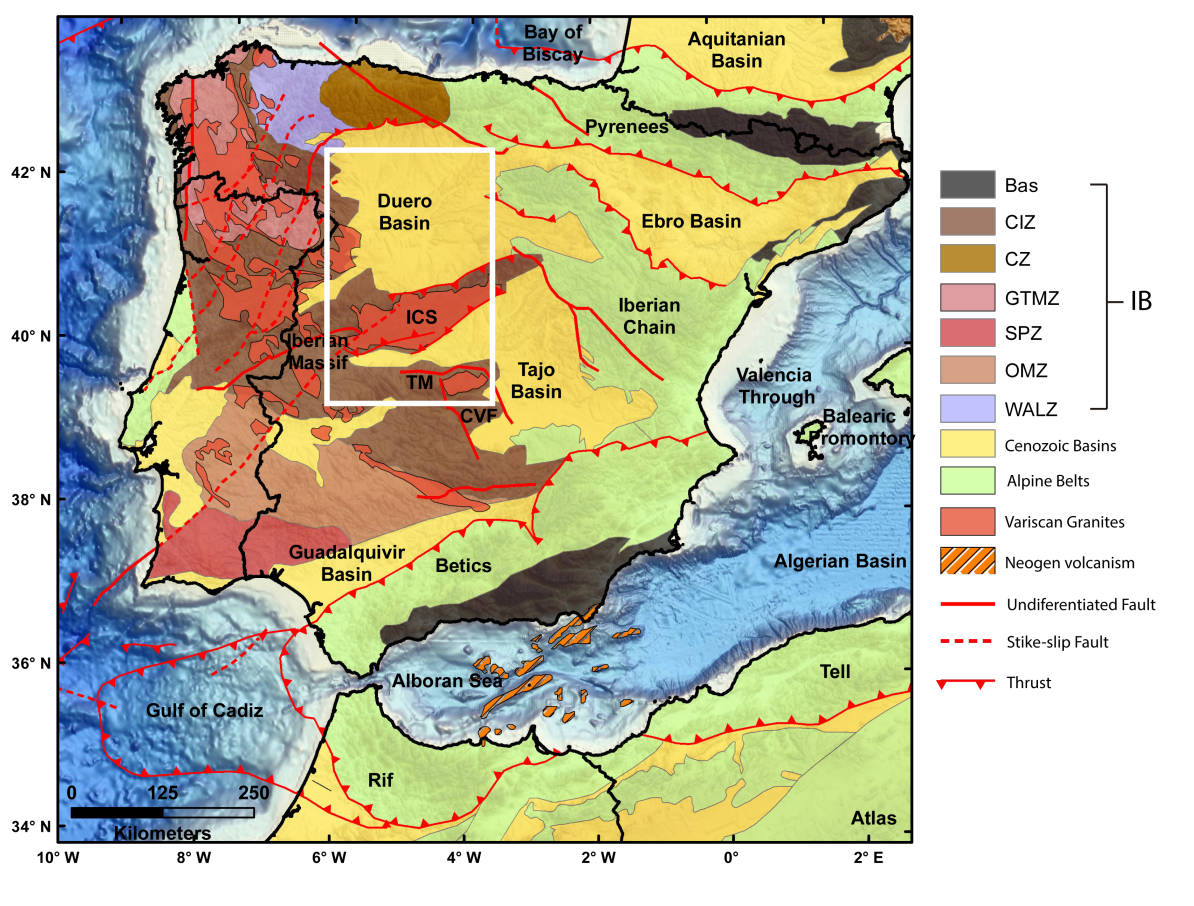

FIGURE 2.1: Simplified geological map of Iberia with major tectonic provinces and structures of the Iberian Massif. TM: Toledo Mountains, ICS: Iberian Central System, DB: Duero Basin, TB: Tajo Basin, CZ: Cantabrian Zone, WALZ: West Asturian Leonese Zone, GTMZ: GaliciaTrás-os-Montes, CIZ: Central Iberian Zone, OMZ: Ossa-Morena Zone, SPZ: South Portuguese Zone. Locations of Variscan granites and granitic zonation are taken from Simancas et al. (2013). White rectangle denotes location of Figure 2.2.

The IM represents the most complete outcrop of the Variscan Belt in Europe. Its main tectonic units are, from $\mathrm{N}$ to $\mathrm{S}$ (Fig. 2.1): The Cantabrian Zone (CZ), the West-Asturian Leonese Zone (WALZ), the Galicia Tras-os- xMontes Zone (GTMZ), the Central Iberian Zone (CIZ), the OssaMorena Zone (OMZ) and the South-Portuguese Zone (SPZ) (Julivert, 1972). The CZ and the SPZ are interpreted as the foreland fold and thrust belts, while the rest of the areas correspond to the internal zones of the orogen. The GTMZ is an allochthonous unit which overlies the CIZ, and it is composed by Gondwana terrains and ophiolites corresponding to vestiges of oceanic crust, with high-pressure metamorphism (Martínez Catalán et al., 2014). These rocks, together with those found between the SPZ, OMZ, and CIZ, suggest the existence of one or more sutures (Simancas et al., 2013). From these domains, the CIZ, CZ and WALZ represent continental portions of a passive margin along Gondwana. Overlying the CIZ, the GTMZ is a relic of the Rheic Ocean formed partly by ophiolites. 
The OMZ is interpreted as a ribbon continental domain that drifted to some extent from Gondwana. Finally, the SPZ is interpreted as a fragment of Laurussia.

Our study area is located within the CIZ, which is the widest among them as it is bended, defining an orocline known as the Central Iberian Arc (Martínez Catalán, 2011). The CIZ is divided in two zones (Díez Balda, 1990): The Ollo de Sapo Zone to the N and the Schist-Grauwaquic Complex to the S (Díez Balda, 1990). The former is characterized by high-grade metamorphism and deformation (Barbero and Villaseca, 2000), and a vast volume of Carboniferous granites (Bea, 2004), whereas the latter, shows NW-SE trending upright folds and faults and a much more moderate volume of granites.

\subsubsection{Alpine Domain}

The Alpine domains were formed after the collision between Eurasia and Africa involving the Iberian microplate, which was disaggregated during the breakup of Pangea in the Mesozoic. As a result, some Variscan areas were reactivated and uplifted,e.g., the Pyrenees, the ICS, and Cantabrian Mountains. The Betic-Rif orogenic system together with the Alboran Domain is a complex compressionalextensional area formed by the collision between Africa and the Iberian microplate. Different models have been proposed to explain the geodynamics of the collision between Africa and Eurasia, which led to the formation of these Alpine chains. Although there is a general agreement on slab roll-back as the primary mechanism to account for the tectonic evolution, two main models have been proposed to explain the current tectonic configuration of the arc and the kinematic evolution of the orogen. Rosenbaum et al. (2002) proposed a model where the Alboran domain migrated from $\mathrm{E}$ to $\mathrm{W}$ by subduction rollback. The second hypothesis (Vergés and Fernàndez, 2012) suggests that the Alboran Domain was originated from a SE dipping subduction of the crust from the Ligurian Tethys, and the consequent rollback toward the NW. Various geophysical studies portray a delaminating slab attached at the Betics and Rif (Palomeras et al., 2014; Thurner et al., 2014), where a thickening of the crust is observed (Diaz et al., 2016).

The intraplate mechanism of accommodation of the Alpine deformation in IB has been proposed to be folding of the lithosphere in undulations of 200 ( $\pm 50 \mathrm{~km}$ ) wavelenght (Cloetingh et al., 2002; de Vicente et al., 2007; Muñoz-Martín et al., 2010). A second hypothesis was proposed to explain the thickening and rise of the crust in the ICS (Quintana et al., 2015). These authors claim that a detachment level runs from the Betic mountains to the $\mathrm{S}$ or the Pyrenees to the N. This solution would mean that a simple shear with a detachment at some crustal level would accommodate the shortening and provide the mechanism to favor the uplift of the ICS.

\subsubsection{The Iberian Central System}

The ICS is considered an intra-plate orogen located in between the Betic and the Pyrenean chains, all Alpine in age. It lies along ca. $700-\mathrm{km}$, from Lisbon (Portugal) to Sigüenza (Spain) with a ENEWSW trending stair case geometry of ranges (up to $2500 \mathrm{~m}$ high) (Fig. 2.2). This outstanding feature divides the high plains of central Iberia into two mesetas: The Duero Basin (DB) to the $\mathrm{N}$ and the 
Tajo Basin (TB) to the S. These are considered, depending on the classifications as major Cenozoic intraplate basins (Friend, 1996; Gibbons, 2002). The DB has an average altitude of 750-800 m, while to the $\mathrm{S}$ of the mountain range, the TB has an average topography of approximately $400 \mathrm{~m}$. Thus, a topographic step of $\simeq 400 \mathrm{~m}$ occurs across the $50 \mathrm{~km}$ wide ICS. The contact of the ICS with both plateaus occurs along major thick-skinned faults, namely the northern and southern thrusts, although the latter seems to accumulate higher displacement.

The ICS features a basement uplift consisting on blocks bounded by high-angle faults and deformed by thick-skinned tectonics which accommodate part of the crustal shortening. As a result, it presents a pop-up/pop-down geometry where high elevations alternate with valleys occupied by rivers. A vast volume of Carboniferous granitoids is concentrated in the ICS (Bea, 2004). Researchers conclude (de Vicente et al., 2007, 2018) that this basement uplift structures are in agreement with the localization and distribution of strain. Alpine tectonics have, most probably, reactivated existing structures generated during the Variscan orogeny. Thus the general configuration of this mountain range is an integrated response of Variscan and Alpine tectonics.

The ICS stands in the most internal part of the CIZ, an area with a complex Variscan tectonic evolution that includes important thickening, extension and thermal re-equilibration along three stages of compressional deformation (C1, C2, and C3) and two extensional phases (E1 and E2) that represent the gravitational collapse of a thickened crust (Alcock et al., 2009; Martínez Catalán et al., 2009; Martínez Catalán et al., 2014). The first contractional stage (C1) took place during late DevonianCarboniferous times and is characterized by the formation of overturned and recumbent folds in the $\mathrm{N}$ and is associated with thickening. The second contractional event $(\mathrm{C} 2)$ developed during the lower Carboniferous and is characterized by the formation of thrusts faults and ductile shear zones, also predominantly in the $\mathrm{N}$. The most important expression of this stage is the emplacement of the GTMZ allochthonous complexes. During the final part of this stage, the thickened crust underwent heating that triggered an extensional event (E1) and partial melting of the crust. As a result, extensional detachments and gneiss domes started to form. Contractional event 3 (C3) took place during upper Carboniferous times, and developed large scale shear zones and vertical E-W folds. The last extensional stage (E2) was characterized by the transition from ductile to brittle extension (Martínez Catalán et al., 2014). During E2, late gneiss domes and extensional detachments formed. During and after E2, a vast volume of late to post-kinematic granitoids were emplaced.

During the Cenozoic the tectonic stress generated by the convergence of Africa with Eurasia, shifted from N-S to NW-SE direction (Dewey et al., 1989). When the formation of the Pyrenees was completed, by the Mid-Oligocene (Vergés et al., 1995), the deformation was absorbed by the Betic-Rift system and the interior of the Iberian Plate. By Tortonian times, the peak of intraplate deformation was reached (Dewey et al., 1989) and the ICS was generated by the reactivation of previous Variscan structures. Furthermore, the formation of two mesetas (plateaus) bounding the ICS to the N and S, along with the mountain chain, represent the most striking resulting features of the interior of Iberia.

The ICS is divided in two areas: The Guadarrama and Somosierra ranges to the E and the 


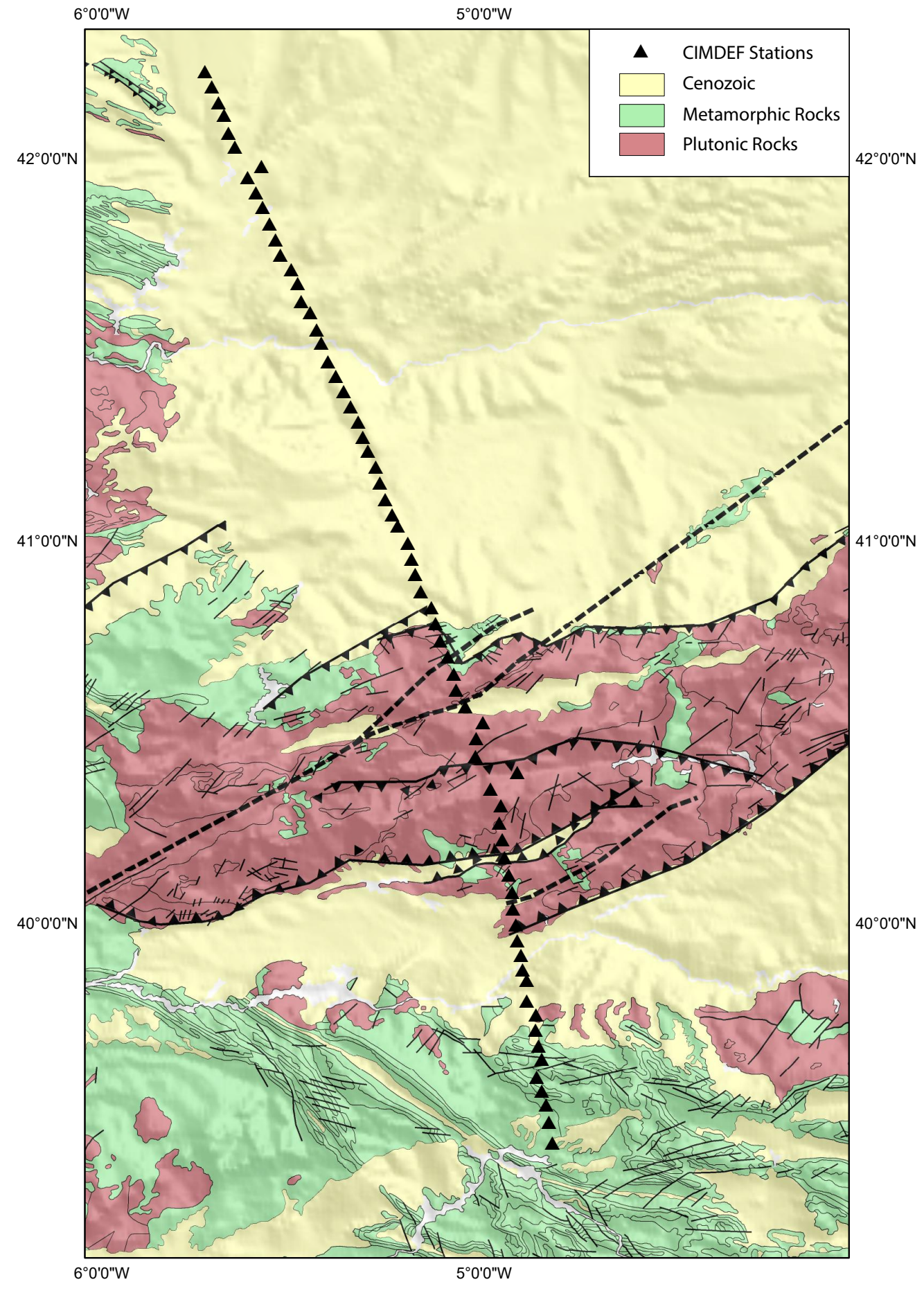

Figure 2.2: Simplified geological map of the ICS with the position of the stations deployed during the CIMDEF experiment. 
Gredos and Paramera sierras to the W (de Vicente et al., 2007). The eastern sector is composed by two ENE-WSW ranges and a depression, formed by two basement pop-ups and a pop-down. It is bounded to the S by the SCST. The western sector is formed by three ranges and three depressions, in the same pop-up, pop-down structure. The ranges are, from N to S, Mingorria, Paramera and Gredos. They are bounded by the depressions of Amblés, Alberche and Tietar, filled with Tertiray and Quaternary sediments. To the W of the sector, a narrow SW-NE depression corresponds to the Messejana-Plasencia left lateral strike-slip fault, which runs across the southwestern part of the IM. In general, this sector shows that the compressive forces were absorbed by NE-SW Variscan faults, while the overall deformation was accommodated by the E-W SCST.
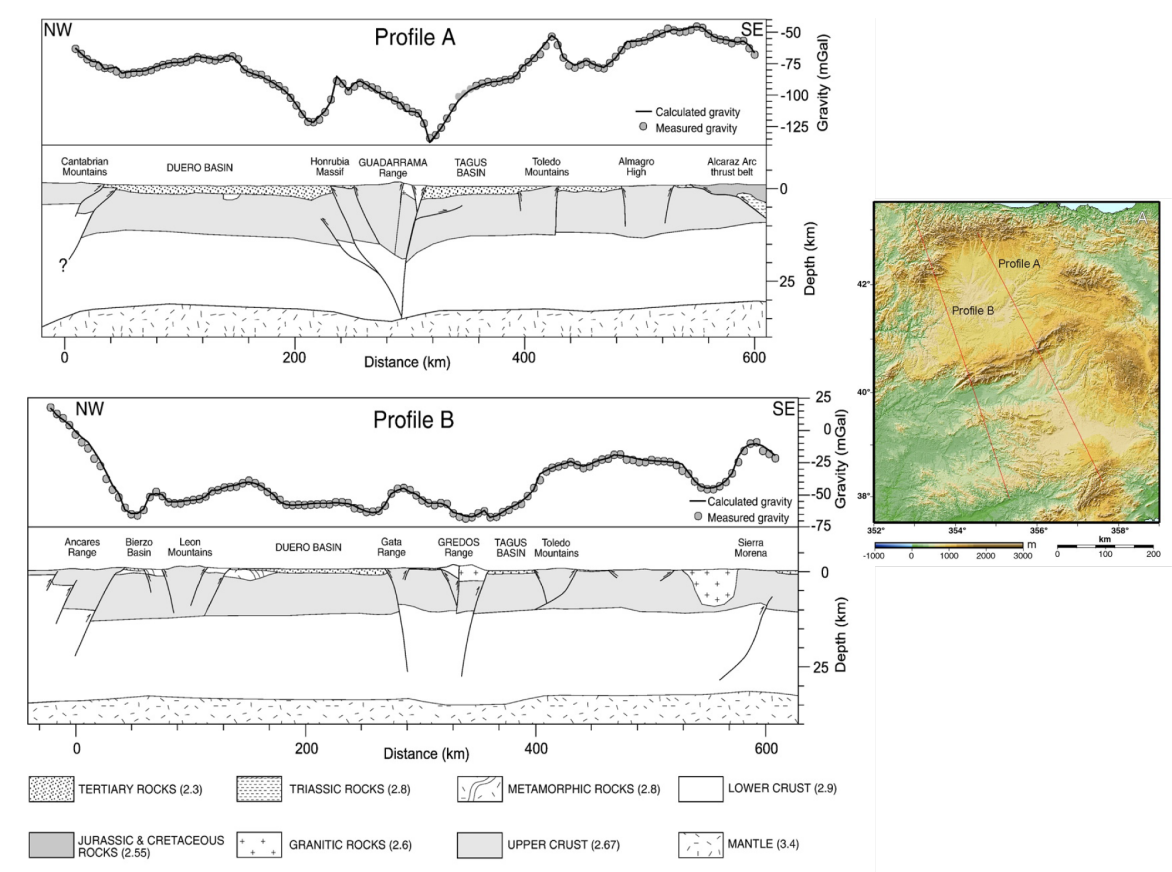

Figure 2.3: Crustal structure of the ICS derived from gravity modelling (modified from de Vicente et al., 2007)

\subsubsection{The Northern and Southern Mesetas}

The northern and southern Mesetas are situated between the Cantabrian mountains to the N, and the Betic mountains to the S. The northern Meseta has an average elevation of 750-800 $\mathrm{m}$ and it is occupied by the Cenozoic Duero Basin. This basin is the largest within Iberia since it formed as the foreland basin of the Cantabrian part of the Pyrenee-Cantabrian mountains, as well as part of the northern limit of the ICS orogenic front. The basin is filled with up to $3 \mathrm{~km}$ of Tertiary sediments (Gómez-Ortiz et al., 2005) and the only exposed part of the Variscan basement is found around the southern edge of the plateau. It is affected by the left-lateral strike-slip faults system located on the western border of the plateau, which defines a positive flower structure. This fault system along with the transmission of the crustal deformation from the compressional orogeny, allowed the mechanism 
of crustal flexure and accumulation of sediments in the plateau. The DB represents a good example of an intraplate basin generated in a constrictive regime.

The southern meseta is comprised between the ICS and the Guadalquivir basin and presents an average elevation of $\simeq 400 \mathrm{~m}$, significanty lower than its northern counterpart. The northern border is delimited by the SCST of the ICS. The main tectonic configuration of the meseta is an alternation of ENE alignments of basins and basement uplifts.

\subsection{Geophysical Background}

One of the geophysically best constrained areas within the European continent is the IB and surrounding areas. In particular, the western Mediterranean (the Gibraltar arc and the Alboran Basin) has been the target of high-resolution multidisciplinary geophysical and geological studies since the 1980s. One of the largest research initiatives developed since 2006 has been the Topo-Iberia research project, aimed to establish an integrated framework to understand the evolution of the topography within the IB, viewed as the interaction between deep, shallow, and atmospheric processes (Gallart et al., 2015). Thus, a varied number of studies have targeted the lithospheric structure of IB. Receiver function imaging and high-resolution tomographic models have been presented (Mancilla and Diaz, 2015; Palomeras et al., 2014; Thurner et al., 2014). Furthermore, of 2-D and 3-D integrated potential field lithospheric modeling studies were carried out (Carballo et al., 2015a,b; Fullea et al., 2010; Torne et al., 2015).

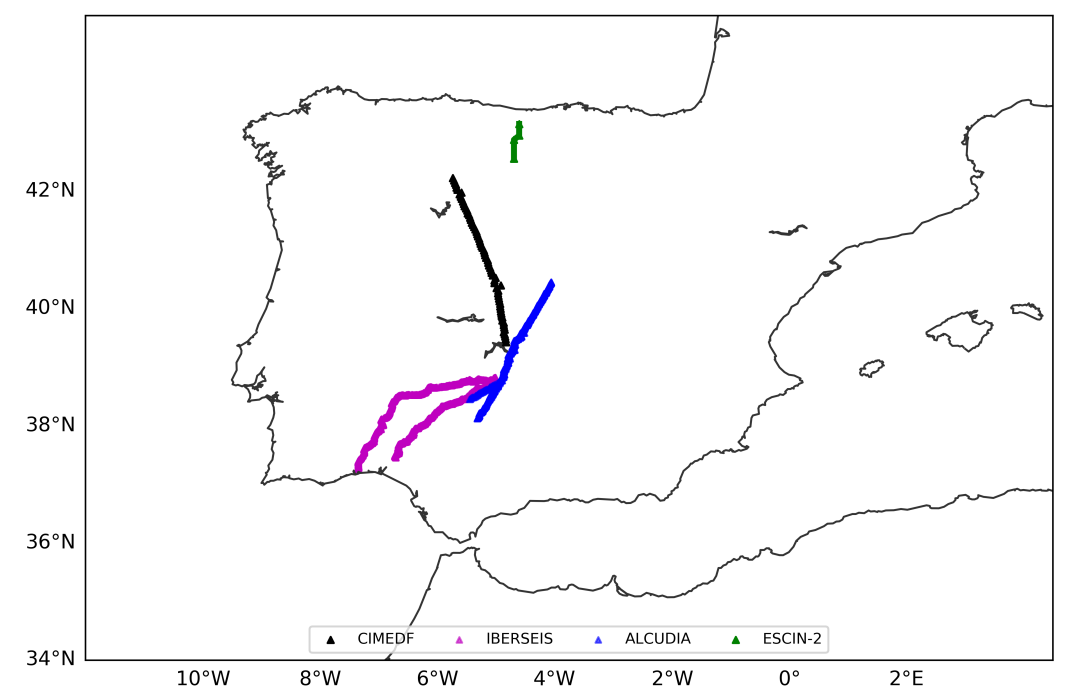

FIGURE 2.4: Map of previous controlled-source seismic experiments developed within the IM. The southern and northern ALCUDIA and ESCIN-2 models are used to aid in the interpretation of the CIMDEF dataset.

The knowledge on the lithospheric configuration beneath the central part of the CIZ and the ICS comes from old seismic refraction transects (e.g., Suriñach and Vegas, 1988), and potential field data (de Vicente et al., 2007). Limited crustal thickening $(<2 \mathrm{~km})$ underneath the Gredos Sierra was 
resolved by a low resolution seismic refraction profile (Suriñach and Vegas, 1988). The velocity model derived from this data set suggests a differential accommodation of the thickening in the upper and lower crust. Potential field data modelling results, also came up with a crustal thickening of $\approx 2 \mathrm{~km}$ in this area, thus placing its base at $35 \mathrm{~km}$ below the ICS. Both type of studies portrait a structure where a gentle deepening of the Moho boundary exists in the central part of this mountain range.

Additionally, in the last decade, plenty of maps depicting the Moho topography in the IB and surrounding areas have been published (Diaz et al., 2016; Mancilla and Diaz, 2015; Palomeras et al., 2017). Most of these maps are the result of the TOPOIBERIA research initiative (Gallart et al., 2015) and use different techniques as receiver function analysis, and/or inversion of shear waves that sometimes are integrate with already existing refraction, wide-angle and normal incidence seismic reflection data sets (e.g. Diaz et al., 2016). In the latter case, results indicate that underneath the ICS, the crust mantle boundary lies at 34-35 km depth, defining a root of $2 \mathrm{~km}$ respect to its surroundings. Results from Palomeras et al. (2017), derived from Rayleigh wave tomography and seismic ambient noise, picture a Moho boundary present at $33 \mathrm{~km}$ below the studied section of the ICS, which marks an increase of crustal thickness of 1-2 km.

High lateral resolution shot records from the ALCUDIA-NI and the ALCUDIA-WA seismic transects also constrain the thickness of the crust beneath the TB (close to the ICS, Fig.2.4) to around $35.5 \mathrm{~km}$ (Ehsan et al., 2015), although higher P-wave velocities than those used by Suriñach and Vegas, 1988 have been deduced. These models place strong constraints on the average crustal seismic velocities and these are used in the analysis of the seismic data set presented in this contribution.

\subsection{Geophysical Methods Applied in this Thesis}

This section is devoted to explain the methodologies used in this thesis as they are the foundation of the results presented and discussed in the following chapters. The methodology used in this work is divided into two sections. The first one, focuses on potential field methods, is devoted to describe the methodology used to calculate the depth to the Curie-Point Depth beneath IB and its surrounding margins. The following parts aim to explain the key fundamentals of Seismic Interferometry. This technique will be later applied to the CIMDEF dataset, as described in chapters 4 and 5 , to obtain two different seismic images across the ICS.

\subsubsection{Curie-Point Depth (CPD) Determination}

This section is the basis of the contribution Andrés et al. (2018) and chapter 3. The Curie-Point Depth is the temperature above which a ferromagnetic material loses the orientation of its magnetic moments and starts to behave as paramagnetic. In the Earths crust, iron-titanium oxides (titanomagnetites and titanohematite series) are the main source for the magnetic anomalies (OReilly, 1976). The temperature of the Curie-Point Depth for these oxides depends on the titanium content. If the titanium fraction is low, the Curie-Point Depth is $580^{\circ} \mathrm{C}$ (for magnetite, the mineral with the highest magnetic susceptibility and thus, the source of most anomalies.). If the titanium fraction increases, the 
Curie-Point Depth decreases to values closer to $500^{\circ} \mathrm{C}$, or even much less, depending on the amount of substitutions between $\mathrm{Fe}^{2+} / \mathrm{Ti}^{4+}$ and $\mathrm{Fe}^{3+}$ (Herrero-Bervera et al., 2011). However, as the increase in $\mathrm{Ti}$ is only common in some tectonic settings and it also diminishes the magnetic susceptibility and sometimes, the remanence, the Curie-Point Depth of magnetite $\left(580^{\circ} \mathrm{C}\right)$ is often used as temperature at the CPD.

Different methodologies have been proposed to estimate the bottom of the magnetic sources $\left(\mathrm{Z}_{\mathrm{b}}\right)$, where the magnetization of rocks is lost due to temperature (CPD), with Fourier spectral methods being the main tool. Bhattacharyya and Leu (1975) developed a method for calculating the depth to the centroid $\left(\mathrm{Z}_{\mathrm{c}}\right)$ of a parallelipipede assuming constant magnetization. The method was further developed by Okubo et al. (1985) and Tanaka et al. (1999) accounting for random magnetization. This method employs the logarithm of the Fourier power spectrum to calculate the depth to the bottom of an infinite magnetic layer. Assuming random magnetization, Tanaka et al. (1999) simplified the calculus of Blakely (1995) formulating the radial average power-density spectra of the total-field anomaly $\Phi_{\triangle T}$ as:

$$
\Phi_{\nabla T}(k)=A e^{-2|k| Z_{t}}\left(1-e^{-|k|\left(Z_{c}-Z_{t}\right)}\right)^{2}
$$

where $\mathrm{k}$ is the wavenumber, $\mathrm{A}$ is a constant, and $\mathrm{Z}_{\mathrm{t}}$ and $\mathrm{Z}_{\mathrm{c}}$ are the top and centroid to the magnetic layer, respectively. This equation was simplified as

$$
\ln \left[\Phi_{\triangle T}(|k|)^{1 / 2}\right]=\ln B-|k| Z_{t}
$$

and

$$
\ln \left[\Phi_{\triangle T}(|k|)^{1 / 2} /|k|\right]=\ln C-|k| Z_{c}
$$

Both are linear equations where $\mathrm{B}$ and $\mathrm{C}$ are constants and $\mathrm{Z}_{\mathrm{t}}$ and $\mathrm{Z}_{\mathrm{c}}$ are the slopes that can be calculated fitting a straight line at high and low wavenumbers in 2.2 and 2.3, respectively. Once these are calculated, $\mathrm{Z}_{\mathrm{b}}$ can be computed as

$$
Z_{b}=2 Z_{c}-Z t
$$

Recently, several authors have pointed out that calculation of $\mathrm{Z}_{\mathrm{b}}$ using this technique may lead to overestimated values due to the assumption of random magnetization (Bouligand et al., 2009; Salem et al., 2014). Accordingly, further developments on the method assume that the magnetic layer responds to a fractal distribution of sources (Bouligand et al., 2009; Maus and Dimri, 1996; Maus et al., 1997). Li et al. (2013) presented a modified centroid method calculation to account for a fractal response of the magnetic layer. This approach has been successfully applied in different scenarios (Bansal et al., 2013; Li and Wang, 2016; Li et al., 2013; Wang and Li, 2015) to model the depth to the bottom of the magnetic layer as follows:

$$
\ln \left[|k|^{(\beta-1) / 2} \times A_{\triangle T}(|k|)\right]=\ln B-|k| Z_{t}
$$

and,

$$
\ln \left[|k|^{(\beta-1) / 2} \times A_{\triangle T}(|k|) /|k|\right]=\ln C-|k| Z_{c}
$$


where $A_{\triangle T}(|k|)$ is the radially averaged amplitude spectra, $\mathrm{Z}_{\mathrm{t}}$ is the top of the centroid, $\mathrm{Z}_{\mathrm{c}}$ is the centroid depth, $\mathrm{B}$ and $\mathrm{C}$ are constants, and $A_{\triangle T}(|k|) /|k|$ is the scaled amplitude spectrum.

$\mathrm{Z}_{\mathrm{t}}$ and $\mathrm{Z}_{\mathrm{c}}$ are estimated from equations 2.5 and 2.6, respectively, fitting a straight line in the high and low wavenumbers (Fig. 2.5), and $Z_{\mathrm{b}}$ is calculated from equation 2.4. The fractal magnetization parameter $\beta$ is strongly correlated to $Z_{t}$ and $Z_{c}$ making the simultaneous inversion of the three parameters very complicated (Bansal et al., 2016; Bouligand et al., 2009). Thus, fixing the fractal exponent provides a better and stable solution.

Blakely (1995) stated that the base of the magnetization could be captured if the window size is big enough as to account for the longest wavelengths. The response of the magnetization is a peak in the spectrum where the central wavenumber of the peak is related to the depth of the bottom of the sources. Salem et al. (2014) used this assumption to correct the power spectrum of the magnetic data in order to detect the peak in every window. For this study we have performed the calculation of $Z_{b}$ with the modified formulation of the centroid method by Li et al. (2013). As stated by Ravat et al. (2016) the selection of the wavenumber range where the slope is picked has to be checked manually for each window and cannot be automated. Therefore, we have checked each window and selected the appropriate wavenumber range to calculate the bottom and the centroid of the magnetic layer. The wavenumber selection is based on the group of points after the spectral peak that gives the highest slope of the spectrum (Fig. 2.5).

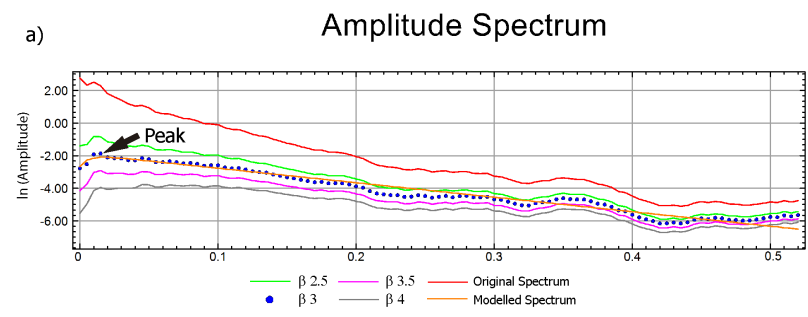

b)

R.A. AMPLITUDE SPECTRUM

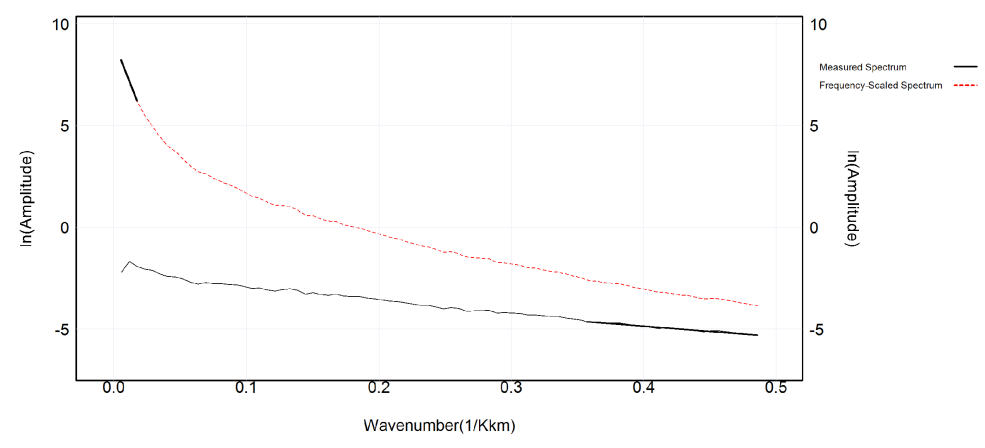

FiguRE 2.5: (a) Example of the change in the shape of the original amplitude spectrum (red line) after correction for different fractal exponents. Note the displacement of the peak from low to higher wavenumbers when increasing the exponent. In orange, the modeled spectrum using the calculated depth to the top and bottom is represented. (b) Example of a final corrected spectrum (black line) and the scaled spectrum (red dashed line) with the selected segments used to calculate $\mathrm{Z}_{\mathrm{t}}$ and $\mathrm{Z}_{\mathrm{c}}$ 


\section{Window Size}

The window size is a critical parameter in the calculation of the bottom of the magnetization, as it constrains the wavelength that will be captured in the window. Several authors (Blakely, 1995;

Bouligand et al., 2009; Maus et al., 1997) have studied the range of acceptable window sizes in order to get a better estimattion of the depth to the bottom of the magnetization. Blakely (1995) pointed out that the window size should be around five times the expected CPD, while a study of Ravat et al. (2007) suggested that the window size should be at least $200300 \mathrm{~km}$. Increasing the size of the window presents various issues as, i) decrease of resolution of the resulting map, ii) there is a big chance of mixing different tectonic environments and sources, making the estimation of the bottom of the magnetization more complicated. However, increasing the window size ensures the capture of the longest wavelengths.

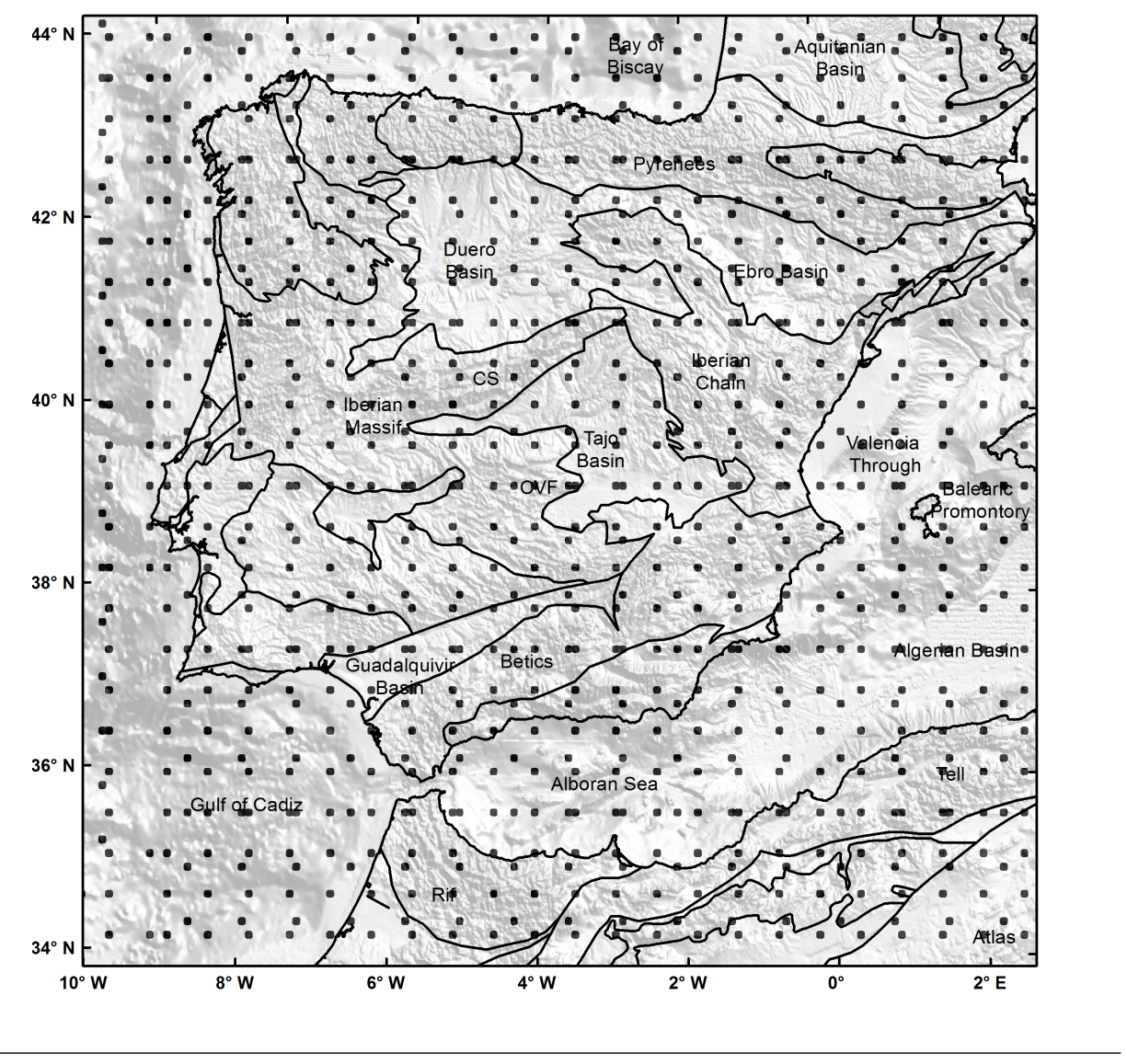

Figure 2.6: Distribution of the center of the window sizes used to calculate the CPD, including both $150 \times 150 \mathrm{~km} 2$ and $200 \times 200$, sizes.

After reviewing the literature, we have performed tests using different window sizes in order to evaluate its impact on the results. Three different window sizes have been tested in three locations at different tectonic settings: $150 \times 150 \mathrm{~km}, 200 \times 200 \mathrm{~km}$, and $300 \times 300 \mathrm{~km}$. Results show that the CPD differences between the smallest and the biggest window are around $10 \%$. The selection of the best window size has taken into account, i) the smallest window size where a peak is found at low 
wavenumbers, and ii) in the study area, the Moho is expected to be around $30 \mathrm{~km}$ depth in continental areas, increasing in the Pyrenees, and shallowing to offshore areas $(<20 \mathrm{~km})$. Therefore, and for the sake of resolution, we have adopted two different window sizes, $150 \times 150 \mathrm{~km} 2$ and $200 \times 200 \mathrm{~km} 2$, with a shift between windows of 50 and $66.66 \mathrm{~km}$, respectively (Fig. 2.6). We have calculated a total of 940 windows and taken the averaged CPD, derived from the two window sizes selected, as our final solution as done by Wang and Li (2015).

\section{Fractal Exponent}

Several authors have studied the implications of using different fractal exponents. Bouligand et al. (2009) suggested that a value of $2 \leq \beta \leq 3.25$ depending on the tectonic setting is appropriate. Bansal et al. (2013) pointed out that a fractal exponent above 1.5 might over-correct the spectrum resulting in shallower estimations. For this study, the outcome of several fractal exponents have been compared using visual inspection of the behavior of the amplitude spectrum as described by Salem et al. (2014). Different values of $\beta$ have been tested $(\beta=2,2.5,3,3.5$, and 4 (Fig. 2.5a)) for every window and compared the resulting de-fractal spectra. Ultimately, one among the previous exponents has been selected, for each window, attempting to correct the fractal distribution (Fig. 2.5b). The selection of $\beta$ was accomplished by assuming that the best value was the one showing a peak at small wavenumbers with at least two points at its left-hand side. Furthermore, as $\beta$ increases, the spectrum is over corrected, which could lead, in some cases, to the displacement of the peak to higher wavenumbers, thus evidencing the invalidity of that specific parameter.

Some authors (Ravat et al., 2016; Salem et al., 2014) have used the centroid method along with forward modeling of the spectral peak (Blakely, 1995; Connard et al., 1983) to constrain $\beta$. Although the comparison could give reliable results, it depends on the calculated values of $Z_{b}$ and $Z_{t}$, and thus on the selection of the wavenumber range where the above parameters are calculated, making the comparison dependent on the subjectivity of picking wavenumber ranges.

The selected solution leads to a high variability in $\beta$ values (Fig. 2.7). For marine areas such as the Alboran Sea or the oceanic crust present in the Algerian Basin, $\beta$ needs to be small, between 2.5 and 3 matching the results from previous studies (Li and Wang, 2016; Li et al., 2013; Wang and $\mathrm{Li}, 2015)$. For continental areas $\beta$ varies between 3 and 4 due to the more heterogeneous geological setting of the continental IB. In general, $\beta=3$ is the best fit for the $\mathrm{S}$ and $\mathrm{N}-\mathrm{NE}$ of the Iberian Plate whereas $\beta=3.5$ works for the central and central-W part. In some particular cases, e.g., NW of the continental IB, we had to choose $\beta=4$ to correctly account for the fractal distribution of sources. 


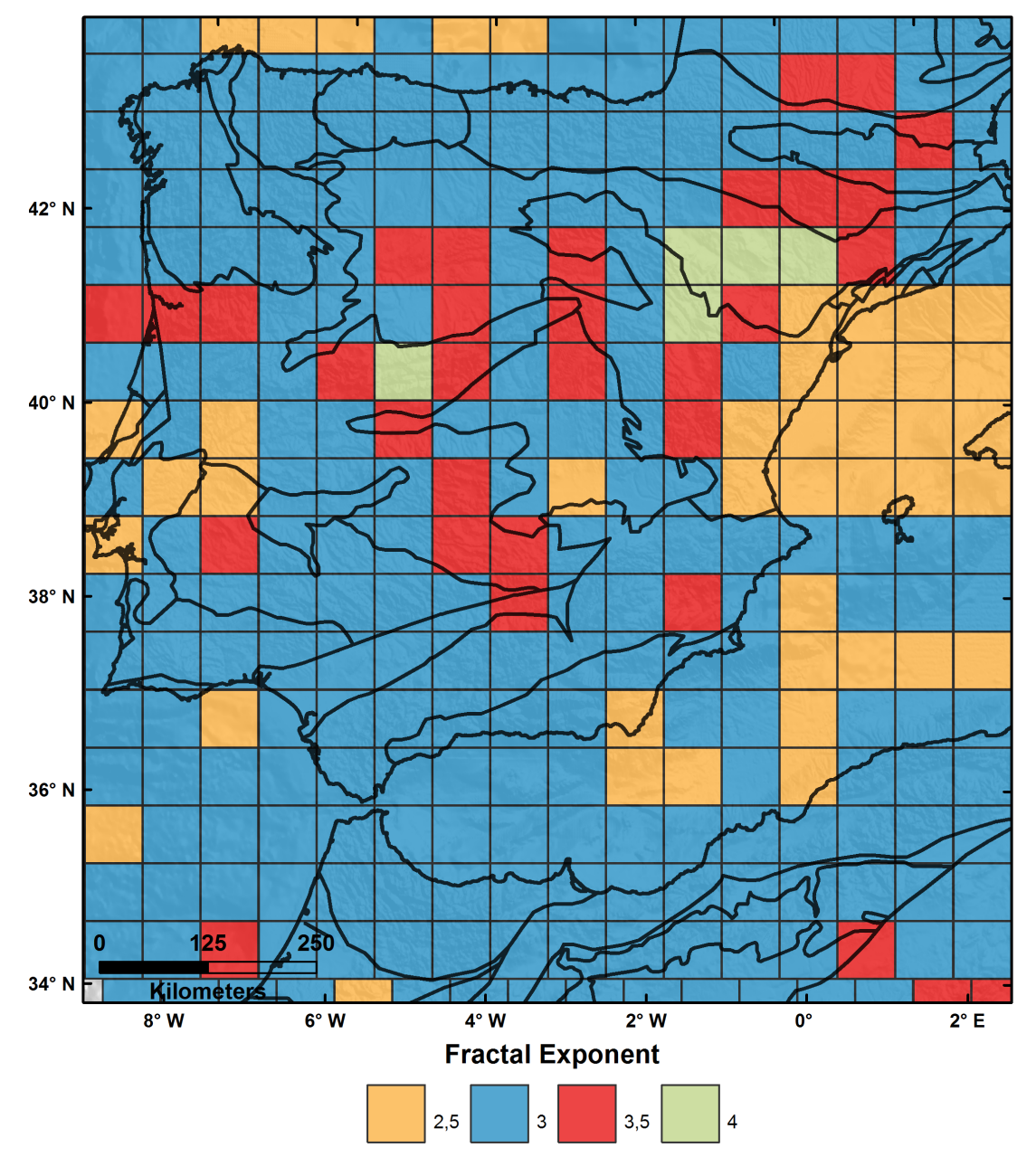

FIGURE 2.7: Map of the distribution of $\beta$ parameter used to calculate the CPD map.

\subsubsection{Seismic Interferometry}

Interferometry methods aim to get in formation of the subsurface by using the general interference phenomena between pairs of signals. Therefore Seismic Interferometry (SI) makes use of the mathematical cross-correlation operation between signal pairs to reconstruct the impulse response of a given media (Aki, 1957).The application of SI relies on the waves that hit one station and reflects to the subsurface, before hitting the second station, to recover the Green's function of the media between both points, as if the source signal was emitted from one point and recorded by the station at the second position. This technique has been developed to work with both controlled seismic sources (Schuster et al., 2004) or natural sources Wapenaar, 2004. In general, SI involves crosscorrelation of responses at different receivers, but it can also be applied to individual stations (autocorrelations).

The application of SI can be regarded as a filtering operation. The foundation of SI was derived by Claerbout (1968) as an autocorrelation of the response recorded at the free surface, due to the incoming waves that enter the medium. Through autocorrelation, the response of the medium can be 
obtained as if a source and receiver were located at the surface (Fig. 2.8). By autocorrelation, the initial arrival and the free surface multiple reflection are cancelled out, leaving only the recording that would be observed as if there were a source and receiver located at the same position on the surface.

This methodology was later generalized to arbitrarily heterogeneous media (Bakulin and Calvert, 2006; Wapenaar, 2003). The responses retrieved by crosscorrelation (or autocorrelation) are then stacked over sources, and given a sufficient and homogeneous distribution of sources, the impulse response between a pair of stations is retrieved, namely the Green's function. SI has been derived, apart from acoustic media, for elastic media (Wapenaar, 2004), and latter generalized for different wave and diffusion phenomena (Snieder et al., 2010; Snieder, 2007; Wapenaar and Fokkema, 2006).

In this thesis I employ natural source seismic data as the signal perturbation used for the application of SI. Throughout this thesis, I apply SI by autocorrelation to natural sources seismic recordings, such as earthquakes (Andrés et al., 2019) as explained in chapter 4, and ambient seismic noise wavefield (Andrés et al., 2020) which will be the focus of chapter 5. In all the work carried out I did use only the seismic signals recorded by the vertical component of the seismic stations.
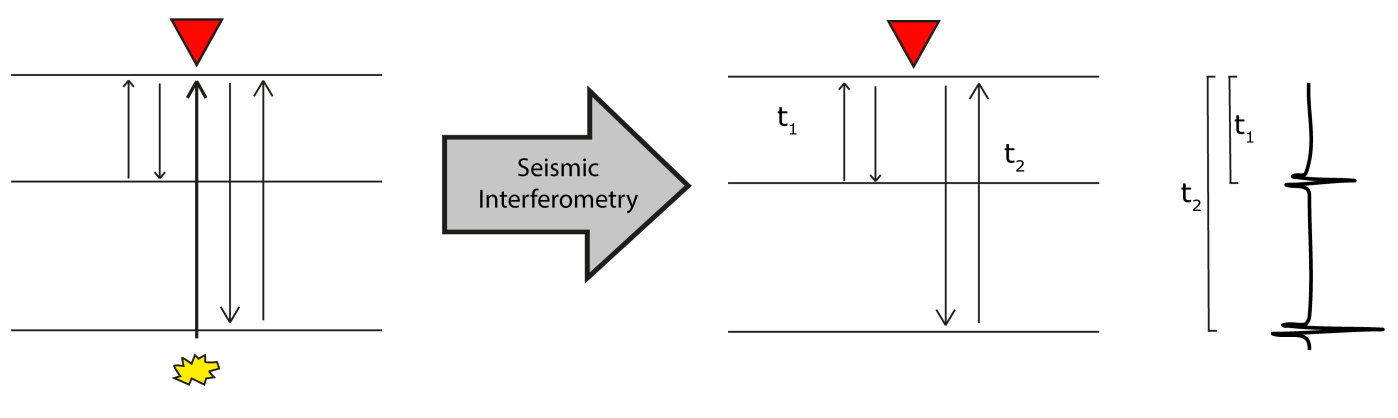

FIGURE 2.8: Seismic Interferometry by autocorrelation applied to vertically arriving energy in a horizontally layered medium. Black arrows represent ray paths and black horizontal lines represent medium discontinuities. Parameter $t_{1}$ represents the two-way travel time between the station at the surface and the reflector $\mathrm{j}$ in the subsurface. The autocorrelation allows the retrieval of a seismogram composed of reflected energy released by a virtual source co-located at the position of the station. Each layer is heterogeneous, which is perceived by the arriving energy at times between strong arrivals. For sake of simplicity,we only show vertical-component results without reflector multiples.

\section{Data Processing}

The SI processing could be divided in two phases, i) pre-processing and ii) construction of stacked autocorrelograms of the vertical component of the ambient noise. In this section I will explain the main processing steps involved in each of these two phases which lead to the results of chapter 4 and 5. Even though what can be considered as the source energy is different in both cases, the core of the methodology is common.

Preparation of the data consists on visually inspecting the recordings in order to assess its quality as it could be affected by instrumental issues or recording problems. Thus, a visual inspection searching for data gaps, anomalous large amplitudes or deviation of the trends of the data needs to be performed. 
In a next step of the workflow, as presented in Figures 2.10 and 2.13, is cutting the recordings are cut into the desired length depending on the energy source. The aim of this step is to either increase the number of data available, or to extract the desired signal to be used for correlation. Next, the mean and linear trends of the data must be removed in order to eliminate any shift from the 0 line and set an equal baseline for all data segments. Afterwards, a band-pass filter is applied to emphasize the frequencies of interest. Final steps of the processing involve autocorrelation of each data segment and stacking over all the available sources to generate a final autocorrelation.

Although not explained in this section, further pre-processing could be needed prior to correlation, as explained by Bensen et al. (2007). These steps would involve 1-bit normalization and spectral whitening. The first consists in a signal normalization and the latter in a frequency normalization, giving the same weights to all frequencies. These steps should be taken into account when working with ambient seismic noise, and applying amplitude-based correlations as transient high-amplitude events could bias the correlation results (e.g. earthquakes). In this thesis I do not use the latter preprocessing steps as a phase-based correlation technique has been used to compute autocorrelations of ambient seismic noise.

Our processing steps rely on the application of the Phase Cross-Correlation (PCC) technique (Schimmel, 1999) and the time-frequency domain phase-weighted stack (tf-PWS) (Schimmel and Gallart, 2007). The PCC utilizes the instantaneous phases of the analytical signal of the data trace (time series) and produces a similarity measurement of the trace relative to a delayed version of itself. The use of the instantaneous phases makes the correlation amplitude unbiased, which eases the pre-processing as no corrections for high amplitude events have to be applied (Bensen et al., 2007; Schimmel and Gallart, 2007; Schimmel et al., 2011, 2018). The tf-PWS is a linear stack weighted by the time-frequency-dependent instantaneous phase coherency. It enhances the signal by the summation of the envelope normalized analytic signals, strengthening coherent arrivals and attenuating incoherent signals. These methodologies will be next described in detail.

\section{Correlation and Stacking Methods}

There are different methods to retrieve the Green's function between a pair of stations or with just one station respect itself (Wapenaar et al., 2010). A classic formulation to compute correlograms between two receivers in the time domain is the classic correlation (CCGN) which is geometrically normalized:

$$
C C G\left(t_{\text {lag }}\right)=\frac{\sum_{t=t_{0}}^{t_{f}} u_{1}\left(t+t_{\text {lag }}\right) u_{2}(t)}{\sqrt{\sum_{t=t_{0}}^{t_{f}} u_{1}\left(t+t_{\text {lag }}\right)^{2}} \sum_{t=t_{0}}^{t_{f}} u_{2}(t)^{2}}
$$

where $u_{1}$ and $u_{2}$ are two time series, $t$ is the recording time between $t_{0}-t_{f}$, and $t_{\text {lag }}$ is the time window that generate positive and negative parts that represent the causal and anti-causal members of the Green's function. 
Although this approach is widely used to compute correlograms, it is sensitive to high-amplitude spurious events that can disturb the correlogram calculation, such as earthquakes. Thus, for ambient seismic noise applications further preprocessing is needed.

A different approach was developed by Schimmel (1999) proposing the use of a phase-based methodology named Phase Cross-Correlation (PCC). It is based on analytic signal theory. Its formulation measures the coherence of the instantaneous phase of two signals as:

$$
S(t)=s(t)+i H(s(t))=A(t) \exp [i \phi(t)]
$$

where, $S(t)$ is the analytic signal of the instantaneous phase of the source $s(t), A(t)$ is the instantaneous phase, and $H(s(t))$ is the Hilbert transform of $s(t)$.

The resulting PCC proposed by Schimmel (1999) as an extension of the phase stack (equation 2.10) Schimmel and Paulssen (1997), is defined as:

$$
P C C\left(t_{\text {lag }}\right)=\frac{1}{2 T} \sum_{t=t_{0}}^{t_{f}}\left\{\left|e^{i \phi_{1}\left(t+t_{l} a g\right)}+e^{i \phi_{2}(t)}\right|^{v}-\left|e^{i \phi_{1}\left(t+t_{\text {lag }}\right)}-e^{i \phi_{2}(t)}\right|^{v}\right\}
$$

where $T$ is the window length for which the level of similarity between the signals is being computed. $\phi_{1}$ and $\phi_{2}$ are the instantaneous phases of two signals. The power $v$ controls the sensitivity of the PCC and increases signal to noise ration. The result of $\mathrm{PCC}$ is either $P C C\left(t_{\text {lag }}\right)=1 \mathrm{denoting}$ perfect correlation or $P C C\left(t_{l a g}\right)=-1$ indicating perfect anti-correlation.

One of the key differences over CCGN is that it is amplitude-unbiased and therefore, there is no need to apply pre-processing like 1-bit normalization or spectral whitening (Bensen et al., 2007) to correct for perturbations produced by transient sources. Moreover, it is more sensitive to weak signals, such those with low amplitude phases. This characteristic allows to enhance the retrieval of signals like body-waves (Schimmel et al., 2011).

During correlation an important parameter to account for is the correlation window. The selection of the time lag is flexible although it should be selected assessing the expected frequency, inter-station distance and speed of waves. The correlation time lag used in the bibliography differs depending on the author, ranging from just minutes, to 1 hour or even 1 day (Bensen et al., 2007; Gorbatov et al., 2012; Schimmel et al., 2011).

The final step of SI aims to improve the coherency of the correlograms by a summation process over all the sources. Following the same principles described in equation 2.9, Schimmel and Paulssen (1997) developed the phase stack (PWS):

$$
c(t)=\left|\frac{1}{N} \sum_{j=1}^{N} \exp \left[i \phi_{j}(t)\right]\right|^{v}
$$


where $c(t)$ is based on the similarity of the instantaneous phase $\phi_{j}(t), N$ is the number of seismic records, and $v$ represents a parameter of tuning. Schimmel and Gallart (2007) presented the timefrequency phase stack (tf-PWS) which uses the S-transform (Stockwell et al., 1996) and described as:

$$
c_{p s}(\tau, t)=\left|\frac{1}{N} \sum_{j=1}^{N} \frac{S_{j}(\tau, f) e x p^{i 2 \pi f \tau}}{\left|S_{j}(\tau, f)\right|}\right|^{\nu}
$$

where $S_{j}(\tau, f)$ represents the S-transform, and $v$ represents an optional tuning parameter. The higher this tuning parameter is set, the heavier the weighting will be towards coherent energy. The phase weighted stack has amplitudes between 0 and 1 as a function of time. In tf-PWS each sample of a linear stack is multiplied with a weighting function (eq. 2.10).

Typically, the stacking procedure aids to obtain a more coherent signal retrieval as anomalous and no stationary signals are cancelled out during the summation process. The needed stacking time, when using ambient noise seismic data, should be assessed in order to obtain a stable response of the medium. However, different authors have used a wide diversity of data duration, ranging from as little as 1 day, to various years of continuous recordings (Bensen et al., 2007; Draganov et al., 2009; Kennett et al., 2015; Nakata et al., 2014; Schimmel et al., 2011, among others), obtaining coherent results.

In this thesis, I have used both correlation techniques described in eq.2.7 and eq. 2.9 to retrieve P-wave reflections from the lithospheric structure beneath the ICS along the CIMDEF array by using different energy sources. In chapter 4 CCGN is applied to construct autocorrelations of recorded signal generated by distant earthquakes. In chapter 5 the autocorrelations are constructed from the ambient noise field recorded continuously by the array.

\section{Global Phase Seismic Interferometry}

Due to its usefulness, seismic interferometry (SI) has lately consolidated itself as a tool for lithospheric imaging. Recent studies have exploited earthquakes and moonquakes recordings (Nishitsuji et al., 2016a,b; Ruigrok and Wapenaar, 2012) to image lithospheric discontinuities such as the Moho (in the Earth and the Moon) or subducting slabs. These studies are based on a technique called Global-Phase Seismic Interferometry (GloPSI) (Ruigrok and Wapenaar, 2012). GloPSI retrieves P-wave reflectivity, coming from distant energy sources, below a single station by autocorrelating earthquake phases coming nearly as a plane wave at (near) vertical incidence angles.

The GloPSI technique leverages body-wave global phases that have travelled through the core and whose energy arrives at the surface nearly vertical. The seismic phases that comply with this requirements are $P K P, P K i K P$, and $P K I K P$ (Fig. 2.9), and are produced by earthquakes at $>$ $120^{\circ}$ epicentral distance. When arriving at the station, the phases and their reverberations in the lithosphere are used as the input data. In general, these arrivals can be considered as plane waves traveling through the Mantle with slowness lower than $0.04 \mathrm{~s} \mathrm{~km}^{-1}$. 


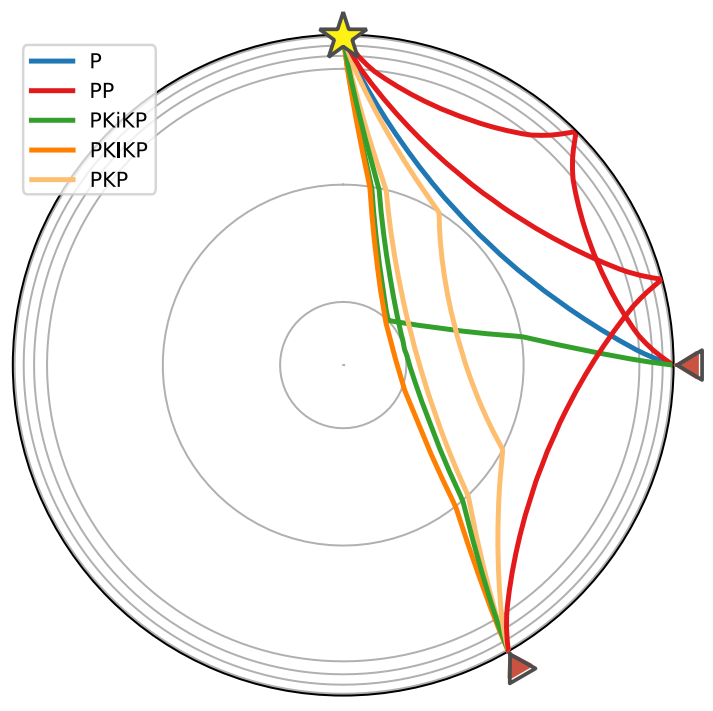

FigURE 2.9: Diagram of the Earth with some of the seismic phases produced by an earthquake at $30 \mathrm{~km}$ depth and recorded by two seismic stations located at different epicentral distances $90^{\circ}$ and $150^{\circ}$. The first one records, among others, direct phases such as the direct $\mathrm{P}$ and $\mathrm{PP}$ waves with a high angle of incidence, whereas the second one records phases that travel through or are reflected at the core, such as PKIKP and PKiKP, which arrive at the station nearly vertical.

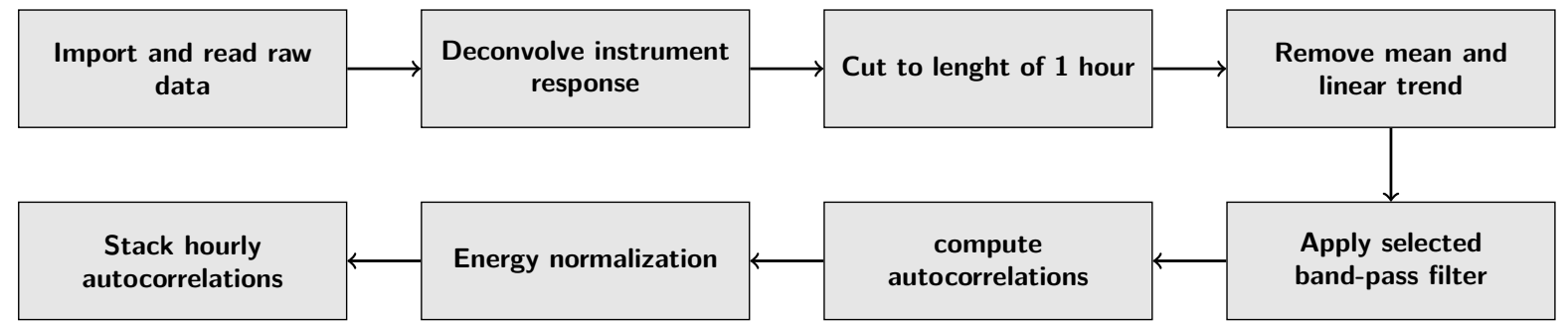

FIGURE 2.10: Workflow used to generate the stacked autocorrelations of ambient seismic noise. 
The reflections produced by the phases and their reverberations can be retrieved using SI. The methodology is based on the 1-D derivation for an acoustic medium by Claerbout (1968), where reflectivity is retrieved by autocorrelation. The GloPSI technique relies on the application of autocorrelation of every earthquake, and stack over sources to retrieve the pseudo zero-offset reflection response below a station from a virtual source that radiates energy nearly perpendicular to the surface. Stacking over the correct illumination range ensures cancellation of spurious events and other cross terms, and enhances stationary events (Snieder, 2004). Thus, we calculated the back azimuths of the selected events. Despite the constraint that the distance $>120^{\circ}$ implies in terms of availability of sources, that the illumination is well covered. This enables a good stacking of the resulting autocorrelations. Limitations of the methodology are related to earthquake distribution and quantity, and with the internal structure of the crust. As GloPSI uses nearly vertical incident energy, reverberations from steep-dipping structures below the station would not be retrieved. However, the lack of imaged reflectivity of such structures can be used to interpret their presence (Nishitsuji et al., 2016a).

\begin{tabular}{ll}
\hline Parameters & Value \\
\hline Frequency Band & $0.7-2 \mathrm{~Hz}$ \\
Correlation Type & CCGN \\
Trace length & Variable \\
Lag Time Window & $60 \mathrm{~s}$ \\
Sampling rate & 50 \\
Stacking technique & tf-PWS \\
$N^{o}$ stacking traces & 81 \\
\hline
\end{tabular}

TABLE 2.1: Parameters used in the processing of earthquake recordings

The methodology we employ for the processing of the earthquake recordings includes pre-processing and construction of stacked autocorrelograms of the vertical component. We base our processing steps on linear autocorrelations (CCGN) and phase weighted stacks (tf-PWS) (Schimmel and Gallart, 2007). The processing workflow is shown in Figure 2.10 and the processing parameters used are summarized in table 2.1. The pre-processing applied to all selected time windows consists of first deconvolving the instrument response from the signal. Then, the data are decimated from 250 to 50 samples per second (sps) in order to reduce computing time. The next step consists of bandpass filtering the data to restrict the frequency bands to those where we expect the target information to be found. We applied a broad band-pass filter of $0.12 \mathrm{~Hz}$ after computing the power-spectral density for different magnitude earthquakes (Fig. 2.11). Subsequently, we apply SI by autocorrelation to each selected phase (transient source). To help the correct stacking, the autocorrelations are normalized by their energy. This step aids the summation process as each phase could have a different spectral balance, thus hindering an optimal stacking. The resulting stack is filtered between 0.7 and $2 \mathrm{~Hz}$ as lower frequencies $(<0.7 \mathrm{~Hz})$ offer low resolution and they are strongly influenced by the microseismic noise (Fig. 2.11).

As a consequence of the autocorrelation process, a strong arrival at $t=0$ is created, representing a smeared Dirac delta function at a time of $0 \mathrm{~s}$ (Claerbout, 1968; Wapenaar, 2003), dominating the earlier part of the trace. This feature affects the initial part of the autocorrelation hindering 

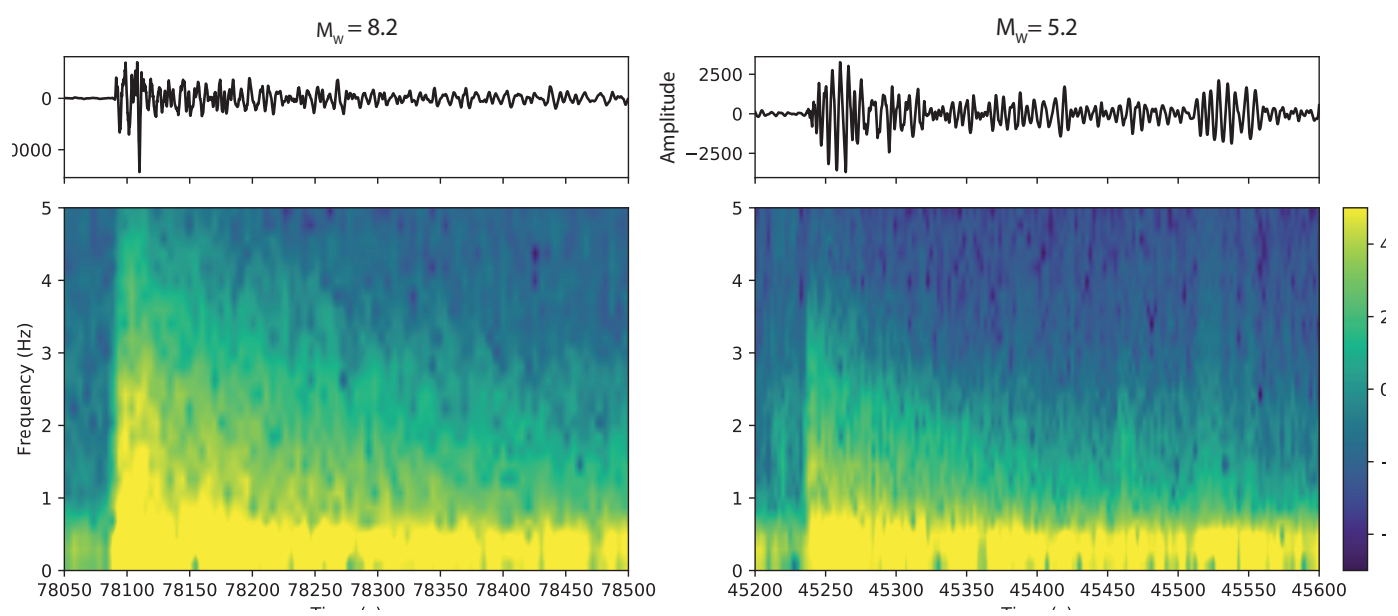

FiguRE 2.11: Power-spectral density plots of two earthquakes recorded by the CIMDEF array. They cover both ends of the used magnitudes, thus proving the existence of energy at the selected frequency band.

its signature and masking the rest of the trace due to its larger amplitude. Two methodologies have been tested to reduce this effect, i) deconvolution of the wavelet around $t=0$ (the virtualsource time function) extracted from the average of all autocorrelations per event and phase, and ii) subtracting the average time function of all the traces from every individual autocorrelation. Both processes partly helped to eliminate the influence of the virtual-source time function but did not deliver optimal results. For the sake of the interpretation, we have preferred to mute the virtual source time function, as the previously mentioned techniques have not been entirely successful. The different approaches used in order to eliminate the influence of the delta pulse are illustrated in Figure 2.12. The entire processing workflow of the earthquake recordings yields a pseudo zero-offset section with the reflection response of the lithospheric structure below all stations. Further post-processing steps, such as elevation correction, have been considered but discarded. The maximum elevation difference in the area is approximately $1 \mathrm{~km}$, which assuming an average crustal P-wave velocity of $5.5 \mathrm{kms}^{-1}$ would represent a time shift of $0.36 \mathrm{~s}$. The latter, would not significantly affect the interpretation of reflection at the lithospheric scale. 


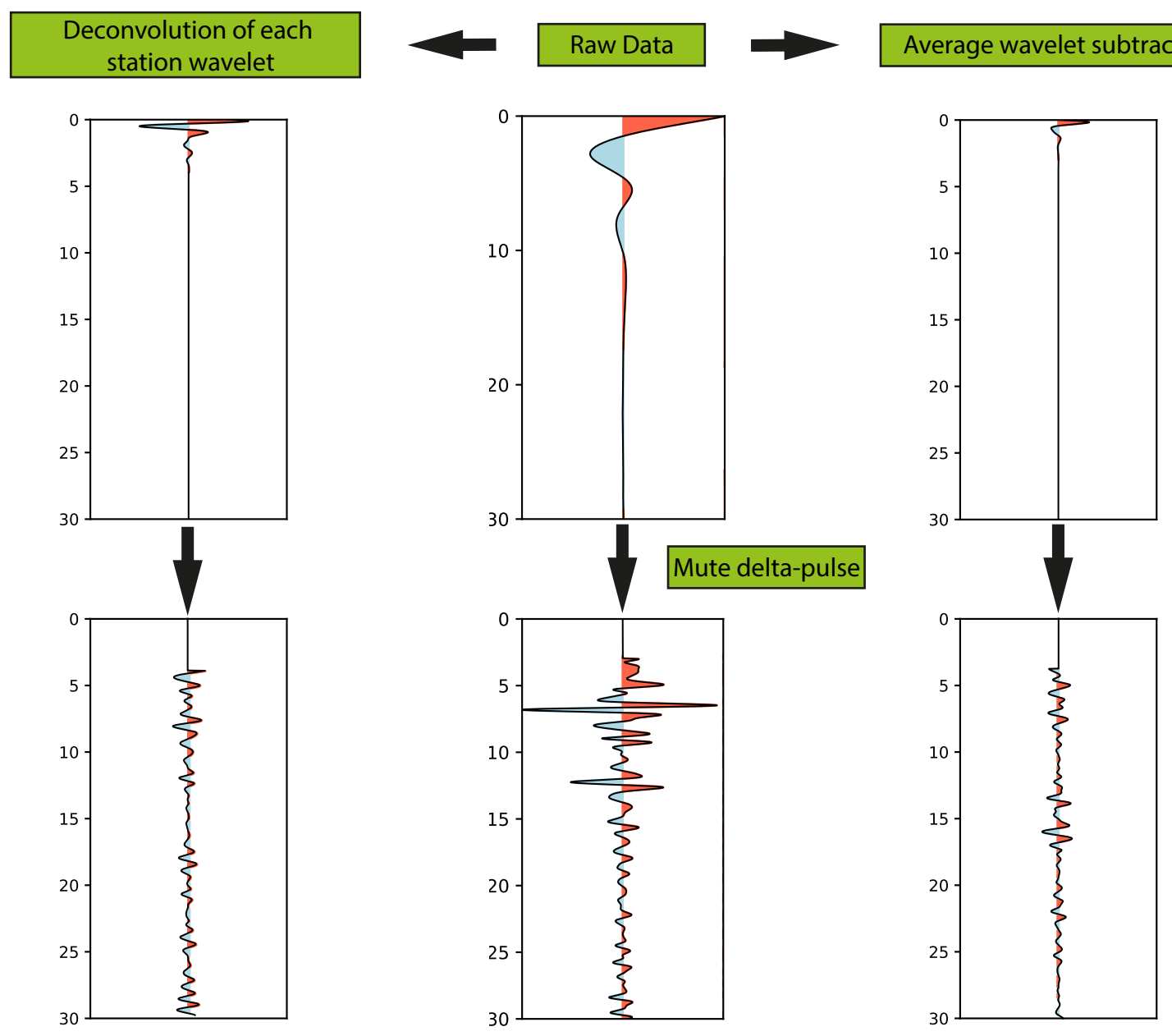

FiguRE 2.12: Representative examples of the three approaches tested to eliminate the high-amplitude sidelobe created at $t=0$ with the resulting autocorrelation trace, and the signal extracted from the original trace. The final selected method was muting the delta pulse between $0-3 \mathrm{~s}$ as the deconvolution of each station wavelet, and the subtraction of the averaged wavelet did not provide consistent results throughout the profile.

\section{Ambient Noise Seismic Interferometry}

The methodology used in this study aims to retrieve the Earths reflection response below single stations by applying autocorrelation of ambient seismic noise. Autocorrelation evaluates the similarity of a seismic trace with a delayed version of itself, whose response depends on the subsurface structure. I have used the vertical component of the data as it is expected to be the one where more P-wave energy is recorded with high energy.

The processing of the continuous recordings is similar to that applied to the earthquake data, but with some modifications. The workflow as presented in Figure 2.13 include, i) pre-processing and ii) construction of stacked autocorrelograms of the vertical component of the ambient noise. We base our processing steps on the Phase Cross-Correlation (PCC) technique (Schimmel, 1999) and 


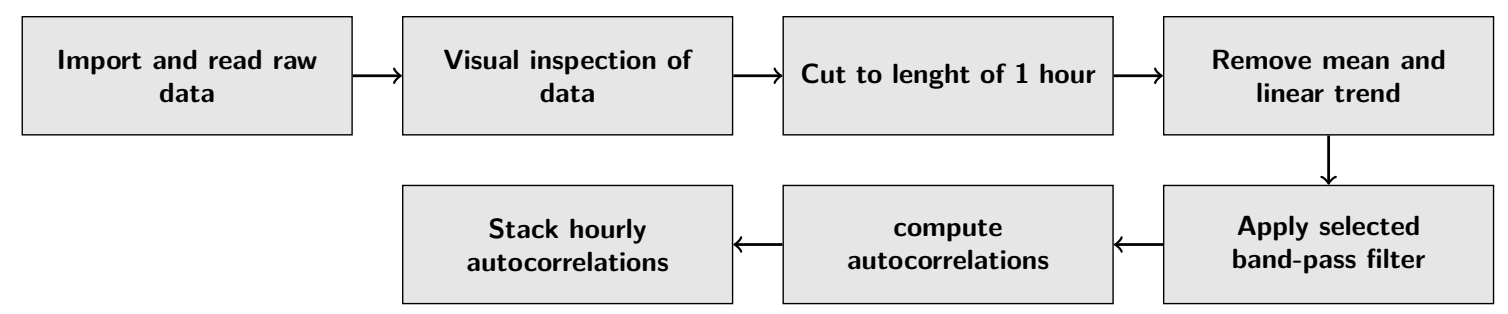

FiguRE 2.13: Workflow used to generate the stacked autocorrelations of ambient seismic noise.

the time-frequency domain phase-weighted stack (tf-PWS (Schimmel and Gallart, 2007) explained in the previous section. The PCC utilizes the instantaneous phases of the analytical signal of the data trace (time series) and produces a similarity measurement of the trace relative to a delayed version of itself. The use of the instantaneous phases makes the correlation amplitude unbiased, which eases the pre-processing as no corrections for high amplitude events have to be applied (Bensen et al., 2007; Schimmel et al., 2011, 2018). The tf-PWS is a linear stack weighted by the time-frequency-dependent instantaneous phase coherency. It enhances the signal by the summation of the envelope normalized analytic signals, strengthening coherent arrivals and attenuating incoherent signals.

\begin{tabular}{ll}
\hline Parameters & Value \\
\hline Frequency Band & $1.5-4 \mathrm{~Hz}$ \\
Correlation Type & PCC \\
Trace length & 1 hour \\
Lag Time Window & $30 \mathrm{~s}$ \\
Sampling rate & 125 \\
Stacking technique & tf-PWS \\
$N^{o}$ stacking days & $28-60$ days \\
\hline
\end{tabular}

TABLE 2.2: Parameters used in the processing of ambient seismic noise

The quality of the data was visually inspected for gaps or anomalous trends. The pre-processing (Fig. 2.13, table 2.2) applied consisted in windowing the daily data in $1 \mathrm{~h}$ long, non-overlapping traces, removing the mean and linear trends and decimating the data from $250 \mathrm{sps}$ to $125 \mathrm{sps}$. The next step consisted in applying a zero-phase band-pass filter to the data to enhance frequency bands (FB) where the target information was expected. There is no general agreement about the best frequency band to be used in autocorrelation of ambient noise data. High frequencies are generally employed to resolve shallow discontinuities which otherwise would be hidden in sidelobes of the zero-lag autocorrelation peak (e.g., Romero and Schimmel, 2018). Different authors have used various sets of frequency ranges for similar purposes. Gorbatov et al. (2012) used 2-4 Hz frequency to retrieve PmP in Australia using autocorrelations of ambient noise. Kennett et al. (2015) utilized 0.5-4 Hz in Australia to image lithosphere-asthenosphere reflectivity. Oren and Nowack (2016) used lower frequencies (between 0.3$0.55 \mathrm{~Hz}$ ) to retrieve body-waves in North America. Recently, Taylor et al. (2016) also utilized low frequencies $(0.2-0.4 \mathrm{~Hz})$ in Turkey to retrieve crustal reflectivity. Higher frequencies between $3-12 \mathrm{~Hz}$ have been used by Romero and Schimmel (2018) to map the crystalline basement of the Ebro Basin in Spain, but they also showed retrieval of Moho reflections with frequencies of 2-4 Hz. Therefore, it can be argued that the best frequency range depends on the data, structural complexities and the 
objective of the study. We have tested frequencies ranging from $0.3-0.5 \mathrm{~Hz}$ to $1.5-4 \mathrm{~Hz}$ to assess the best suited band to retrieve body-waves for lithospheric imaging in the study area.

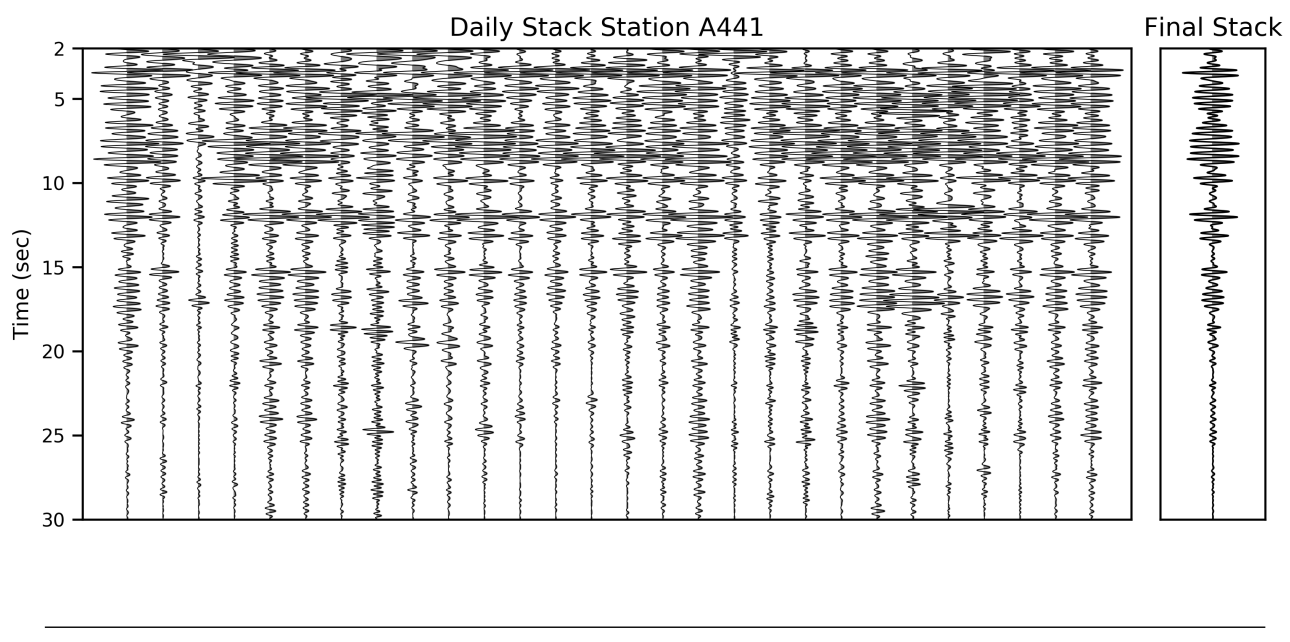

FIGURE 2.14: Example of a daily autocorrelation section for a central station of the profile, showing the consistency of the retrieved reflections. On the right, the final stack is shown to compare the signal. Autocorrelations were computed using phase cross correlation within a frequency band between 1.5 to $4 \mathrm{~Hz}$.

As seen in Figure 2.14, at higher frequencies the vertical resolution increases. The red box marks a reflection that at a lower FB range only resolves a big amplitude event, whereas at higher FB it is clear that it also contains signal from other features. Therefore, the selection of the best frequencies was based on the recovered reflectivity and the consistency of the daily stacks of the stations. Daily stacks for each frequency were computed from the available the data and the convergence of the autocorrelations were checked. For frequencies above $4 \mathrm{~Hz}$ the daily stacks did not converge as expected. Accordingly, and due to the limited amount of recorded days, the top frequency was set to $4 \mathrm{~Hz}$. The bottom limit of the filter was set to avoid the microseismic noise peaks that strongly influences the lower frequencies. Thus, the selected frequency band applied to all stations was $1.5-4 \mathrm{~Hz}$ as it provides good reflectivity down to upper mantle depths along with consistent daily stacks for all stations. After applying the band-pass filter, the $1 \mathrm{~h}$ data segments were autocorrelated for a 0 -30s lag-time window using the PCC (Schimmel, 1999). The consistency of the autocorrelograms is checked by plotting the daily autocorrelations together to highlight coherent arrivals (Fig. 2.14). Where arrivals are consistently retrieved for most of the days, they are considered reflections responding to the subsurface structure. Note that a P-to-P wave reflection at an impedance increase is expected to have a negative amplitude (blue and/or troughs) owing to the free-surface reflection. The data is then daily stacked using the PWS and finally the daily stacks are summed to get the final autocorrelogram. Through stacking autocorrelograms we obtain the P-wave reflectivity of the subsurface. As in the GloPSI case, the autocorrelation process also creates at $\mathrm{t}=0 \mathrm{~s}$ a strong arrival which ideally corresponds to a delta function (Claerbout, 1968) and whose sidelobes dominate and obscure the early time of the autocorrelation trace. The sidelobes are due to the convolution of the zero-lag delta pulse with the effective noise source time function. To eliminate this effect and for visualization purposes, we have 
muted the signal from 0 to $3 \mathrm{~s}$, and data has been amplitude normalized.

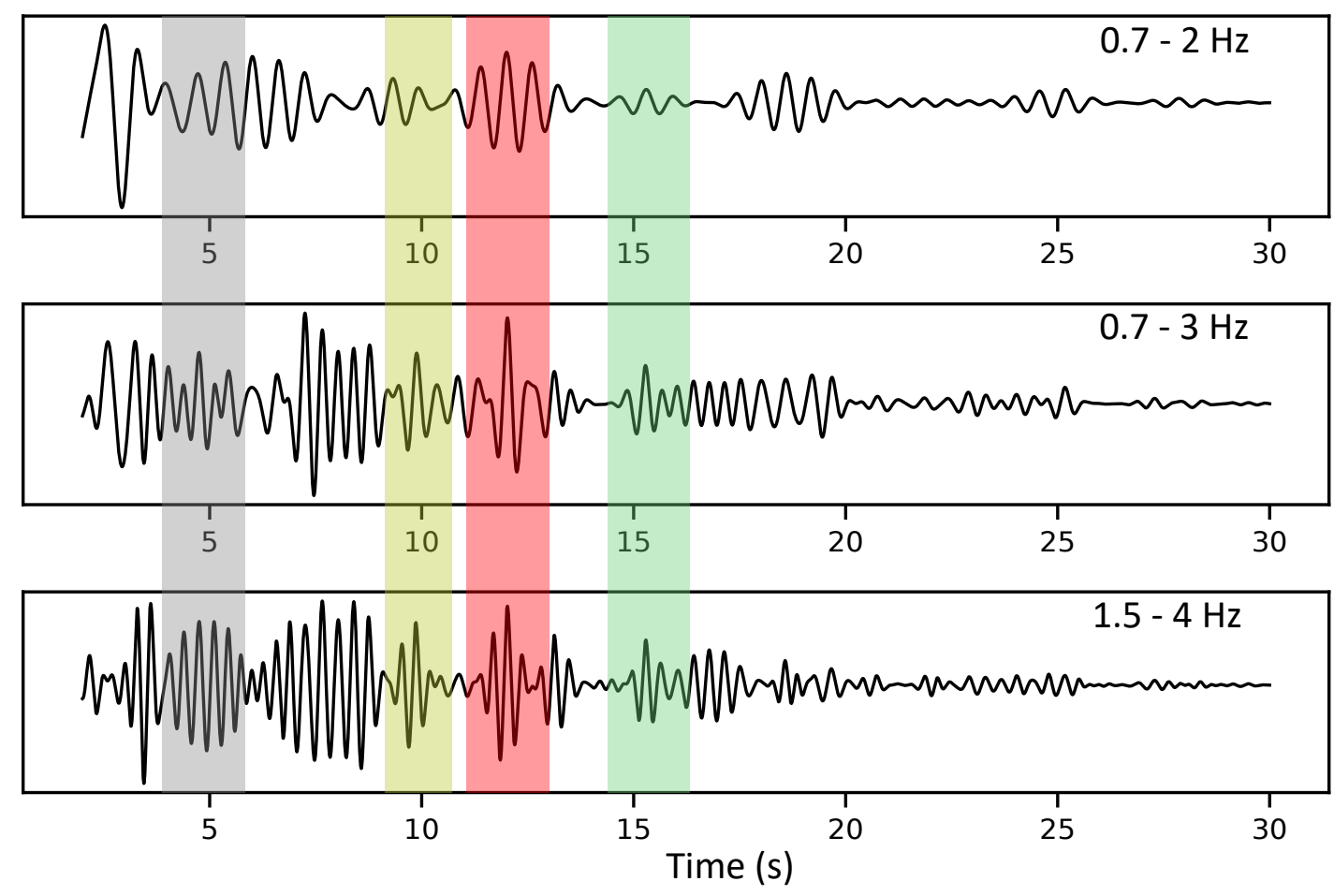

FiguRE 2.15: Example of frequency bands tests, ranging from low frequencies (top) to higher frequencies (bottom). Coherent identified reflections are enclosed in colour bands. It is clear that, as frequency increases, more details are retrieved in the autocorrelations, while consistently capturing the main reflections. 



\section{Chapter 3}

\section{Curie Point Depth of the Iberian Peninsula and Surrounding Margins}

Most of this chapter, regarding data gathering, objectives, data processing, results and discussion, have been published in:

Andrés, J., Marzán, I., Ayarza, P., Martí, D., Palomeras, I., Torné, M., et al. (2018). Curie point depth of the Iberian Peninsula and surrounding margins. A thermal and tectonic perspective of its evolution. Journal of Geophysical Research: Solid Earth, 123, https://doi. org/10.1002/2017JB014994.

This chapter presents a slight modification of this paper to make the text consistent with other chapters and the thesis itself. 


\begin{abstract}
In this chapter the thermal structure of the Iberian Peninsula is derived from magnetic data by calculating the depth to the bottom of the magnetization, assumed to be the Curie-point depth (CPD) isotherm, which accounts for the depth at which magnetite becomes paramagnetic $\left(580^{\circ} \mathrm{C}\right)$. Comparison of the resulting CPD map with crustal thickness maps along with a heat flow map derived from the CPD values provides new insights on the IB lithospheric thermal regime. Results show that the CPD isotherm is located in the range of 17 to $29 \mathrm{~km}$. This isotherm is shallow ( $<18 \mathrm{~km}$ ) offshore, where the lithosphere is thinner. In continental Iberia, the NW IM presents a magnetic response that is most probably linked to late Variscan extension triggered by earlier crustal thickening. This resulted in crustal thinning, widespread crustal melting and emplacement of granites. The signature of the CPD at the Gibraltar Arc reveals a geometry consistent with the slab roll-back geodynamic model that shaped the western Mediterranean. In offshore areas, a broad extension of magnetized upper mantle is inferred. Serpentinization of the upper mantle, probably triggered in an extensional context, is proposed to account for this magnetic signal. The Atlantic margin presents up to $8 \mathrm{~km}$ of serpentinites, which, according to the identification of exhumed mantle, correlates well with its interpretation as a hyperextended margin. The Mediterranean also presents generalized serpentinization up to $6 \mathrm{~km}$ in the Algerian Basin. Furthermore, a heat flow map and a Moho temperature map derived from the CPD are presented.
\end{abstract}




\subsection{Introduction}

The thermal structure of the crust and lithosphere is related to ancient and active tectonics, and its knowledge constrains geodynamic reconstructions. It provides insights on the internal state of the mantle, its evolution, and its geochemistry, as the mechanical/physical properties of the lithosphere are temperature dependent Afonso et al. (2005). Understanding of the regional variations in the thermal regime is an important target in geophysics, as it influences crustal magmatism, seismicity, rheology, the distribution of the seismic wave velocities, and seismic wave attenuation. (Li and Wang, 2016) state that surface heat flow variations cannot be faithfully used in inferring deep thermal structures, which can be better constrained overall through Curie-point depth (CPD) maps derived from magnetic anomalies. Furthermore, heat flow is one of the most elusive geophysical observable, it is difficult to measure directly, and its measurements are irregularly distributed and characterized by large variability (Davies, 2013). Therefore, the calculation of the CPD is a good proxy for the thermal configuration of the lithosphere.

The Curie point is the temperature above which a ferromagnetic material starts behaving as paramagnetic. In the Earths crust, iron-titanium oxides (titanomagnetite and titanohematite series) are the main source of magnetic anomalies (OReilly, 1976). The temperature of the Curie point for these oxides depends on the titanium content. If the titanium fraction is low, the Curie point can be approximated to $580^{\circ} \mathrm{C}$ (the value for magnetite). In some rocks the titanium fraction can be important and the Curie point decreases to values closer or below 500C (Herrero-Bervera et al., 2011). However as the most important magnetic anomalies are sourced by magnetite, its Curie point $\left(580^{\circ} \mathrm{C}\right)$ is often used as temperature at the CPD.

The topography of the CPD can be used to estimate the geothermal gradient, the heat flow, and the lithospheric thickness of an area, all of them key components in understanding the tectono-thermal structure and evolution of a region. However, the use of the CPD in calculating the heat flow and in the interpretation of results relies on the assumption that it corresponds to the $580^{\circ} \mathrm{C}$ isotherm. Issues could arise due to compositional heterogeneities or where the bottom of the magnetization does not correspond to that temperature because of the absence of magnetite at depth.

Historically, aeromagnetic data have been used to estimate the CPD by undertaking spectral analysis in the Fourier domain. Several authors have later developed new methods to calculate the CPD, first assuming random magnetization (Bhattacharyya and Leu, 1975; Okubo et al., 1985; Tanaka et al., 1999), and later, introducing the fractal distribution of the magnetization into the equations (Bouligand et al., 2009; Li et al., 2013; Salem et al., 2014).

The aim of this work is to estimate, the bottom of the magnetization, which we assume to be the $580^{\circ} \mathrm{C}$ isotherm, in the Iberian Peninsula and surrounding margins. The position of this boundary provides the first step to calculate a heat flow map of Iberia. The calculated CPD map is also compared to a crustal thickness (CT) map obtained by compilation of active and passive seismic data results to assess the likelihood of an upper magnetic mantle and its tectonic implications. Lateral changes in 
the topography of the CPD give useful insights on the thermal state of Iberia and can be correlated with the present and past geodynamic evolution of the area. However, some of the observations raise new questions about the structure and the tectonothermal history of Iberia.

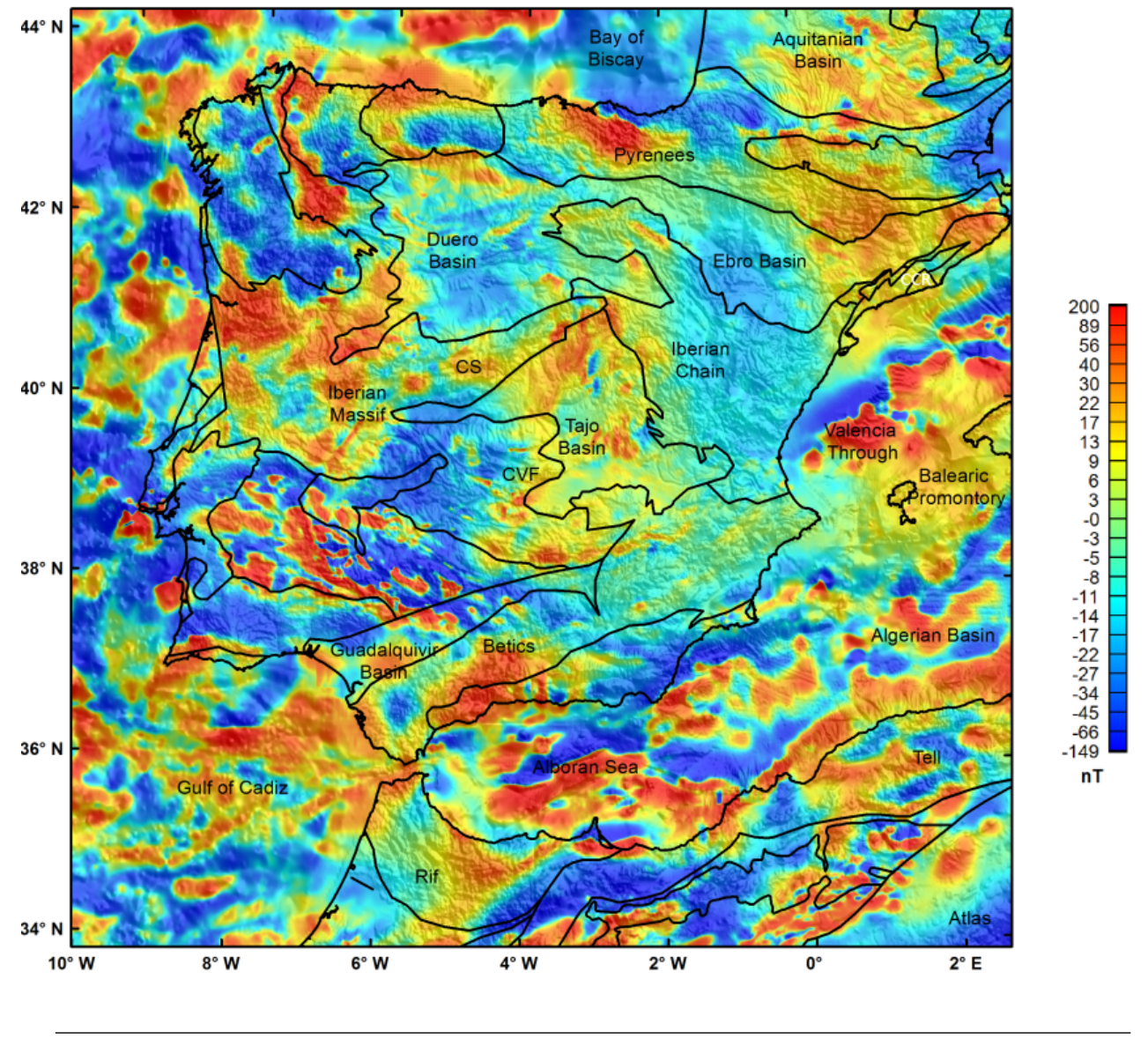

Figure 3.1: Map of the total magnetic field anomalies of the Iberian Peninsula and North Africa used in this study with overlapped major tectonic areas. The data come from Getech Group Plc. Data gaps have been filled with the EMAG 2 data set (see text for merging details).

\subsubsection{Magnetic Data}

The total magnetic field anomaly data (TMI) (Fig 3.1) are based on a compilation provided by Getech Group Plc. (Getech) and cover the Iberian Peninsula as well as northern Africa, from $45^{\circ} \mathrm{N}$ to $34^{\circ} \mathrm{N}$ and from $10^{\circ} \mathrm{W}$ to $5^{\circ} \mathrm{E}$. The magnetic data are included in Getechs European and Mediterranean Magnetic Project, which compiles data derived from many magnetic surveys with various acquisition parameters (Fletcher et al., 2011). The African part of the TMI map comes from Getechs African Magnetic Mapping project (Green et al., 1992). The distribution and limit of all individual surveys could be consulted in Getechs website (Surveys). Flight height and line spacing varies from survey to survey. The data was acquired offshore in form of shipborne, and airborne onshore. Therefore, offshore data acquisition height is $0 \mathrm{~m}$ above sea-level. For onshore data the range of flight elevation 
varies from $3000 \mathrm{~m}$ above terrain to just about $150 \mathrm{~m}$, being the majority below $2000 \mathrm{~m}$. Regarding the line spacing, the range goes from $250 \mathrm{~m}$ to $20000 \mathrm{~m}$ in some shipborne surveys. The majority of surveys have a line spacing below $3000 \mathrm{~m}$. All surveys were checked for errors and corrected prior to being joined together to form the contiguous digital grid. All data were adjusted to $1 \mathrm{~km}$ above terrain and are provided as continuous, merged $1 \mathrm{~km}$ grids (details on surveys and processing methodology can be found in previous references). The EMAG2 model (Maus et al., 2009) was used to fill some gaps in the data. Thus, it was resampled to $1 \mathrm{~km}$ grid spacing and downward continued to adjust it to $1 \mathrm{~km}$ height above terrain before merging it with Getechs data.

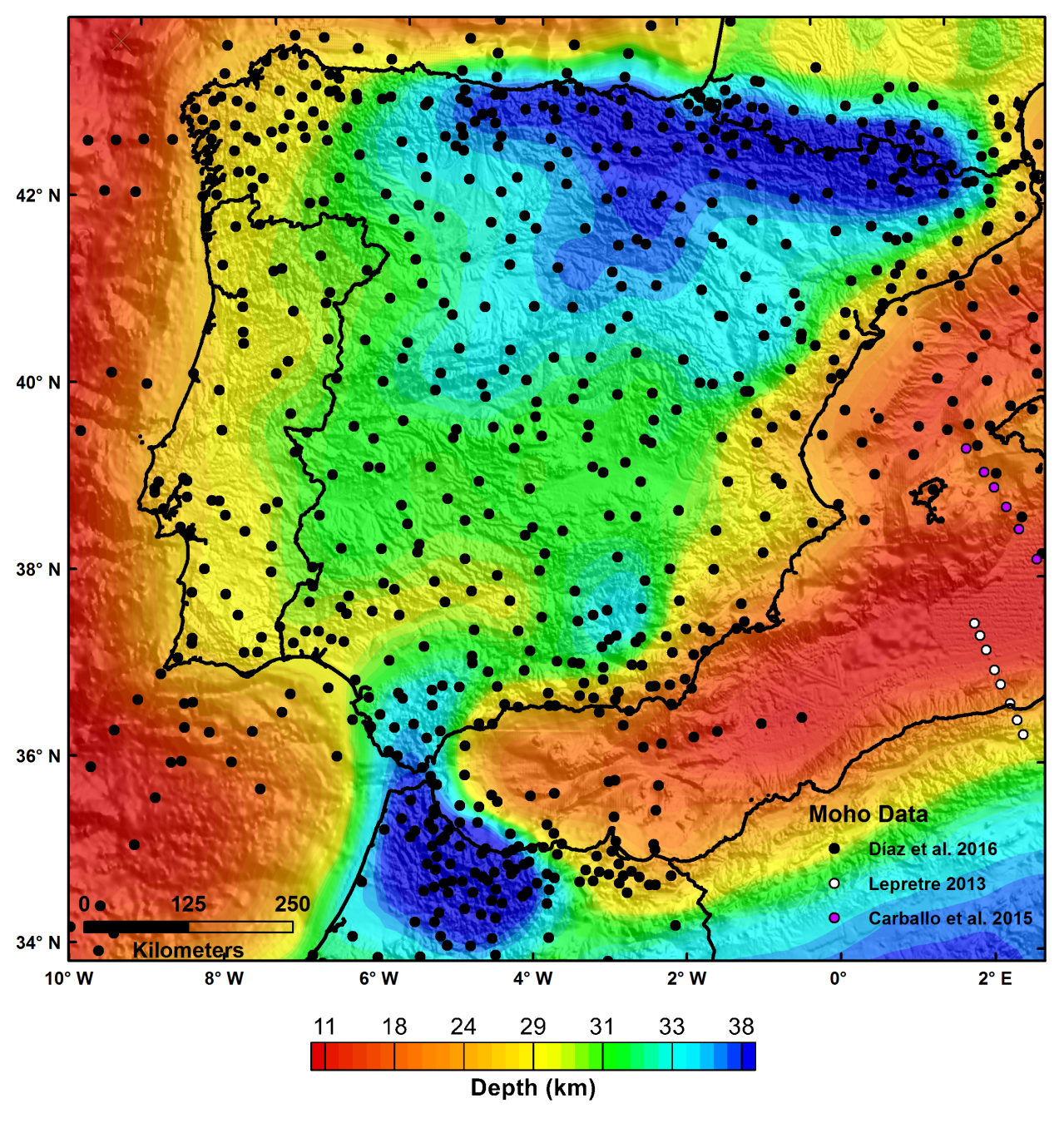

FiguRE 3.2: Moho map compiled from the data sets from Diaz et al. (2016), Carballo et al. (2015a), and Laske (2013). The bold lines represent geologic units as seen in Figure 3.1. 


\subsection{Data and Methods}

\subsubsection{Crustal Thickness Map}

For the purpose of comparing the bottom of the magnetization with the CT map in the study area, we have used a combination of data sets to represent the latter (Fig. 3.3): Diaz et al. (2016) supplies most of the CT of the continental Iberian Peninsula and the Valencia Trough. For the Algerian Basin, data come from Leprêtre et al. (2013) and Carballo et al. (2015a), while the global data set CRUST 1.0 (Laske, 2013) has been used for the areas where there is no local data (Fig. 3.2). The data from Diaz et al. (2016) result from active and passive seismic sources but lack information in the Atlantic Domain, which is covered by the CRUST 1.0 compilation (Laske, 2013). The data provided by Carballo et al. (2015a) come from potential field modeling.

\subsection{Results}

CPD corresponds to the depth at which rocks in a particular location reach their Curie temperature. It is assumed that this is an isotherm and corresponds to the bottom of the magnetization calculated by spectral analysis of magnetic data. This property provides the link between magnetism and thermal state (in the lithosphere). This surface represents the base of the magnetization below topography onshore and below bathymetry offshore. Therefore, it can be regarded as the thickness of the layer that is magnetized. For the sake of clarity, the CPD will be described and discussed in depth below elevation (topography and bathymetry). In the IB, the CPD obtained following the approach presented in chapter 2, corresponds to a surface located at depths between 27 and $13 \mathrm{~km}$ below elevation (Fig. 3.2). The resulting CPD map shows clear differences between $\mathrm{E}$ and $\mathrm{W}$, and also between onshore and offshore areas. Considering the CPD as an isotherm, we can define hot areas where CPD is shallow and cold areas where the CPD is deep. Cold values usually appear in the older and more stable Iberian Massif and the Alpine domains to the E, including the Cenozoic basins. Hot areas lie mostly offshore.

The W Mediterranean domain, including the Alboran Sea, is characterized by a relatively shallow $\mathrm{CPD}$, ranging between 17 and $20 \mathrm{~km}$ below elevation. There are three minima in this area, i) the Alboran Sea, ii) the Algerian Basin, and iii) N of the Balearic Promontory. All three describe a SW-NE lineation sub-parallel to the Mediterranean Coast.

These shallow values reach the interior of the Iberian Peninsula mostly in the NE (Fig. 3.2). A prominent feature is the relatively deep $(\simeq 3 \mathrm{~km}$ deeper $)$, N-S CPD located in the Valencia trough. The southern part of the study area, which includes the Gibraltar Arc and N Africa, is represented by deep CPD values reaching depths between 22 to $24 \mathrm{~km}$. Here the geometry of the Curie isotherm follows the geometry of the Betic-Rif orogenic system in the continental areas and continues to the Tell Mountains in NE Africa. To the S, in the edge of the study area, the CPD becomes shallower. Westward of the Gulf of Cadiz, the Atlantic margin shows shallow values ranging from 21 up to 16 $\mathrm{km}$ in its westernmost end, minimum values that extend over the Western Iberia Atlantic Margin, 
with the exception of the region offshore found at the same latitude of the Galicia Bank. These values extend to the $\mathrm{S}$ of Portugal but do not reach the interior of the Peninsula, being bounded by the Gibraltar Arc deep CPD values. In central Spain, shallow CPD values (up to $22 \mathrm{~km}$ ) appear locally over the Quaternary Calatrava Volcanic Field (CVF). To the NW of Iberia, the CPD deepens reaching more than $26 \mathrm{~km}$. These deep values extend to the E, getting to the Central System and part of the Iberian Chain. Over the Pyrenees there is not a marked trend in the CPD values, being quite variable and locally shallow, in contrast with the deeper values $(22-24 \mathrm{~km})$ observed in the western region of the Cantabrian Mountains. The Bay of Biscay presents shallow CPD $(<20 \mathrm{~km})$ toward the N except locally near $-7^{\circ}$. Marked minima of the CPD within the continental areas are located to the NE beneath the Catalan Coastal Ranges, in the SW area of Portugal, and in the western limit of the Algerian basin.

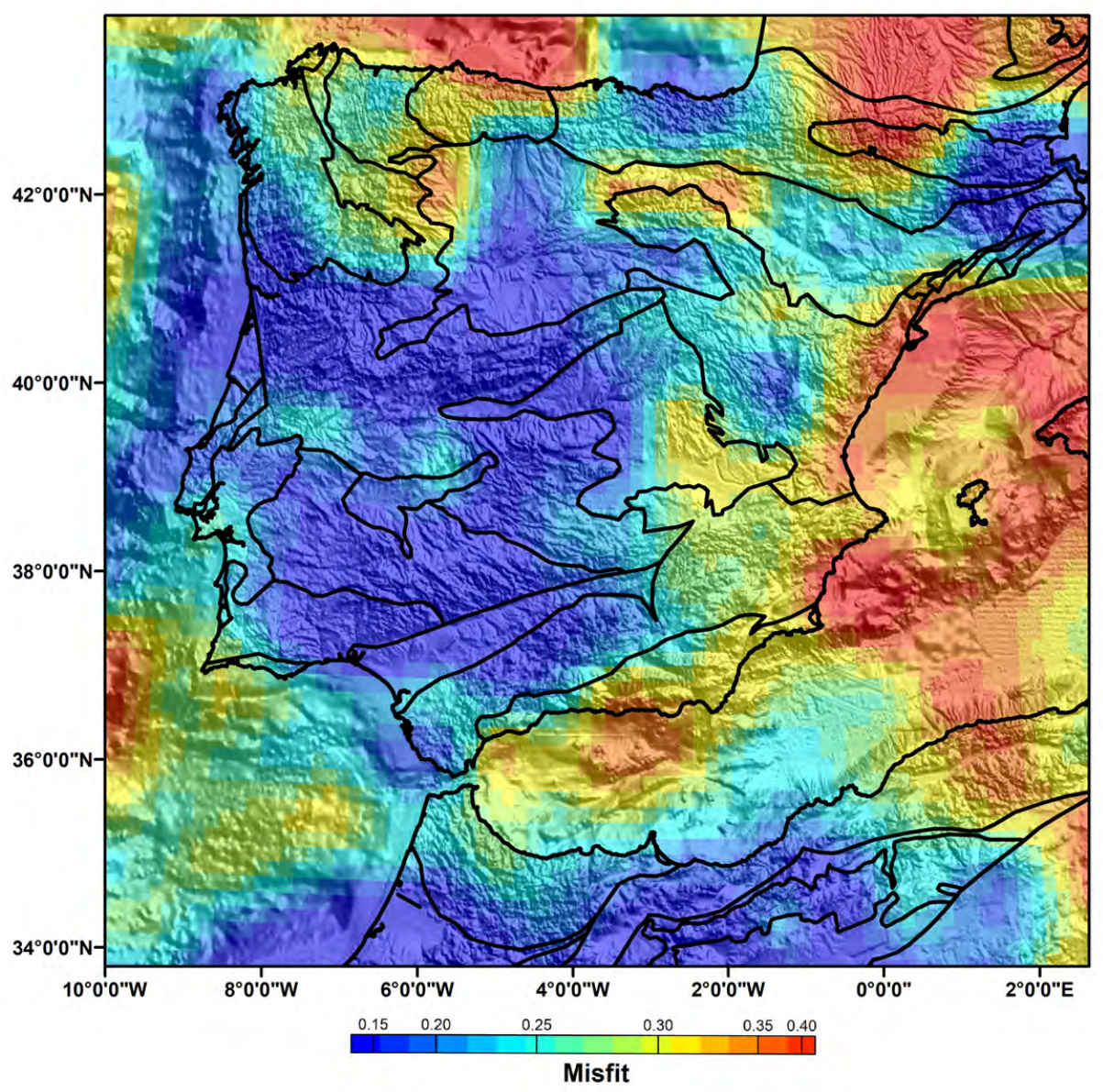

FiguRE 3.3: Map of the misfit between the observed amplitude spectrum and the modeled one using our CPD solutions. The Root-Mean-Square of the misfits is 0.27.

The bold lines represent geologic units as seen in Figure 3.1.

A global model of the CPD was presented by Li (2017). In this work the estimation of the CPD was performed using the EMAG2 data set, and calculating the CPD with a constant fractal exponent 
of 3. Comparison of these results with our CPD calculation presents consistent results. The mean value of the misfit between both maps is $3.4 \mathrm{~km}$ with the $\mathrm{Li}$ (2017) results being deeper than the results presented here. The minimum disagreement is found in the Mediterranean area where the misfit is mainly between $\pm 2 \mathrm{~km}$. Maximum differences are found in the Gibraltar Arc and in the Iberian Chain. There, a sharp contrast is found in the data set of Li (2017) from the Mediterranean to the onshore. The contrast is presented as a straight change with N-S direction. This sharp feature in the $\mathrm{Li}$ (2017) results could represent a problem in the data set used to calculate the CPD or an incorrect selection of $\beta$ for the area.

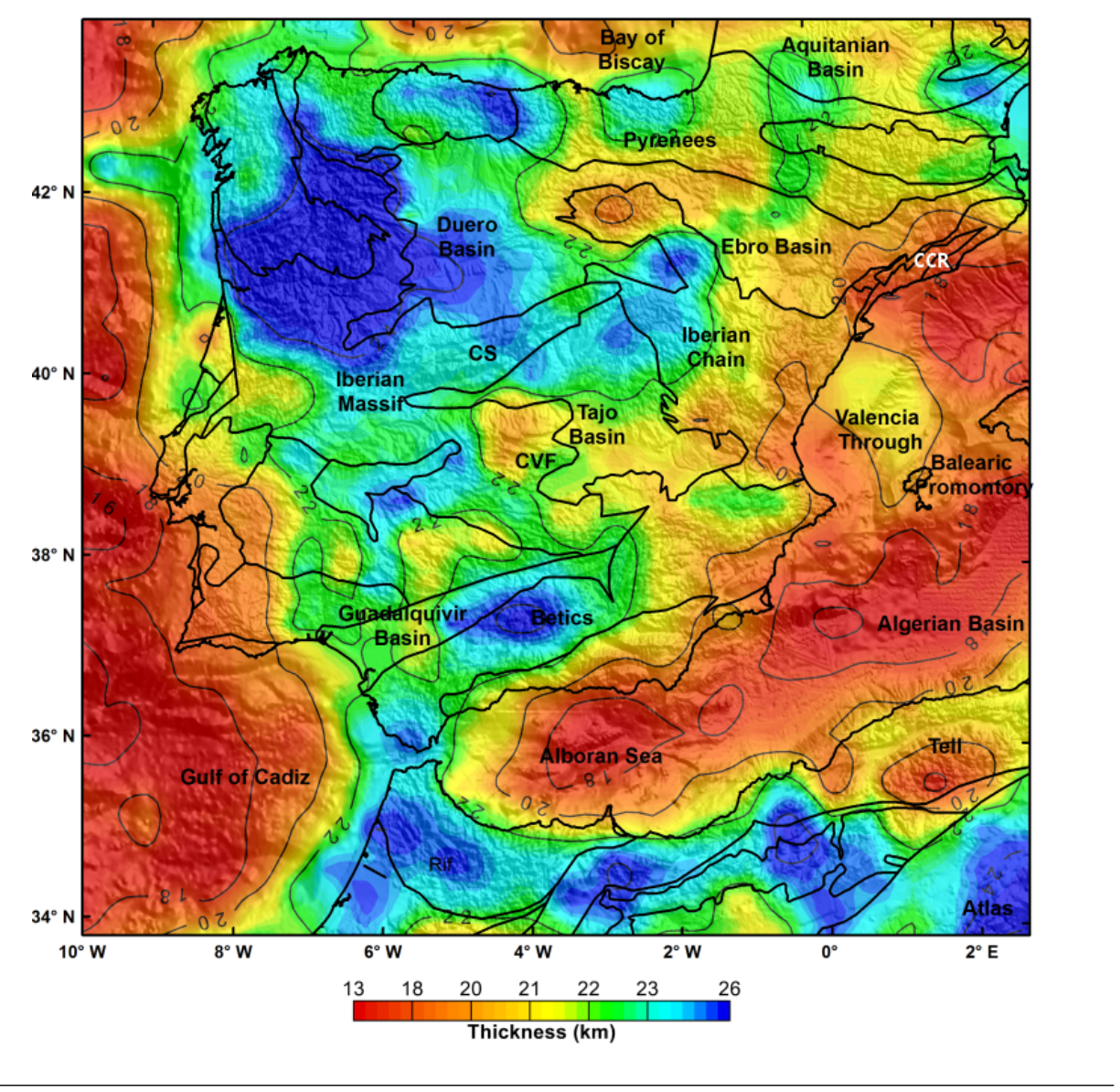

Figure 3.4: Curie-point depth (CPD) map of the Iberian Peninsula averaged from the CPD maps calculated with window sizes of $150 \times 150 \mathrm{~km}^{2}$ and $200 \times 200 \mathrm{~km}^{2}$. The map shows the thickness of the magnetic layer. The isolines correspond to contours of the CPD. The bold lines represent geologic units as seen in Figure 3.1.

Furthermore, we have adopted the methodology of Salem et al. (2014) in order to better constrain the fractal parameter. Our approach was based in visual inspection of the corrected amplitude spectrum applying different fractal parameters with the calculated values of $z_{b}$ and $z_{t}$ to check the goodness of fit. The resulting and a misfit map is provided in Figure 3.4. The calculated misfit assess the quality of the results by comparing the corrected amplitude spectrum with the synthetic amplitude spectrum generated with the obtained $z_{b}$ and $z_{t}$ values. In general, onshore the misfit is low when 
compared to offshore areas, specially around the Balearic promontory, but overall, it is in agreement with the expected error margin of the methodology (Bansal et al., 2013; Salem et al., 2014).

\subsubsection{Comparison of Crustal Thickness with Curie-Point Depths}

The relationship between the CT (Fig. 3.3) and CPD values (Fig. 3.4) is important to assess whether the mantle is magnetic or not and thus, to establish the tectonic settings where the mantle may contribute to magnetic anomalies. The CPD/CT offset (Fig. 3.5) depicts negative values representing CPD values deeper than the Moho and positive values representing areas where the CPD is shallower than the Moho. Onshore, the CPDs are mainly above the Moho (up to $25 \mathrm{~km}$ ) and offshore they are locally below this boundary (up to $10 \mathrm{~km}$ ). Continental and thermally stable areas like the Iberian Peninsula are expected to feature CPDs above the Moho, since they are, at present, thermally reequilibrated.

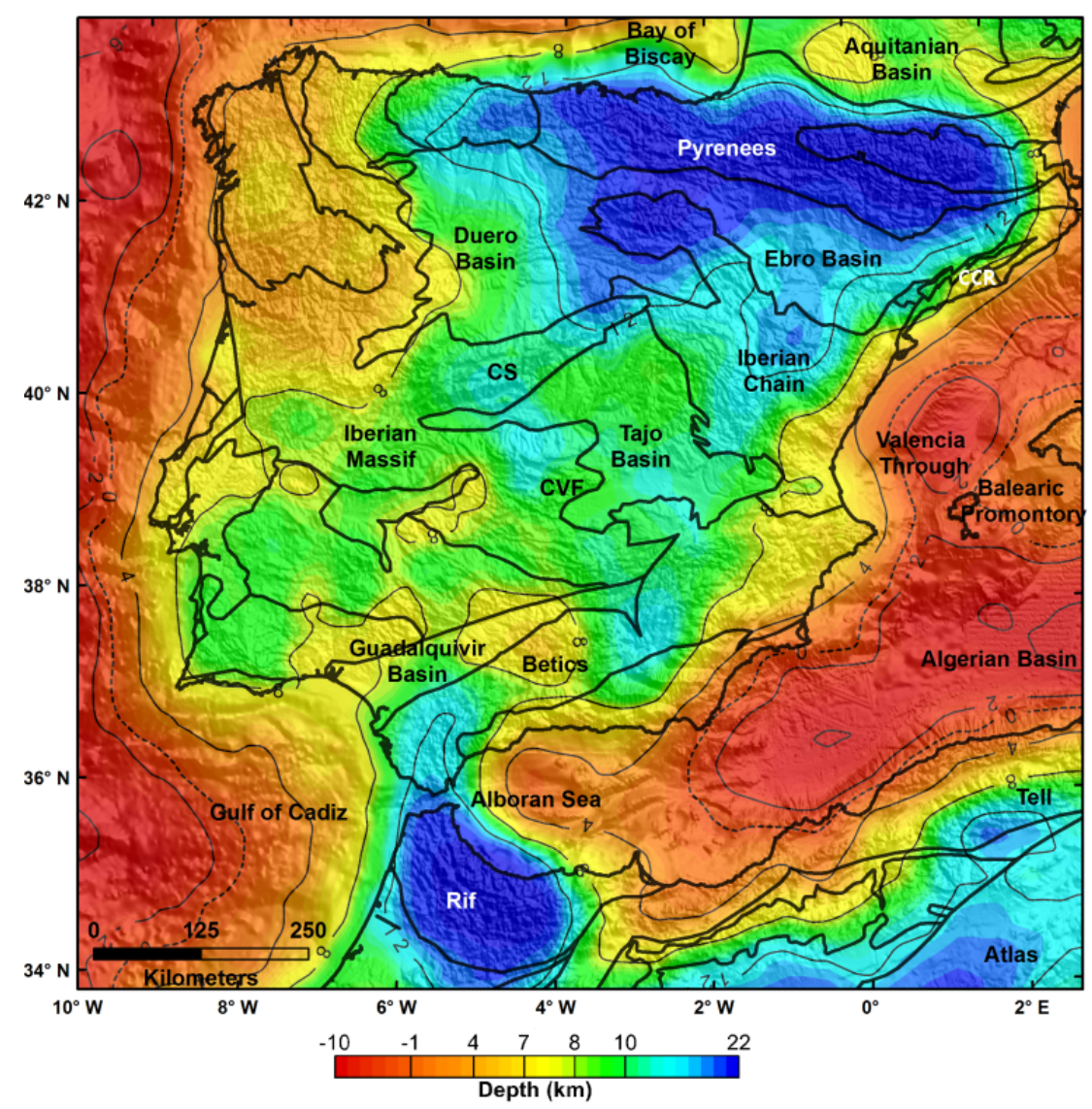

FiguRE 3.5: Map showing the differences between the crustal thickness and the Curie point depth (CPD) (Figure 3.4). Negative values (red) correspond with CPD (Fig. 3.4) deeper than the Moho (black dashed line). Positive values (orange/green/blue) represent CPD above the Moho. The bold lines represent geologic units as seen in Figure 3.1 
Among the onshore areas, the Betic-Rif and Pyrenees mountain belts present the highest differences between the CT and CPD as deep crustal roots have been proposed for both orogens (Diaz et al., 2016). In addition, the CPD/CT offset in the Pyrenees extends to the S into the Iberian Chain. The western part of the IB, mostly corresponding to the Iberian Massif, is more homogeneous presenting CPD/CT differences around 8 to $10 \mathrm{~km}$ depth. The NW part of the Iberian Massif shows an elongated, NNW-SEE directed area where the CPD/CT differences are below $8 \mathrm{~km}$, even descending to $4 \mathrm{~km}$ in its central part.

For offshore areas we find that the CPD is usually located beneath the Moho, such as in the Atlantic Margin areas, including the Gulf of Cadiz and the Bay of Biscay. This pattern is also observed in the Alboran Sea, and the Algerian Basin. The mean depth difference between CPD and $\mathrm{CT}$ in these areas is $3 \mathrm{~km}$ but locally can get up to $8 \mathrm{~km}$. The CPD/CT offset characterizing the western Mediterranean is high in part of the Alboran Sea and increases constantly toward the Algerian Basin, and the Valencia Trough, with a local decrease in the Balearic Promontory. This configuration indicates an altered upper mantle.

However, not every offshore area presents CPD values deeper than the Moho. The Atlantic margin does feature CPDs deeper than the Moho along the coast line. But in the Gulf of Cadiz, this negative offset is displaced to the WSW where the Moho map (Fig. 3.3) places this boundary at depths within the 20-25 km range. The Bay of Biscay is also characterized by a Moho deeper than the CPD close to the coast but this configuration seems to change to the $\mathrm{N}$.

\subsubsection{Heat Flow Map}

We have calculated a heat flow $\left(Q_{\mathrm{o}}\right)$ map for the Iberian Peninsula and surrounding margins from the CPD map assuming steady state condition. The surface heat flow for a layer has two components: the background heat and the heat production inside the layer from radiogenic decay. From the Fouriers law, the 1-D surface heat flow in steady state, with constant heat production $(A)$, constant thermal conductivity $(k)$, surface temperature $\left(T_{\mathrm{o}}\right)$, and temperature at $Z$ depth $\left(T_{\mathrm{z}}\right)$, is as simple as

$$
Q_{o}=\frac{A Z}{2}+\frac{\left(T_{z}-T_{o}\right) k}{Z}
$$

In our case, $T_{z}=T_{c p d}$ is the temperature of the bottom of the magnetic layer. When CPD is above the Moho, we calculate as a one-layer problem:

$$
Q_{o}=\frac{A Z_{c p d}}{2}+\frac{T_{c p d}-T_{0} k_{c}}{Z_{c p d}}
$$

but when CPD is below the Moho, we calculate as a two-layer problem (Fig. 3.6):

$$
Q_{o}=\frac{\left[T_{c p d}-T_{o}+A Z_{m}\left(C P D-Z_{m}\right) / k_{m}+\left(A Z_{m}^{2} / 2 k_{c}\right)\right]}{\left[Z_{m} / k_{m}+\left(C P D-Z_{m}\right) / k_{m}\right]}
$$




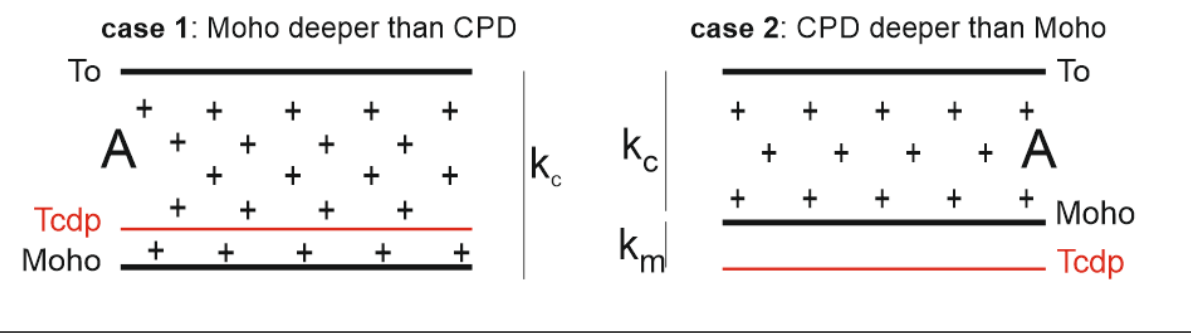

Figure 3.6: Surface heat flow has been calculated as a one layer problem when the Moho is deeper than Curie point depth (CPD) and as a two layers problem when CPD is deeper than the Moho. We assume that heat production (A) and thermal conductivity ( $k_{\mathrm{c}}$ for the crust and $k_{\mathrm{m}}$ for the mantle) are constant.

Values of surface temperature for continental Iberia were taken from a map of mean surface temperature from Hijmans et al. (2005). For offshore areas, this information was taken from Boyer et al. (2005). The calculations have been performed assuming steady state conditions. Values for thermal parameters such as thermal conductivity and radiogenic crustal heat production are assumed constant for the crust and upper mantle. A thermal conductivity of $2.2 \mathrm{~W} / \mathrm{mK}$ is used for the crust where $\mathrm{CT}>\mathrm{CPD}$, as a mean value accounting for sediments, upper and lower crust. In offshore areas where the CPD is thicker than the CT, a value of $2.7 \mathrm{~W} / \mathrm{mK}$ has been used to account for the altered upper mantle (Osako et al., 2010) in the Mediterranean area. We assumed a radiogenic heat production of $1 \mu \mathrm{W} / \mathrm{m}^{-3}$ for the crust (Fernández et al., 1998) and null for the lithospheric mantle.

The $Q_{o}$ map (Fig. 3.7) presents similar features to the CPD map shown in Figure 3.4. In general, continental areas present the lowest values ranging from 60 to $72 \mathrm{mV} / \mathrm{m}^{-2}$ except for some coastal regions where values up to $80 \mathrm{mV} / \mathrm{m}^{-2}$ are reached.

Low $Q_{o}$ values are found throughout the IB, with minima in the GTMZ area. We believe that this minima derives from the use of constant thermal parameters for the $Q_{o}$ calculations as this is a highly crystalline area where high thermal conductivity and heat production values are expected. Relative minima are found as well in the Betics and in the Rif cordillera. Offshore areas present high $Q_{o}$, with the Atlantic margin showing the highest values. The Mediterranean portrays a NE-SW lineation of high $Q_{o}$, except in the Balearic Promontory where a minimum of $7276 \mathrm{mV} / \mathrm{m}^{-2}$ is found. Singularities in this map are found over the Tell Mountains, where a relative maximum stands out over the relative low values of the eastern Atlas Mountains. In continental Iberia, two singularities are found: the relative maxima enclosing at the CVF in central Iberia and that at the Sierra de la Demanda, to the N. A comparison with available heat flow $\left(Q_{o}\right)$ measurements (Fernández et al., 1998) depicts a good correlation between the calculated and the measured $Q_{o}$ values (Fig. 3.7) despite that short wavelength anomalies cannot be captured by the gradient map due to its resolution. Small discrepancies could be regarded as the effect of using constant values of thermal conductivity and radiogenic heat production. The best correlation is found in the western Mediterranean where most data are concentrated. Transitions from high to low $Q_{o}$ measured values are captured by the calculated $Q_{o}$ map in the Algerian Basin (Fig. 3.7) and toward the W in the Alboran Sea and Gibraltar Arc. In onshore areas, the lack of a good $Q_{o}$ values coverage makes the relationship between both variables 
difficult. However, good correlations are found in the SW Iberian Peninsula, where high $Q_{o}$ coincides with the measured values. Still, direct comparison between both variables should be taken with care. The calculated $Q_{o}$ has a better coverage onshore than the measured one. Furthermore, measured $Q_{o}$ data respond to the thermal state of the shallowest crust and can be affected by hydrothermal processes, which may alter the measurements.

\subsubsection{Moho Temperature Map}

Following the calculation of the $Q_{\mathrm{o}}$ map for the Iberian Peninsula and surrounding areas, we have computed the temperature at the Moho (Fig. 3.8). We have used the same thermal parameters as in the calculations of $Q_{\mathrm{o}}$, according to the steady state formulation,

$$
T_{m}=-A Z_{m}^{2} / 2 k_{m}+Q_{o} Z_{m} / k_{c}+T_{o}
$$

where $T_{\mathrm{m}}$ is the temperature of the Moho, $Z_{\mathrm{m}}$ is the Moho depth, $k_{\mathrm{c}}$ is the crustal thermal conductivity, and $T_{\mathrm{o}}$ is the surface temperature.

The map portrays a clear differentiation between Variscan and Alpine terrains, where the latter are clearly hotter than the former. The maximum values are found where the crust is thickest, i.e., in the Pyrenees and Rif mountains, with temperatures between 800 and $850^{\circ} \mathrm{C}$. For the rest of continental Iberia, the Moho temperature values are in the range of $600750^{\circ} \mathrm{C}$, with the exception of SW Portugal where values of $750-800^{\circ} \mathrm{C}$ are found. For offshore areas, values are in the range of $400600^{\circ} \mathrm{C}$ being lower in the Algerian Basin and close to the Alboran Sea in the Mediterranean and in the Atlantic.

\subsection{Discussion}

Magnetic data of the Iberian Peninsula and surrounding margins are used to estimate the bottom of the magnetic layer, which we reconcile with the CPD. Assuming that magnetization responds to the magnetite content, the resulting CPD represents the $580^{\circ} \mathrm{C}$ isotherm (Fig. 3.4. This is later compared with a CT map of the Iberian Peninsula (Fig. 3.3) in order to provide constraints in its thermal regime. Furthermore, the data are then used to compute the $Q_{\mathrm{o}}$ map and Moho temperature map for the area (Fig. 3.7 and 3.8). The more relevant findings and implications of this study are addressed in the following sections.

\subsubsection{Betic-Rif Orogenic System/Gibraltar Arc}

The Gibraltar arc is described as an arcuate orogenic system originating from the convergence of the IB with the African plate. Different geophysical studies have pointed out the possibility of the Alboran delaminating slab to be attached at some parts to the orogen (Palomeras et al., 2014; Thurner et al., 2014). From a thermal perspective, the presence of a sunken slab would perturb the thermal regime, decreasing the geothermal gradient (Syracuse et al., 2010) and thus deepening the CPD and 
decreasing $Q_{o}$. These issues are consistent with the maps provided in Figures 3.5 and 3.7. We therefore

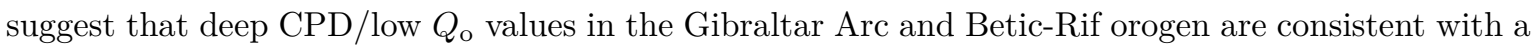
thickened crust (55 km in the Rif; Diaz et al. (2016)) and lithosphere. If this relationship is correct, it can be proposed that the slab is still attached or has been recently detached under the Betics between $6^{\circ} \mathrm{W}$ and $3^{\circ} \mathrm{W}$, and $\mathrm{N}$ and $38^{\circ} \mathrm{N}$.

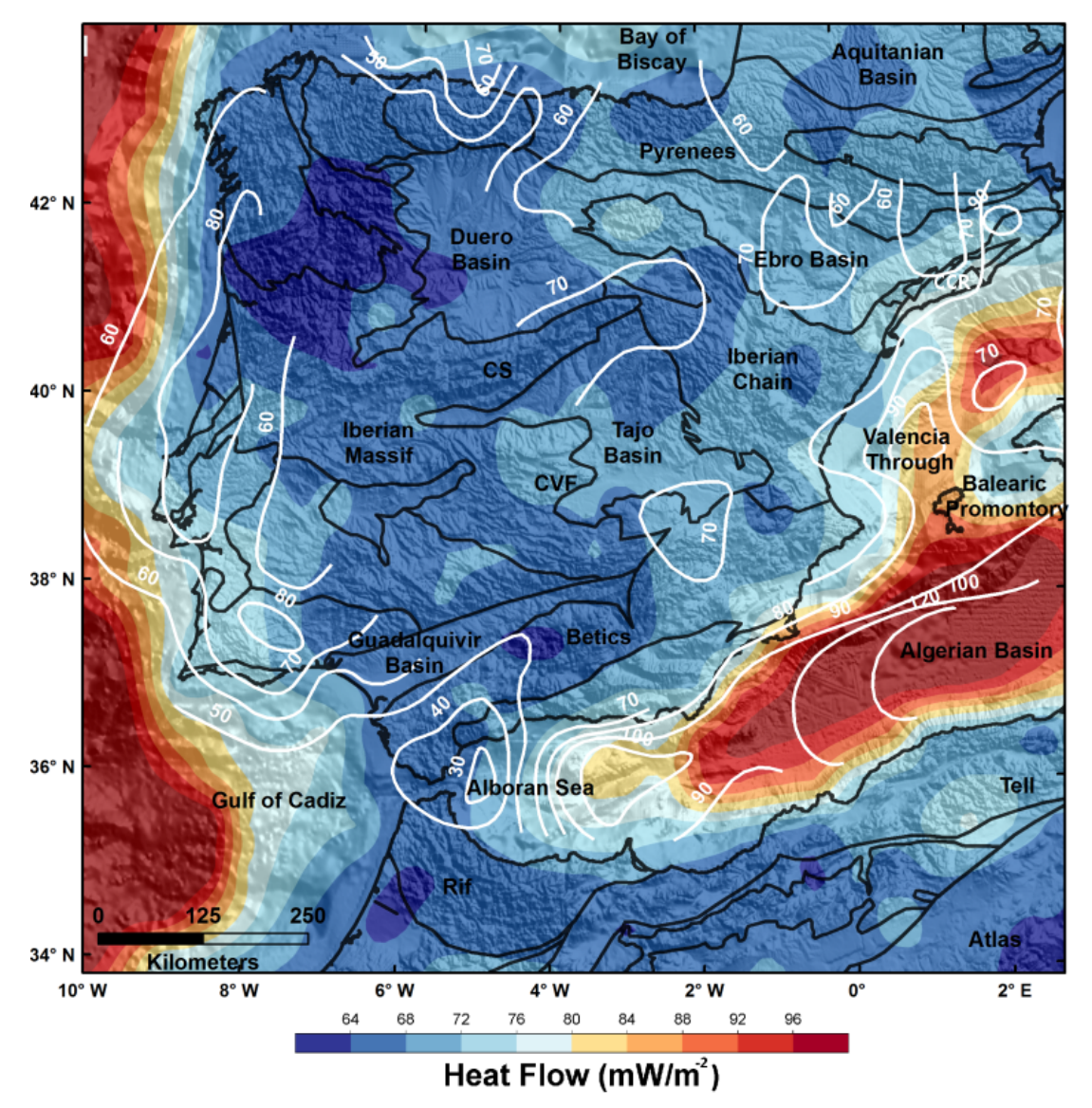

Figure 3.7: Heat flow map of the Iberian Peninsula and surrounding areas derived from the CPD map presented in Figure 3.4. The bold lines represent geologic units as seen in Figure 3.1. The white lines represent heat flow trends measured by Fernández et al. (1998).

According to our data, the slab might have a NE-SW direction with a significant change in the trend of the CPD shallowing toward the E. In the African margin, deep CPD and low $Q_{\mathrm{o}}$ are observed in the Rif area (in northern Morocco) continuing to Algeria into the Tell Mountains. There, the E-W trend of the CPD changes its orientation to NE-SW, probably in relation to the crustal thickening of the latter mountain belt, continuation of the Atlas Mountains.

To the S of the Rif Mountains, the CPD becomes shallower as we approach the Atlas Mountains. Even though the Tell Mountains are a prolongation of the Atlas Mountains and the same CPD distributions should be expected, a lithospheric thinning has been identified underneath the latter (e.g., Palomeras et al., 2014; Teixell et al., 2005; Zeyen et al., 2005) possibly related to the Canary 
Islands mantle plume (Duggen et al., 2009) or lateral flow of the Alboran slab (Levander, 2014). Our data support the existence of a high thermal gradient in the Middle and High Atlas even though this area is located at the southern edge of our data set. This may lead to shallower CPD values (Fig. 3.4) and higher Moho temperatures (Fig. 3.8) in response to the asthenospheric upwelling and is also consistent with outcrops of Quaternary volcanism.

\subsubsection{Western Mediterranean}

The western Mediterranean tectonic evolution is strongly linked to the development of the Gibraltar Arc. Geographically, it includes the Alboran domain, the Algerian Basin, the Valencia Trough, and the Balearic Promontory (Fig. 2.1).

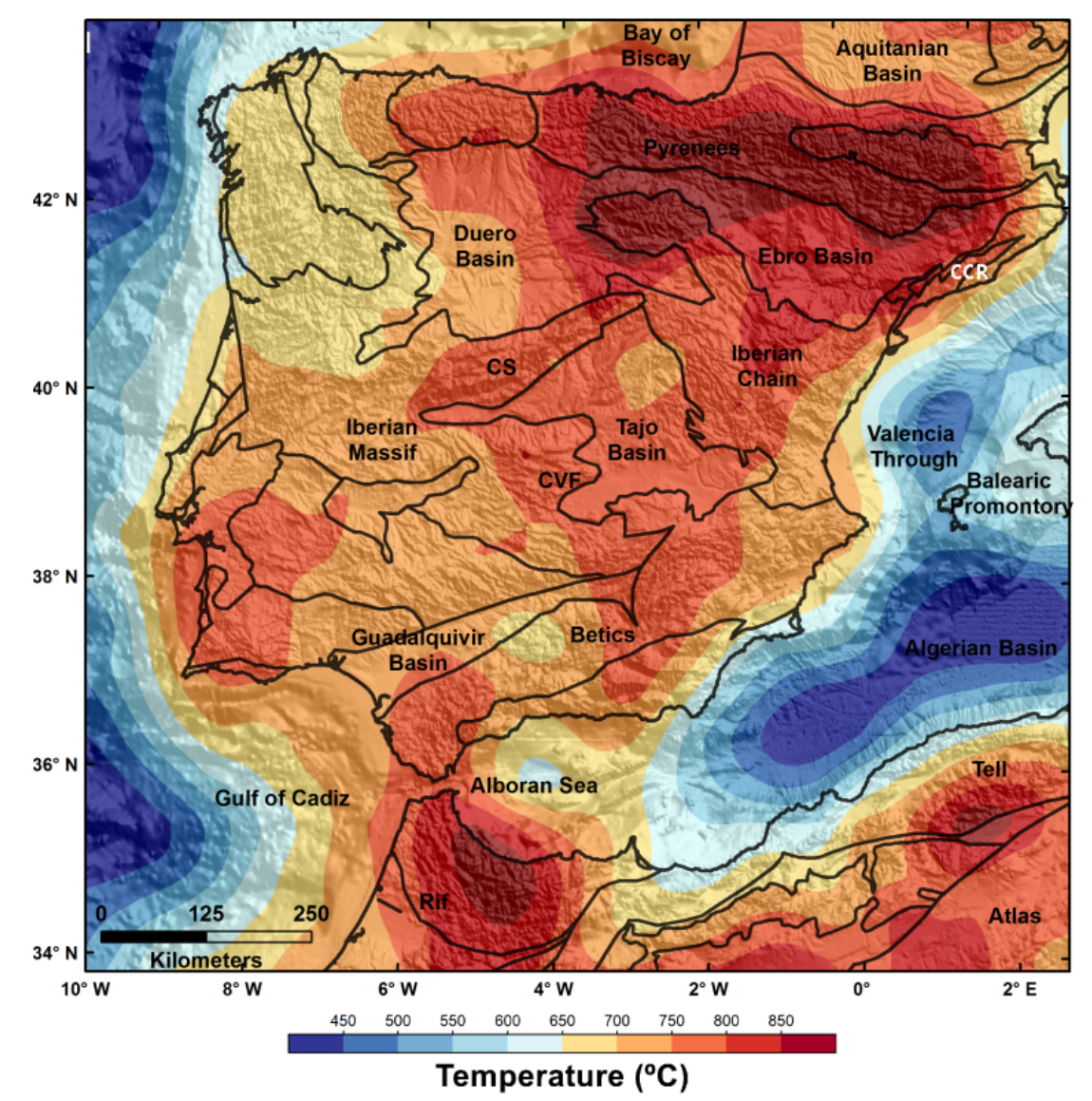

Figure 3.8: Moho temperature map of the Iberian Peninsula and surrounding areas derived from the CPD map presented in Figure 3.4. The bold lines represent geologic units as seen in Figure 3.1.

As seen in the CT map, the western Mediterranean represents an area of thin crust $(\sim 15 \mathrm{~km})$. Comparison of the CT map with our final solution for the base of the magnetized layer (Fig. 3.5) reflects that the Moho is shallower than the CPD, suggesting an almost generalized magnetization of the upper mantle in the Mediterranean. This magnetization follows the geometry of Iberia and Africa shorelines and reaches onshore areas in the Tell Mountains and locally in NE Iberia. The magnetized 
mantle layer extends northward until the Valencia Trough, where no magnetic mantle is identified near the coast. Instead, contours are displaced to the E, until they reach the Ibiza Island within the Balearic Promontory, where mantle seems to contribute to the magnetization again. The maps suggest a relatively thick layer of magnetized mantle in the Algerian Basin and the E part of the Alboran domain, but none close to the subduction zone. Another thick layer of magnetized mantle is found in the Valencia Trough, located between the coast and the Balearic Islands.

Magnetic mantle is commonly interpreted as an alteration of peridotites to serpentines (Ferré et al., 2013). In serpentines, magnetite is formed as a secondary phase, and it is responsible for most of the magnetic signal within the mantle. Serpentinites appear in some geodynamic contexts, such as subduction zones or extended margins. In the former, they result as the product of the mantle alteration due to hydration in the trench and the slab wedge, forming a thin layer that favors the exhumation of high-pressure rocks. In the latter, they appear as an interaction between extension, exhumation, and hydration. The change in mineralogy that serpetinization implies disturbs the rheological properties of the mantle (Guillot et al., 2015) due to the significant reduction in density and strength involved. This provokes a change in buoyancy that has been interpreted as a mechanism that further triggers crustal extension (Guillot et al., 2015). In this context, we propose that the magnetized mantle present in the western Mediterranean is formed by intrusion of water in the system, creating the alteration of upper mantle to serpentinites. The CPD/CT offset in the western Mediterranean (Fig. 3.5) could represent the maximum thickness of serpentinites. However, the possibility that the CPD just pictured the bottom of serpentinites, and not the depth to the $580^{\circ} \mathrm{C}$ isotherm (or vice versa), cannot be excluded. The latter would imply that serpentinites might exist deeper, but above the $\mathrm{Tc}\left(580^{\circ} \mathrm{C}\right)$ or contrarily just reach a depth that is above the $580^{\circ} \mathrm{C}$ isotherm. In any of these cases, the heat flow deduced would be wrong for this area.

Previous studies have pointed out the presence of altered mantle in the W Mediterranean. Different authors have studied the Valencia Trough and found slow velocities in the upper mantle from wide-angle and refraction seismic sections (Torné et al., 1992) and from thermal modeling (Carballo et al., 2015a; Torne et al., 2015). Our study portrays a relatively thick layer of serpentinite of variable thickness, ranging from 1 up to $6 \mathrm{~km}$ in the center of the Valencia Trough. Furthermore, serpentinized peridotites have been exhumed in the Alpujárride Complex (southern Spain) and in Beni Bousera (northern Morocco) (Pedrera et al., 2016). Figure 3.5 also infers magnetic mantle in the Algerian Basin. It is reasonable to correlate these features with serpentinization since the Algerian Basin is likely formed by thin oceanic crust.

The geodynamic evolution of the western Mediterranean is highly complex, and the origin of the serpentinized upper mantle could be attributed to different causes and temporal scenarios. First, it could be the result of the extension due to slab roll-back of the Gibraltar Arc. Extensional tectonic settings favor the intrusion of water through normal faulting (Guillot et al., 2015). The increasing buoyancy induced by the serpentinization could severely feedback in the amount of crustal extension. This may be the case of the thick serpentinized layers in the Valencia Trough and Algerian Basin, although the first was aborted during Late Miocene (Etheve et al., 2016), while the second progressed. 

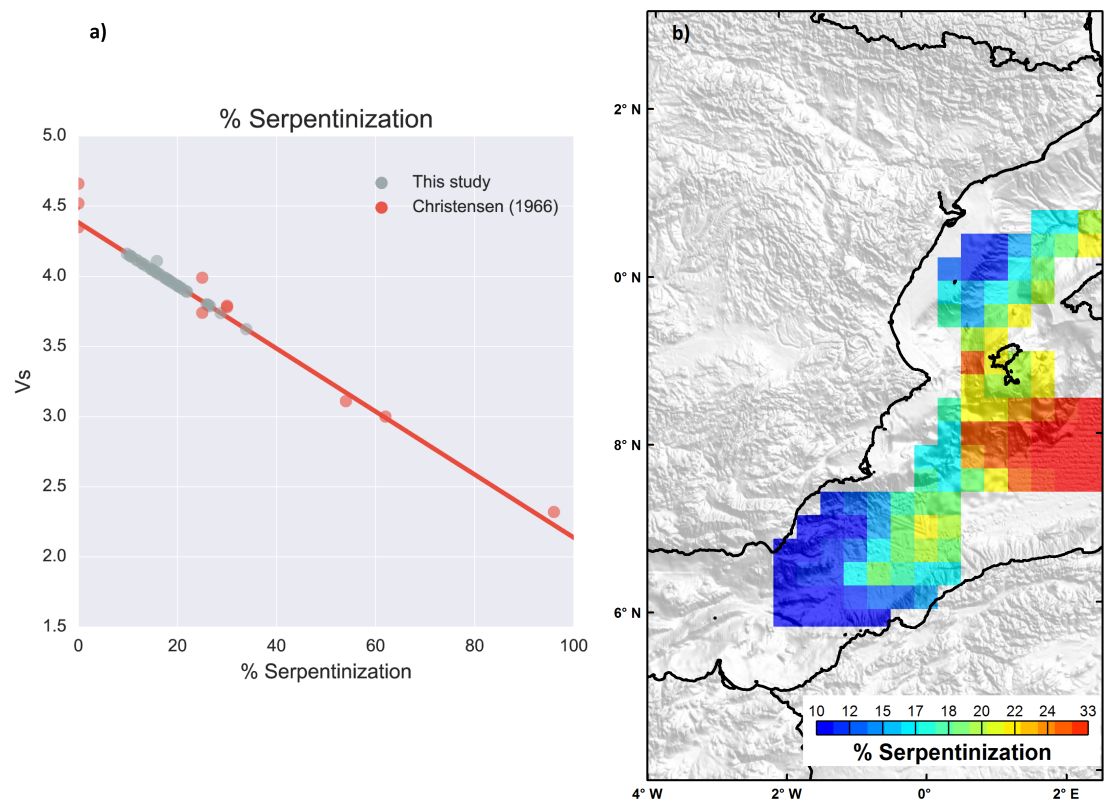

Figure 3.9: (a) $S$ - wave velocity of the upper mantle as a function of degree of serpentinization. The red dots represent laboratory measurements by Christensen (1966); the grey dots are based on Vs velocities from Palomeras et al. (2017). (b) Degree of serpentinization of the upper mantle. The extent is derived from the Curiepoint depth/crustal thickness offset, and the percentage is obtained from Figure 3.9a

Thus, the serpentinization could be the expression of the upper mantle evolution during the post-slab retreat.

However, the presence of serpentines might not only be the result of the most recent geodynamic evolution of the Mediterranean, but an inherited feature. A process like the subduction rollback in the W Mediterranean needs a low strength interface to trigger the decoupling of the slab. Thus, the presence of a layer of hydrated mantle could act as a weak shear zone. The Balearic Promontory underwent different extensional events associated with the opening of the Alpine-Maghrebian Tethys from Late Triassic to Early Cretaceous, and extensional-compressional events from Late Cretaceous to Cenozoic. This evolution is similar to that of adjacent areas such as the W Alps, Corsica, and the Pyrenees, where hyperextended rifted margins and exhumed serpentinites have been described (Beltrando et al., 2014; Jammes et al., 2009). Some authors have made numerical modeling of the evolution of the subduction rollback (Chertova et al., 2014). Their results pictured the initiation of the lithospheric decoupling within the Valencia Trough and the Balearic Promontory, between the Iberian coast, Ibiza, and Mallorca. The location of this feature coincides with a relative maximum in our CPD map and the major thickness of magnetized upper mantle in the area. Accordingly, the presence of a serpentinite layer in this point could have helped the decoupling of the lithosphere and the initiation of the slab retreat. As a result, the current serpentinization of the W Mediterranean could be the expression of different stages of its geodynamic evolution, covering the pre-syn-subduction and postsubduction rollback range. The altered peridotites could be consequence of hydration of the mantle 
wedge, extension due to slab roll-back, or a combination of both. We propose that serpentinization of the mantle in the $\mathrm{W}$ Mediterranean might have played a crucial role in the geodynamics of the area and could be responsible of the initiation of the lithospheric detachment, exhumation of high-pressure rocks, and the uplift of the Betic-Rif orogen due to the reduction of the density and buoyancy of the mantle. The age of serpentinization cannot be deduced from this work as it can be linked to several tectonic stages.

Serpentinization produces a decrease in the seismic velocities of the mantle due to the existence of hydrated mineral assemblages. In order to assess the degree of serpentinization in the upper mantle, we have used S-wave velocity information from Palomeras et al. (2017) as proposed by Christensen (1966). As the $S-$ wave information available is restricted to the Mediterranean, data were set to a pressure of $400 \mathrm{MPa}$ appropriate for the base of an $\simeq 15 \mathrm{~km}$ thick crust. For a high degree of serpentinization $(96 \%)$, the S-wave velocity could be as low as $2.29 \mathrm{~km} / \mathrm{s}$, whereas velocities of $4.6 \mathrm{~km} / \mathrm{s}$ correspond to fresh mantle (Christensen, 1966). To compute the velocity of the magnetized Mediterranean mantle, we have averaged the $S$ - wave velocities of the layer comprised between the Moho and the CPD. These velocities allow us to estimate the mean percentage of serpentinization of the magnetized upper mantle by comparing them with laboratory measurements. Results presented in Figure $3.9 \mathrm{~b}$ show the percentage of hydrothermal alteration of the mantle of the western Mediterranean. We can observe a variable degree of serpentinization ranging from as little as 10\%, increasing up to $33 \%$ to the E-NE presenting a maximum in the Algerian Basin. The Valencia Trough presents low values of serpentinization with maxima of $15 \%$. The percentage of serpentinization does not show a linear relationship with the thickness of magnetized mantle, and thick magnetic mantle does not always present major degrees of serpentinization. The Algerian Basin presents the highest percentage and the largest thickness of the magnetic layer (Fig. 3.9b), which complies well with the evolution of an area that was affected by intense extensional processes. As discussed above, the origin of serpertinization could respond to different mechanisms and times, thus hindering any further interpretations.

\subsubsection{Variscan Belt}

The thickness of the magnetic layer shows quite a homogeneous response throughout the Variscan Belt, where the CPD is located at least $22 \mathrm{~km}$ below the topography. A prominent feature is the elongated small CPD/CT offset at the NW Iberian Peninsula. This area corresponds to the GTMZ and the NW part of the CIZ, extending S to the Iberian Central System and the Tajo Basin. Furthermore, this feature coincides with the position of the internal part of the CIA (Martínez Catalán, 2012; Martínez Catalán et al., 2014). The emplacement of GTMZ allochthonous complex took place during the contractional events of the Variscan orogeny (Martínez Catalán et al., 2014) along large thrust systems. This stage represented the pressure peak reached during the collisional event and resulted in a thickened crust of up to $60 \mathrm{~km}$ (Martínez Catalán et al., 2014). This thickening led to heating and extension, triggering the intrusion of the largest volume of granites within the Iberian Massif. Two principal groups have been described (Bea, 2004): one consisting of synkinematic granodiorites derived from lower crustal melting, with ages of approximately 325-320 Ma, and another derived from 
partial melting of the middle crust with age approximately 320-305 Ma. Actually, Ayarza (2016) suggests that the magnetic anomalies defining the CIA all coincide with gneiss domes and probably have the same origin. There is a straightforward correlation (Fig. 3.10) between the area occupied by outcropping and occasionally magnetic granites, the geometry of this minimum CPD/CT offset, and the area described by Martínez Catalán et al. (2014) based on the development of gneiss domes. Accordingly, we suggest that the oval shape of the minimum corresponds to an area of similar Variscan tectonic evolution characterized by the emplacement of the allochthonous complexes over the CIZ, which resulted in Variscan crustal thickening, melting, and extension. These processes are responsible for the present magnetic CPD signature of this area and the thinning of the crust. Thermal relaxation must have followed this stage, and no posterior significant thermal events are identified. To the $\mathrm{S}$ of the Iberian Massif, the S of the CIZ does not present the same CPD signature limiting the geographical extension of the processes described above. Furthermore, we propose that this cold anomaly may be also aided by the high thermal conductivity linked to the crystalline crust existing in this area. The western part of the OMZ and SPZ presents the shallowest CPD values for the entire Variscan area. We suggest that they respond to the existence of generally basic igneous rocks emplaced at shallow crustal levels instead of to large volumes of granites. Also, the presence of a near plate boundary between Africa and Iberia may play an important role on the thermal configuration of SW Iberia as well as in the Gibraltar Arc. This result agrees with high heat flow observations and has been explained by a thin lithosphere in the area (Fernández et al., 1998).

Isolated features are recognized throughout the IB. A single relative maximum is highlighted over the CVF. This could be related to the upwelling of the asthenosphere in this volcanic region and coincides with areas of thin lithosphere as pictured by $S$-wave tomography (Palomeras et al., 2017). Similarly, a thermal anomaly can be identified N of the Atlas, also coincident with Quaternary volcanism and high asthenosphere (Palomeras et al., 2014; Teixell et al., 2005; Zeyen et al., 2005)

\subsubsection{Alpine Tectonics Domains and Atlantic Margin}

Alpine terranes within the Iberian Peninsula present the highest positive offsets in CPD/CT, along with the Rif domain. The Pyrenees and the Iberian Chain show constant values $>12 \mathrm{~km}$. The $Q_{o}$ map shows for these areas higher values than for the rest of IB and with high lateral variability. Contrarily to what might be expected, the Pyrenees shows no thermal anomaly. The reason could be that the low expected basal heat flow is compensated by a high radiogenic heat production in the thick crust, resulting in a flat thermal signal. However, the lack of a characteristic magnetic signature in these Alpine domains, e.g., magnetic anomalies in these chains are weak and sparse, provides little constraints to image the CPD.

The Atlantic domains show negative $\mathrm{CPD} / \mathrm{CT}$ offsets. The direct implication is that there is a general magnetization of the upper mantle. This has been already described for the oceanic domain by Li et al. (2013), who recall extensive magnetization in oceanic mantle. Serpentinites have been described along the Iberian Margin from drilling and geophysical studies (Boillot et al., 1980; Reston, 2009). The proposed interpretation of the CPD/CT offset agrees with previous studies and could be 
the result mantle exhumation occurred in this magma-poor hyperextended margin (Reston, 2009). The CPD/CT offset map in the Bay of Biscay reveals negative values close to the thrust system, which we reconcile with serpentinites formed in a hyperthinned crust by entrance of water through the rifting process, which to the $\mathrm{N}$ is replaced by exhumed mantle (Tugend et al., 2014). Also, southward subduction of the oceanic crust of the Bay of Biscay (Ayarza et al., 2004) must have played an important role in the serpentinization of the mantle wedge.

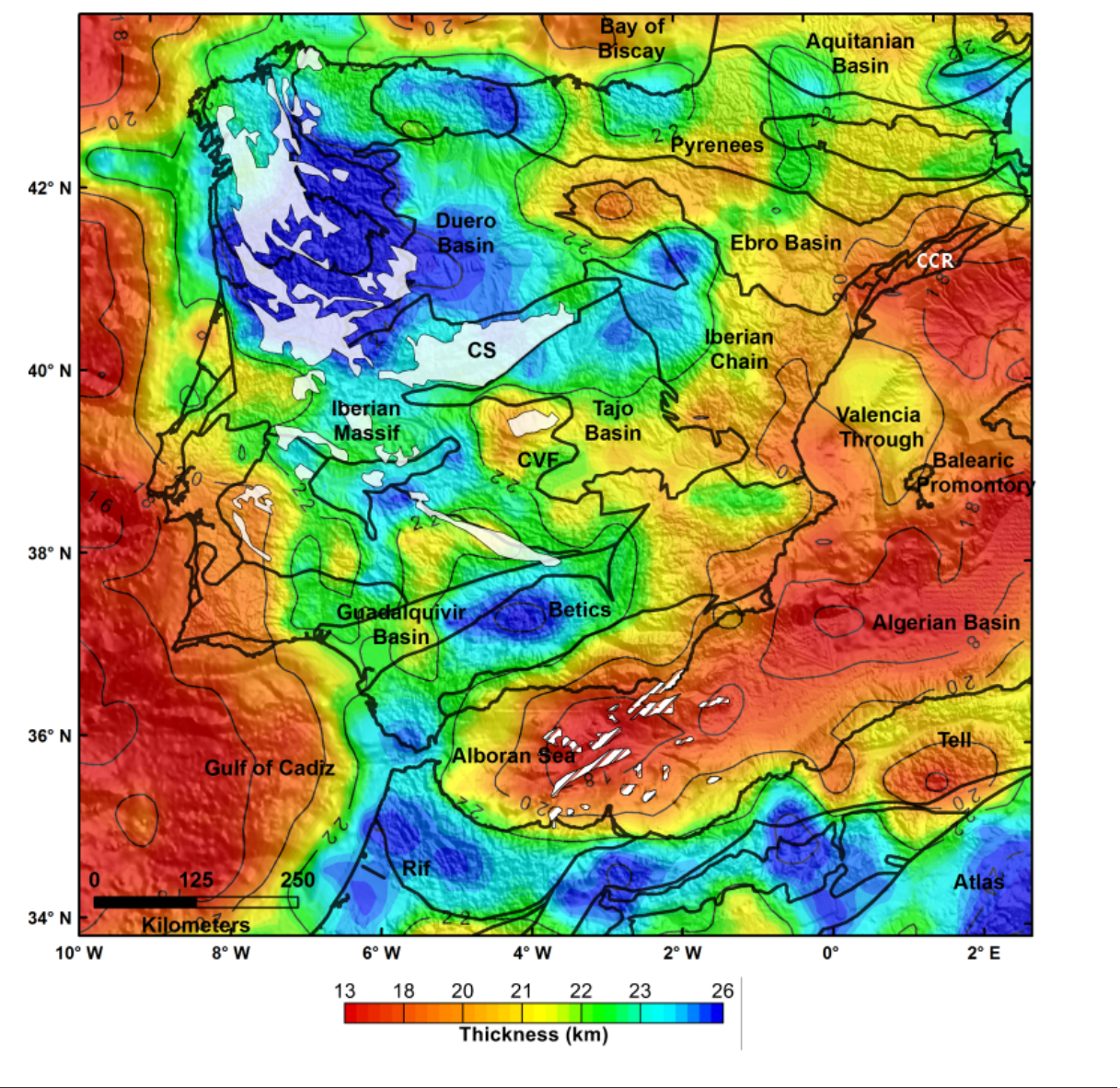

Figure 3.10: Curie-point depth map of the Iberian Peninsula overlain with outcropping Variscan granites (white polygons) and the Alboran Domain volcanism (dashed white polygons). The bold lines represent geologic units as seen in Figure 3.1

Our results are based on a methodology that uses magnetic data to compute the bottom of the magnetization. Differences in resolution within the data set could affect the results. Furthermore, we are assuming a fractal distribution of the magnetization, which is more reasonable than assuming random distribution (Salem et al., 2014), but implies the calculation of the $\beta$ correction parameter. Limitations in the applicability of the method and its assumptions imply errors in the geometry of the calculated heat flow and Moho temperature map that affect the conclusions of this work. However, the coherency of the results, which are in accordance with known geological data, suggests that the results of this work are reasonable. 


\subsection{Conclusions}

This is the first attempt to determine the $\mathrm{CPD}\left(580^{\circ} \mathrm{C}\right)$ surface (isotherm) the heat flow map and the Moho temperature map of the Iberian Peninsula with the aim of providing a view of its evolution and thermal structure. The method we have used relies on spectral analysis of magnetic data and averages the results of using two window sizes to minimize errors and ensure the capabilities to image deep magnetic sources. The resulting CPD map has been analyzed jointly with a CT map with the aim of constraining the thermal gradient of the study area.

The results (CPD and CPD/CT offset) reveal a clear differentiation between Variscan and Alpine domains. The Iberian Massif provides a more homogeneous response. An extensive area in the NW that correlates with the internal part of the CIA presents deep CPD values that suggest that the Variscan evolution of the latter is linked to the extension and to the magnetizing processes. This area, is characterized by Variscan thickening followed by intensive heating and extension in the last orogenic stages. As a consequence, these processes resulted in the development of an important volume of granites. A link between this highly crystalline crust and a high thermal conductivity is proposed to account for the cool anomaly of the area.

The maps offshore indicate that the W Mediterranean upper mantle is magnetic. It most probably contains areas of heterogeneous serpentinization (remnants of a hydrothermally altered mantle). This serpentinization is compatible with the geodynamics of the western Mediterranean (subduction and subduction roll-back of the Alboran lithosphere and extension of the Mediterranean basins). The serpentinites could act as the detachment level for the slab roll-back mechanism. The slab geometry in the Gibraltar Arc is captured by the signature of the CPD. In this area, the CPD increases, which can be explained by the existence of a thickened lithosphere that alters the thermal regime.

The maps reveal that, along the Iberian Atlantic margin, extensive mantle magnetization serpetinization must have occurred, correlating with the existence of the hyperextended crust, which must have favored the exhumation of the mantle toward the W. 


\section{Chapter 4}

\section{Global-Phase Seismic interferometry lithospheric image}

Most of this chapter, regarding data gathering, objectives, data processing, results and discussion, has been published in the following paper and its annex:

Andrés, J., Draganov, D., Schimmel, M., Ayarza, P., Palomeras, I., Ruiz, M., and Carbonell, R.: Lithospheric image of the Central Iberian Zone (Iberian Massif) using global-phase seismic interferometry, Solid Earth, 10, 19371950, https://doi.org/10.5194/se-10-1937-2019, 2019.

This chapter presents a slight modification of this paper to make the text consistent with other chapters and the thesis itself. 


\begin{abstract}
The Iberian Central System (ICS) is an intraplate mountain range that divides the Iberian Inner Plateau in two sectors the northern Duero Basin (DB) and the Tajo Basin (TB) to the S. The topography of the area is highly variable with the TB having an average altitude of $\simeq 350-450 \mathrm{~m}$ and the DB having a higher elevation of 750-800 $\mathrm{m}$. The ICS is characterized by a thick-skin pop-up and pop-down configuration formed by the reactivation of Variscan structures during the Alpine orogeny. The high topography is, most probably, the response of a tectonically thickened crust that should be the response to (1) the geometry of the Moho discontinuity, (2) an imbricated crustal architecture, and/or (3) the rheological properties of the lithosphere. Shedding some light on these features is the main target of the current investigation. In this work, we present the lithospheric-scale model across this part of the Iberian Massif. We have used data from the Central Iberian Massif Deformation (CIMDEF) project, which includes recordings of an almost-linear array of 69 short-period seismic stations, which define a $320 \mathrm{~km}$ long transect. We have applied the so-called global-phase seismic interferometry. The technique uses continuous recordings of distant earthquakes $\left(>120^{\circ}\right.$ epicentral distance) to extract global phases and their reverberations within the lithosphere. The processing provides an approximation of the zero-offset reflection response of a single station to a compressional source, sending (near)-vertical seismic energy perpendicular to the surface plane. Results indeed reveal a clear thickening of the crust below the ICS, resulting, most probably, from an imbrication of the lower crust. Accordingly, the crust-mantle boundary is mapped as a relatively flat interface at, approximately, $10 \mathrm{~s}$ two-way travel time except beneath the core of the mountain range in the ICS, where this feature deepens towards the NW reaching more than $12 \mathrm{~s}$. The boundary between the upper and lower crust is well defined and is found at $5 \mathrm{~s}$ two-way travel time. The upper crust has a very distinctive signature depending on the region. Reflectivity at upper-mantle depths is scattered throughout the profile, located between 13 and $18 \mathrm{~s}$, and probably related to the Hales discontinuity. The research developed in this contribution constitutes also an innovation in terms of methodology. It is probably one of the first crustal scale images accomplished by using global seismic phases from very distant earthquakes.
\end{abstract}

\title{
4.1 Introduction
}

The ICS represents the most prominent topographic feature in central Iberia. It is bounded by two major Tertiary basins, namely the DB to the $\mathrm{N}$ and the TB to the $\mathrm{S}$, forming the Meseta Central. This mountain range extends in a NE-SW direction for over $300 \mathrm{~km}$, with peaks more than $2500 \mathrm{~m}$ in height, and is actively increasing its elevation at the rate of 1 mmyr $^{-1}$ (Cloetingh et al., 2002), while the Meseta Central features an average altitude of 600-700 m. The average elevation of the central Iberian Peninsula is the highest among those in the European continent. A current interest of solid-earth science is focusing towards constraining and understanding topography as a whole. Changes in topography are the expression of the characteristics of the lithosphere and processes that affect it, i) on the surface (such as erosion and therefore climate), ii) within the lithosphere itself 
(such as intrusion of volcanics and magmas, faulting, rifting, compression, extension, etc.), and iii) corresponding isostatic rebounds. How the crust responds to these processes is mostly controlled by its internal architecture and the distribution of its physical properties. Since the early 1990s, a number of multidisciplinary geophysical studies have been undertaken to characterize the crust and lithosphere in the Iberian Massif: first to the NW, then to the SW, and up to and across the Toledo mountains (Fig. 2.1). Detailed crustal and, sometimes, lithospheric structures have been delineated primarily from high-resolution controlled source (normal-incidence and wide-angle) seismic reflection/refraction data (Ayarza et al., 1998; Carbonell, 2004; Ehsan et al., 2014, 2015; Flecha et al., 2009; Martínez Poyatos et al., 2012; Palomeras et al., 2009, 2011; Pulgar et al., 1995; Simancas et al., 2003). However, there is a gap in seismic information at the ICS and surrounding basins.

This work aims to contribute to the knowledge on the lithospheric structure and crustal thickness across the ICS and to its relationship with the contrasting topography of the DB and TB, constraints that are an asset to study the origin and evolution of the elevation and the deformation dynamics of the Iberian Peninsula.

The profile presented here crosses three main geological domains within central Iberia, namely the Iberian Central System, the DB, and the TB. The ICS is an intraplate mountain range characterized by a thick-skin pop-up and pop-down configuration with E-W and NE-SW orientations from E to W, respectively.

\subsection{The CIMDEF Experiment}

The data used in this study were acquired within the CIMDEF project. The set-up consisted of a three-stage deployment (Fig.2.2). The first part of the profile was recorded between May and June 2017 by 24 short-period stations equipped with $2 \mathrm{~Hz}$ three-component geophones. The second stage was acquired between February and April 2018 and consisted of a deployment of 15 stations, while the third deployment was undertaken between July and September 2018 and 30 new stations were installed using the same configuration of geophones and data loggers for all deployment stages. The data were acquired in continuous recording mode at 250 samples per second (sps) during periods ranging from 28 to 60 days. The stations were installed along an almost linear NW-SE array with an average inter-station spacing of $4.8 \mathrm{~km}$, covering a total length of $320 \mathrm{~km}$ (Fig. 2.2). For every station, at least 28 days of continuous recording is available, although in the northern and southern part of the profile almost 2 months of data are available. For the processing, we select the vertical component of global earthquakes (Fig. 4.1) with $M w \geq 5$ from the United States Geological Survey catalogue. The limited deployment time of the experiment determined the choice of $M w \geq 5$ in order to allow for the use of more sources. For each deployment, all earthquakes with $M w \geq 5$ and epicentral distance $>120^{\circ}$ were selected. The selection of the minimum magnitude to be considered was taken as a balance between the signal quality of the earthquakes and the number of recorded sources for each deployment. The 163 gathered events were checked by computing the power-spectral density to confirm the existence of useful energy within the selected frequency band. This process gave the 81 
finally selected sources (Table 4.1). For the first deployment, a total of 44 earthquakes were analysed and 17 proved to have useful energy. In the second deployment, 59 earthquakes were evaluated, from which 38 were selected for further processing. For the final deployment, 60 earthquakes were analyzed and 26 were selected to produce the final image.

For each of the three deployments a different number of earthquakes is available, 17 for the first, 38 for the second, and 26 for the third. Among those, there are 3 in the first deployment, 16 in the second deployment, and 14 for the last deployment that feature $M w \geq 6$. This number of events per deployment is insufficient for the application of GloPSI. To suppress retrieval of artefacts, for example due to the PKP triplication, it is important to sum phases from a wide range of ray parameters (Nishitsuji et al., 2016a; Ruigrok and Wapenaar, 2012).

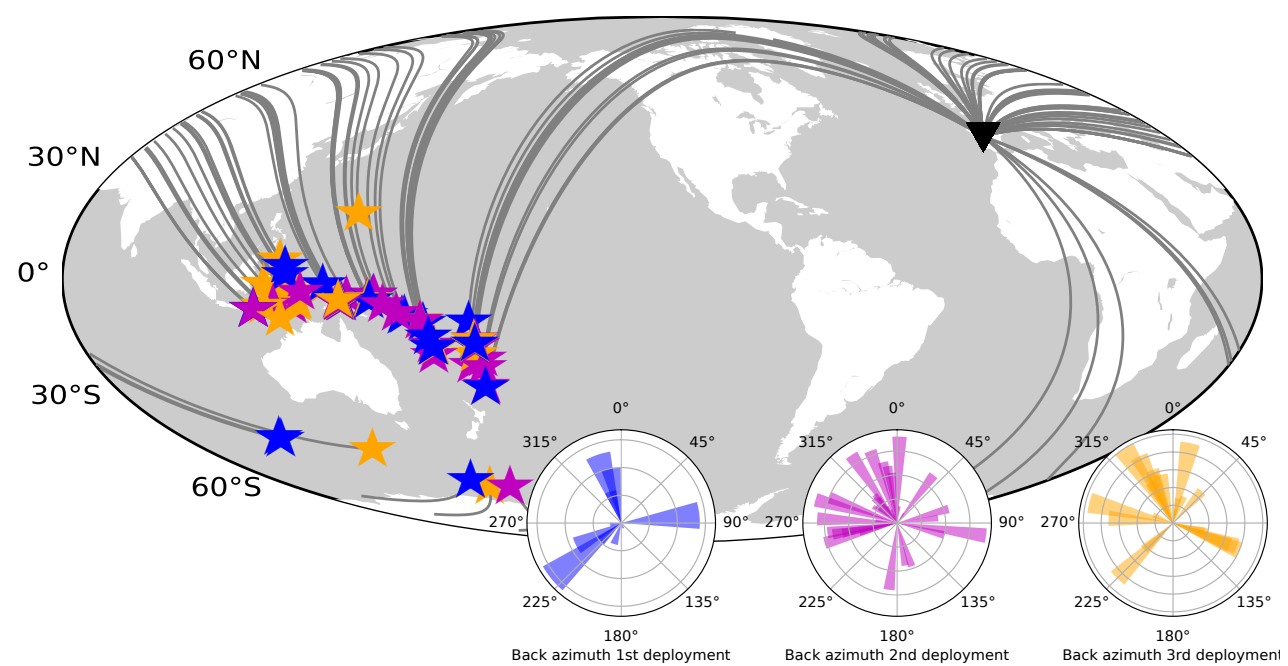

Figure 4.1: Colour-coded earthquakes $(M w \geq 5)$ used for the three deployments. There were 17 earthquakes (blue stars) used for the central deployment, 38 (purple stars) for the southern segment, and 26 (orange stars) for the northern part of the profile. Polar plots represent the back azimuth of selected earthquakes for each deployment.

The use of low-magnitude events, between $M w 5.1$ and 5.4, is restricted to the first acquisition where the deployment time was the shortest, and therefore we were forced to include this type of events in the processing scheme. They represent $7.4 \%$ of the total events used to produce the central part of the image. 
TABLE 4.1: Selected earthquakes used to apply Seismic Interferometry.

\begin{tabular}{|c|c|c|c|c|c|}
\hline Date & Latitude (o) & Longitude (o) & Depth (km) & Magnitude & Deployment \\
\hline $24 / 05 / 2017$ & -10.0191 & 161.9535 & 52 & 5.5 & Central \\
\hline $25 / 05 / 2017$ & -22.3132 & -176.3299 & 127 & 5.6 & Central \\
\hline $29 / 05 / 2017$ & -1.2923 & 120.4313 & 12 & 6.6 & Central \\
\hline $30 / 05 / 2017$ & -12.113 & 167.266 & 257.42 & 5.2 & Central \\
\hline $02 / 06 / 2017$ & -4.7348 & 145.1363 & 192.85 & 5.9 & Central \\
\hline $03 / 06 / 2017$ & -62.5792 & 155.834 & 10 & 5.9 & Central \\
\hline 09/06/2017 & -16.855 & -177.6 & 10 & 5.6 & Central \\
\hline 09/06/2017 & 5.486 & 125.139 & 13.99 & 5.2 & Central \\
\hline 09/06/2017 & -10.26 & 161.185 & 53.2 & 5.2 & Central \\
\hline $10 / 06 / 2017$ & -54.3039 & -146.639 & 10 & 5.6 & Central \\
\hline $10 / 06 / 2017$ & -11.503 & 166.433 & 48.46 & 5.1 & Central \\
\hline $12 / 06 / 2017$ & 3.69 & 126.776 & 56.82 & 5.4 & Central \\
\hline $14 / 06 / 2017$ & -18.3246 & 168.728 & 13.6 & 5.8 & Central \\
\hline $15 / 06 / 2017$ & -30.5156 & -178.0563 & 34 & 6 & Central \\
\hline $15 / 06 / 2017$ & -55.414 & -124.789 & 10 & 5.8 & Central \\
\hline $17 / 06 / 2017$ & -24.0927 & 179.6041 & 511 & 6.1 & Central \\
\hline $17 / 06 / 2017$ & 51.76 & -173.371 & 29.46 & 5.3 & Central \\
\hline $25 / 02 / 2018$ & -6.0699 & 142.7536 & 25.21 & 7.5 & South \\
\hline $25 / 02 / 2018$ & -5.8339 & 142.263 & 10 & 5.7 & South \\
\hline $26 / 02 / 2018$ & -5.4592 & 151.8089 & 20.16 & 5.6 & South \\
\hline $26 / 02 / 2018$ & -6.3991 & 143.2581 & 9 & 5.9 & South \\
\hline $26 / 02 / 2018$ & -6.4973 & 143.5497 & 22 & 5.8 & South \\
\hline $26 / 02 / 2018$ & -2.7774 & 126.6859 & 9 & 6.1 & South \\
\hline $26 / 02 / 2018$ & -6.5052 & 143.255 & 19 & 6.3 & South \\
\hline $27 / 02 / 2018$ & -18.8679 & 169.2903 & 203 & 5.5 & South \\
\hline $27 / 02 / 2018$ & -6.4033 & 143.0332 & 12 & 5.7 & South \\
\hline $27 / 02 / 2018$ & -60.2494 & 150.7793 & 10 & 6.1 & South \\
\hline $28 / 02 / 2018$ & -6.1696 & 142.4681 & 16 & 6.1 & South \\
\hline 02/03/2018 & -6.1353 & 130.2782 & 135 & 5.9 & South \\
\hline 04/03/2018 & -6.0741 & 142.7211 & 6 & 5.7 & South \\
\hline 04/03/2018 & -6.331 & 142.5994 & 10 & 6 & South \\
\hline 06/03/2018 & -6.2314 & 142.4131 & 10 & 5.5 & South \\
\hline 06/03/2018 & -6.3043 & 142.6116 & 20.49 & 6.7 & South \\
\hline $07 / 03 / 2018$ & -5.4456 & 151.3913 & 50 & 5.6 & South \\
\hline 08/03/2018 & -3.3428 & 130.9337 & 10 & 5.6 & South \\
\hline 08/03/2018 & -4.3762 & 153.1996 & 22.86 & 6.8 & South \\
\hline 09/03/2018 & -4.2814 & 153.3875 & 30 & 5.8 & South \\
\hline
\end{tabular}


Table 4.1 continued from previous page

\begin{tabular}{|c|c|c|c|c|c|}
\hline Date & Latitude (o) & Longitude (०) & Depth (km) & Magnitude & Deployment \\
\hline $09 / 03 / 2018$ & -21.0006 & -178.606 & 540.34 & 5.7 & South \\
\hline $12 / 03 / 2018$ & -46.3559 & 95.9296 & 10 & 5.6 & South \\
\hline $22 / 03 / 2018$ & -30.1742 & -177.7218 & 22.22 & 5.5 & South \\
\hline $24 / 03 / 2018$ & -5.4959 & 151.4971 & 33 & 6.3 & South \\
\hline $24 / 03 / 2018$ & -45.7783 & 96.0692 & 10 & 6 & South \\
\hline $25 / 03 / 2018$ & -7.3049 & 128.4848 & 144 & 5.7 & South \\
\hline $25 / 03 / 2018$ & -6.6343 & 129.8172 & 169 & 6.4 & South \\
\hline $26 / 03 / 2018$ & -5.5024 & 151.4025 & 40 & 6.7 & South \\
\hline $29 / 03 / 2018$ & -9.4211 & 159.5792 & 32 & 5.8 & South \\
\hline $29 / 03 / 2018$ & -5.5321 & 151.4999 & 35 & 6.9 & South \\
\hline $29 / 03 / 2018$ & -5.899 & 151.8542 & 10 & 5.7 & South \\
\hline $02 / 04 / 2018$ & -24.719 & -176.8865 & 92 & 6.1 & South \\
\hline $05 / 04 / 2018$ & -18.2946 & -177.9138 & 511 & 5.8 & South \\
\hline $06 / 04 / 2018$ & -1.4171 & 138.2026 & 10 & 5.6 & South \\
\hline $07 / 04 / 2018$ & -6.3608 & 142.6662 & 10 & 5.5 & South \\
\hline $07 / 04 / 2018$ & -5.8382 & 142.5314 & 18.07 & 6.3 & South \\
\hline $15 / 04 / 2018$ & 1.4083 & 126.8759 & 34 & 6 & South \\
\hline $17 / 04 / 2018$ & -3.5216 & 131.3032 & 10 & 5.5 & South \\
\hline $06 / 07 / 2018$ & -49.6301 & 126.0404 & 10 & 5.5 & North \\
\hline $07 / 07 / 2018$ & -30.5662 & -178.0701 & 35 & 6 & North \\
\hline 08/07/2018 & -21.2766 & 168.4961 & 10 & 5.5 & North \\
\hline 08/07/2018 & -19.0182 & 169.4901 & 255 & 5.5 & North \\
\hline $13 / 07 / 2018$ & -18.9279 & 169.0467 & 167 & 6.4 & North \\
\hline $17 / 07 / 2018$ & -11.5936 & 166.432 & 37.96 & 6 & North \\
\hline $20 / 07 / 2018$ & 18.45 & 145.993 & 121 & 5.6 & North \\
\hline $22 / 07 / 2018$ & -18.9577 & 168.8868 & 103.46 & 5.5 & North \\
\hline $28 / 07 / 2018$ & -7.1039 & 122.7263 & 578.16 & 6 & North \\
\hline $28 / 07 / 2018$ & -8.2395 & 116.508 & 14 & 6.4 & North \\
\hline 05/08/2018 & -8.2579 & 116.4403 & 34 & 6.9 & North \\
\hline $10 / 08 / 2018$ & -62.6208 & 165.635 & 10 & 5.6 & North \\
\hline $17 / 08 / 2018$ & -7.3718 & 119.8017 & 529 & 6.5 & North \\
\hline $19 / 08 / 2018$ & -18.1132 & -178.1523 & 600 & 8.2 & North \\
\hline $19 / 08 / 2018$ & -18.4447 & -177.6404 & 575.76 & 6.3 & North \\
\hline $19 / 08 / 2018$ & -18.2293 & -178.1002 & 537.63 & 5.6 & North \\
\hline $19 / 08 / 2018$ & -18.2748 & -178.3539 & 618.29 & 5.7 & North \\
\hline $19 / 08 / 2018$ & -8.3366 & 116.5993 & 16 & 6.3 & North \\
\hline $19 / 08 / 2018$ & -16.9783 & -178.0332 & 415.6 & 6.8 & North \\
\hline $19 / 08 / 2018$ & -8.319 & 116.6271 & 21 & 6.9 & North \\
\hline
\end{tabular}


Table 4.1 continued from previous page

\begin{tabular}{llllll}
\hline Date & Latitude $(\circ)$ & Longitude $(\circ)$ & Depth $(\mathrm{km})$ & Magnitude & Deployment \\
\hline $19 / 08 / 2018$ & -8.3511 & 116.5565 & 10 & 5.8 & North \\
$20 / 08 / 2018$ & -18.1559 & -178.1888 & 526.17 & 5.5 & North \\
$21 / 08 / 2018$ & -16.0295 & 168.145 & 9 & 6.5 & North \\
$22 / 08 / 2018$ & -6.9675 & 155.7284 & 34 & 5.8 & North \\
$28 / 08 / 2018$ & -10.8859 & 124.1187 & 14 & 6.2 & North \\
$28 / 08 / 2018$ & -18.0299 & -177.9387 & 600.62 & 5.7 & North
\end{tabular}

The selection of the beginning of the time window to be used was based on the theoretical travel time of the phases calculated by the ak135 model (Kennett et al., 1995). We visually inspected the recordings and selected phases with a high signal-to-noise ratio. The time window is set to start $30 \mathrm{~s}$ before the onset of specific phases of interest (e.g. PKiKP or PKIKP) and to end $300 \mathrm{~s}$ after the onset and before the onset of the first $S$ - wave phase.

\subsection{Results}

We present a P-wave reflectivity profile obtained by stacking autocorrelograms from phases of global earthquakes (Fig. 4.2). The section crosses, from NW to SE, the DB, ICS, TB, and also the Toledo mountains in the Central Iberian Zone (CIZ) (Fig. 2.2), and it can be regarded as an image of the reflectivity of the upper lithosphere down to $30 \mathrm{~s}$ two-way travel time (TWT).

We have applied a time-to-depth conversion to display the estimated depth at which we obtain reflectors. The conversion is applied to the time axis, but the velocity model is not too certain, thus the depth serves only as a reference. This conversion uses the velocity profile of shot 3 from the ALCUDIA-WA experiment, down to Moho depths (Ehsan et al., 2015), which is fairly close to the southern end of our profile but at an offset of around $20 \mathrm{~km}$ (see Fig. 2.4). Below the Moho, a constant velocity of $8 \mathrm{kms}^{-1}$ has been used in the conversion. In areas with a sedimentary cover as the DB in the northern part of the profile, the depth conversion might not be accurate because of the lower velocity in sediments, thus overestimating the real reflector depths. In addition, in areas where the crust is thicker, the resulting depth would also be overestimated as we might have used mantle velocities in crustal areas.

The relatively long distance covered by the profile and the relatively close station spacing $(\simeq 4.8$ $\mathrm{km}$ ) ensure a high lateral resolution of the lithospheric structure of the study area. The section shown in Figure 4.2 shows alternating bands of high and low reflectivities and also distinct areas of high and low frequencies. The most conspicuous observations are, i) a high-reflectivity band from the surface down to 9.5-12 s TWT, with much lower reflectivity below and ii) another band of high-amplitude low-frequency arrivals in the southern half of the profile above $5.5 \mathrm{~s}$ TWT. This band continues to the $\mathrm{N}$ with slightly higher frequency and lesser amplitude arrivals that are slightly shallower. Also, apparently random reflectivity appears below $12 \mathrm{~s}$ TWT. 
The first of the above mentioned reflective layers represents the highly reflective continental crust which can be easily separated from a more transparent mantle in this part of the CIZ and is the key to calculate the crustal thickness. Among the reflectors found within the crust, a marked package of arrivals is found between 3 and $5.5 \mathrm{~s}$ TWT throughout the profile. This displays an almost flat structure underneath the ICS, while thinning towards the $\mathrm{N}$ and $\mathrm{S}$ of the profile. As seen in the wiggle image in Figure 4.2, this shallower band of reflectivity presents a different signature in the three studied domains, the ICS, the TB, and the DB, displaying much lower frequencies in the ICS. Accordingly, to the $\mathrm{N}$ and $\mathrm{S}$, the reflectivity band is defined by higher-frequency wiggles, which become very coherent to the S. Moreover, in the first $70 \mathrm{~km}$ of the profile this band of reflectivity features lower amplitudes and exhibits less continuity while showing a similar waveform to the wiggles further $\mathrm{S}$. The bottom of this thick band of reflectivity defines a discontinuity at an average depth of $5.5 \mathrm{~s}$ TWT. Based on the characteristics of this feature, we can state that this discontinuity is shallower, sharper, and better defined in the northern and southern parts of the profile, although it covers the entire section. We interpret this discontinuity as the upper-crustlower-crust boundary. Thus, the upper crust features a homogeneous (low-frequency) signature in the ICS and is probably thinner and more heterogeneous to the $\mathrm{N}$ and $\mathrm{S}$.

The lower crust features a high and heterogeneous reflectivity that is interpreted as the seismic expression of a laminated layer, as seen in the ALCUDIA-NI experiment (Ehsan et al., 2014; Martínez Poyatos et al., 2012). Within this lower band of reflectivity, differences also exist between the centralsouthern part and the northern sector. Below the DB, a less reflective lower crust exists up to $135 \mathrm{~km}$ of distance, while below the TB and the ICS the reflections have higher amplitudes overall, indicating higher impedance contrasts in that area and a coherent response regardless of the differences at upper crustal levels. The crust-mantle discontinuity is marked by a transition from high-amplitude reflections to a much lower-amplitude seismic signature although, it is difficult to define a sharp Moho discontinuity with this dataset. This transition features an increase in seismic impedance and is located between 9.5 and $12 \mathrm{~s}$ TWT (peak wiggles in Fig. 4.2 and 4.3). The Moho is shallower and more difficult to define in the northern sector where it appears slightly above $10 \mathrm{~s}$. Following the abrupt end of the crustal reflectivity from the $\mathrm{N}$, we observe a slight fluctuation around $10 \mathrm{~s}$ TWT until $180 \mathrm{~km}$ distance along profile. Below the ICS a clear step is found, and we might speculate on a possible Moho duplication. At this point, below the highest elevation of the mountain range, the highest reflectivity is extending down to $12 \mathrm{~s}$ TWT, possibly marking the presence of a deeper Moho. Then it shallows southwards until $230 \mathrm{~km}$ distance, where it becomes almost flat again, featuring depths of $10 \mathrm{~s}$ TWT until the end of the profile.

As expected, the mantle is more transparent than the crust and reflections are scattered and less abundant. In general, the northern sector is characterized by slightly higher reflectivity than the central and southern areas. A reflector can be followed up below the TB and Toledo mountains at 12 to $14 \mathrm{~s}$ TWT. Another possible reflector at 19-20 s TWT is doubtfully visible under the DB and at a distance of $230 \mathrm{~km}$. At latter times, there are no clear arrivals with high enough continuity as to define a reflector (Fig. 4.2). 

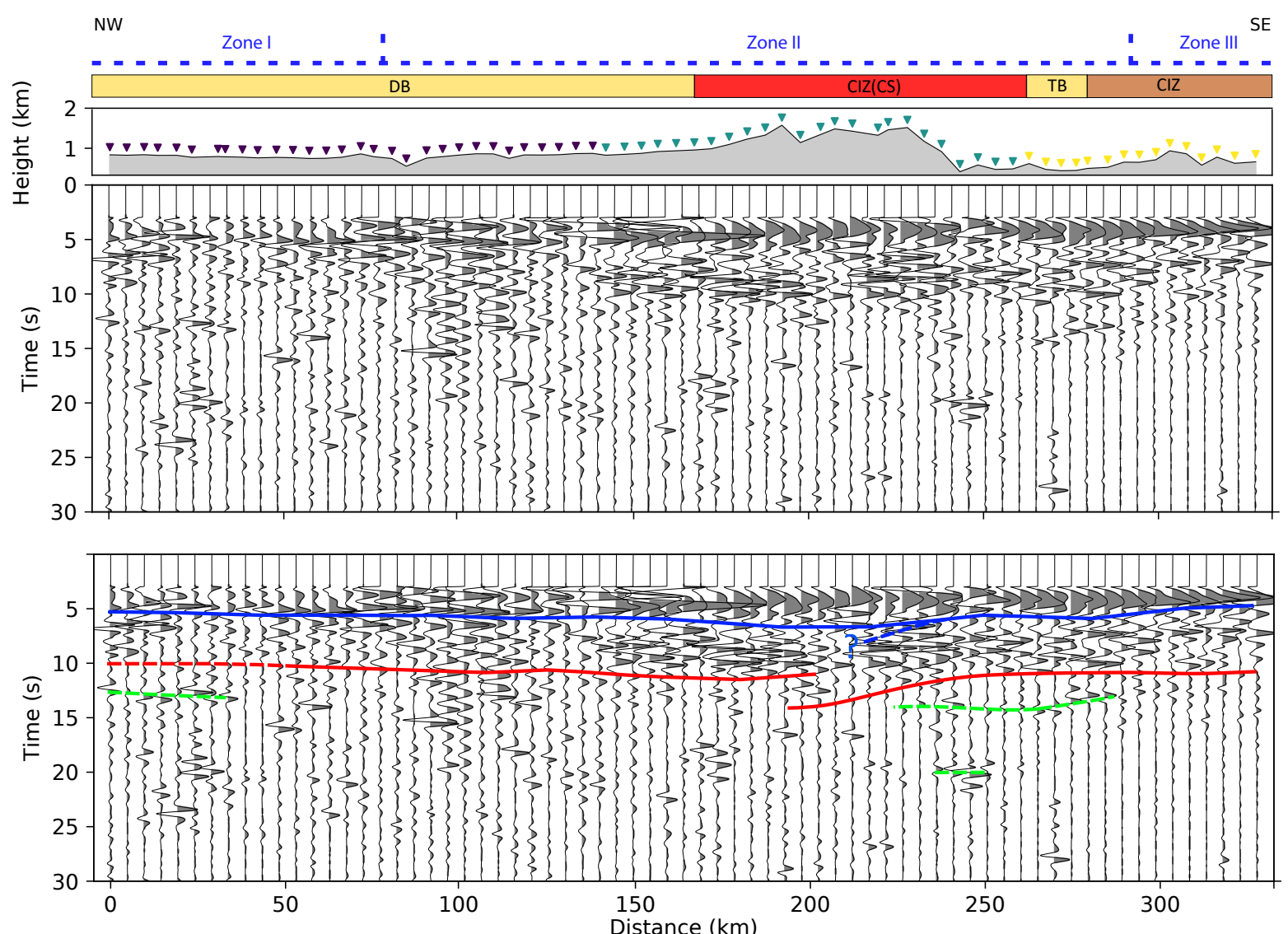

FIGURE 4.2: (a) Reflectivity profile retrieved by global-phase seismic interferometry. In the wiggle plot, the grey lobes indicate positive polarity. On top is the lateral extent of the geological areas crossed by the profile and the boundaries of the granitic magmatism. Coloured triangles represent the different acquisition stages (from $\mathrm{N}$ to S: third, first, and second deployments). (b) Interpretation of the lithospheric reflectivity profile. Solid lines represents coherent continuous stable features, and dashed lines indicate possible features. The blue line marks the boundary between the upper crust and the lower crust. The red line is the crust-mantle boundary. Scattered reflectivity within the upper mantle is marked by the dashed green lines. 


\subsection{Discussion}

In this work, we present the first reflectivity profile of the lithosphere under the CIZ, in the Iberian Massif, by means of SI applied to global-earthquake data. The resulting image (Fig. 4.4) provides key insights into understanding the internal structure and tectonic evolution of the ICS and the surrounding sedimentary basins. In the following sections, we analyse and address the nature and geometry of the crust and mantle reflectors and their possible origin. Our interpretation approach relies on the identification of arrivals which have lateral coherence, along with similar waveforms. In general terms, good lateral reflectivity is retrieved along the profile where clear crustal reflections can be identified. Although in this work we use low-frequency global phases, the crust can be divided into upper and lower crust, both coinciding with the main reflectivity zones seen in the ALCUDIA-NI profile, which uses a higher-frequency dataset $(8-80 \mathrm{~Hz})$. The upper crust extends from 0 to $5.5 \mathrm{~s}$ TWT on average $(0-15 \mathrm{~km})$, while the lower crust goes down to 9.5-12 s TWT (29-38 km). Therefore, two crustal-scale discontinuities are identifiable: the base of the upper crust at 5-5.5 s TWT and the crust-mantle discontinuity between 9.5 and 12.5 s TWT. Finally, the lithospheric mantle covers the rest of the profile from depths of 29 to $39 \mathrm{~km}$ and also features two discontinuities at 13-14 s TWT and around 19-20 s TWT.

\subsubsection{Upper Crust}

The upper crust observed as part of the CIMDEF experiment (Fig. 4.2, 4.4) is identified between 3 and $5.5 \mathrm{~s}$ TWT $(7-15 \mathrm{~km})$ and is characterized by a package of reflectivity with high amplitude events and, in places, rather low frequencies. However, this package shows some differences along the profile. Below the DB two different types of reflectivity are found. From 0 to $70 \mathrm{~km}$ distance, relatively low amplitude reflectivity at high frequencies is observed. Then, higher amplitudes appear up to the ICS location. There, the reflectivity has much lower frequencies and even higher amplitudes. The signature changes again below the TB and the Toledo mountains where higher frequencies are present again and high amplitudes are exhibited. These changes in reflectivity do not coincide with the areas surveyed in each one of the three deployments and therefore, could be attributed to lithological changes associated with the outcropping geology.

The upper crustal image observed in this section allows us to establish a correlation between the reflectivity signatures and the Carboniferous-Permian magmatic zonation of the Iberian Massif (Simancas et al., 2013). According to these authors, the magmatism in the Iberian Varsicides can be divided into four areas depending on its characteristics. From $\mathrm{N}$ to $\mathrm{S}$, the CIMDEF profile crosses zones I, II, and III (Fig. 4.2). Zone I includes the Cantabrian and Asturian Leonese zones, is characterized by a negligible volume of post-orogenic granitoids, and corresponds to the first $70 \mathrm{~km}$ of the profile. Zone II has large volumes of Carboniferous granitoids (Bea, 2004) related to recycled metasediments from the continental crust (Bea et al., 2003; Villaseca et al., 1998). In this context, crustal thickening and extension has been proposed to support the high production of granites (Martínez Catalán et al., 2014; Pérez-Estaún et al., 1991). This area represents $170 \mathrm{~km}$ of the profile. The final zone intersected 
by the experiment has much less abundant granitoids than the previous zone and represents the last $80 \mathrm{~km}$ of the southern end of the profile. The boundary between zones I and II coincides with a reflectivity change at the upper crustal level in our profile, as the first $70 \mathrm{~km}$ features a low-amplitude signature, more heterogeneous reflectivity, and higher-frequency events than the rest of the profile. Within zone II, another change in signature is found around $140 \mathrm{~km}$ distance, where high-frequency high-amplitude reflectivity is followed by a high-amplitude low-frequency reflectivity. This transition lies slightly to the $\mathrm{N}$ of the contact between the Tertiary sediments of the DB and the outcropping granitoids of the ICS. Despite the fact that our profile cannot constrain the uppermost part of the upper crust, the surface geology and our results feature a marked correlation, and we assume that the main contacts observed at the surface are at the same locations as observed here at $3 \mathrm{~s}$ TWT (8-9 km). Accordingly, we suggest that the extension of granites in zone II can be prolonged to the $\mathrm{N}$ of the ICS, even though they do not outcrop as they are covered by the DB sediments. In this context, it can be stated that below the ICS the upper crust is mainly formed by granites down to $5.5 \mathrm{~s}$ TWT, as they are massive lithologies that do not feature sharp impedance contrasts at the scale of the sampling waves. Zone III is imaged by the upper crustal reflectivity in the TB and further $\mathrm{S}$, which depicts the seismic response of metasediments featuring vertical folds accompanied by few granites, thus providing scarce impedance contrasts visible to high-frequency waves and giving a high-amplitude but relatively low-frequency response. As a summary, it can be inferred that the seismic signature of the upper crust sampled by the CIMDEF experiment is strongly influenced by the amount of granites. Overall reflectivity differences respond to the contrast between the reflecting power of igneous (granitoids) rocks and that of (meta)sedimentary rocks, the former being the source of a low-frequency homogeneous seismic signature.

\subsubsection{Lower Crust}

Below the upper crust, the CIMDEF transec shows a highly reflective lower crust along most of the central segment. However, low-amplitude reflectivity is found in the first $130 \mathrm{~km}$ to the N. Also, from the southern border of the ICS to the end of the profile, amplitudes at a lower-crustal level are somehow lower than underneath the ICS.

Although GloPSI has low resolution when compared to active-source vertical-incidence reflection data, a similar reflective pattern is again identified between both types of datasets. The lower limit of the upper crust directly correlates with a mid-crustal discontinuity identified in the IBERSEIS-NI and ALCUDIA-NI datasets to the S (Ehsan et al., 2014; Martínez Poyatos et al., 2012; Simancas et al., 2003) and a similar discontinuity can be identified in the ESCIN-2 and ESCIN-3.3 profiles to the N (Ayarza et al., 1998; Pulgar et al., 1995). This interface is present in the SPZ, the OMZ, and the southern part of the CIZ as well as in the WALZ and in the northern border between the DB and the Cantabrian Mountains. It has been regarded as the Variscan brittleductile transition (Ehsan et al., 2015; Martínez Poyatos et al., 2012; Palomeras et al., 2009; Simancas et al., 2003), although ductile Variscan deformation is widespread at outcrop level in these areas, i.e. in what is supposed to be the fragile part of the Variscan crust. From a seismic point of view, this interface characterizes 
the division between the top of a highly laminated lower crust and a more transparent upper crust. Furthermore, this boundary separates areas with different patterns of deformation suggesting that the former have might acted as a detachment. The seismic discontinuity is further discussed and defined as a generalized feature in Ayarza et al. (2020). Estimates of shortening at upper- and lower crust levels suggest that this detachment might have accommodated most of the deformation (Martínez Poyatos et al., 2012; Simancas et al., 2013). Nevertheless these estimates are lower limits, as they don't account for the amount of deformation accumulated through ductile deformation processes. Furthermore, with the currently available data the distribution of the existing deformation in terms of tectonics events is also limited.

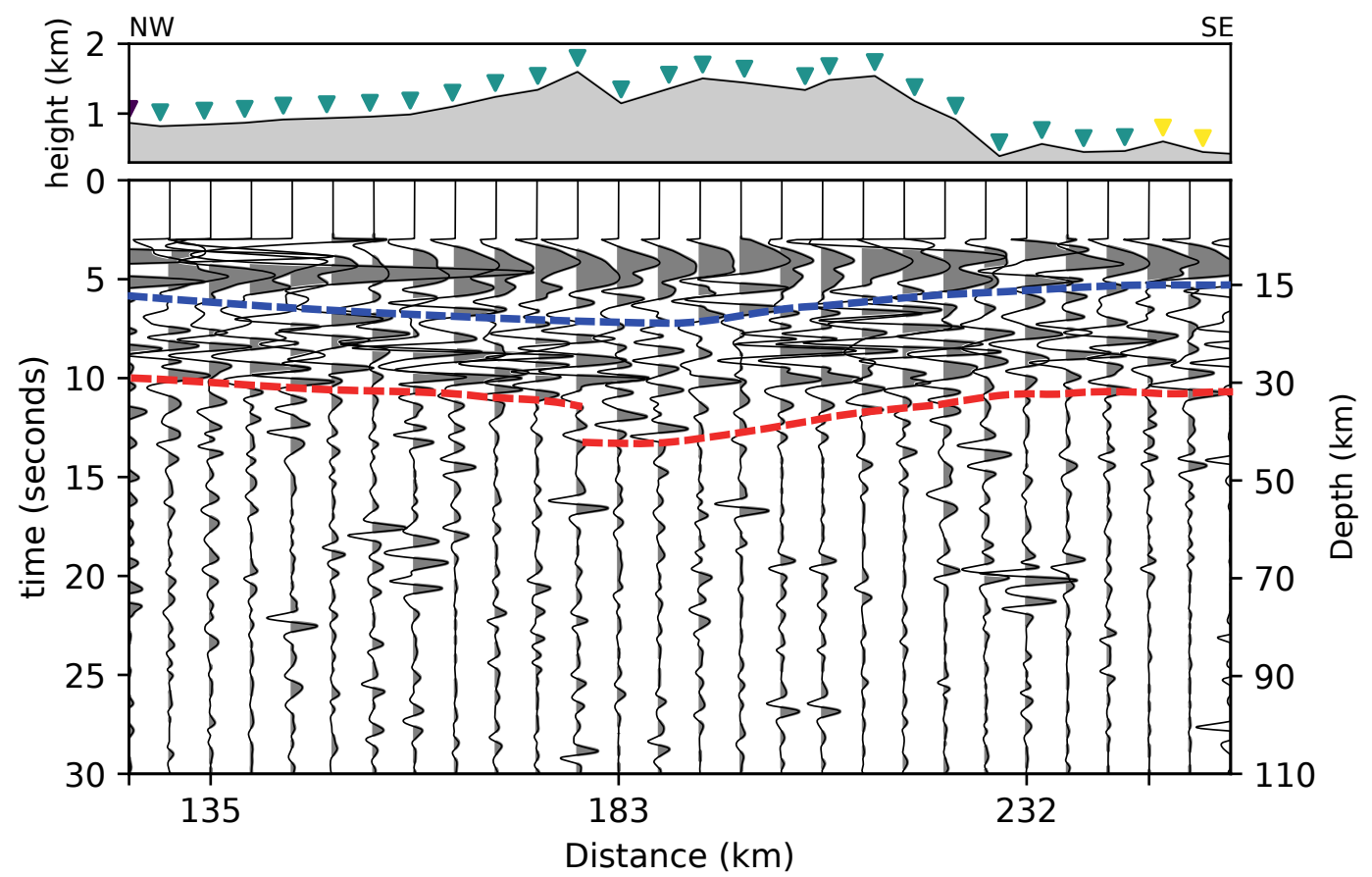

FiguRE 4.3: Zoom in of the reflectivity profile retrieved by global-phase seismic interferometry presented in 4.2. In the wiggle plot, the grey lobes indicate positive polarity. The blue line marks the boundary between the upper crust and the midlower crust. The red line is the crust-mantle boundary.

As in the previous datasets, in the CIMDEF profile this boundary is not identifiable by a marked reflection but rather by a change in the reflectivity pattern between the upper crust and the lower crust. In our profile (Fig. 4.2b and 4.4), we have also imaged how this interface continues to the $\mathrm{N}$ at approximately the same depth (5 s TWT). The existence of this discontinuity, which represents a boundary between layers with different deformation patterns, indicates that the upper and lower crusts should have had some degree of decoupling during their tectonic evolution. If this boundary was Variscan in age, its original position could have been modified by the late Variscan igneous activity affecting the CIZ, mostly the ICS area. This may be the reason why it appears slightly deeper in the 
central part of the profile. In the southern border of the ICS, this interface could be continuous but also could be imbricated as an effect of the shortening, as imaged in Figure 4.4b. Below the southern border of the ICS, there is a small area where the high-reflectivity pattern of the lower crust seems to be above that of the upper crust thus suggesting the existence of this imbrication. Nevertheless, to confirm this feature higher-resolution studies are needed.

Variscan orogenic evolution led to a thickening of the crust in the central and northern part of the CIZ during Carboniferous times. This triggered extension and widespread magmatism (Balda et al., 1995; Martínez Catalán et al., 2014; Martínez Poyatos et al., 2012; Pérez-Estaún et al., 1991) during late Carboniferous and early Permian times. The presence of high-frequency reflections at lower crustal levels below the ICS evidence that here, not all the crust melted during the Variscan orogeny. Massive granitoids do not produce reflections but rather a transparent low-frequency response (scattered reflected energy). We infer then that the lower crust below the ICS was not entirely affected by crustal melting as intense reflectivity remains. Northwards, below the DB, the lower crust is less reflective. To explain this difference, three scenarios could be invoked. First, the presence of a partly melted and homogeneous lower crust that could imply the existence of extension and melting of the area. However, the outcropping rocks present a low metamorphic degree, which is incompatible with this scenario. Second, the pre-Variscan lower crust of this area had a slightly different composition and deformation compared to its continuation to the S and N. These contrasting features might have translated into a different response to deformation during the Variscan compressional and extensional stages. Last but not least, the northern part of the CIMDEF profile lies on in the Duero sedimentary basin, where relatively thick Tertiary and Quaternary sedimentary layers might have absorbed part of the seismic energy, thus attenuating the corresponding amplitudes. This hypothesis is supported by the fact that, in general, amplitudes are lower in the northern part of the profile.

The Moho topography beneath the ICS has been studied by gravity modelling (de Vicente et al., 2007) and seismic receiver functions (RF) (Mancilla and Diaz, 2015). These datasets suggest that the crust-mantle boundary, features a gentle bulk defining a synform-like structure of long wavelength, increasing its thickness up to $2-3 \mathrm{~km}$ with respect to its surroundings. The crust-mantle discontinuity here (Fig. 4.2 and 4.4) is not presented as a unique and sharp reflection but by a change in the reflectivity pattern instead. We have interpreted this discontinuity (Fig. 4.4) at 9.5-12 s (29-38 km), based on the position of a boundary between a highly reflective crust that passes to an upper mantle characterized by low-reflectivity and small-amplitude events. In normal incidence seismic data, the contrast between high and low reflectivity (or transparent) has been used as the criteria to define the position of the Moho (Carbonell et al., 2013). This reflectivity boundary is irregularly distributed, being shallower to the $\mathrm{N}$, around 9.5-10 s (29 km) and deepening below the core of the orogen, and shallowing again to the S. Accordingly, below the highest peak of the ICS, an overlap of two Moho branches is interpreted (Fig. 4.2b and 4.4), being the deepest set of reflectors at $12 \mathrm{~s}$ TWT $(38 \mathrm{~km})$. This package of reflectivity is limited to the recordings of two stations and covers a distance of over 15 $\mathrm{km}$, while the whole thickening covers an area of $100 \mathrm{~km}$, going from the southern border of the ICS to the southern part of the DB. The fact that the presence of these deep reflections is limited to two 
stations might not be a structural feature but be related to the methodology itself. Because GloPSI uses near-vertical incident energy, it is insensible to steeply deeping structures, as the reflection of these cannot be recorded below the same station. Thus, if a steep angle is found in a structure below the ICS, it would not be visible by the technique itself. Furthermore, the frequency content of such distant earthquakes is quite low, limiting the vertical resolution of the dataset. As a consequence, other reflections that are shallower than those two already retrieved but deeper than the Moho to the $\mathrm{N}$, might not be resolved with the frequency range used in our study, or the signal could be mixed with that of the lower crust.

In Figure 4.4, we have interpreted this crustal thickening as the result of the lithospheric compression that occurred during the Alpine orogeny, which has further modified the structure of the Variscan crust, triggering a possible imbrication and developing a crustal root that can be only partly observed with this dataset. This structure would be similar to the imbrication of lower crust identified in the Cantabrian Mountains and Pyrenees as a result of Alpine compression (e.g., Pulgar et al., 1995; Teixell et al., 2018). Although in our case the observation of this underthrusting is limited by the number of recording stations, a clear thickening of the crust below the ICS can be observed. The northern boundary of this crustal thickening reveals no apparent correlation with major outcropping structures. However, the southern boundary of the thickened crust lies close to the South Central System Thrust (SCST) thrust and to the fault system that defines the Tiétar River Basin (TRB) (Fig. 4.4). A prolongation of this lower crustal imbrication into the upper crust could project in any of these thrusts and would imply that the whole crust is in fact somehow imbricated, giving us additional insights into the origin of the low topography of the meseta to the S of the ICS (Fig. 4.4b). However, this would require that the identified Variscan mid-crustal detachment did not work as such during the Alpine compression (as shown in Fig. 4.4b), allowing compressive structures to affect both the upper and the lower crust simultaneously. In addition, seismic profiles crosscutting the Madrid Basin and the ICS thrust to the NE of our profile (de Vicente et al., 2007) do not show underthrusting of sediments, indicating that if this tectonic feature exists, it is probably related to the Tiétar River Fault system.

The crustal pattern suggested above correlates well with the results of a magnetotelluric profile carried out in the same area (Pous et al., 2012). In their image, a zone of lower resistivity is found around the TRF, which affects not only the upper crust but also extends into the lower crust, and connects even with the Moho. This low resistivity is associated with a set of faults cutting the upper crust and could be extended to cut the whole crust, although they do not need to be necessarily connected. Furthermore, preliminary results from ambient seismic noise data (Andrés et al., 2019) illustrate the same scenario for the crust-mantle boundary, as do new control source wide-angle seismic data acquired within the CIMDEF experiment, where the mid-crust discontinuity and crustal structures are clearly visible. In any case, the resolution of this dataset does not allow us to identify steeply dipping crustal features. Higher-resolution solutions and estimations of the shortening at upper and lower crustal levels should be used to support any of these hypotheses. In any case, the structure of the ICS suggested by the present dataset is that of an orogen featuring an asymetric root. 
Figure 4.4 shows a sketch of the interpretation of the CIMDEF GloPSI profile overlapped with the Moho geometry deduced from gravity inversion (Torne et al., 2015) and a compilation of controlsource and RF Moho depths (Diaz et al., 2016). Also, the geometry of the inferred imbrication, involving just the lower crust (Fig. 4.4a) or the upper and lower crust (Fig. 4.4b), is included. In general, there is a good agreement between the three models, with only limited differences in the root area. To the S, a similar thickness of around $32-34 \mathrm{~km}$ is depicted from the different models. To the $\mathrm{N}$, the model presented in this paper shows a thinner crust of around $30 \mathrm{~km}$, while the two other models present thicknesses of 32-33 km. This difference, which is reduced along the profile towards the northern border of the ICS, could be due to the existence of low-velocity sediments in the DB that lead to errors in the time-to-depth conversions. The differences below the ICS affect the depth as well as the geometry of the crust-mantle interface. The Moho discontinuity in Diaz et al. (2016) presents a rather horizontal geometry, depicting a small $1 \mathrm{~km}$ thick root. The results from gravity inversion, while being closer to our results regarding crustal thickness, are highly influenced by the inclusion of the topography in the inversion procedure. Accordingly, the crustal thickening starts further to the $\mathrm{S}$, showing a progressive thinning in the area where our crustal thickness is maximum. This implies that the model based on gravity inversion corelates the root with local isostasy, whereas our model infers a tectonic influence in the geometry and position of the crust-mantle boundary. In any case, the resolution of the datasets, the limitations of the GloPSI technique and the uncertainties in velocities used for the time-to-depth conversion in imaging steeply dipping interfaces allow for the observed small differences in the results of different techniques.

The mechanism that gives rise to the uplift and crustal thickening of the ICS is an ongoing discussion where two main hypotheses are proposed. First, several studies (Bruijne and Andriessen, 2002; Cloetingh et al., 2002; de Vicente et al., 2007, 2018) have suggested lithospheric folding of Iberia to be the driving force. They base their hypothesis on gravity and analogue modelling, basin infill, and structural analysis of outcropping geology. They propose a model where the crust has buckled entirely, and deformation is represented in the upper crust by the formation of pop-ups that uplift the basement, while ductile deformation is present in the lower crust. The folding wavelength in continental Iberia is calculated to be between 150 and $250 \mathrm{~km}$ (Muñoz-Martín et al., 2010). The second hypothesis proposes that a detachment level runs from the Betics to the $\mathrm{S}$ or the Pyrenees to the $\mathrm{N}$ (Quintana et al., 2015). This solution would implies that a simple shear with a detachment at some crustal level would accommodate the shortening and provide the uplift of the ICS. Our reflectivity image provides insights that might shed some light onto its structure. Despite the presence of a clear thickening under the ICS, which affects the upper crust, the lower crust is not much bulked, but it seems tectonically imbricated below the mountain belt, suggesting an orogen with an asymmetric root. Furthermore, the wavelengths proposed for the lithospheric folding should be visible in our array length, but contrarily the thickening of the crust under the ICS seems to be the only remarkable curvature within the crust. The second hypothesis discussed above is mainly based on the idea that the ICS has a small crustal root. This statement is based on the current geophysical knowledge of the area which includes gravity modelling (de Vicente et al., 2007), gravity inversion (Torne et al., 


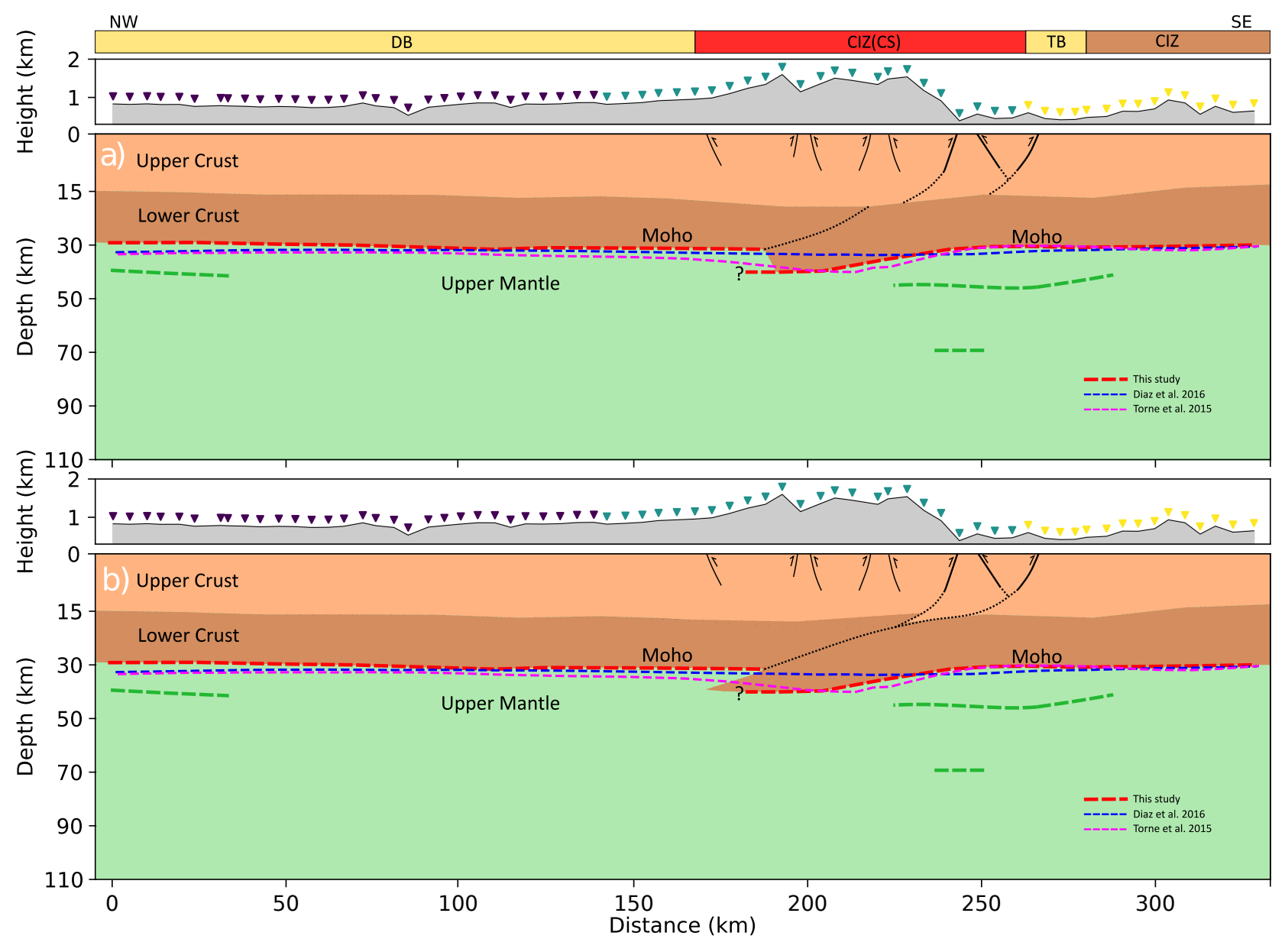

FiguRE 4.4: Sketch of the proposed crustal geometry, overlapped with Moho results from gravity inversion and receiver function (RF). (a) Model where the South Central System Thrust (SCST) and the Tiétar River Fault (TRF) lie within the upper crust and only the lower crust imbricates; (b) model where the entire crust imbricates below the ICS. 
2015), and receiver-function studies (Mancilla and Diaz, 2015). Considering our results, the crustal root is not as small as previously seen in other geophysical datasets, and at the deepest point it might define an offset of 6-7 km. We suggest that the crustal root should have formed during the Alpine orogeny by the compression of Africa in the NW direction. Consequently, we infer underthrusting or stacking and imbrication of two layers of (lower) crust as the formation mechanism. This might have accommodated much the shortening produced during the compression. If the entire crust (and not just the lower crust) were imbricated, this hypothesis could further explain the elevation difference between the TB and DB, as the latter is isostatically supported by a thicker crust and the former is underthrusting.

\subsubsection{Upper Mantle}

The upper-mantle reflections are scattered within the profile at two main levels (Fig. 4.4) between 13 and 14 s TWT and between 19 and 20 s TWT. Both reflections have low lateral continuity and, although they are visible almost throughout the entire array, the lack of continuity among patches of reflectivity hinders their interpretation and definition of their geometry. Both sets of reflectivity are nearly parallel except below the ICS, where the first reflection features a marked dip while the second does not. At these depths, 45-55 km for the top reflection and 70-75 km for the bottom one (assuming $\mathrm{Vp}=8 \mathrm{~km} / \mathrm{s}$ for the mantle). Events at similar depths have been identified in southern Iberia. In the IBERSEIS profile, a zone between 61 and $72 \mathrm{~km}$ depth was modelled, corresponding to what the authors interpreted to be the Hales discontinuity (Ayarza et al., 2010). A similar interface has been imaged by the ALCUDIA-WA dataset. The discontinuity, modelled by wide-angle seismic data, is proposed to be related to the mineral phase transition from spinel-lherzolite to garnet-lherzolites (Hales, 1969). To compensate for the low reflection coefficient of this phase change and to explain the thickness and high reflectivity of this feature, a layered sequence characterized by alternating seismic velocities, and/or alternatively lenses with different ratios of spinel/garnet and thicknesses that allow constructive interferences of the seismic waves have been proposed. Moreover, to the N, below the ALCUDIA-NI profile (Martínez Poyatos et al., 2012), conspicuous scattered reflectors are found at the same time/depth, between 13-14 and 19 s TWT. These have been interpreted as evidence for the Hales discontinuity in the area. In the same form, the reflectivity seen below the CIMDEF experiment between 45 and $75 \mathrm{~km}$ might be related to a mineral phase transition. To confirm the existence and extent of this area, accurate velocity information would be needed. In this regard, a similar scenario is found below the Urals, where a heterogeneous upper mantle, as the one of this study, was sampled by a dense wide-angle seismic experiment (Carbonell, 2004). However, the lack of control on possible artefacts within the upper mantle should be noted and these results should be taken carefully.

\subsection{Conclusions}

In this work, we present a lithospheric-scale reflectivity profile of the central part of the Iberian Peninsula by means of global-phase seismic interferometry (GloPSI) acquired as part of the CIMDEF project. The transect runs across the Cenozoic DB and TB to the $\mathrm{N}$ and S, respectively, of the 
Iberia Central System. The most relevant finding of the resulting image is the thickening of the ICS crust through a northward-directed imbrication of its lowermost part. In general, the crust-mantle boundary presents depths between 29 and $31 \mathrm{~km}$ to the $\mathrm{N}$ and $\mathrm{S}$ of the profile, while below the ICS it reaches depths of $38 \mathrm{~km}$. The crustal thickening has a wavelength of around $100 \mathrm{~km}$, and encloses the entire ICS from its southern thrust, the boundary to the $\mathrm{S}$ with the TB, until the southern border of the DB. As yet, it is not clear if the imaged lower crust imbrication affects also the upper crust. In fact, the surface continuation of this feature could be projected on top of the Southern Central System Thrust or the Tiétar River Fault system, thus indicating that the whole crust might be affected by this feature and further explaining the low topographies of the meseta to the S of the ICS. However, the fact that a Variscan mid-crustal detachment has been inferred and the lack of estimates of lowercrustal shortening hinder this interpretation. Higher-resolution datasets are necessary to image these features.

Furthermore, the profile reveals a clearly different reflectivity signature within the crust. The crust is subdivided into two main layers, the upper and lower crust. The upper crust is inferred to be formed mainly by massive granitoids under the ICS down to $5.5 \mathrm{~s}$ TWT, as its seismic response is dominated by low frequencies and high amplitudes. Below this layer, the lower crust is characterized by high-frequency high-amplitude arrivals, supporting the existence of high-impedance-contrast layers that have been already imaged with vertical incidence data in the lower crust to the $\mathrm{S}$ and $\mathrm{N}$ of the CIMDEF profile.

The interface that separates the upper and lower crusts $(\simeq 12.5-15 \mathrm{~km}$ depth) is proposed to be a detachment level between both crusts. However, the characteristics of the outcropping rocks, showing ductile deformation in many areas, hinders its interpretation as a fragile-ductile transition. Further studies about this interface are in progress and will be presented elsewhere.

Within the upper mantle, patches of reflectivity are found in two bands, $45-55 \mathrm{~km}$ depth and $70-75 \mathrm{~km}$ depth. Both reflections are scattered through the profile and appear almost horizontal. We relate them, with the possible $\mathrm{N}$ extension of the Hales discontinuity, the transition zone from spinel-lherzolite to garnet-lherzolite already observed to the $\mathrm{S}$ of the study area. 


\section{A Data Selection and Processing}

To highlight the importance of including lower magnitude events in the processing, we have created an image of the central deployment only with earthquakes with $M w \geq 6$, and compare it to that using all of the available events (Fig. 4.A.1). In the image with only $M w \geq 6$ events, the amplitude and frequency of the autocorrelations it is clearly different, and there is small reflectivity retrieved. This could be due to a lack of information in the stacking process, or to the lack of retrieval of the stationary phase during the stack. This would mean, that these 3 events could interfere destructively in the summation process or that the events do not cover a wide range of ray parameters, needed to produce a quality image.
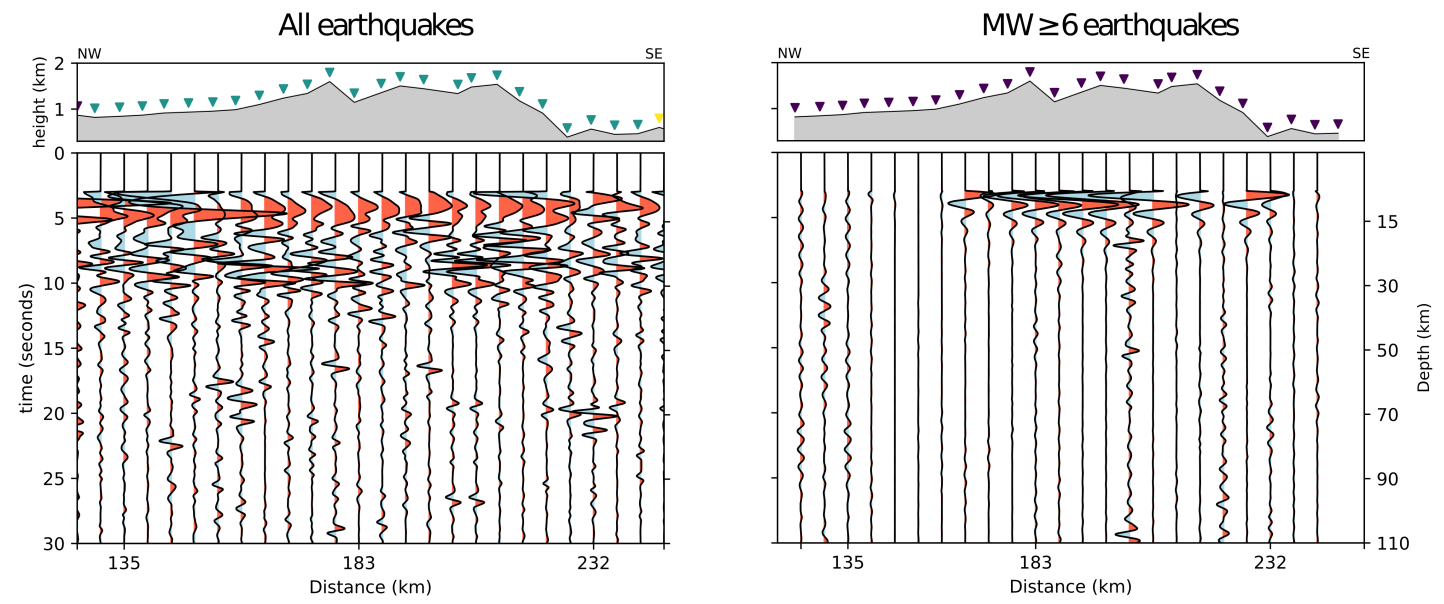

Figure 4.A.1: Comparison of the image of the central segment created with all the earthquakes (left) and only with those $M w \geq 6$ events (right).

\section{B Delta Pulse Suppression}

Three different approaches were used in order to eliminate the influence of the delta pulse at time $t=0$ (Fig. 4.B.2).

First deconvolution of the wavelet for each station was tested. For each station the wavelet dominating the trace around $\mathrm{t}=0 \mathrm{~s}$ is extracted and used for deconvolution. The construction of the wavelet used the full autocorrelation stack (i.e., positive and negative times). The time window of the wavelet was selected by visual inspection and it was selected to be 5s. This approach did not yield good results as it suppressed most of the reflectivity throughout the profile.

The second approach is based on the subtraction of the average delta pulse. To construct the wavelet, all the stations are stacked together. The selection of the time-window to extract the wavelet followed the same procedure as in the deconvolution approach. Then the wavelet is subtracted from 
each station stack. This approach seems to produce similar results to the deconvolution above described, except it preserves more reflectivity earlier than $5 \mathrm{~s}$. Still, most of the coherent reflectivity was suppressed.

The selected technique to eliminate the delta pulse was muting. We selected the time window to be muted as in the other two procedures, but to keep it long as possible. A window of $3 \mathrm{~s}$ was selected, even though the wavelet is probably slightly longer at the southern stations compared to the northern ones. This procedure preserved the reflectivity of the profile and was selected for that reason.
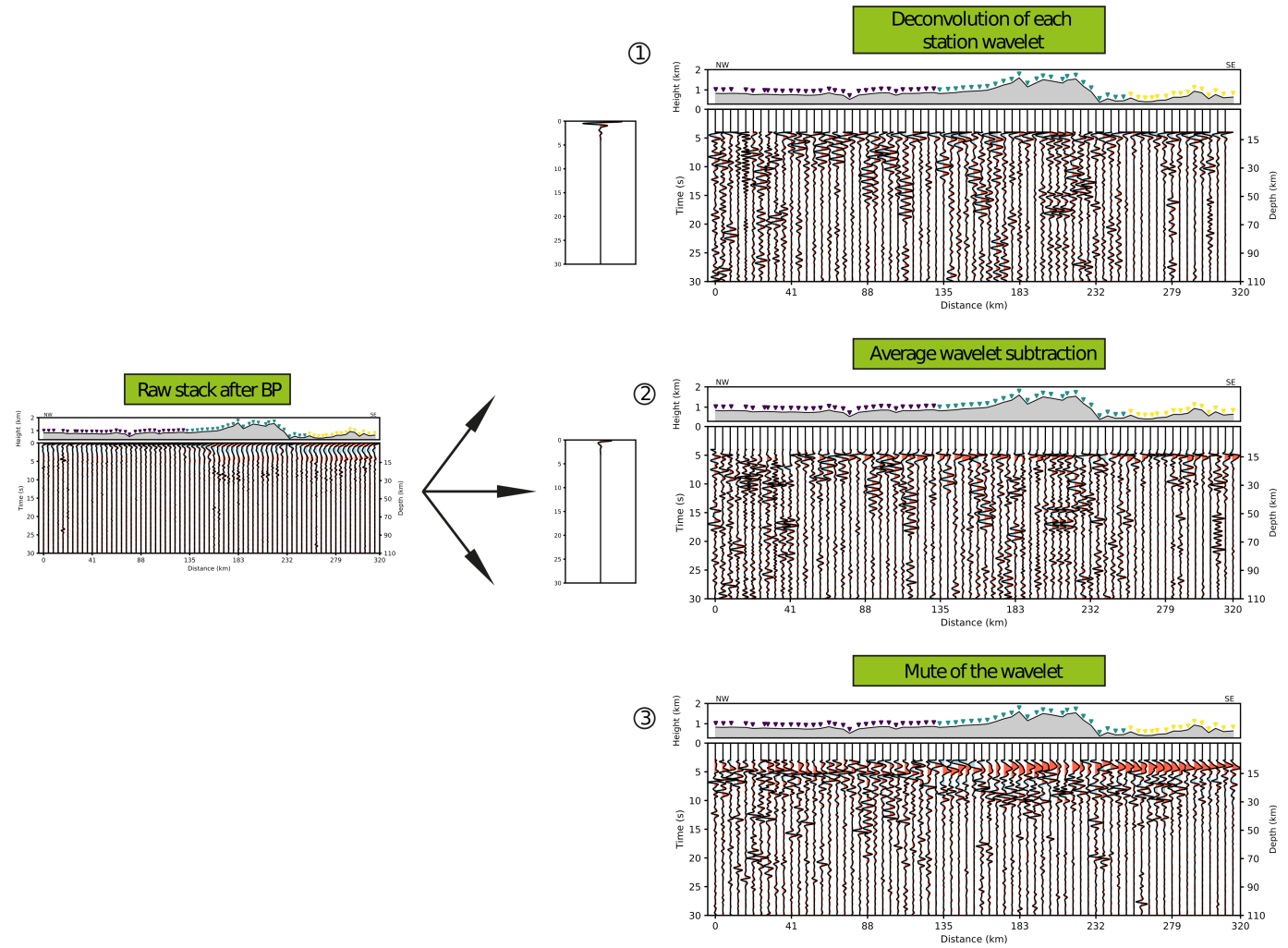

Figure 4.B.2: Approaches to eliminate the influence of the delta pulse at $t=0.1$ ) deconvolution for each station of the wavelet, 2) subtraction of the average wavelet of all the station, 3) muting of the wavelet. 


\section{Chapter 5}

\section{Ambient seismic noise lithospheric image of the Central Iberian Zone and the Iberian Central System}

Most of this chapter, regarding data gathering, objectives, data processing, results and discussion, have been published in:

Andrés, J., Ayarza, P., Schimmel, M., Palomeras, I., Ruiz, M., and Carbonell, R.: What can seismic noise tell us about the Alpine reactivation of the Iberian Massif?

An example in the Iberian Central System, Solid Earth Discuss., .

This chapter presents a slight modification of this paper to make the text consistent with other chapters and the thesis itself. 


\begin{abstract}
The Iberian Central System, formed after the Alpine reactivation of the Variscan Iberian Massif, features maximum altitudes of $2500 \mathrm{~m}$. It is surrounded by two foreland basins with contrasting elevation: The Duero Basin to the $\mathrm{N}$, located at 750-800 $\mathrm{m}$ and the Tajo Basin to the S, lying at $450-500 \mathrm{~m}$. The deep crustal structure of this mountain range seems to be characterized by the existence of a moderate crustal root that provides isostatic support for its topography. New seismic data is able to constrain the geometry of this crustal root, which appears to be defined by a northward lower crustal imbrication of the southern Central Iberian crust underneath this range. Contrarily to what was expected, this imbrication also affects the upper crust, as the existing orogenscale mid-crustal Variscan detachment was probably assimilated during the Carboniferous crustal melting that gave rise to the Central System batholith. In addition, the lower crust might have thinned, allowing coupled deformation at both crustal levels. This implies that the reactivated upper crustal fractures can reach lower crustal depths, thus allowing the entire crust to sink. This new model can explain the differences in topography between the Central System foreland basins. Also, it provides further constrains on the crustal geometry of this mountain range, as it seems to be that of an asymmetric Alpine-type orogen, thus hindering the existence of buckling processes as the sole origin of the deformation. Results presented here have been achieved after autocorrelation of seismic noise along the CIMDEF profile. Although the dataset features limited resolution $(0.5-4 \mathrm{~Hz}$, stations placed at $\simeq 5 \mathrm{~km}$ ), this methodology has allowed us to pinpoint some key structures that helped to constraint the deformation mechanisms that affected Central Iberia during the Alpine orogeny. This contribution innovates also in seismic methodological aspects of imaging crustal scale targets as it uses natural source environmental seismic noise recordings to investigate the structure.
\end{abstract}

\title{
5.1 Introduction
}

The Iberian Central System (ICS) is an intraplate mountain range that divides the Iberian Central Meseta in two sectors the northern Duero Basin (DB) and the Tajo Basin (TB) to the S (Fig. 5.1, Andrés et al. (2019). The most striking feature of the Central Meseta is its highly variable topography, with the Tajo Basin having an average altitude of $400 \mathrm{~m}$ while the Duero Basin presents a higher altitude of $\simeq 750-800 \mathrm{~m}$. It is thought that this contrast in altitude of about $300 \mathrm{~m}$ should mainly respond to subsurface characteristics (e.g. crustal structure or rheological properties of the lithosphere) but its origin is, as yet, unknown. The ICS range acts as a boundary between the two basins, that are enclosed within the Iberian Massif (IM) and extends in a NE-SW to ENE-WSW direction across the Iberian Peninsula (IB) for over $300 \mathrm{~km}$, with elevations above $2500 \mathrm{~m}$.

The lithospheric structure of the IM has been largely studied since the 1990s by different seismic techniques, e.g., controlled source seismic studies (Ayarza et al., 2004; Ayarza et al., 1998; Banda et al., 1981; Carbonell, 2004; Díaz et al., 1993; Ehsan et al., 2014, 2015; Flecha et al., 2009; Julià and Mejía, 2004; Martínez Poyatos et al., 2012; Palomeras et al., 2009, 2011; Pulgar et al., 1996; 
Simancas et al., 2003; Suriñach and Vegas, 1988), receiver functions (Mancilla and Diaz, 2015), shear wave tomography (Palomeras et al., 2017), etc. Also, potential field modelling (e.g., Andrés et al., 2018; de Vicente et al., 2007; Torne et al., 2015) has been used to unravel the crustal structure of the lithosphere of the IB. Most of these studies have focused mainly on its southern and northern parts. Only the regional study of de Vicente et al. (2007) and the large scale studies of Mancilla and Diaz (2015), Diaz et al. (2016), Palomeras et al. (2017) and Torne et al. (2015) cover the ICS, the DB and the TB. However, the lack of detailed seismic data on the centre of the IM hinders the complete comprehension of the current lithospheric structure of the ICS, its evolution and that of its bounding basins.

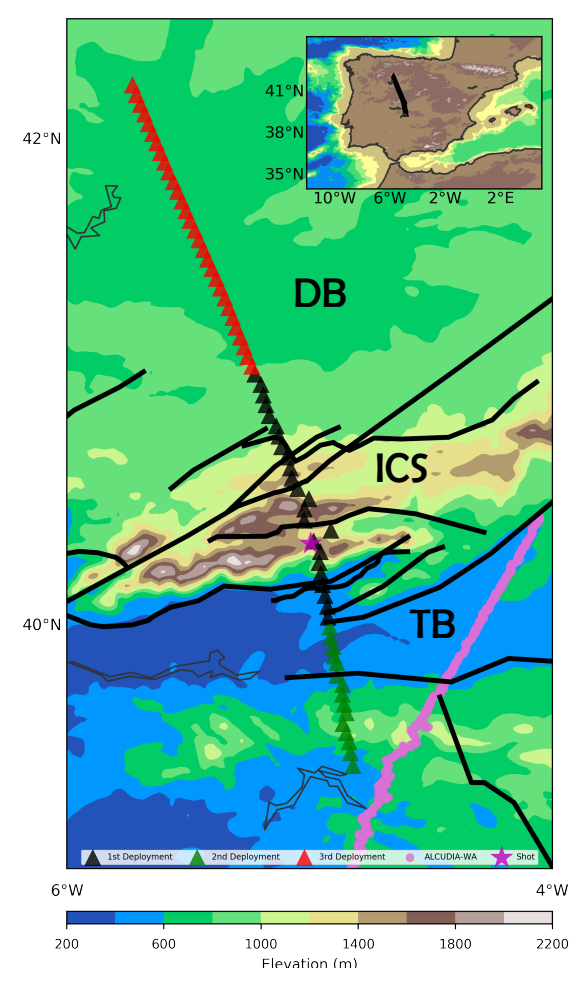

Figure 5.1: Topographic map of the ICS, DB and TB, to the N and S respectively, overlapped by the available seismic datasets in the area, and the situation of the recording stations deployed during the CIMDEF experiment (triangles).

To overcome this problem, the CIMDEF project was designed to acquire natural and controlled source seismic data across the ICS, the DB and the TB. The resulting data and models can be integrated with the existing ones and provide a complete section of the IM. As the first result of this effort, Andrés et al. (2019) presented a lithospheric model of the area using Global Phase Seismic Interferometry (GloPSI) of teleseismic data (Ruigrok and Wapenaar, 2012). In this paper, ambient seismic noise recordings are used to construct a lithospheric profile coincident with that of Andrés et al. (2019). Ambient noise has lately proven to be a useful and inexpensive tool for lithospheric imaging. Recent studies have exploited the recorded ambient noise field (Becker and KnapmeyerEndrun, 2017; Buffoni et al., 2019; Gorbatov et al., 2012; Kennett et al., 2015; Kennett, 2015; Taylor et al., 2016; Tibuleac and Seggern, 2012) to image lithospheric discontinuities such as the Moho, 
the Hales discontinuity or the Lithosphere-Astenorsphere Boundary (LAB). These studies rely on the construction of autocorrelograms of the recorded ambient seismic field as they retrieve the Greens function of the response of the subsurface structure.

This work aims to contribute to the knowledge on the crustal structure and thickness across the ICS and its relationship with the DB and TB. The results will provide us with constraints that are an asset to study the origin and evolution of the topography and the intraplate deformation dynamics of Central Iberia during the Alpine Orogeny. The observations presented in this work are derived from the CIMDEF experiment and present a continuation and additional support to those of Andrés et al. (2019), complementing and extending the previous knowledge of the ICS mountain range.

\subsection{Data}

Data used in this study was acquired within the CIMDEF experiment by 69 short-period (2 Hz), 3component stations. These were operational during 3 different time periods. The central segment (Fig. 5.1) of the profile was recorded between May and June 2017 by 24 stations and covered almost 120 $\mathrm{km}$. The second acquisition time was held from February to April 2018 and consisted in a deployment of 15 stations, covering the southern part of the profile. The northern and longest part, almost 170 $\mathrm{km}$, was acquired between July and September 2018 and 30 new stations were installed. The data was acquired in continuous recording mode at 250 samples per second (sps) during a period ranging from 28 to 60 days depending on the deployment. The stations were deployed in a linear array running NW-SE with an average interstation spacing of 4,8 km covering a total length of almost $330 \mathrm{~km}$ (Fig. 5.1). All data was collected using the same equipment, sensors and dataloggers, and the same acquisition parameters. While the duration of each deployment was different, the minimum amount of time devoted to recording data was 28 days.

\subsection{Results}

The procedure described above, led us to obtain a P-wave reflectivity profile (Fig. 5.2), crossing the ICS, the DB and the TB. It can be regarded as the reflectivity of the upper lithosphere down to 30s two-way travel-time (TWT). To estimate the approximate depth at which reflections are present, we adopted the same time-to-depth conversion used by Andrés et al. (2019). This conversion takes as a reference for the crust the velocity profile of shot 3 from the ALCUDIA wide-angle (WA) experiment Fig. 5.1, Ehsan et al. (2015)). For sub-Moho reflections a constant velocity of $8 \mathrm{~km} / \mathrm{s}$ has been used. In areas with a sedimentary cover or where the crust is thicker than that of the ALCUDIA-WA shot 3 section, the conversion might not be accurate because of the lower velocities existing in sediments, therfore resulting in an overestimation of the depths at which reflectors are present. The profile covers a distance of approximately $330 \mathrm{~km}$, but the inter-station spacing $(\simeq 4.8 \mathrm{~km})$ ensures a high lateral resolution of the crustal structure of the study area. As explained in chapter 2, the application of Seismic Interferometry (SI) by autocorrelation creates sidelobes at $\mathrm{t}=0 \mathrm{~s}$ (Claerbout, 1968)which 
dominate the early time of the autocorrelation trace. To eliminate this effect and for visualization purposes, we have muted the signal from 0 to $3 \mathrm{~s}$, and data has been amplitude normalized.

In general, the profile shows bands of high reflectivity and other rather transparent areas (Fig. 5.2). This allows us to divide the crust in upper and lower crust, similar to the pattern obtained in the ALCUDIA and previous CIMDEF datasets. The upper crust extends from 0 to $5-6 \mathrm{~s}$ TWT, while the crust-mantle boundary is located between 10-12.5 s TWT. The deepest reflection present in the profile is located between 18-19 s and it is visibly scattered throughout the array. Laterally, the profile can be divided into three areas on the basis of its geological interpretation: northern, central and southern segments. The northern sector comprises 30 stations, covering almost $140 \mathrm{~km}$, and is crossing the Tertiary DB. The central segment covers the core of the ICS (around $120 \mathrm{~km}$ ) and presents the highest structural complexity of the profile. The southern segment is the shortest one and covers only $72 \mathrm{~km}$, crossing part of the TB/Tietar River Basin (TRB) and the southern CIZ.

Although this experiment was set to record P-waves, we cannot rule out the presence of S-wave reflections or P-to-S reflection conversions. These waves are not expected to have a high amplitude on the vertical components, but can occur due to lateral heterogeneities and to an ambient noise wave field which is not diffuse. Here, we interpret dominant signals as P-waves and assume that S-waves are much weaker on the vertical components, and thus, not considered here.

\subsubsection{Northern Segment}

The northern sector (Fig. 5.2a) covers a distance of $140 \mathrm{~km}$ and lies entirely within the Cenozoic DB. In general, good reflectivity is recovered down to almost $20 \mathrm{~s}$ TWT, despite the fact that the first 8 stations to the N present poor reflectivity below 5-6 s TWT. Nonetheless, several bands of reflectivity within the crust are observed. First, an upper band of reflectivity appears at 5-6 s as a high amplitude event. Below this reflection, another less reflective band appears to be limited by a strong reflector at around $8 \mathrm{~s}$. Further down, at $\simeq 9.5-10.5 \mathrm{~s}$, a sharp and laterally continuous reflection can be identified along the entire section. Below, reflectivity and coherency decrease, and only two more sets of reflections seem to be visible throughout the segment. These events are enclosed between 12.5 and $14 \mathrm{~s}$ TWT. Finally, some local reflections appear, e.g. at 18 s TWT, but they are only detected below a few stations.

\subsubsection{Central Segment}

The central segment hosts the most complex reflectivity pattern. Nevertheless, clear events are identified at various depths (Fig. 5.2). First, a package of clear reflectivity is found between 3 to $5-8$ s, slightly thinning towards the $\mathrm{N}$ and $\mathrm{S}$ limits of the ICS. It is characterized by higher amplitudes and lower frequencies compared to the reflectivity seen elsewhere, where higher frequencies are found. The boundary of this reflective area is deeper in the centre of the ICS ( $8 \mathrm{~s}$ TWT) and shallower towards $\mathrm{N}$ and $\mathrm{S}$, getting up to $3 \mathrm{~s}$ in the upper part of the section. It also presents higher but less coherent amplitude towards the northern sector while decreasing towards the S of the ICS. Between 200 and 
$250 \mathrm{~km}$ along the profile, the bottom of this band of reflectivity is poorly defined as more events are probably interfering. Nonetheless, its lateral continuity is easily identified.

An interesting feature located underneath this upper band of reflectivity is the contrasting signature and opposite polarity of events to the $\mathrm{N}$ and $\mathrm{S}$ of the $200 \mathrm{~km}$ point. Between 160 and $200 \mathrm{~km}$, the sub-horizontal low amplitude reflectivity located at $\simeq 10 \mathrm{~s}$ contrasts with that found between 200 and $250 \mathrm{~km}$, where a slightly $\mathrm{N}$ dipping, high-amplitude and high-frequency package of reflectivity appears. The high amplitude reflectivity observed at $\simeq 10 \mathrm{~s}$ to the $\mathrm{N}$ of the ICS, appears to sink down to $\simeq 12.5 \mathrm{~s}$ in the central part of the segment. This band of reflections, which is sub-horizontal elsewhere, is characterized by a marked lateral continuity throughout the profile. However, underneath the northern part of the ICS, this event presents a $\mathrm{N}$ dipping attitude. Another package of high-amplitude reflections parallel to the one just described but 1-1.5 s shallower (E in Fig. 5.2) is found along the section, also in the southern and central parts of the ICS, at 11 to $11.5 \mathrm{~s}$.

At later times, two sub-parallel reflectors are found at 12.5 and $13.5 \mathrm{~s}$ TWT, and are visible at both ends of the segment but not in the central part. Below these reflections, the coherence of the reflectivity decreases. Still, some tentative events can be followed locally at $15 \mathrm{~s}$ TWT and between 18-19 s TWT.

\subsubsection{Southern Segment}

The southern segment represents the shortest section of the profile, approximately $70 \mathrm{~km}$, and is located to the S of the ICS. The deployment was undertaken during an anomalous period of heavy rainfall in the area. Thus, variations in the seismic velocities have been observed due to the presence of highly saturated media in shallow layers (Fores et al., 2018; Obermann et al., 2014; Sens-Schönfelder and Wegler, 2006). According to previous studies, high rainfalls can be related with de-coherence in the retrieved signal, and increasingly at higher frequencies. During the deployment period, precipitations two to three times above the average took place. As a consequence, the coherency of the calculated autocorrelations is worse compared to that of the other two deployments, i.e., reflections are weaker and more noise was to be retrieved. Altogether, this makes the assessment of the retrieved autocorrelations difficult to interpret and results should be taken with caution.

In this context, the main reflections found in the Central Segment (5-6 s and $\simeq 10 \mathrm{~s}$ reflections, Fig. 5.2a) can be followed to the $\mathrm{S}$. The $5-6 \mathrm{~s}$ reflection has a rather horizontal geometry shallowing towards the $\mathrm{S}$, getting up to $4.5-5 \mathrm{~s}$. The reflection at around $10 \mathrm{~s}$ is more difficult to recognize although the one parallel to it but shallower (8.5-9 s TWT) is a bit more conspicuous. In any case, clear reflections of both events are retrieved just at a few stations, but not continuously along the array. Moreover, their amplitude and coherence is low. Finally, reflectivity underneath $10.5 \mathrm{~s}$ is scarce and difficult to correlate. 


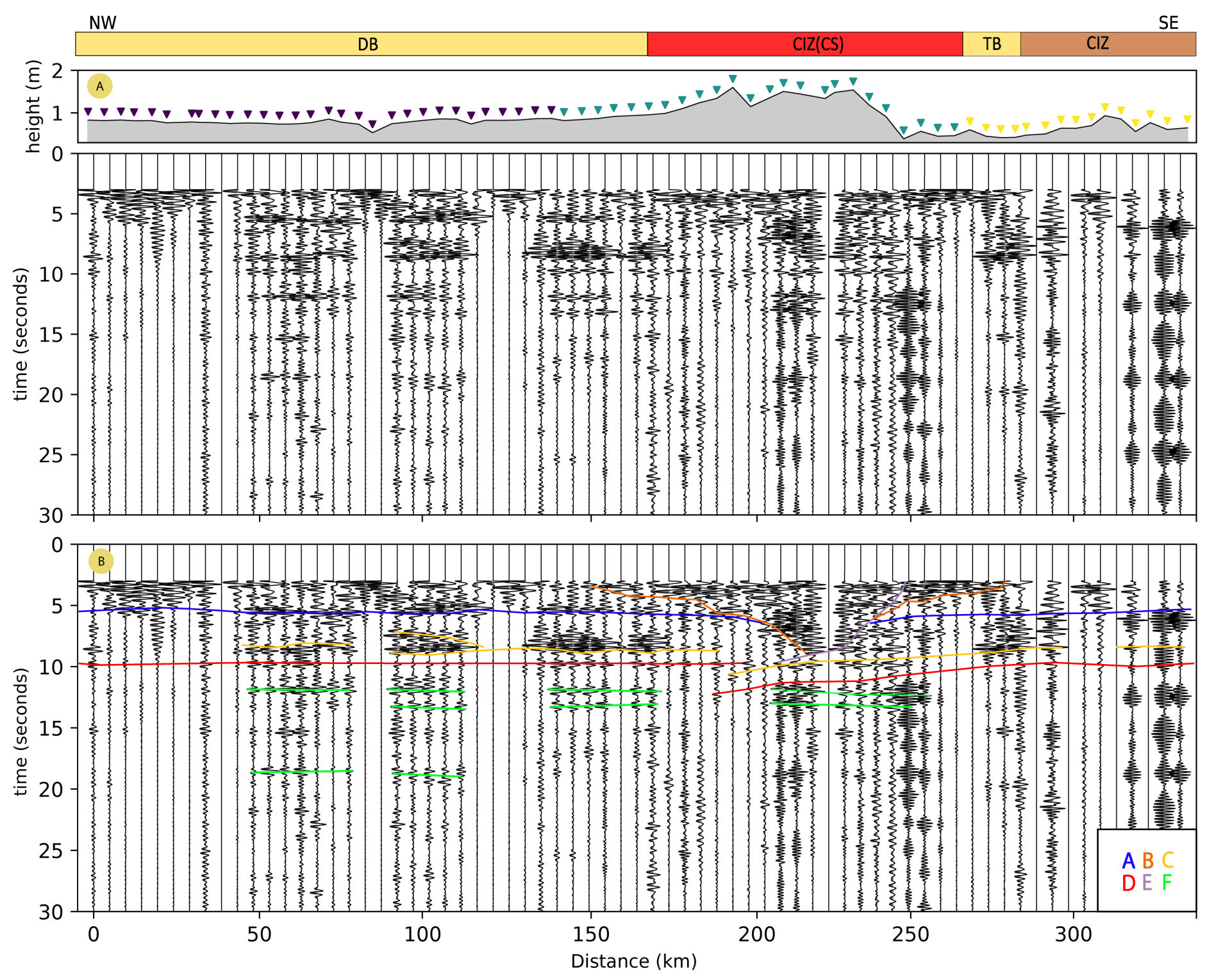


FiguRE 5.2: a) Reflectivity profile retrieved by autocorrelation of ambient seismic noise. In the wiggle plots, the grey lobes indicate negative polarity. Coloured triangles placed over a topographic section represent the different acquisition stages (from $\mathrm{N}$ to S: third, first, and second deployments). b) Interpretation of different reflectors, which are labelled between A-F. A marks the boundary between the upper crust and the lower crust. B represents the interpreted depth extension of granites below the ICS. C marks an intracrustal reflector within the lower crust. D is the crustmantle boundary. E represents a key $\mathrm{S}$ verging thrust affecting the southern end of the ICS.

$\mathrm{F}$ marks the scattered reflectivity within the upper mantle.

\subsection{Discussion}

The interpretation of our data relies on the identification of arrivals with high amplitudes, lateral coherence, and similar waveforms as those on their neighbouring stations. In addition, it is supported by previous knowledge of geological/geophysical features of the study area. In this regard, the ALCUDIA Wide-Angle (WA) profile (Ehsan et al., 2015) located to the S (Fig. 5.1) is especially helpful and, therefore, the velocity model constrained by this dataset was used to carry out the depth conversion of main features. Also, we have used the information provided by the recently published CIMDEF coincident transect, where interferometry of earthquake phases with epicentral distance $>120^{\circ}$ was carried out (Andrés et al., 2019) to investigate the crustal and lithospheric architecture.

In general, clear reflectivity and good lateral continuity is retrieved along the profile presented here (Fig. 5.2b). Unfortunately, to the SE, where higher frequency data could indicate the existence of more heterogeneities and small-scale features, noise due to weather conditions hinders a reliable detailed interpretation. Nevertheless, the resulting profile allows us to identify crustal and even upper mantle reflectivity.

The crust could be divided into upper and lower crust according to the present reflections. The upper crust extends from the surface to $\simeq 5-6 \mathrm{~s}$ TWT where a clear crustal scale discontinuity is observed (Fig. 5.2b, line A, Fig. 5.3). The lower crust extends down to $12.5 \mathrm{~s}$ TWT in its deepest part, with the Moho being marked by a discontinuity placed between 9.5 and $12.5 \mathrm{~s}$ TWT (Fig. 5.2b, line D). Below this discontinuity, and within the upper mantle, lower amplitude scattered events are present at different times, e.g., 12-13 s TWT and 18-19 s TWT (Fig. 5.2b, line F). As expected, the upper mantle presents less reflectivity than the crust.

\subsubsection{Crustal Features}

As described above, two crustal scale discontinuities can be traced in the reflectivity image (Fig. 5.2b and 5.3): a mid-crustal discontinuity and the crustal-mantle boundary. Moreover, a conspicuous package of high amplitude reflectivity is observed in the lower crust, at $\simeq 8 \mathrm{~s}$ TWT (Fig. $5.2 \mathrm{~b}$, line C), in some parts of the profile. 


\section{Upper Crust}

The upper set of reflections is related to the upper-lower crust boundary. It appears mainly at $5 \mathrm{~s}$ TWT, being shallower towards both ends of the profile and slightly deeper below the ICS, mostly in its southern part $(\simeq 6 \mathrm{~s}$ TWT). It constitutes a high amplitude reflection which underlies an upper crust featuring heterogeneous reflectivity. This boundary is well correlated with a mid-crustal discontinuity interpreted as the upper-lower crust boundary by Andrés et al. (2019) along this same transect and it is also consistent with a similar one identified in the ALCUDIA dataset (Ehsan et al., 2014, 2015; Martínez Poyatos et al., 2012). In all cases, this upper-lower crustal boundary coincides in geometry, depth and regional extent character. A small discrepancy exists below the NW end of the ICS, where the boundary, as identified by GloPSI, is slightly deeper than that presented in this work (compare Fig. 5.3 in this chapter and Fig. 4.2 in chapter 4).

The upper crust presents a heterogeneous response throughout the profile, being the central segment where the highest amplitude events are localized. The outcropping rocks of the ICS are mainly Carboniferous granites (Bea, 2004). In fact, previous studies have inferred that granites below the ICS exist down to $18 \mathrm{~km}$ based on the low frequency/high amplitude reflectivity retrieved above that depth (Andrés et al., 2019). Nonetheless, in our profile we found two distinctive zones within the upper crust below the ICS (Fig. 5.3), i) from 210-240 km, i.e., the central part, and ii) in the extension to the $\mathrm{N}$ and $\mathrm{S}$ the boundary of the ICS. The latter is defined by the edge of the low frequency/high amplitude reflections (Fig. 5.2b, lines B and E). This signature can be regarded as the expression of a highly homogenous body or structure with scarse internal reflectivity. When considered as a whole, the ICS granitic area defined here would correlate well with that identified with in the GloPSI image (Andrés et al. (2019), and chapter 3 in this volume) as the upper granitic crust (Andrés et al., 2019). However, the higher frequencies used in this study allow us to improve this interpretation. In the central part of the granitic area (210-240 km), a pattern of higher frequency/higher amplitude reflections is found, which extends down to $8 \mathrm{~s}$ TWT (Fig. 5.2), cross-cutting the proposed upperlower crustal boundary. However, towards both ends, this pattern of reflectivity is located at shallower levels, showing $\mathrm{N}$ and $\mathrm{S}$ dipping contacts with the neighbouring areas. Given these two zonations, we can infer that, the granitoids representing the ICS reach down to $8 \mathrm{~s}$ TWT (Fig. 5.2b, lines B and E) in its deepest point, shallowing to 3.5/4 s TWT towards the $\mathrm{S}$ and N. To the N, this characteristic granitic signature fades away when entering the DB, as according to our section, it partly overlaps the granites. To the $\mathrm{S}$, this package of reflectivity is bounded by an area of low reflectivity that could define some sort of ICS southern thrust. The reflectivity package south of this thrust present high frequencies and amplitude. This higher frequency content could be related to the presence of a mixture of granites with metasediments from the Schist-Greywake Complex, which dominates the outcrops of the southern part of the CIZ when not overlapped by the TB. Although, this is a feasible interpretation, additional geophysical information is needed to confirm this feature. Finally, a loss of coherency in the autocorrelations marks the end of the granites although the existence of granitic rocks outcropping further to the SE of the CIMDEF profile (E of the Toledo Mountains) might indicate that they somehow continue in depth, irregularly distributed underneath the TB. Unfortunately, the 
lack of information above $3 \mathrm{~s}$ TWT hinders a more accurate interpretation of the geometry of these granitoids.

The ICS granites represent a large volume of Carboniferous melts derived from crustal thickening and extension during the Variscan orogeny (Pérez-Estaún et al., 1991). The fact that the base of the granites presented in this work extends below the proposed mid-crustal discontinuity (Fig. 5.3) could indicate that melting of the crust below the central part of the ICS was greater than in other areas of the CIZ and affected a major portion of the crust, partly including the lower crust. In fact, some authors have evidenced the marked presence of I-type granites in the ICS (Villaseca, 2017) suggesting that they have a deep protoliths origin.

It is not clear how the faults controlling the pop-up/pop-down structure (de Vicente et al., 2007) of the ICS affect its deep configuration. They probably play an important role in defining the northern and, the southern limit of the ICS (Fig. 5.2b lines B and E). In the external areas of the identified ICS granitoids, where the upper-lower crustal boundary is deeper than the granites, the lower amplitude reflectivity below the granites would represent the seismic response of the Schist-Greywake Complex (Vendian to Lower Cambrian metasediments) and underlying rocks. These lithologies extend southwards and dominate the outcropping geology until the southern end of the transect.

As stated above, the interpreted upper-lower crust boundary correlates well with that deduced in Andrés et al. (2019) and with similar reflectors seen in the IBERSEIS and ALCUDIA datasets (e.g., Ehsan et al., 2014, 2015; Martínez Poyatos et al., 2012; Simancas et al., 2003, 2013). Accordingly, this reflection runs from the southern part of the SPZ, along the OMZ and up to the southern part of the ICS in the CIZ, i.e., it has, at least, a length of around $500 \mathrm{~km}$. This boundary has been proposed to represent the brittle/ductile transition (Ehsan et al., 2014; Martínez Poyatos et al., 2012; Simancas et al., 2003), being the boundary between two crustal levels where tectonic shortening is resolved by different mechanisms (Simancas et al., 2013). In the CIMDEF profile, the heterogeneous seismic signature of the upper crust seems to picture some dipping reflectors while the lower crust presents mostly sub-horizontal and laterally coherent features. This different response, partly observed by Andrés et al. (2019) might be the representation of two decoupled zones, making the correlation between this reflection and the brittle/ductile transition also feasible. However, due to the fact that presumably ductile deformation exists above this boundary, we suggest that this feature mostly represents a detachment, and/or a rheological boundary between a Pre-Variscan basement and the deformed rocks on top. According to the interpretation included in this paper, the development and emplacement of the ICS granites erased the imprint of this detachment underneath this mountain range. Therefore, it has not been active in this area since the Late Carboniferous, thus imposing some constraints to the Alpine accommodation of the deformation that will be discussed later.

\section{Lower Crust}

The lower crust is characterized by some thick sub-horizontal and coherent packages of high-frequency/highamplitude reflections that seem fairly continuous and well defined at places. The northern sector is less reflective, being almost transparent between 0 and $40 \mathrm{~km}$ along the profile. Further to the $\mathrm{S}$, 

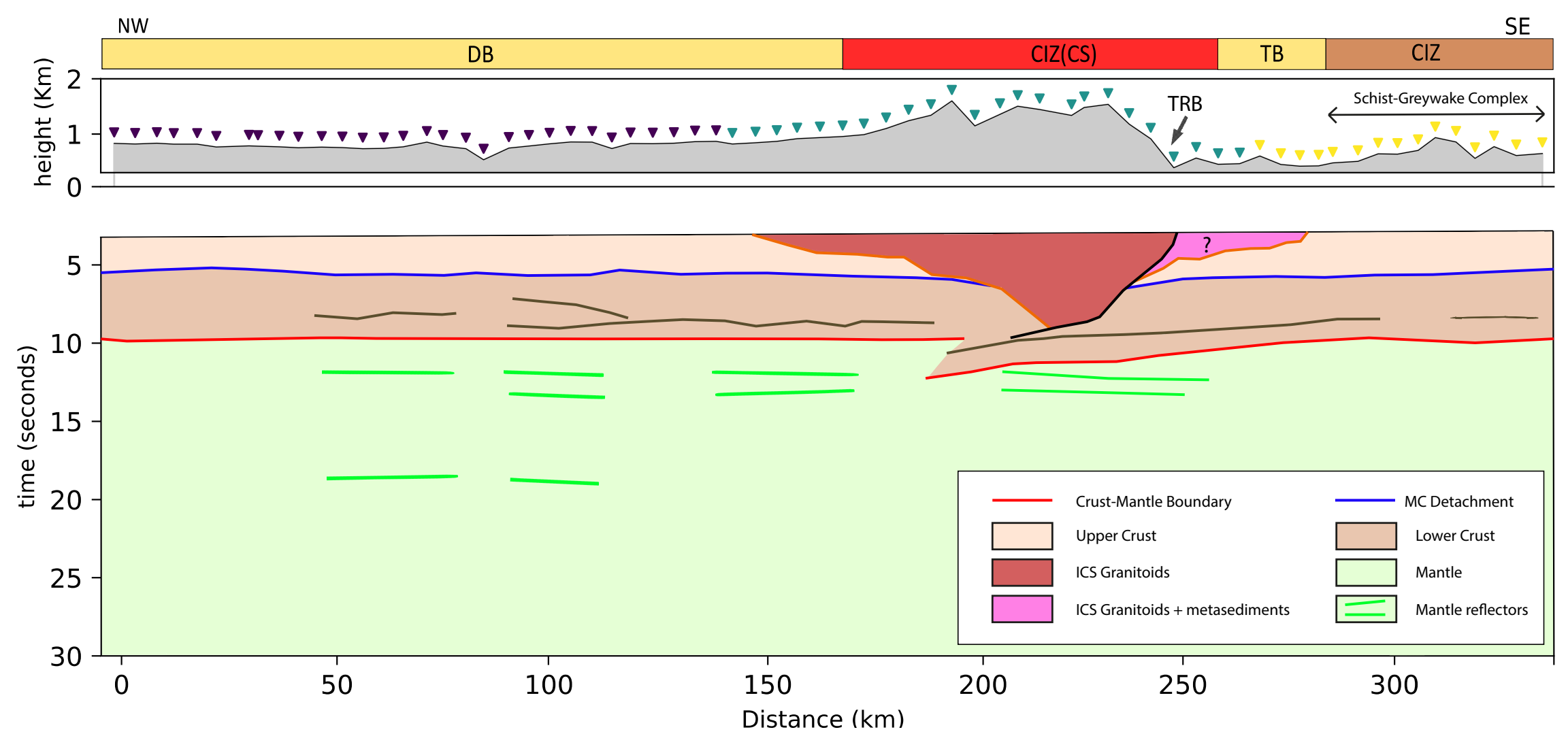

FiguRE 5.3: Sketch of the proposed crustal structure below the Iberian Central System, and the Duero and Tajo Basins. 
high-amplitude sub-horizontal events are retrieved between 7-8 s TWT, e.g. from 40 to $75 \mathrm{~km}$, from 90 to $160 \mathrm{~km}$ and from 190 to $280 \mathrm{~km}$ along the profile. Those features could represent a highly laminated lower crust, beneath the CIZ, a similar seismic signature that is observed southward of this profile (e.g. ALCUDIA-NI and IBERSEIS-NI). Again, this same reflectivity is also imaged by Andrés et al. (2019), after autocorrelations of teleseismic data. However, in the northern end of the ALCUDIA-NI profile (Martínez Poyatos et al., 2012), below the granites of the Mora pluton, there is a strong reflector, that the authors correlate with the top of the lower crust. This feature matches the arrival time of the strong intra-crustal reflections identified in this dataset. The presence of such a thin lower crust could be explained as the result of the intense late-orogenic Variscan extension, that resulted in partial melting of the lower crust and the generation of big volumes of granites. Nevertheless, northwards, such a thin lower crust below the DB is not expected as there is no significant outcrops of granites. The latter, would indicate that intra-lower crust reflectivity might be a remnant feature that indicates the onset of the extension on places where it did not progress.. Nonetheless, this relationship needs more information to be confirmed or disregarded.

The fact that the lower crust is less reflective in the northernmost part of the profile underneath the DB indicates either a change in the nature of the lower crust (i.e. the pre-Variscan basement), a different tectonic evolution for this area, or a high attenuation of P-wave energy by the DB sediments. In fact, reflectivity is low at every level below $5 \mathrm{~s}$ TWT in the first $40 \mathrm{~km}$ of the seismic profile thus suggesting that attenuation of the seismic energy may play a key role. On the other side, some cross-cutting relationships can be addressed at lower crustal levels in this section (e.g., $\simeq 100 \mathrm{~km}$ ). Even though this dataset does not have enough resolution, other authors have seen similar features in vertical incidence datasets, also including the CIZ, further S (ALCUDIA-NI and IBERSEIS-NI) and have interpreted it as the tectonic imprint on the lower crust of the pre-Variscan and Variscan deformation (Ayarza et al., 2020).

\section{Crust-mantle Boundary}

Probably, the most relevant reflection in this profile is the crust-mantle boundary. Previous studies based on gravity modelling (de Vicente et al., 2007), and receiver functions (Mancilla and Diaz, 2015) have proposed that the Moho underneath the ICS has a synform-like structure, with a gentle thickening of $2-3 \mathrm{~km}$ beneath the core of the orogen. However, Andrés et al. (2019) proposed that there is an imbrication of the lower crust below the ICS, where the southern CIZ lower crust underthrusts that to the N, defining a Moho offset underneath the highest peaks of the mountain range. In our study, the Moho is presented as a distinctive and sharp reflection identified between $\simeq 9.5 \mathrm{~s}$ and $12.5 \mathrm{~s}$ TWT (29-38 km depth). The boundary between the crust and the mantle presents a rather horizontal geometry, being shallower to the $\mathrm{N}$, around $9.5-10 \mathrm{~s}$ and deepening below the ICS, and shallowing again towards the $\mathrm{S}$. In the central part, a set of N-dipping features can be inferred between 10.5 and $12.5 \mathrm{~s}$. These reflections run from the southern end of the central segment until the centre of the ICS and represent the base of the reflective crust. Therefore, this new image pictures a Moho boundary featuring an offset compatible with an imbrication of the lower crust underneath the ICS. 
This structure defines the ICS crustal thickening, picturing an asymmetric crustal structure for this mountain range. The crustal thickening identified here appears at the same location as in Andrés et al. (2019) thus supporting the interpretation. The underthrusted lower crust, would account for the crustal root seen in gravimetric models although with a different geometry, which has geodynamic implications. The time offset observed in the Moho is $\simeq 2-2.5, \mathrm{~s}$ translates into a thickening of around 6-8 km. The shortening addressed by this crustal imbrication can be estimated to be $\simeq 20 \mathrm{~km}$, although it could be larger.

Comparing the profile and interpretations presented in this study (Figs. 5.2 and 5.3) with those generated with earthquake recordings (Andrés et al., 2019), the same Moho offset can be identified. However, some differences are observed as the resolving power of both datasets is different. The present data shows that, reflections picturing the imbrication partly define a staircase configuration, describing a smooth underthrusting. Crustal thickening is defined by the signal retrieved from five stations, from 185 to $210 \mathrm{~km}$ approx., and not only by two or three, like in Andrés et al. (2019). Moreover, now we can observe another reflection at $\simeq 10 \mathrm{~s}$ TWT in the root zone. This feature is clearly visible below the three stations that recover the deepest part of the imbrication, from 185 to $200 \mathrm{~km}$. These stations present two reflectors, one located at $\simeq 10 \mathrm{~s} \mathrm{TWT}$ and another located at $\simeq$ $12.5 \mathrm{~s}$ TWT, clearly defining the Moho offset that affects the internal parts of the lower crust. We suggest that this pattern is identifiable due to the higher resolution of the data used in this study. The band limited frequency filter applied to the data, might limit the resolution, thus, not being able to properly resolve the complexity of the structure at hand and its length, it does image an imbrication whose lateral extent (around $20 \mathrm{~km}$ at lower crustal level) could be used to compare with the amount of shortening estimated from field data at the upper crust. High conductivity at lower crustal level found by Pous et al. (2012) at this same location, is consistent with the existence of such an imbrication affecting the entire lower crust, as proposed here.

The imbrication of the lower crust below the ICS can be understood as a consequence of the compression that occurred during the Alpine orogeny within the Iberian Peninsula, driven by the collision between Eurasian and African plates. This compressional stage reactivated normal faults formed during the late orogenic Variscan extension, and made them play a critical role in the formation of the ICS. These faults are the main drivers for the development of the pop-up/pop-down structure that configures the topography of the ICS (de Vicente et al., 2007). In its south-western border, the Tietar River Fault (TRF) and the South Central System Thrust may play a crucial role in the crustal structure of the area and the topographic differences between the DB and the TB, as they may be involved in the crustal imbrication process (Andrés et al., 2019). In our image, the upper part of the underthrusting lower crust is well defined and seems to continue upwards, to at least, the lower part of the granitic complex defining the mountain rage ( $\mathrm{km} \mathrm{220).} \mathrm{From} \mathrm{there,} \mathrm{it} \mathrm{continues,} \mathrm{along}$ the southern edge of the ICS, linking upwards with what we interpret as the depth continuation of the TRF (E in Fig. 5.2). As the ICS granitoids have assimilated the mid crustal detachment in this area, we argue that some of the faults affecting the upper crust (e.g., the TRF), do not root in this detachment but continue to depth, thus forcing the upper crust to sink. This would imply that 
the upper crust to the S of the ICS is slightly underthrusting it, lowering the topography and thus defining a contrast in altitude between the two ICS foreland basins, one located to the $\mathrm{N}$ and the other to the $\mathrm{S}$, the $\mathrm{DB}$ and $\mathrm{TB}$ respectively, being the $\mathrm{TB} \simeq 300-400 \mathrm{~m}$ lower. Therefore, the depth extent of the granitoids implies the local lack of a mid-crustal detachment, that would prevent the CIZ upper crust located to the S of the ICS from underthrusting, as suggested by Andrés et al. (2019). Contrarily, if the detachment has been assimilated, upper crustal fractures can find their way into the lower crust thus allowing the upper crust to sink. This model is partly in conflict with the seismic images obtained for transects along the TB further to the E (de Vicente and Muñoz-Martín, 2013), which do not show evidences of upper crustal underthrusting. However, they show some downward bending of sediments in the contact between the TB and the ICS. In addition, the present dataset does not cross the NE-SW oriented TB but the E-W TRF (Fig. 2.1) and the configuration might be slightly different. An estimation of the shortening at upper and lower crustal levels implied by each of the involved structures could help us to support this interpretation.

Previous estimates of the shortening accommodated by the ICS in IB based on field observations portrait a minimum of 5-9 km and a maximum of $20 \mathrm{~km}$ (de Vicente et al., 2007, 2018). These values suggest that the amount of shortening observed at upper crustal level is similar to that imaged at the lower crust in Figsures 5.2 and 5.3, thus supporting the proposed model. However, other possibilities exist and cannot be ruled out. Further seismic studies are needed in order to assess the amount of shortening accommodated at lower crust levels.

\section{Upper Mantle}

Within the upper-mantle, locally continuous and well defined reflections are retrieved (Fig. 5.2b, line $\mathrm{F}$ and 5.3). They are observed within the northern and central sector, while in the southern sector less coherent mantle reflectivity is retrieved. These reflections are found within the profile at two main levels: between 13 and $14 \mathrm{~s}$ TWT $(40-45 \mathrm{~km})$ and between 19 and $20 \mathrm{~s}$ TWT ( $\simeq 70 \mathrm{~km})$. The upper set is observed at the northern and central segments, while the deepest reflections are only found in restricted areas between 50 and $120 \mathrm{~km}$ and 200 to $250 \mathrm{~km}$ along the profile. The top package of reflectivity is composed by two subparallel and sub horizontal reflections separated by $\simeq 1 \mathrm{~s}$ TWT and slightly deepening towards the $\mathrm{S}$. The second set of reflections is also tilted towards the $\mathrm{S}$ but it is less continuous.

In southern Iberia reflectors at depths similar to our deepest feature have been reported previously (Andrés et al., 2019; Ayarza et al., 2010; Martínez Poyatos et al., 2012), e.g. between 61-72 km in the IBERSEIS profile. These reflections have been proposed to be related to a mineral phase transition from spinel-lherzolite to garnet-lherzolites within the upper-mantle: The Hales discontinuity (Hales, 1969). The coincidence in depths between previous observations and, the deepest events found in this work suggest a correlation between them. This suggest that the Hales discontinuity might also exist below the ICS and surrounding basins. No interpretations exist so far for the upper band of mantle reflectivity. Travel time estimations of $\mathrm{P}$ to $\mathrm{S}$ conversions and multiples indicate that they are not related to these events. Further modelling is necessary to interpret these reflections. 


\subsection{Conclusions}

In this study, we present a new lithospheric model of the Central Iberian Zone within the Iberian Massif constructed by autocorrelations of ambient seismic noise, as part of the CIMDEF project. The present work shows that this methodology has potential to provide key structural constraints at orogen scale studies and, complements previous results obtained along the same transect by autocorrelation of teleseismic data. Resulting models have important implications on the understanding of the accommodation of intraplate deformation during the Alpine reactivation of Central Iberia. The profile runs through three major geological features within central Iberia, namely the Iberian Central System, and its foreland Duero and Tajo basins. Our results highlight a crust divided between an upper part, that is in average $15 \mathrm{~km}$ thick, and the lower crust with thickness between 15 to $18 \mathrm{~km}$. The boundary between both crusts is well defined throughout most of the profile. Within the upper-crust the new dataset has allowed us to map, laterally and in depth, the extension of the granites forming the Iberian Central System. This batholith has an extension along the profile of around $120 \mathrm{~km}$, although only half of it outcrops. Based in this new dataset, we have estimated a maximum thickness of $8 \mathrm{~s}$ TWT, equivalent to approximately $24 \mathrm{~km}$ for these granitic batholit, although it gets thinner towards its northern and southern boundaries.

The most important findings of the study are, i) the presence of an imbrication of the crust below the Central System, and ii) the assimilation of the orogenic scale mid-crustal detachment by the granitoids of the Iberian Central System. The former defines a crustal root, where the Central Iberian Zone crust to the $\mathrm{S}$ of the Central System underthrusts this mountain range depicting a Moho offset of $\simeq 6-8 \mathrm{~km}$, from $\simeq 30 \mathrm{~km}$ to $36-38 \mathrm{~km}$. The disruption of the mid-crustal detachment by Carboniferous crustal melting at the Central System allows upper crustal fractures to reach deep levels into the crust, as they are not forced to root into the detachment. This implies that the imbrication of the crust is not restricted to its lower part but also affects the upper crust. Accordingly, the crustal thickening appears to be bounded to the $\mathrm{S}$ by a system of interconnected fractures that might outcrop at the Tietar River Basin, or further to the E at the Southern Central System thrust. In fact, a conspicuous area of highreflectivity/high-amplitude events interpreted as granitoids (with variable but probably low amounts of metasediments) are found to bound with the main faults, Although, it is not yet clear how much of the upper crust is affected by this deformation, this configuration would force it to sink. This would account for the topographic differences between the Tajo Basin, to the S of the Central System, and the Duero Basin, to the $\mathrm{N}$ of this mountain range. Estimated shortening at upper and lower crustal level suggest that this model is coherent. Only limited amount of underthrusting is required to account for the 300-400 $\mathrm{m}$ difference in altitude between both foreland basins. Within the upper mantle, scattered reflectivity is found below the northern and central segments of the profile. This define two bands enclosed at depths of 40-45 km for the top band and around $70 \mathrm{~km}$ for the bottom one. The geometry of these reflectors is relatively horizontal, however, a small deepening towards the $\mathrm{S}$ is visible below the Iberian Central System. We describe the deepest of these features as part of the transition zone from spinel-lherzolite to garnet-lherzolite, known as the Hales discontinuity, a regional 
Chapter 5. Ambient seismic noise lithospheric image of the Central Iberian Zone and the Iberian Central System

scale discontinuity already described towards the $\mathrm{S}$ of the profile by other studies. 
Chapter 6

\section{Discussion and Conclusions}


In this section I will integrate the results and interpretations presented in chapters 3,4 and 5 , and give an overall interpretation synthesis and give an overall summary of the interpretation, including the implications that our results have in the understanding of the structure of the central CIZ and the ICS, together with its surrounding foreland Duero and Tajo Basins. Furthermore, I will discuss the mechanisms that gave raise to this mountain belt, those that have allowed an outstanding offset in the topographies of its northern and southern foreland basins and the thermal footprint resulting in relation to the tectonic evolution of the area.

\subsection{Crustal Extension and Melting in the CIZ: The Heritage of the Late Variscan Evolution}

The thermal model for IB derived from inversion of magnetic data and presented in chapter 3 , give insights into the current thermal configuration of the CIZ. This discussion will try to discern the origin of the thermal footprint left by the Variscan and Alpine orogenies that affected this area. As a rule of thumb, if the thermal configuration presents some correlation with the actual lithospheric structure, it can be argued that it has a recent origin.

As seen in Figure 3.4, the ICS and the northern meseta present the deepest calculated CPD, which translates into being some of the coldest areas within the IB (Fig. 3.7). However, there is no direct correlation between the depicted crustal structure and the calculated CPD isotherm: the ICS is a thickened area resulting from the shortening associated to the Alpine compression whereas the northern meseta comprises its foreland basin, which furthermore occupies the top of a thinner crust. Therefore, it can be argued that the Alpine orogeny did not produce a thermal footprint visible at present day. In fact, we state that thermal relaxation and equilibration of the IM was reached after the Variscan orogeny and little thermal disturbance was derived from the Alpine orogeny in continental areas. Accordingly, there are no Alpine derived melts in IB, supports the lack of relevant thermal footprint of the latest compressional stage.

Most of the lower crust in the IM presents a thickness of around 4-6 s TWT. However in the NW part of the CIZ and in the northern part of the ALCUDIA profile (southern CIZ), a much thinner lower crust is observed $(\simeq 1-2 \mathrm{~s}$ TWT). These zones correlate with areas where late orogenic Variscan extension led to the intrusion of syn-collisional and late orogenic granitoids (Fig. 3.10) that outcrop nowadays (Simancas et al., 2013). These granites represent a large volume of Carboniferous and Permian crustal melts that evidence the dominant tectonics at the end of the Variscan orogeny (Martínez Catalán et al., 2014).

In central and NW Iberia, magnetic anomalies seem to be related to this late Variscan extensional tectonics (Ayarza and Martínez Catalán, 2007; Martínez Catalán et al., 2018). Therefore, the calculation of the CPD is well supported by the data as it is geared by the anomalies associated to thermal domes, often cored by these granites. The results in the calculation of the bottom of the magnetic layer in this area of the IM, indicate that magnetic rocks exist down to high depths, almost 
to the base of the crust, constraining the thermal gradient and heat flow of the area. The obvious conclusion is that the thermal structure of the central and NW IB is mostly the heritage of Variscan tectonics. Alpine reactivation represented mostly by the ICS and the Cantabrian mountains have left a minor imprint when compared with the consequences of late Variscan tectonics.

The depth at which late Variscan extension and melting has affected the crust in the ICS is evidenced by the location of the base of its batholith as deduced by the CPD and by the associated reflectivity, which is presented and interpreted in Figure 5.3. These data indicate that the lower crust was also affected by extension and melting. The presence of I-type granites in the ICS (Villaseca, 2017) supports a deep source. The existence of granitoids hidden under the DB cannot be ruled out, although the metamorphic degree of pre-late Carboniferous rocks cropping out in its margin does not support an important contribution.

Finally, the CIMDEF profile presented here shows a conspicuous lower crustal reflection that extends almost entirely throughout the image. This reflector could represent the imprint of a late Variscan extension and melting at a lower crustal level in this part of the CIZ. However, in this area, these processes did not succeed to thin the entire lower crust, as otherwise observed in the NW CIZ or along the northern part of the ALCUDIA profile. Thus, we suggest that in the central part of the CIZ, crustal thinning and melting could have affected the lower crust to some degree but did not redefine it along the entire CIMDEF transect, but only in its central part, around the ICS.

\subsection{Alpine Lithospheric Structure of the Iberian Central Sys- tem and its Foreland Basins}

The general consensus regarding the ICS crustal configuration is that it is marked by a gentle thickening of the crust below the mountain chain. Estimated values of this thickening are on the order of 2-6 $\mathrm{km}$ depending on the methodology, i.e., gravity modelling (de Vicente et al., 2007), receiver functions (Mancilla and Diaz, 2015), or shear wave tomography (Palomeras et al., 2017). To date, the geometry of this thickening, which defines a crustal root, has not been attributed to any tectonic structure, but rather to distribution of deformation by buckling processes across the interior of IB during the Oligocene Alpine compressional stage. This hypothesis states that the convergence between Africa and Eurasia provoked a general lithospheric folding within IB (Cloetingh et al., 2002; Muñoz-Martín et al., 2010) where the main wavelength is in the 150-250 km range (Fig. 6.1). Although this model accounts for the elevation of the ICS, it fails to explain, among other issues, the relation between the uplifted areas of the ICS and its surrounding northern and southern mesetas. Furthermore, the mechanism that produces the elevation step between the northern meseta (750-800 $\mathrm{m}$ average altitude) and the southern meseta ( $\simeq 400 \mathrm{~m}$ average altitude) is not constrained by this model.

The structural models derived from the seismic images (Fig. 6.2) presented in this thesis reach, both of them, similar conclusions and are easy to correlate, shedding more light to the ICS structure and providing insights that allow us to understand those, as yet, uninterpreted features. The 2D 
profile derived from the autocorrelations of global seismic events described (GloPSI) presented in chapter 4 presents the general structural configuration of the mountain belt and its contact with the northern and southern mesetas. Furthermore, the main extension of the granites that compose the ICS can be drawn from the resulting image (Fig. 6.2a). Finally, reflections within the upper mantle, although very scarce, are observed through the profile. On the other side, the seismic image derived from autocorrelations of seismic ambient noise (Fig. 6.2b) presents a fine-tuned version of the above described profile, where similar features are observed with a better detail. The main improvement is the increase of the vertical resolution of the profile. This enhancement has helped to constrain the lateral extension, depth and location of the major crustal boundaries. Moreover, new features become evident within the crust and the upper mantle.
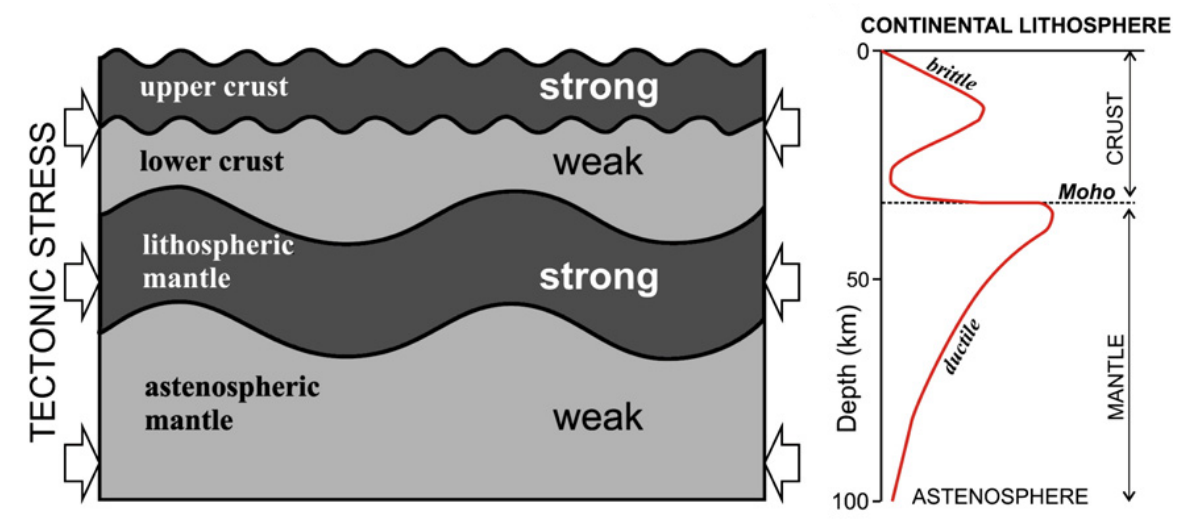

FiguRE 6.1: Model for the lithospheric folding for continental lithosphere, modified after Muñoz-Martín et al., 2010. To the right, strength profile for a two layer continental crust.

Results show that the crust extends from the surface until 9.5-12 s TWT being thinner to the $\mathrm{N}$ and $\mathrm{S}$ ends of the profile and thicker in the central part. It is divided into upper and lower crust throughout the profile, as no evidence of middle crust is found. Due to the methodology employed, the first $3 \mathrm{~s}$ TWT $(6-9 \mathrm{~km})$ remain unconstrained as the data has been muted. Thus, the boundary between the Duero and Tajo Basin sediments and the basement cannot be drawn.

The upper crust is defined between surface and around 5.5 s TWT on average. The contact between the upper and lower crust is subhorizontal, although slightly shallower towards both ends of the profile and significantly deeper around the ICS (Fig. 6.2). The upper crustal thickness correlates well with that deduced from adjacent seismic sections. To the N, the W-E ESCIN-1 profile (PérezEstaún et al., 1994) presents an upper crust that extends down to 6-6.5 s TWT. In addition, the N-S oriented ESCIN-2 seismic transect (Pulgar et al., 1995), that links the Cantabrian mountains and the Duero Basin, images an upper crust that reaches 5-6 s TWT. Although both profiles are off-line and relatively far from the CIMDEF transect, and sample different tectonic zones, the interpreted upper crustal thickness matches that observed in this thesis, implying that it has regional character. To the S, the ALCUDIA-NI and ALCUDIA-WA datasets (Ehsan et al., 2015; Martínez Poyatos et al., 2012) present a similar thickness for the upper crust as seen in the southern end of the CIMDEF profile. 
The lower crust extends from $\simeq 5.5 \mathrm{~s}$ TWT to $\simeq 9.5-12 \mathrm{~s}$ TWT. It is marked by an almost constant thickness of $4-6 \mathrm{~s}$ TWT which is also in agreement with the interpretations from the ESCIN-1 and ESCIN-2 NI seismic sections to the N, and the ALCUDIA-NI/WA and IBERSEIS-NI/WA seismic sections to the S. However, as explained in chapter 5 and seen in Figure $6.2 \mathrm{~b}$, the ICS granites extend down to $8 \mathrm{~s}$ TWT below the mountain range, thus thinning the lower crust and reworking the upperlower crust boundary. This characteristic is observed in another two areas into the IM, both of them in the CIZ and featuring granitic rocks at outcrop level: the northwestern part (see seismic profile ESCIN-3.2, Ayarza et al., 2004) and in the northern end of the ALCUDIA-NI profile (Ehsan et al., 2015; Martínez Poyatos et al., 2012).

One of the most relevant conclusions of this work is the identification of a vertical offset in the crust-mantle topography. The seismic images (Fig. 4.2 and 5.2) presented in chapter 4 and chapter 5 and summarized in Figure 6.2, show that the Moho is sub-horizontal throughout most of the section except below the core of the ICS, where it deepens and appears imbricated. Accordingly, the crust to the $\mathrm{S}$ of the ICS (southern meseta) presents a northward underthrusting below the northern meseta. Otherwise, northward of the ICS the Moho appears rather horizontal until it reaches the ICS and it is found at $9.5 \mathrm{~s}$ TWT (29 km depth). Also, to the S of the ICS, the Moho presents the same configuration, deepening from $\mathrm{S}$ to $\mathrm{N}$, from $9.5 \mathrm{~s}$ TWT $(29 \mathrm{~km})$ to $12 \mathrm{~s}$ TWT in its deepest point $(38 \mathrm{~km})$, below the ICS. The position and depth of the Moho boundary outside the ICS correlate nicely with adjacent seismic profiles to the N (Gallastegui et al., 2016; Pulgar et al., 1996), and those to the S (Ehsan et al., 2015; Martínez Poyatos et al., 2012). But the newly imaged structure defines an asymmetric root underneath the ICS that adds geometrical constrains to that observed in other geophysical studies (Carballo et al., 2015b; de Vicente et al., 2007; Mancilla and Diaz, 2015; Palomeras et al., 2017; Torne et al., 2015). The underthrusting crust accounts for the crustal root seen in gravimetric and seismic models. High conductivity at lower crustal level found at this same location (Pous et al., 2012), is consistent with the existence of such an imbrication affecting, at least, the lower crust, as interpreted here. The vertical time offset observed is $\simeq 2-2.5, \mathrm{~s}$ which translates to a thickening of around $6-8 \mathrm{~km}$.

The topography step between the mesetas to the $\mathrm{N}$ and $\mathrm{S}$ of the ICS suggests that the upper crust to the $\mathrm{S}$ of this mountain range is also, somehow, imbricated. According to our results, the structures that may allow such a mechanism are the Tietar River Fault (TRF) and the Southern Central System Thrust (SCST). Our data suggest that they may both may form part of a new crustal-scale discontinuity that offsets the entire crust allowing its upper part to sink and the lower crust to partly subduct. Such a configuration would be possible if the generalized partial melt of the crust in the ICS area had led to the assimilation of the upper-lower crustal boundary, which in other areas has acted as a mid-crustal detachment, hindering the possibility that structures root in the middle crust and letting them offset the entire crust. While the TRF and the SCST form a thrust system identifiable at the surface, they may continue at depth following the southern end of the ICS granites and reaching the the lower crust, offsetting it. This structure may play a crucial role in the crustal configuration of the area, being key to explain the topographic differences between the DB and 

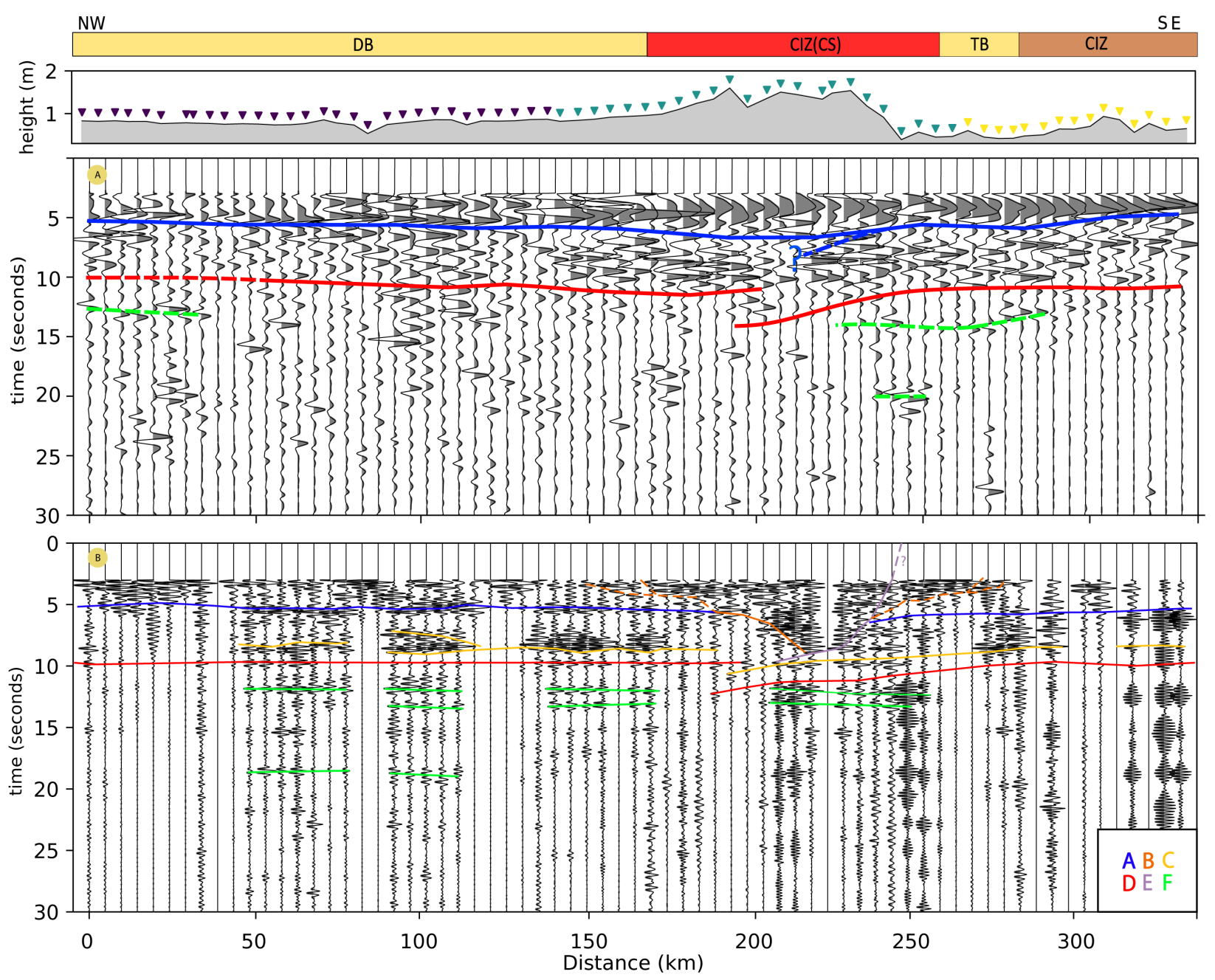

FIGURE 6.2: Interpreted seismic sections created in this thesis. Top, lithospheric image result of applying GloPSI to the CIMDEF dataset. Bottom, reflectivity profile derived from autocorrelations of ambient seismic noise. Both images are presented together to compare the interpreted major boundaries, e.g., the upper-lower crust and crust-mantle boundaries. 
the TB, as the upper crust may be involved in the crustal imbrication process (Andrés et al., 2019). In our image, the upper part of the underthrusting lower crust is well defined and seems to continue upwards, to at least, the lower part of the ICS granitic batholith defining the mountain range $(\mathrm{km}$ 220). From there, it continues, still at depth, along the southern edge of the ICS, linking upwards with what we interpret as the depth continuation of the TRF (E in Fig. 5.2) However, the prolongation to the surface could be related to both the TRF and the SCTS (Fig. 6.4).

The geometry of the crustal imbrication below the ICS is very similar to that found in the Cantabrian mountains (Fig. 6.4) and the Pyrenees, also resulting from Alpine compression and interpreted by other authors (Pulgar et al., 1995; Teixell et al., 2018). However, in these mountain ranges, it is only the lower crust that underthrusts while in the ICS, the entire crust is imbricated. The key process that explain this difference is the assimilation of the mid-crustal discontinuity/detachment by the ICS granitoids. Such a process has not affected other Alpine mountain belts and thus, the topography at their northern and southern parts is similar (Figure 6.3). In the ICS, faults affecting the upper crust (e.g., the Tietar River Fault), do not root into a mid-crustal detachment but continue to depth, as shown in Figures 5.2, 5.3 and 6.4, thus letting the upper crust to sink. This crucial difference is the key of the contrasting altitudes between the northern and southern border of the ICS, different to that of its Alpine analogues. The fact that the entire crust sinks, creates the big topographic step in the S (Fig. 6.3).

The boundary that divides the upper and lower crust is interpreted to be the same one observed throughout the IM at similar depths. This discontinuity is observed from the SPZ (IBERSEIS profiles, Palomeras et al., 2009; Simancas et al., 2003) in southern IB to the northern Cantabrian mountains (ESCIN-2 and WALZ (ESCIN-3.3) (Ayarza et al., 1998; Gallart et al., 2015; Pulgar et al., 1996). This means that the whole crust of the IM is affected by this discontinuity. The latter has been proposed to be related with the Variscan brittle-ductile transition (Ehsan et al., 2015; Martínez Poyatos et al., 2012; Palomeras et al., 2009; Simancas et al., 2003). However, ductile deformation is observed in upper crustal outcropping rocks along the IM, (e.g., in the Schist-Greywacke complex in the IM). More recently, Ayarza et al. (2020) argue that this boundary represents a detachment that acts as a rheological boundary between an old and long deformed lower crust and the rocks on top. However, as suggested above, this discontinuity is erased below the ICS as crustal melting and granitoids development have assimilated it underneath the mountain range. This characteristic of the late Variscan evolution of the central CIZ imposes some constraints to the Alpine accommodation of the deformation. The local lack of the mid-crustal detachment eased coupled deformation of the upper and lower crust that allowed thrusts to somehow affect the the entire crust, thus favoring the upper crust to sink. This pattern differs from that observed in the Cantabrian mountains or the Pyrenees, where the existence of this detachment allows the lower crust alone to underthrust the mountain range.

The conclusions reached in this work contrast with the above mentioned lithospheric folding models of the ICS. None of the features expected from this process are seen in the seismic images presented in chapter 4 and 5 . Instead, the imbrication of the crust below the ICS would explain its 

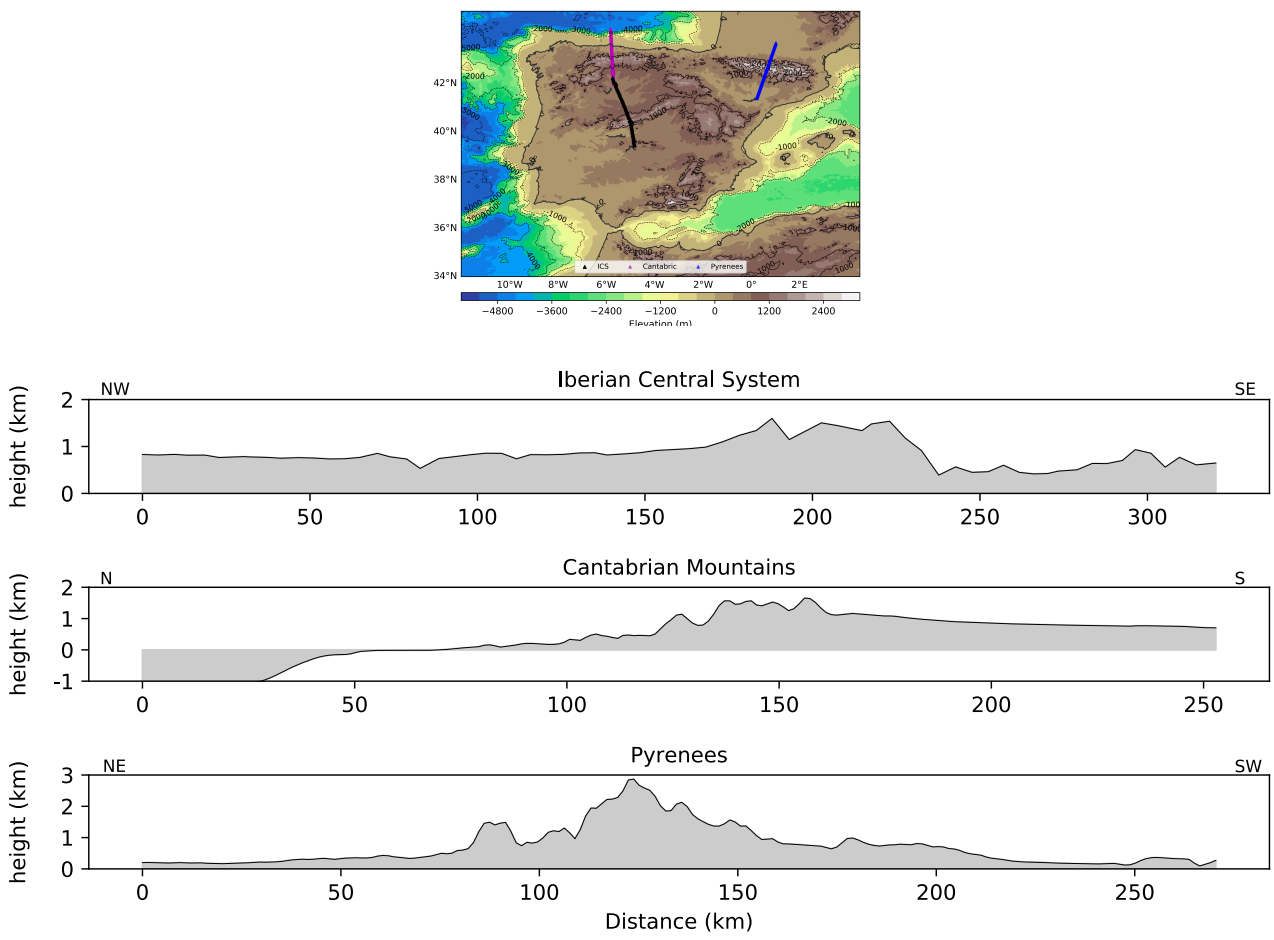

Figure 6.3: Comparison of the topography across three Alpine mountain belts within IB. The Pyrenees and the Cantabrian mountains are characterized by subduction of just the lower crust, while in the ICS the whole crust underthrusts. Only the latter shows lower topography on the underthrusting (southern) side than to the N, evidencing differences in the way the whole crust responds to Alpine compression. 


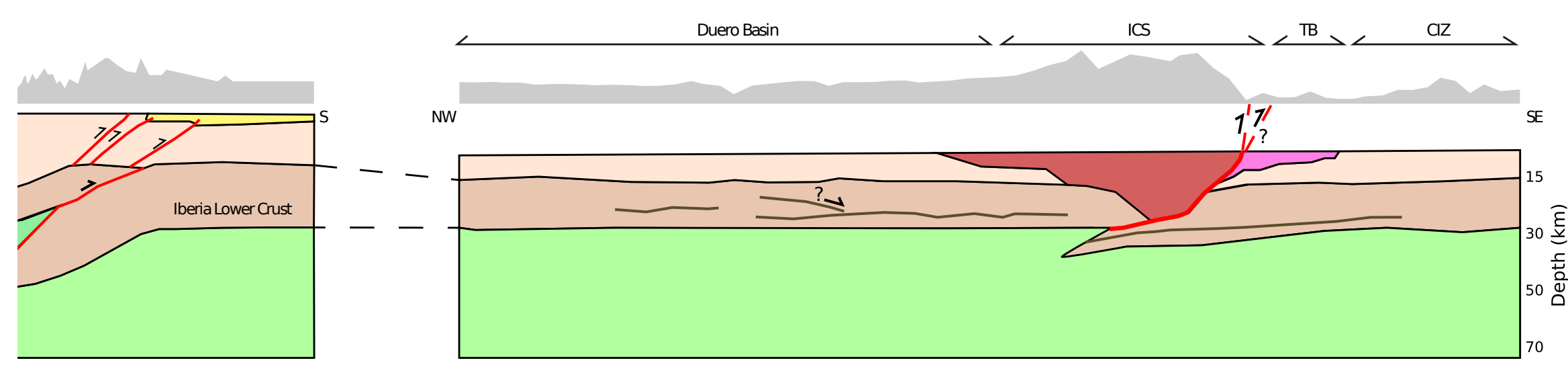

Figure 6.4: Sketch of the proposed crustal structure below the Iberian Central System and the Duero and Tajo Basins, along with the continuation towards the northern ESCIN-2 profile (Pulgar et al., 1996), modified from Gallastegui et al., 2016, and the correlation of the crust-mantle boundary and the mid-crustal detachment. 
crustal root and the topographies of both mesetas, shedding light on the processes contributing to the accommodation of deformation.

\subsection{Concluding Remarks}

In this thesis, different geophysical methodologies have been applied to unravel the lithospheric structure of the ICS and surrounding mesetas. Inversion of magnetic data has provided constraints in the thermal configuration of the Iberian crust. Seismic Interferometry has been used to construct precise seismic profiles across the mountain belt from the upper crust to the lithospheric mantle, extracting body waves reflection from ambient seismic noise and correlated earthquake phases. Those profiles produce independent images which mutually complement and build information upon each other.

In summary the thesis research has generated new innovative contributions in seismic imaging technologies and remote characterization of heat flow beneath Iberia. Both have helped to constrain a crustal/lithospheric structure across the Central Iberian System. The integration of this findings has contributed to develop new knowledge on the geodynamics of the development of this intra-plate orogen. 


\section{Resumen en Castellano / Spanish}

summary 


\section{Capítulo 1. Introducción y Objetivos}

La topografía actual de la Península Ibérica (en adelante IB) es el resultado de su reciente evolución tectónica, pero también de los procesos profundos y superficiales que la han afectado a lo largo de us historia geológica. Su estructura profunda está íntimamente condicionada por la orogenia Alpina, que tuvo lugar durante el Cenozoico como consecuencia de la convergencia entre las placas africana y euroasiática. Sin embargo, la respuesta de la corteza a esos esfuerzos está fuertemente influenciada por su configuración anterior, heredada de la orogenia Varisca y de su evolución posterior.

La estructura litosférica de IB sigue siendo un campo de estudio interesante dentro de las Ciencias de la Tierra. Su parte más occidental presenta un excelente afloramiento de la orogenia Varisca: el Macizo Ibérico (IM). Esta es el resultado de la colisión Devónico-Carbonífera entre Gondwana, Laurentia y algunos terrenos peri-Gondwanicos. La orogenia Alpina posterior afectó a estructuras Variscas, que se reactivaron y en su mayoría ha conformado la topografía actual de IB.

La estructura litosférica de IB ha sido ampliamente estudiada mediante diferentes técnicas sísmicas, por ejemplo, estudios sísmicos de fuente controlada (Ayarza et al., 2004; Ayarza et al., 1998; Banda et al., 1981; Carbonell, 2004; Ehsan et al., 2014, 2015; Flecha et al., 2009; Julià and Mejía, 2004; Martínez Poyatos et al., 2012; Palomeras et al., 2009, 2011, 2014; Pulgar et al., 1996; Simancas et al., 2003; Suriñach and Vegas, 1988), funciones receptoras (Mancilla and Diaz, 2015), tomografía de ondas de superficiales (Palomeras et al., 2017), etc. Además, la modelización de campos potenciales (p. ej., de Vicente et al., 2007; Torne et al., 2015) se ha utilizado para desentrañar la estructura cortical de la litosfera de IB. Sin embargo, la mayoría de estos estudios se ha centrado principalmente en las partes S y N del IM. Entre esos estudios, solo el estudio regional de de Vicente et al. (2007) y los estudios a gran escala de Mancilla and Diaz (2015), Diaz et al. (2016), Palomeras et al. (2017) y Torne et al. (2015) cubren el interior de IB.

Esta tesis presenta los resultados del proyecto CIMDEF (2017-2019) recientemente finalizado, que fue diseñado para adquirir datos sísmicos de fuente natural y controlada en el segmento central del IM, y supone un vínculo que permite establecer correlaciones estructurales entre los conjuntos de datos adquiridos al $\mathrm{N}$ y al $\mathrm{S}$.

Esta tesis está estructurada en seis capítulos. En el capítulo 2 se presenta el contexto geológico/geodinámico en el que se emmarca la tesis. En él se explica que la configuración actual de la topografía de la Península Ibérica es el resultado de su reciente evolución tectónica, procesos profundos y, más recientemente, procesos superficiales. La configuración estructural actual es el resultado de la orogenia Alpina, que tuvo lugar durante el Cenozoico por la convergencia entre las placas africana y euroasiática. Sin embargo, la respuesta de la corteza a las fuerzas aplicadas está fuertemente influenciada por su configuración anterior, heredada de la orogenia Varisca y de su evolución posterior. Asimismo, se presentan las metodologías empleadas en esta tesis con el objetivo de proporcionar el contexto adecuado para los siguientes capítulos. 
En el capítulo 3 se analiza la estructura térmica de la Península Ibérica obtenida a partir de la inversión de datos magnéticos. A pesar de ser objetivo principal de esta tesis el estudio del Sistema Central Ibérico (ICS), en este capítulo se evalua la estructura térmica de la IB por completo ya que la metodología requiere grandes extensiones para ser efectiva y evitar así verse afectada por efectos de borde en los márgenes. Debido a esto, se eligen las longitudes de onda más altas y por ello, se ha aplicado a toda la IB. Como resultado de este estudio, se presentan mapas de la isotérma de $580^{\circ} \mathrm{C}$ de IB, así como mapas de flujo de calor (HF), y un mapa de la temperatura a la profundidad del Moho.

En los siguientes dos capítulos se presentan los resultados obtenidos de la aplicación de técnias de Interferometría Sísmica (SI) a los datos obtenidos por el proyecto CIMDEF. Se utiliza SI para obtener una imagen de la litosfera bajo el ICS y sus cuencas adyacentes, utilizando fuentes naturales de energía, tales como terremotos y ruido sísmico ambiental.

En el capítulo 4 se presenta una primera aproximación para desentrañar la estructura interna del ICS, la cual se consigue mediante la aplicación de técnicas de sísmica pasiva. Se presentan las características y datos del proyecto CIMDEF, que supone el primer experimento de sísmica pasiva adquirido en el IM. El perfil cruza la Zona Centro Ibérica (CIZ) y las cuencas Cenozóicas del Duero y Tajo. La adquisición de los datos y la metodología empleada para el procesado han sido explicados en el capítulo 2. La energía usada como fuente para producir la imagen de la litosfera presentada en este capítulo, son registros de terremotos. El perfil de reflectividad producido muestra dos discontinuidades corticales: el límite entre la corteza superior e inferior y el límite corteza-manto. Además, se ha identificado una imbricación de la corteza bajo el ICS que aporta nuevas ideas sobre los mecanismos que produjeron la elevación de la cadena montañosa.

El capítulo 5 se basa de nuevo en los datos del experimento CIMDEF. En este caso, se emplea como fuente de energía el registro de ruido sísmico ambiental grabado durante toda la duración del despliegue, para producir una imagen coincidente con la presentada en el capítulo 4. Ambas imagenes son complementarias y presentan similitudes. Las dos discontinuidades corticales observadas en la imagen producida a partir de los registros de terremotos distantes se observan también en el perfil presentado en este capítulo. Un aspecto clave que diferencia ambas imágenes es el uso de frecuencias más altas empleadas en este perfil $(1.5-4 \mathrm{~Hz})$, lo cual aporta una imagen más detallada de la estructura cortical al tener una mayor resolución vertical.

Aunque al final de cada capítulo se presenta una discusión y conclusiones, en el capítulo 6 aparecen las conclusiones generales derivadas de esta tesis.

Esta tesis tiene como objetivo presentar nuevos datos que permitan desarrollar un nuevo modelo litosférico bajo el ICS. Dicho modelo ha de incluir la relación del ICS con sus cuencas de antepaís al N y S (Duero y Tajo respectivamente, DB y TB) que ayude a explicar su contexto dentro del IM. De especial interés son, i) el grosor de la corteza y ii) la configuración estructural debajo de la cordillera. Además, las características de la corteza debajo de la cuenca $\mathrm{N}$ dan una idea de la evolución de la meseta N durante la orogenia Varisca. En general, estos son parámetros importantes para explicar la evolución tectonotérmica de esta parte de IB y cómo las características heredadas de la orogenia 
Varisca afectaron la evolución posterior de la corteza durante la orogenia Alpina. Para hacerlo, se han utilizado varias técnicas geofísicas, cada una de las cuales proporciona información única sobre diferentes propiedades físicas y características de la litosfera. En particular se han empleado métodos de campos potenciales, como el magnetísmo, y métodos sísmicos.

\section{Capítulo 3. Profundidad del Punto Curie de la Península Ibérica y Márgenes Circundantes}

En este capítulo se deriva la estructura térmica de IB a partir de datos aeromagnéticos, calculando la profundidad hasta la que se extiende la magnetización en la corteza. Dicha profundidad se asocia a la isoterma correspondiente a la profundidad del punto de Curie (CPD) de la magnetita. Este punto corresponde a la profundidad a la que la magnetita pierde su magnetismo y se empieza a comportar como paramagnética (

Los resultados (el mapa de CPD y la diferencia entre CPD/CT, Figs. 3.4 y 3.5) revelan una clara diferenciación entre los dominios Varisco y Alpino. La comparación del CPD calculado con mapas de espesor cortical, junto al mapa de flujo de calor derivado, proporciona nuevos datos sobre el régimen térmico litosférico. Dentro de IB, la isoterma CPD tiene espesores en el rango de 17 a $29 \mathrm{~km}$. Esta isoterma es menos profunda $(<18 \mathrm{~km})$ en zonas de mar, donde la litosfera es más delgada y, por ello, las temperaturas más altas.

En la parte continental de IB, el dominio Varisco en el NO presenta una respuesta magnética que muy probablemente está ligada a procesos de engrosamiento y posterior extensión durante el final de la orogenia Varisca, lo que resultó en fusión cortical generalizada y emplazamiento de granitos. La posición del CPD en el Arco de Gibraltar revela una geometría consistente con el modelo geodinámico de delaminación que dio lugar al Mediterráneo occidental. En los dominios oceánicos, una amplia extensión de manto superior parece magnetizada. Esto se interpreta como consecuencia de la existencia de procesos de serpentinización afectando al manto superior, probablemente desencadenados en un contexto extensional. La integración de estos resultados con modelos de tomografía de velocidades de ondas S sugieren que el margen Atlántico presenta hasta $8 \mathrm{~km}$ de serpentinitas, lo que unido a la existencia de manto exhumado, implica una evolución de margen hiperextendido. El Mediterráneo también presenta serpentinización generalizada hasta $6 \mathrm{~km}$ en la cuenca Argelina compatible con su evolución tectónica y con la existencia de peridotitas serpentinizadas emplazadas en el S de IB. Finalmente, en este capítulo se presenta un mapa de flujo de calor y un mapa de temperatura de Moho derivado del obtenido para el CPD.

Las conclusiones de este capítulo indican que en gran parte del Mediterráneo occidental el manto superior está magnétizado, y por ello, probablemente serpentinizado, pero de manera heterogénea (restos de un manto alterado hidrotermalmente). Esta serpentinización es compatible con la evolución geodinámica propuesta para el Mediterráneo occidental (subducción y "slab roll-back" de la litosfera en el mar de Alborán y posterior extensión de las cuencas mediterráneas). Dichas serpentinitas podrían 
actuar como un nivel de despegue que facilite los mecanismos de delaminación propuestos para la zona. Por otro lado, la geometría de la subducción en el Arco de Gibraltar es compatible con la señal obtenida en el mapa de CPD. En esta zona, el CPD aumenta, lo que puede explicarse por la existencia de una litosfera engrosada que altera el régimen térmico. Finalmente, los resultados sugieren que a lo largo del margen Atlántico Ibérico debió ocurrir una magnetización/serpetinización extensa del manto, compatible con el desarrollo de un margen hiperextendido que permitió la exhumación del manto hacia el $\mathrm{O}$.

\section{Capítulo 4. Imagen Litosférica de Interferometría Sísmica de Fase Global}

El Sistema Central Ibérico (ICS) es una sierra intraplaca que divide la Meseta Ibérica en dos sectores, la Cuenca del Duero (DB) al N y la Cuenca del Tajo (TB) al S. La topografía de la zona es muy variable, donde la TB presenta una altitud media de $\simeq 350-450 \mathrm{~m}$ y la DB una altitud media superior, del orden de 750-800 m. El ICS se caracteriza por tener una configuración estructural en "pop-u" y "pop-down" en la corteza más superficial, formada por una tectónica tipo"thick-skinned" como consecuencia de la reactivación de estructuras Variscas durante la orogenia Alpina. La alta topografía de la cadena es, muy probablemente, la consecuencia de una corteza tectónicamente engrosada que debería ser la respuesta a, i) la geometría de la discontinuidad del Moho, ii) la existencia de una corteza imbricada, y/o iii) las propiedades reológicas de la litosfera. En este capítulo se presenta un perfil sísmico, de escala litosférica, de esta parte del Macizo Ibérico (IM), utilizado los datos adquiridos por el proyecto CIMDEF. El perfil está configurado por 69 estaciones sísmicas de corto período que definen una transecta de $320 \mathrm{~km}$ de longitud en dirección NO-SE. La metodología aplicada a los datos ha sido Interferometría Sísmica de Fase Global. La técnica usa registros continuos de telesísmos $(>$ $120^{\circ}$ de distancia epicentral) para extraer fases globales (PKP, PKIKP, PKiKP), que viajan a través o son reflejadas en el núcleo, y llegan a la superficie (casi) como energía vertical. Dichas llegadas y sus reverberaciones dentro de la litosfera contienen información de la estructura litosférica bajo la estación de registro. El procesado proporciona una aproximación de la reflectividad a la adquirida por las estaciones en lasque la energía llega de manera (casi) vertical.

El hallazgo más relevante de la imagen resultante es el engrosamiento de la corteza bajo el ICS como consequencia de la imbricación dirigida $\mathrm{N}$ de la corteza inferior de la TB. En general, el límite corteza-manto presenta profundidades entre 29 y $31 \mathrm{~km}$ al N y S del perfil, mientras que por debajo del ICS alcanza profundidades de $38 \mathrm{~km}$. El engrosamiento de la corteza tiene una longitud de onda de unos 100 km y abarca todo el ICS desde el cabalgamiento S del ICS (SCST), situado en el límite con la TB, hasta el límite sur de la DB. Hasta el momento no está claro si la imbricación observada para la corteza inferior afecta también a la corteza superior. De hecho, la proyección en la superficie de esta imbricación se acerca a la traza del SCST o del sistema de fallas del Rio Tietar (TRF), lo que indica que toda la corteza podría verse afectada por el accidente geológico, las que permite esta imbricación. Sin embargo, el hecho de que se haya inferido un despegue en la corteza media Varisca 
y la falta de estimaciones del acortamiento a nivel de la corteza inferior dificultan esta interpretación. Se necesitarían nuevos datos de mayor resolución para obtener imágenes que puedan revelar dichas características.

Como resultado de lo anterior, el límite entre la corteza y el manto se puede cartografiar como una interfaz relativamente plana localizada, aproximadamente, a $10 \mathrm{~s}$ TWT. Sin embargo, en el ICS el Moho se hunde, alcanzando más de $12 \mathrm{~s}$. El límite entre la corteza superior e inferior está bien definido y se encuentra a $5.5 \mathrm{~s}$ TWT.

Por otro lado, el perfil revela una reflectividad claramente diferente dentro de la corteza. La parte superior llega hasta $5.5 \mathrm{~s}$ TWT y es poco reflectiva. Debajo del ICS, formado en su mayor parte por granitoides, la reflectividad es además de baja frecuencia y alta amplitud, compatible con la existencia de litologías que no presentan contrastes de impedancia bien definidos. Debajo de esta capa, la corteza inferior se caracteriza por una reflectividad de alta frecuencia y gran amplitud, lo que respalda la existencia de altos contrastes de impedancia que ya han sido observados con datos de incidencia vertical en la corteza inferior al $\mathrm{S}$ y $\mathrm{N}$ del perfil CIMDEF.

El límite entre corteza superior e inferior (12.5- $15 \mathrm{~km}$ de profundidad) define una discontinuidad que ha sido onterpretada como un despegue. Sin embargo, el hecho de que la geología superficial muestre rocas deformadas dúctilmente en muchas áreas a lo largo de la transecta dificulta su interpretación como la transición frágil-dúctil.

Dentro del manto superior, se detectan parches de reflectividad localizados en dos bandas, entre 45 y $55 \mathrm{~km}$ de profundidad (13 s TWT) y de 70 a $75 \mathrm{~km}$ de profundidad (18 km TWT). Ambas zonas de reflectividad se encuentran dispersas en el perfil y son prácticamente horizontales. Esta reflectividad se relaciona con la posible extensión hacia el $\mathrm{N}$ de la discontinuidad de Hales, definida como la zona de transición interpretada entre la espinela y el granate, que ya ha sido observada hacia el S del perfil.

\section{Capítulo 5. Imagen Litosférica de Ruido Sísmico Ambiental}

En este catítulo se presenta un nuevo modelo litosférico de la Zona Centro Ibérica (ZCI) del Macizo Ibérico (IM), construido a partir de autocorrelaciones de ruido sísmico ambiental. Los datos empleados forman parte del proyecto CIMDEF, al igual que los presentados en el captítulo 4 . El presente trabajo muestra que esta metodología tiene potencial para proporcionar imágenes en estudios de escala litosférica y complementa los resultados anteriores. El modelo obtenido tiene implicaciones importantes a la hora de entender como se acomoda la deformación en el interior del IM durante la orogenia Alpina. El perfil atraviesa tres zonas geológicas dentro de IB: el Sistema Central Ibérico (ICS), y sus cuencas de antepais, las cuencas del Duero y Tajo (DB y TB).

Los resultados evidencian una corteza dividida en corteza superior, que tiene un espesor promedio de $15 \mathrm{~km}$, y corteza inferior, con un espesor de entre 15 y $18 \mathrm{~km}$. El límite entre ambas también está bien definido en la mayor parte del perfil. Dentro de la corteza superior, estos nuevos datos han 
permitido definir, lateralmente y en profundidad, la extensión de los granitos que forman el ICS. Este batolito tiene una extensión a lo largo del perfil de unos $120 \mathrm{~km}$, aunque solo la mitad aflora. Sin embargo, la información obtenida mediante la autocorrelación de ruido sísmico permite situar la parte inferior del mismo a una profundidad máxima de $8 \mathrm{~s}$ TWT, equivalente a $24 \mathrm{~km}$, aunque en la imagen se aprecia como el batolito se adelgaza hacia sus límites N y S.

Los resultados más importantes de este trabajo son, i) la presencia de una imbricación de la corteza por debajo del ICS y ii) la asimilación del despegue de la corteza media identificado en el IM por parte de los granitoides del ICS. El primero de estos resultados permite definir una raíz donde la corteza del S de la CIZ se imbrica bajo la cadena montañosa. Esta imbricación se caracteriza por un desplazamiento del Moho en la vertical, de $\simeq 6-8 \mathrm{~km}$, pasando de una profundidad $\simeq 30 \mathrm{~km}$ a $36-38 \mathrm{~km}$ en la zona más profunda. Por otro lado, la asimilación del despegue medio-cortical por la extensión y fusión de la corteza al final del Carbonífero en el centro de la CIZ (actual ICS) permite que las fracturas de la corteza superior alcancen niveles profundos en la corteza, ya que no se ven obligadas a enraizarse en el despegue. Esto implica que la imbricación de la corteza no se limita a su parte inferior sino que también afecta a la corteza superior. En consecuencia, el engrosamiento de la corteza parece estar limitado al S por un sistema de fracturas interconectadas que podrían aflorar en la Falla del Rio Tietar (TRF), o más al E en el Cabalgamiento del S del ICS (SCST). Esta configuración obligaría a toda la corteza a hundirse, explicando así la diferencia de topografía entre la TB, al S del ICS, frente a la DB, al N. El acortamiento tectónico estimado para la corteza superior e inferior sugiere que este modelo es coherente y no necesita una cantidad importante de subducción de la corteza superior para explicar la diferencia de $\simeq 400 \mathrm{~m}$ en la topografía entre ambas cuencas de antepaís.

Por último, dentro del manto superior la dispersa reflectividad se encuentra debajo de los segmentos N y central del perfil. Esta define dos bandas a profundidades de 40-45 km y alrededor de 70 $\mathrm{km}$ respectivamente. La geometría de estas reflexiones es relativamente plana, aunque se aprecia una ligera profundización hacia la S por debajo del ICS. La más profunda de estas bandas de reflectividad se ha intrepretado como parte de la zona de transición entre espinela y granate, conocida como discontinuidad de Hales. Se trata de una discontinuidad de escala regional ya descrita hacia la S del perfil CIMDEF en otros estudios.

Los resultados presentados aquí se han logrado después de la autocorrelación del ruido sísmico a lo largo del perfil CIMDEF. Aunque la resolución de estos datos es limitada (0.5-4 Hz, estaciones ubicadas $\mathrm{a} \simeq 5 \mathrm{~km}$ ), esta metodología nos ha permitido identificar algunas estructuras clave que ayudan a restringir los mecanismos de deformación que afectaron a IB central durante la orogenia Alpina. La geometría aqui deducida mejora el conocimiento estructural del ICS ya que sugiere que se trata de una cordillera asimétrica de tipo Alpino, al igual que los Alpes o los Pirineos. Por otro lado, estos resultatos no apoyan la existencia de procesos de flexura litosférica como único origen de la deformación. 


\section{Capítulo 6. Discusión y Conclusiones}

La investigación realizada durante esta tesis ha contribuido a generar nuevas imágenes litosféricas usando tecnologías innovadoras y poco costosas económicamente como, i) caracterización remota del flujo de calor de IB, y ii) Interferometría Sísmica con datos de fuente natural. Además, ha contribuido a desarrollar nuevos conocimientos sobre la geodinámica de una cordillera intraplaca: el Sistema Central Ibérico (ICS).

El modelo térmico de la Península Ibérica (IB) derivado de la inversión de datos magnéticos y presentado en el capítulo 3, da una idea de la configuración térmica actual de la Zonza Centro-Ibérica (CIZ). Como se ve en la Figura 3.4, en el ICS y la meseta N el punto de Curie (CPD) se situa a grades profundidades, lo que implica que estas son algunas de las áreas más frias de IB (Fig. 3.7). Sin embargo, no existe una correlación directa entre la estructura cortical representada y la isoterma CPD calculada: el ICS es un área engrosada resultante del acortamiento asociado a la compresión Alpina, mientras que la meseta norte comprende su cuenca de antepaís, que además ocupa la parte superior de una corteza más delgada. Por tanto, se puede argumentar que la orogenia alpina no produjo una huella térmica visible en la actualidad. De hecho, se interpreta que la relajación y equilibrio térmico del Macizo Ibérico (IM) se alcanzó después de la orogenia Varisca. La orogenia Alpina ha contribuido muy escasamente al diseño de la estructura térmica de IB, como lo demuestra el hecho de que no exista fusión cortical asociada a dicha orogenia.

La mayor parte de la corteza inferior en el IM presenta un grosor de alrededor de 4-6 s TWT. Sin embargo, en la parte NO de la CIZ y en la parte N del perfil ALCUDIA (S de la CIZ), se observa una corteza inferior mucho más delgada ( $~ 1-2 \mathrm{~s}$ TWT). Estas zonas se correlacionan con áreas donde la extensión tardi-Varisca desembocó en la intrusión de granitoides orogénicos tardíos y post-tectónicos (Fig. 3.10) que afloran hoy en día. Estos granitos representan un gran volumen de fusión de la corteza del Carbonífero y Pérmico que evidencia la tectónica dominante al final de la orogenia Varisca.

La profundidad a la que la extensión tardí-Varisca y la fusión cortical han afectado al ICS se evidencia por la ubicación de la base de su batolito tal y como se observa en este trabajo y se presenta en las Figuras 5.2 y 5.3. Estos datos indican que la corteza inferior también se vio afectada por dicha extensión y fusión. La presencia de granitos tipo I en el ICS respalda una fuente profunda. No se puede descartar la existencia de granitoides ocultos bajo la DB, aunque el grado metamórfico de las rocas Carboníferas anteriores a la extensión y que afloran en su margen no respalda una contribución importante.

Finalmente, el perfil CIMDEF que se presenta en el capítulo 5 muestra una intensa reflexión en la corteza inferior que se extiende casi por completo a lo largo de la imagen. Esta reflexión podría representar la huella que la extensión tardi-Varisca dejó a este nivel, donde la fusión cortical pudo comenzar pero no progreso de manera notable. Esto implicaría que aqui la tectónica tardi-Varisca no logró adelgazar toda la corteza inferior, al contrario de lo que aparece en el NO de la CIZ o en la parte $\mathrm{N}$ del perfil ALCUDIA. Por lo tanto, sugerimos que en la parte central de la CIZ, el adelgazamiento y la 
fusión de la corteza podrían haber afectado a la corteza inferior en algún grado pero no la redefinieron a lo largo de toda la transecta muestreada por el pefil CIMDEF, sino solo en la parte correspondiente al ICS 

Appendix A

\section{Complementary publications}




\title{
Basement structure of the Hontomín $\mathrm{CO}_{2}$ storage site (Spain) determined by integration of microgravity and 3-D seismic data
}

\author{
Juvenal Andrés ${ }^{1,3}$, Juan Alcalde ${ }^{2}$, Puy Ayarza $^{1}$, Eduard Saura ${ }^{3}$, Ignacio Marzán ${ }^{3}$, David Martí ${ }^{3}$, José \\ Ramón Martínez Catalán ${ }^{1}$, Ramón Carbonell ${ }^{3}$, Andrés Pérez-Estaún ${ }^{2}$, José Luis García-Lobón ${ }^{4}$, and \\ Félix Manuel Rubio ${ }^{4}$ \\ ${ }^{1}$ Departamento de Geología, Universidad de Salamanca, Salamanca, Spain \\ ${ }^{2}$ Department of Geology and Petroleum Geology, University of Aberdeen, UK \\ ${ }^{3}$ Instituto de Ciencias de la Tierra "Jaume Almera" ICTJA-CSIC, Spain \\ ${ }^{4}$ Instituto Geológico y Minero de España - IGME, Spain \\ Correspondence to: Juvenal Andrés (juvenalandrescabrera@gmail.com)
}

Received: 19 January 2016 - Published in Solid Earth Discuss.: 26 January 2016

Revised: 18 April 2016 - Accepted: 3 May 2016 - Published: 24 May 2016

\begin{abstract}
A multidisciplinary study has been carried out in Hontomín (Spain) to determine the basement structural setting, its geometry and the geometry of the sedimentary succession of an area aimed to be the first Spanish pilot plant for $\mathrm{CO}_{2}$ storage. An integration of coincident 3-D seismic results, borehole data and unpublished microgravity data were used to reproduce the deep structure and topography of the basement and to quantify the thickness of the Triassic Keuper evaporites. The subsurface structure is characterized by a half-graben setting filled with Keuper evaporites (up to $2000 \mathrm{~m}$ thick), forming an extensional forced fold. All data sets clearly identify two main fault systems, compartmentalizing the main structural domain into three differentiated blocks. These faults have been interpreted to be reactivated normal faults that have led to the formation of the Hontomín dome.
\end{abstract}

\section{Introduction}

Gravity data have proven to be useful for modelling the basement topography in settings where it is overlaid by thick sedimentary successions (e.g. Døssing et al., 2014; Engen, et al., 2006; Chappell et al., 2008). This approach is sensitive to the effective removal of the gravimetric signature of the sedimentary cover and the regional, long wavelength anomaly contribution. Thus, basement topography modelling requires a good knowledge of the sedimentary succession and its con- figuration in depth. More importantly, the nature of the gravity methods allows a mutual benefit with the seismic method: gravimetric inversion profits from constraints provided by the seismic data by helping to minimize the number of possible solutions, and gravity can aid with the imaging in areas in which the seismic method is less effective, such as in subsalt areas (e.g. Contrucci et al., 2004; Filina, et al., 2015; Staedtler et al., 2014) or crystalline environments (e.g. Malehmir et al., 2009; Hedin et al., 2014).

The Hontomín structure was chosen among other options (Prado et al., 2008) to encompass the first technological development plant for $\mathrm{CO}_{2}$ storage in Spain. Following the European Union regulation (European Union, 2009) and best practice recommendations from international experts (e.g. IEAGHG, 2008), a multidisciplinary study was carried out to assess Hontomín's suitability for geological storage of $\mathrm{CO}_{2}$. This included the implementation of detailed geophysical/petrophysical (Alcalde et al., 2013a, b; Ogaya et al., 2013, 2014; Ugalde et al., 2013; Vilamajó et al., 2013; Rubio et al., 2011), geomechanical (Canal et al., 2013) and hydro/geochemical (Elío et al., 2013; Nisi et al., 2013; Permanyer et al., 2013) characterization methods.

Among this multidisciplinary approach, the acquisition, processing and interpretation of a 3-D seismic data set provided the first detailed image of the subsurface of Hontomín (Alcalde et al., 2014). However, seismic data have problems when imaging the subsalt configurations due to the high velocities of salt rock (Rousseau et al., 2003; Sava et al., 2004).

Published by Copernicus Publications on behalf of the European Geosciences Union. 
This commonly results in the disappearance of the base of the salt or in an unclear image of its surface (Leveille et al., 2005). In this context, gravity data can help to constrain the contact between the salt and the underlying basement due to the density contrast between them. The salt typically has low density $\left(2.16-2.25 \mathrm{~kg} \times \mathrm{m}^{-3}\right)$, while the layers below usually have a higher density. This density contrast can be used to resolve the geometry of the salt body (Jacoby et al., 2005).

A microgravity survey was carried out at the Hontomín Technology Development Plant (Andrés, 2012) with the goal of providing additional structural constraints to areas poorly imaged from the 3-D seismics. Gravity information becomes especially important in this area where, unlike other places (Stadler et al., 2014), the seismic image was unable to provide enough information on the deepest part of the sedimentary succession and, more importantly, of the basement (Alcalde et al., 2014). The acquired high-resolution data have an excellent quality, providing a complementary approach for unravelling the subsurface structure of the area. The good control of the sedimentary sequence has allowed us to accurately remove the sedimentary cover gravity signature from the Bouguer anomaly map in order to focus on the basement structure. The gradients presented on the resulting map suggest the existence of important faults, some of which affect the basement, which are clearly related to those reported by Alcalde et al. (2013b, 2014). This supports their interpretation and represents a further step in the understanding of the geological evolution of the area. The integration of geophysical data sets presented in this paper is the best contribution to the knowledge of the overall geological structure of this injection site and a good example of how multidisciplinary high-resolution approaches can shed light on the shallow and/or deep investigation of geologically complex areas.

\section{Geological setting}

The Hontomín structure is located within the doubly verging Pyrenean orogen, in the south-eastern part of the Plataforma Burgalesa, to the south of the Mesozoic Basque-Cantabrian Basin (Serrano and Martínez del Olmo, 1990; Tavani and Muñoz, 2012) (Fig. 1). This area is characterized by an ESE-dipping monocline bounded to the south by the rightlateral Ubierna Fault System (Tavani et al., 2011) and by the Sierra de Cantabria Thrust to the north. Geographically, the Plataforma Burgalesa is bounded to the south by the Duero and Ebro basins and to the north by the Sierra de Cantabria.

The Plataforma Burgalesa was affected by three major deformation stages after the Permian period. The first stage corresponds to a Permian-Triassic extension (GarcíaMondejar et al., 1996), which reactivated wrench-fault systems (Manspeizer, 1988), giving rise to a set of ESE-WNW and E-W trending normal faults. The second event is related to the continental break-up and opening of the Bay of

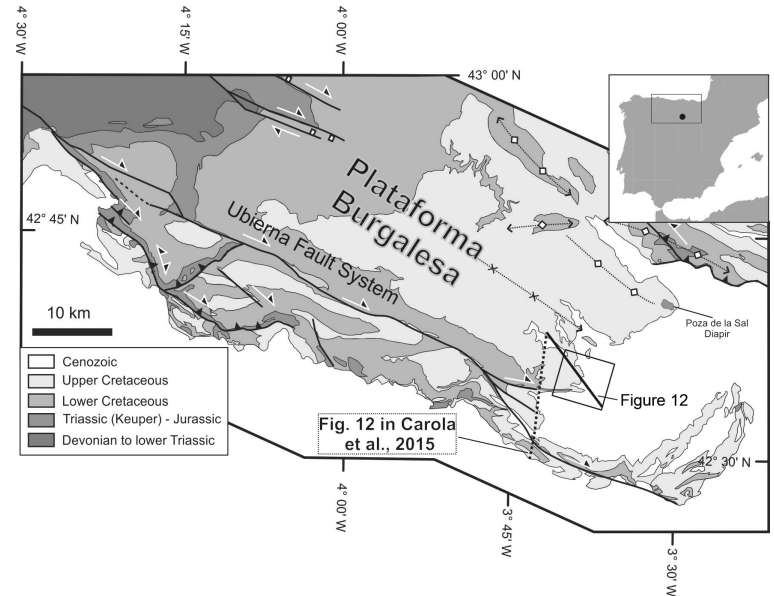

Figure 1. Location of the Hontomín site (black square) within the Plataforma Burgalesa (after Alcalde et al., 2014). Bold line represents the location of the section shown in Fig. 12.

Biscay (García-Mondejar et al., 1996; Ziegler, 1988). This extensional episode triggered the formation of the BasqueCantabrian Basin and the Plataforma Burgalesa. During this deformation episode, NNE-SSW faults were formed almost perpendicularly to the previous fault systems, and the Keuper rocks provided the decoupling surface that ensured different deformation styles between the sedimentary sequences above and the basement below (Tavani and Muñoz, 2012; Tavani et al., 2013). The evaporites themselves were folded with geometries that are diagnostic of extensional forced folds (Brown, 1980; Laubscher, 1982; Tavani et al., 2011, 2013). Finally, the Pyrenean orogeny provided the compressional tectonic setting in which previous faults were reactivated with inverse and lateral offsets (Quintá et al., 2012; Tavani et al., 2011, 2013). Among these, the Ubierna Fault System stands out as the most prominent tectonic feature in the study area. In some places, rocks of similar ages are exposed on both fault walls despite the presence of second-order faults and folds in its southern block. This, together with the well-preserved Mesozoic extensional architecture and with macro- and meso-structural data (Tavani et al., 2011), highlights an almost exclusive strike-slip behaviour during the Cenozoic inversion stage, with a much-subordinated reverse component.

The sedimentary succession of the study area (Fig. 2) lies over a Palaeozoic basement and includes a Mesozoic cover topped by Cenozoic sediments. The stratigraphic succession begins with the Triassic Keuper facies formed by evaporites and anhydrites which are followed by Lower Jurassic anhydrites and dolomites (Pujalte et al., 2004). Above this, a succession of Lower to Middle Jurassic pelagic and hemipelagic carbonate sediments is found. Following the stratigraphic succession, Purbeck facies of the Late Jurassic to Early Cre- 


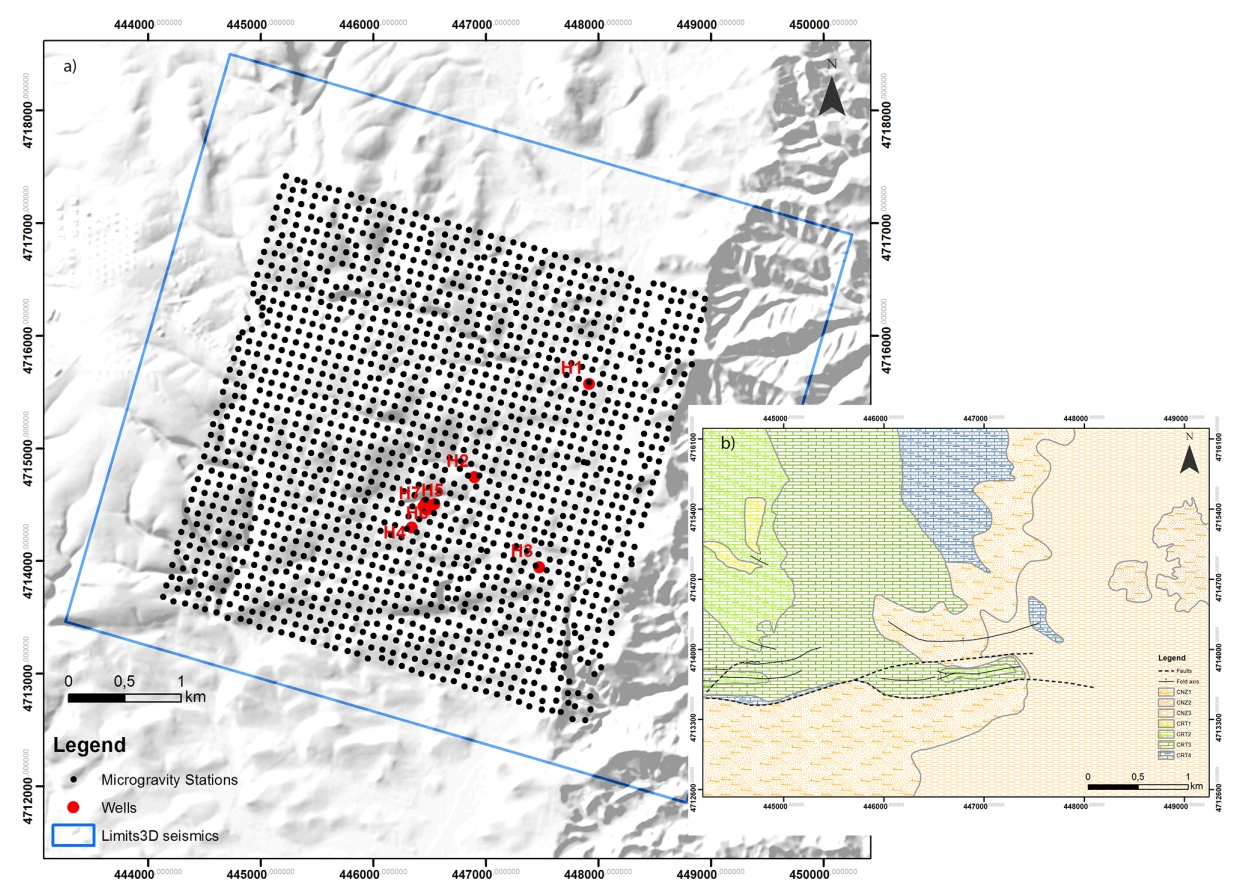

Figure 2. (a) Location of the gravimetric stations (dark dots), boundaries of the 3-D seismic experiment (blue line) and location of wells (red dots) and (b) geological setting of the Hontomín site and the stratigraphic succession (Alcalde et al., 2014).

taceous period formed by clays, carbonates and sandstones lay unconformably above the marine Lower to Middle Jurassic rocks. Up-sequence, a siliciclastic succession is found, comprised by the Weald facies and the Escucha and Utrillas formations, which are interpreted as fluvial successions with sandstone infilled channels alternating with flood plain sediments. The stratigraphic succession ends up with Upper Cretaceous carbonates and lacustrine and detritic Cenozoic sediments lying unconformably above the Mesozoic series (Vera, 2004).

\section{Data sets and methodology}

\subsection{Seismic and well data}

A 3-D seismic data set was acquired in summer 2010 in Hontomín, across an area of $36 \mathrm{~km}^{2}$ centred according to the target dome-shaped structure (Alcalde et al., 2013a) (Fig. 2). The acquired seismic data set was processed down to $1500 \mathrm{~ms}$ up to post-stack time migration (Alcalde et al., $2013 b$ ). Critical steps in processing were related to the existence of an unexpected velocity inversion near the surface, which decreased the general quality of the data. However, the final migrated volume provided clear images from the subsurface structures down to the anhydrite level (i.e. the bottom of the dome structure). Further details on the seismic data acquisition and processing can be found in Alcalde et al. (2013a, b, 2014).

The seismic data were integrated with well-log data from four hydrocarbon exploration boreholes ( $\mathrm{H} 1$ to $\mathrm{H} 4)$ and three shallow groundwater sampling wells (GW1 to GW3) (Fig. 2). Results indicate that the structure of the Hontomín dome includes eight different sedimentary packages, from Triassic to Cenozoic and four sets of faults. The target Mesozoic dome structure has a NW-SE orientation and is bounded by two major faults, the south (S) and the east (E) faults, showing vertical offsets of up to 450 and $250 \mathrm{~m}$ respectively. Another two sets of faults have been singled out: they trend $\mathrm{N}-\mathrm{S}$ and $\mathrm{E}-\mathrm{W}$ and have been related to extensional episodes that occurred during the opening of the Bay of Biscay. The dips of the dome flanks decrease upwards suggesting a protracted and discontinuous growth. The joint interpretation of the seismic and well log data allowed for inferring three evolutionary stages for the Hontomín structure (Alcalde et al., 2104): (1) the development of N-S trending faults as a consequence of differential loading around Triassic E-W faults could have allowed the development of the lowermost Jurassic units and probably produced forced folding of the Hontomín dome. (2) Later on, the development of E-trending faults during the opening of the Bay of Biscay is recorded by the accumulation of Purbeck deposits. Simultaneously, the migration of the Triassic salts would have further increased 


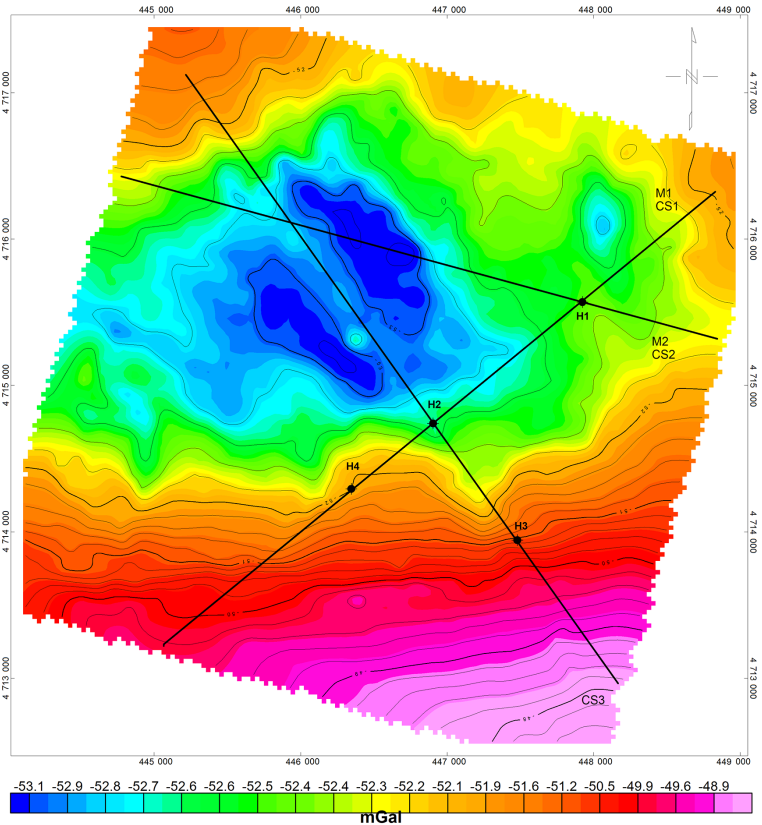

Figure 3. Complete Bouguer anomaly map of the Hontomín area calculated with a reduction density of $2400 \mathrm{~kg} \mathrm{~m}^{-3}$. Black dots mark the position of well data. Black lines represent the position of 2-D models 1 and 2 and cross sections (CS) 1-3 (Fig. 6) extracted from the final 3-D model (Fig. 7).

the dome's growth. (3) Finally, the Pyrenean orogeny caused the reactivation of the south and east faults and the final development of the dome structure.

\subsection{Gravity data}

Microgravity data were acquired between August and December 2010 by Implemental System Company. A highdensity mesh covering an area of $4 \times 4 \mathrm{~km}^{2}$ was recorded with measurements taken at every $100 \mathrm{~m}$, which resulted in 1600 total measured points (Fig. 2). The measurements were carried out using a Scintrex CG-5 2008 gravity meter with a resolution of $0.001 \mathrm{mGal}$. The acquisition parameters ensured a resolution lower than $4 \mu \mathrm{Gal}$, with over three measurements per grid point on average. Seventy-one of those gravimetric measurement points were concreted, along with the seven gravimetric stations used to calibrate the gravitymeter, delivering an accuracy of $0.5 \mathrm{~cm}$. The positioning of the 1600 measured points was performed with a LEICA GPS 9000 and has an accuracy of $1 \mathrm{~cm}$ or less. The calibration of the topographic instrument was carried out with respect to a geodesic vertex located within the study area. This ensures that measurement points were within the high-quality range of the device.

The gravity data were provided without the effects of moon/sun/earth tides and instrumental drift, which were al- ready corrected by the contractor. The data were then processed using Geosoft Oasis Montaj ${ }^{\text {TM }}$ to produce the complete Bouguer anomaly (BA) map of the area. This includes carrying out the Bouguer slab, free-air and terrain corrections (Blakely, 1995). The resulting Bouguer anomaly map is shown in Fig. 3. The reduction density used was $2400 \mathrm{~kg} \mathrm{~m}^{-3}$, although several values were tested to assess the better reduction density for performing the Bouguer slab correction. Anomaly maps obtained using densities of 2000, 2400 and $2600 \mathrm{~kg} \mathrm{~m}^{-3}$ were compared with the topography, being $2400 \mathrm{~kg} \mathrm{~m}^{-3}$ which showed less correlation with the relief.

Several procedures may be applied to Bouguer anomaly data in order to enhance features that may later on help in the interpretation. Accordingly, the following processes were carried out in the present data set: (1) separation of the long and short wavelength components, (2) calculation of the gravity derivatives (vertical and total horizontal derivatives, THD), (3) construction of two 2-D gravity models and (4) inversion of gravity data. To carry out a qualitative assessment of the source depth of the Bouguer anomaly data, the short and long wavelength number components had to be separated. This separation was performed by applying an upward continuation to the gravity field (Jacobsen, 1987) of up to $350 \mathrm{~m}$. The filter was selected in order to minimize distortion and ringing effects (Fig. 4a). The regional component was then subtracted from the complete Bouguer anomaly to generate a residual anomaly map presented in Fig. $4 \mathrm{~b}$.

Edge enhancements are often used to aid in the potential field data interpretation (Verduzco et al., 2004). Accordingly, two sets of derivatives were performed to our data set aiming to highlight the gradient zones and accordingly the structural setting of the area. The vertical derivative (Fig. 4c) (Blakely and Simpson, 1986) and total horizontal derivative (THD, Fig. 4d) show a coherent result between them. Both maps highlight coincident areas with maximum gradient, that is, areas where the contacts between materials of different density exist. However, the vertical derivative also enhances those that are shallow.

Finally, two 2-D gravity profiles were extracted from the Bouguer anomaly map in order to produce a model of the structure of the area along them (see location in Fig. 3): Model 1, striking NE-SW and Model 2 striking almost E-W (Fig. 5). First, these models were computed with the assistance of the information provided by wells $\mathrm{H} 1$ and $\mathrm{H} 2$ but without the input of 3-D seismic data (Andrés, 2012) (Table 1). The models were then revisited to include the variations in layer depth and fault offset observed in the seismic model (Fig. 5a). It is worth highlighting that changes introduced to the models were not significant and provide a good match with the seismic model and 2-D sections derived from the inversion procedure (Fig. 6). 

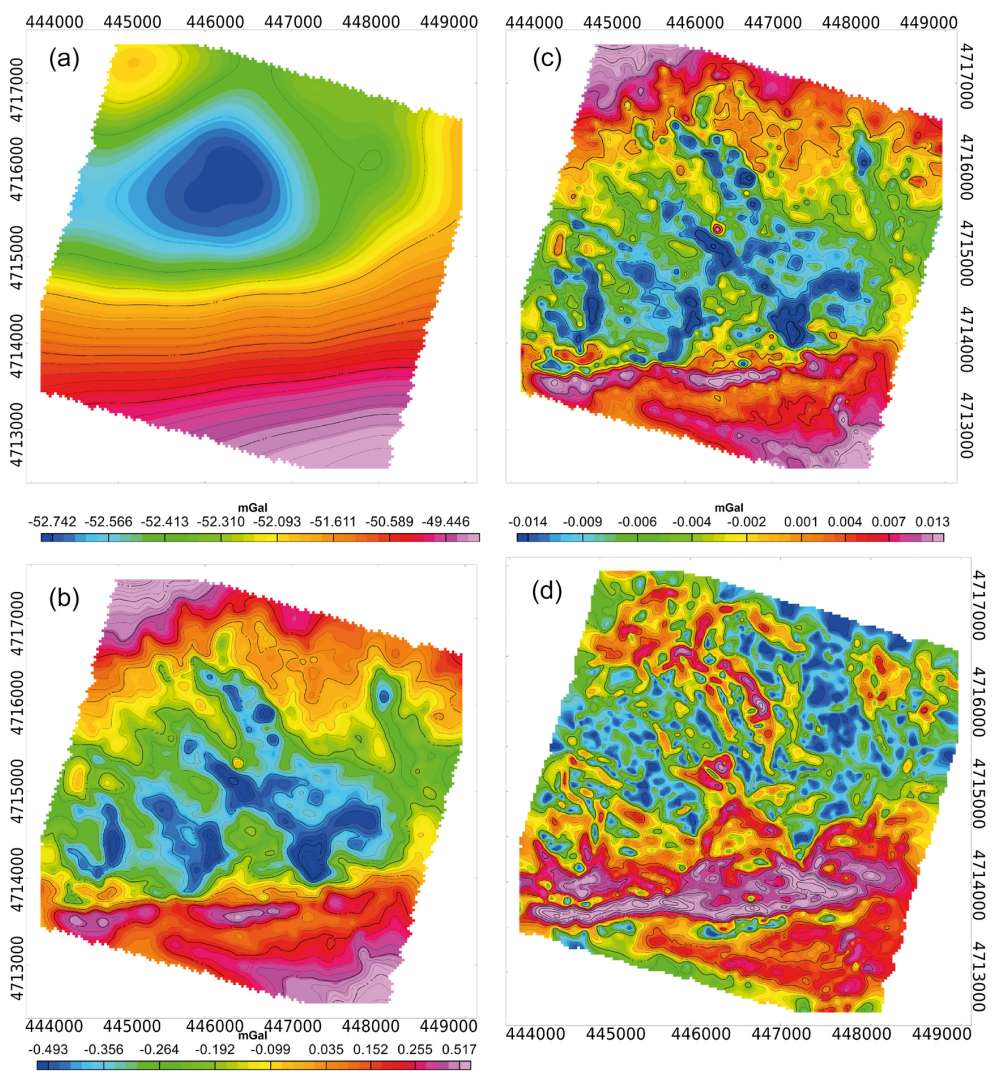

Figure 4. (a) Regional gravity anomaly of the study area obtained by upward continuation up to $350 \mathrm{~m}$, (b) resulting residual anomaly, (c) first vertical derivative of the Bouguer anomaly (BA) map (order 0.75), (d) total horizontal derivative (THD) of the BA map.

Table 1. Formation densities used in the gravity modelling and constraints for the inversion of the microgravity data.

\begin{tabular}{llr}
\hline Age & Formation & $\begin{array}{r}\text { Density } \\
\left(\mathrm{kg} \mathrm{m}^{-3}\right)\end{array}$ \\
\hline Cenozoic & & 2330 \\
Cretaceous & Utrillas and Escucha Fm. & 2500 \\
Cretaceous & Weald & 2320 \\
Cretaceous & Dogger and Purbeck & 2340 \\
Jurassic-Cretaceous & 2580 \\
Jurassic & Marly Lias & 2620 \\
Jurassic & Limestones Lias & 2690 \\
Triassic & Anhydrite & 2890 \\
Triassic & Keuper & 2250 \\
Paleozoic & Basement & 2750 \\
\hline & &
\end{tabular}

\subsection{Gravity inversion}

Gravity data can be inverted in order to obtain the topography of a desired layer (Oldenburg, 1974). However, inversion results are more reliable when the number of variables to in- vert decrease. Inverting just the topography of one layer can provide us with excellent results if we can preliminarily establish the density of every layer and the thickness of every density interval. The method utilized in this study is based on the Parker's algorithm (Blakely, 1996; Parker, 1972). It works in the frequency domain and is integrated in GM-SYS 3-D platform. Here, we inverted the microgravity data in order to obtain the geometry of the basement.

The large amount of information available in the Hontomín area has granted us the basis to build a wellconstrained model that allows us to perform a successful inversion. Well data, seismic horizons and 2-D gravity models were used to construct an initial model. The inversion process, which was then applied, consisted of isolating all the gravity contributors, i.e. different sources (sediments and regional component) and calculating their gravity responses. That was then subtracted from the Bouguer gravity anomaly (BA) map (Fig. 3) and the residual was inverted.

Accordingly, building the gravity model for the inversion consisted of the following steps: 


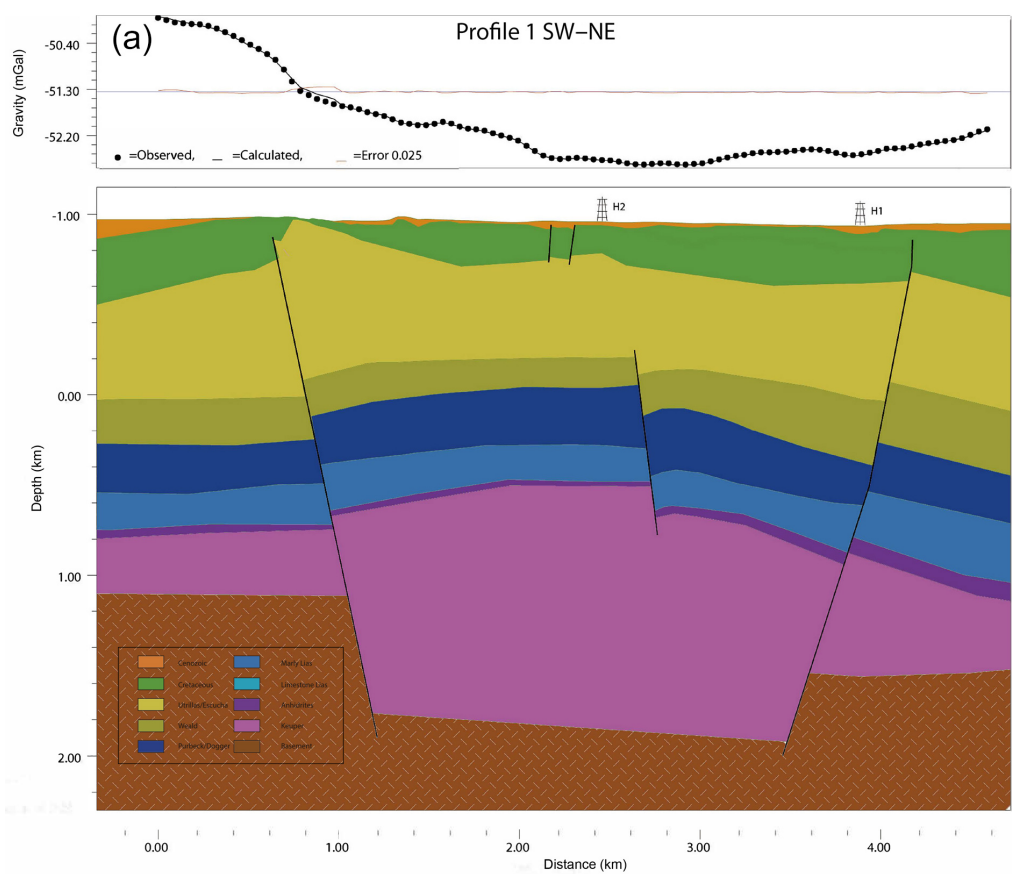

(b)

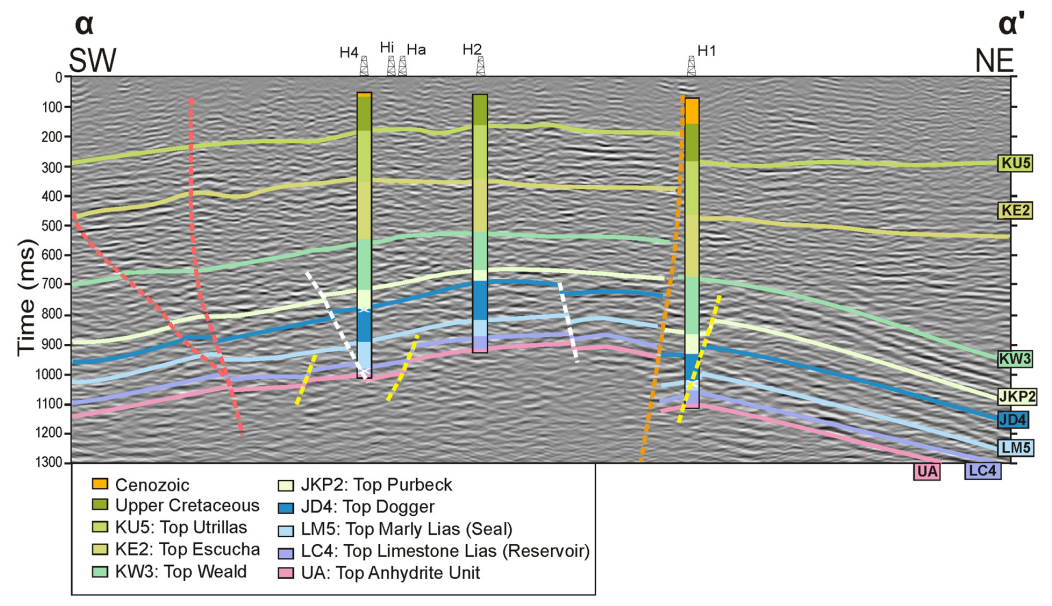

Figure 5.

- Calculation and removal from the BA map of the gravity anomaly generated by the stratigraphic succession below $0 \mathrm{~m}$ (Fig. 7a and c), assuming a constant density for each layer (Table 1).

- Analysis, calculation and removal of the long wavelength/deep signal corresponding to first-order polynomial (Fig. 7b and d). This filter was selected in order to avoid removing the signal from the Keuper succession.
- Generation of the basement topography by inverting the residual anomaly after subtracting the above-mentioned contributions (Fig. 8).

The sedimentary succession was interpreted and modelled from the 3-D seismic cube generated by Alcalde et al. (2014). Eight layers were used to characterize the signal of the sediments. Three of them, corresponding to the CenomanianMaastrichtian, Early Cenomanian (Utrillas Fm.) and Aptian- 
Profile $2 \mathrm{E}-\mathrm{W}$

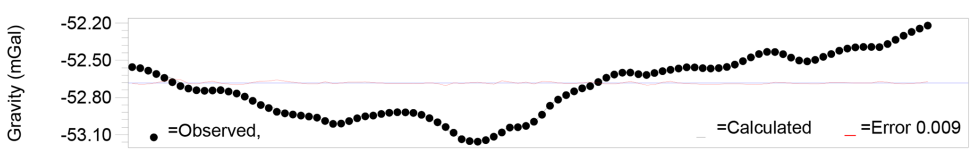

(c)
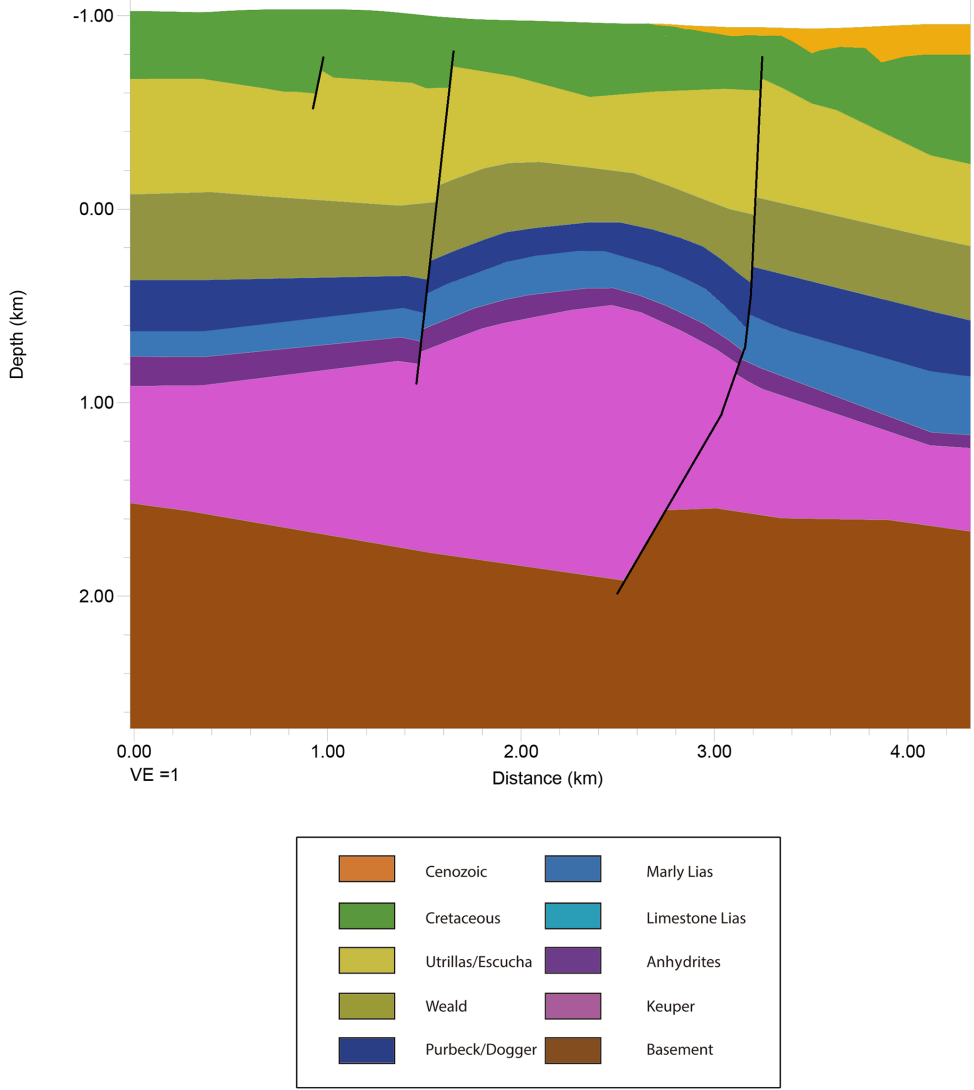

Figure 5. (a) Initial 2-D gravity Model 1 and (b) approximate corresponding two-way travel time seismic section (after Alcalde et al., 2014) both sections are crossed by faults south and east (marked as bold lines in the figure). Note that the offsets of the east fault are opposite in (a) and (b). The seismic section is interpreted down to the top of the anhydrite unit, marking the beginning of the evaporitic layers. (c) 2-D gravity model striking in an almost W-E direction (see Fig. 3 for location). For colour key see Fig. 5a.

Albian (Escucha Fm.) layers, lie above the sea level. They were used to compare the BA obtained using a reduction density of $2400 \mathrm{~kg} \mathrm{~m}^{-3}$ with that obtained using a model based on Alcalde et al. (2014). The latter map had a higher wavelength number component that needed to be filtered out, worsening the resolution of the final results and accordingly was discarded. The remaining five layers are below sea level and correspond, from shallower to deeper, to Late Jurassic to Early Cretaceous Purbeck, Dogger, marly Lias, Lias limestones and Lower Jurassic anhydrites.

The forward calculation of the sediment gravity anomaly was performed using a constant density (Table 1) for each of the five layers described above, including the topography, down to the top of the anhydrites. To solve the ambiguity generated by the unknown depth of the base of the anhydrites we used the constraints provided by the 2-D gravity models and the seismic profile shown in Fig. 5a. These data sets support the use of a constant thickness $(100 \mathrm{~m})$ layer of anhydrites. Furthermore, the seismic profile presented by Alcalde et al. (2014) shows a general homogeneity in the thickness of the layers for the study area. A bottom flat imaginary boundary for the Keuper rocks was used in order to avoid cutting the overlaying strata so no errors were carried into the inversion process. Finally, the long wavelength/deeper contribu- 

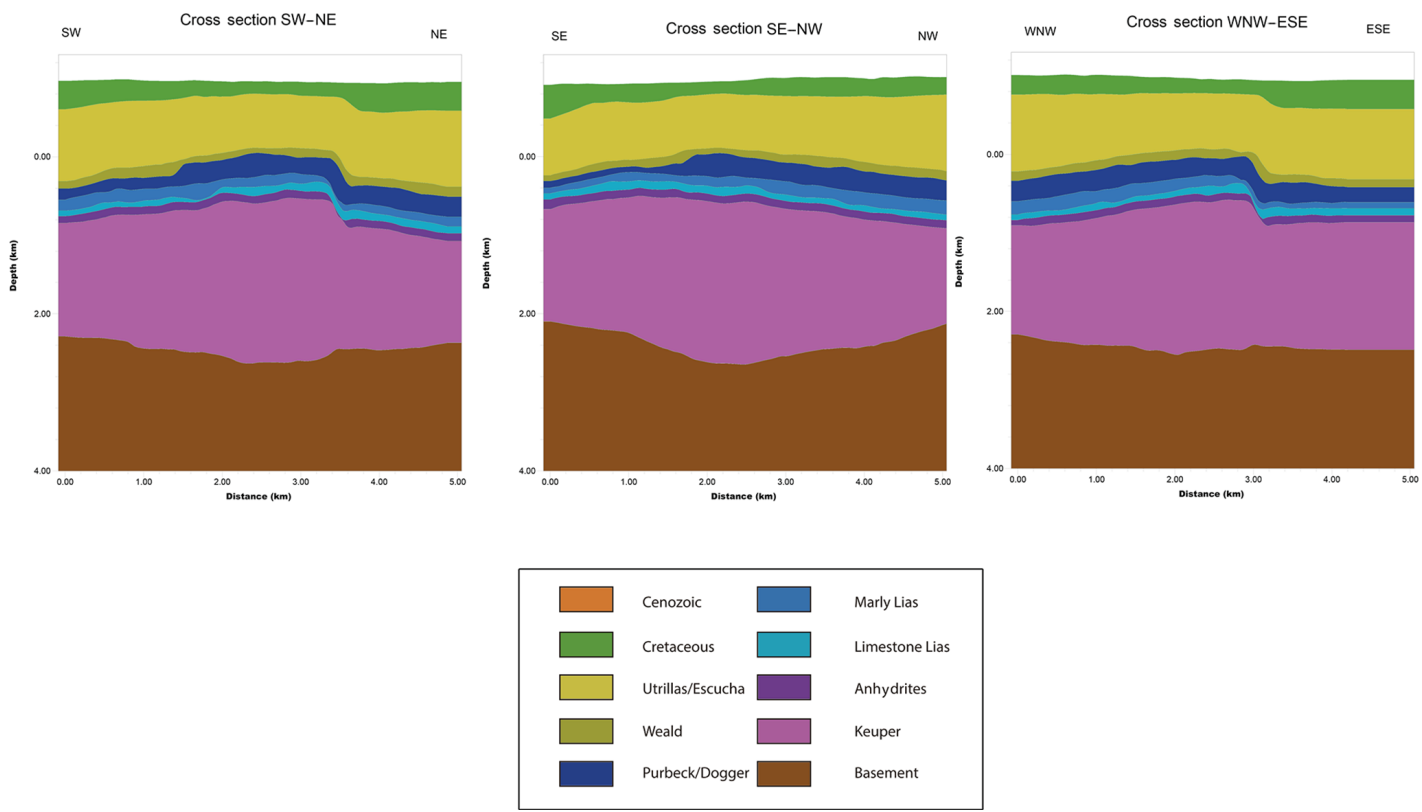

Figure 6. Cross sections extracted from the 3-D gravity inversion model of the basement presented in Fig. 8a (see Fig. 3 for location of the cross sections).

tion to the BA was removed by using the simplest first-order polynomial.

Three cross sections (Fig. 6) were extracted from the results of the gravity inversion. These include the sedimentary layers down to the anhydrites and the basement. Two of them coincide with the location of the 2-D gravimetric models, NE-SW and WNW-ESE (Figs. 3, 5a, c) and the third one has a NW-SE direction (Fig. 3). The cross sections have been used to make a comparison with the previous 2-D models shown in Fig. 5 and to assess the basement structure crossing the main tectonic features that are also highlighted by the derivatives (Fig. 4c, d).

\section{Results from the microgravity data}

The BA map (Fig. 3) shows negative values ranging between -53.2 and $-48.5 \mathrm{mGal}$, which are characteristic of the Iberian Peninsula continental crust. The BA map is portrayed by a minimum located in the west-central part of the survey area where two parallel rows of low values are identified with a NW-SE direction. From there, the anomaly increases towards the south and the north, suggesting a concave ENEWSW direction structure, with maximum values found in the $\mathrm{SE}$ area. The gravity gradients found to the south of the minimum are strong.

The separation of the long and short wavelength components by upward continuation of the gravity field shows that the regional anomaly (Fig. 4a) is characterized by an E-
W directed low in the central/north-western area. This low shows values ranging between -52.6 and $-49 \mathrm{mGal}$ and is bounded by highs to the SE and partly to the NW. The residual anomaly resulting from subtracting the regional anomaly from the Bouguer anomaly map (Fig. 4b) shows variations of $1.5 \mathrm{mGal}$. The residual anomaly is characterized by NW-SE lows located in the centre of the study area and bounded by highs to the S and NW. Furthermore, an E-W strong gradient in the southern part of the map appears.

The derivatives presented in Fig. $4 \mathrm{c}$ and $4 \mathrm{~d}$ aid in the interpretation of the structures affecting the Hontomín area. Above all, the gravity gradient existing to the south of the gravity data set and already evidenced in Figs. 3 and $4 b$ is clearly imaged by both derivatives. The vertical derivative shows, as does the residual map in Fig. 4b, NW-SE minima that appear to be cross-cut by an E-W maximum in the southern part of the map. The short wavelength that these features present in the vertical derivative map indicates that they respond to shallow density contrasts.

The computed 2-D models have helped to capture the deep structure of the area. These showed to be more sensitive to the variations in the shallower layers and in the basement topography than to those in the mid-sections of the sedimentary succession. This can be due to the small differences in density found across the Jurassic succession. Model 1 has a NE-SW direction (Fig. 5a) and crosses the major faults of the area, i.e. south and east faults (Alcalde et al., 2014). Both faults are identified in the model to have affected the base- 

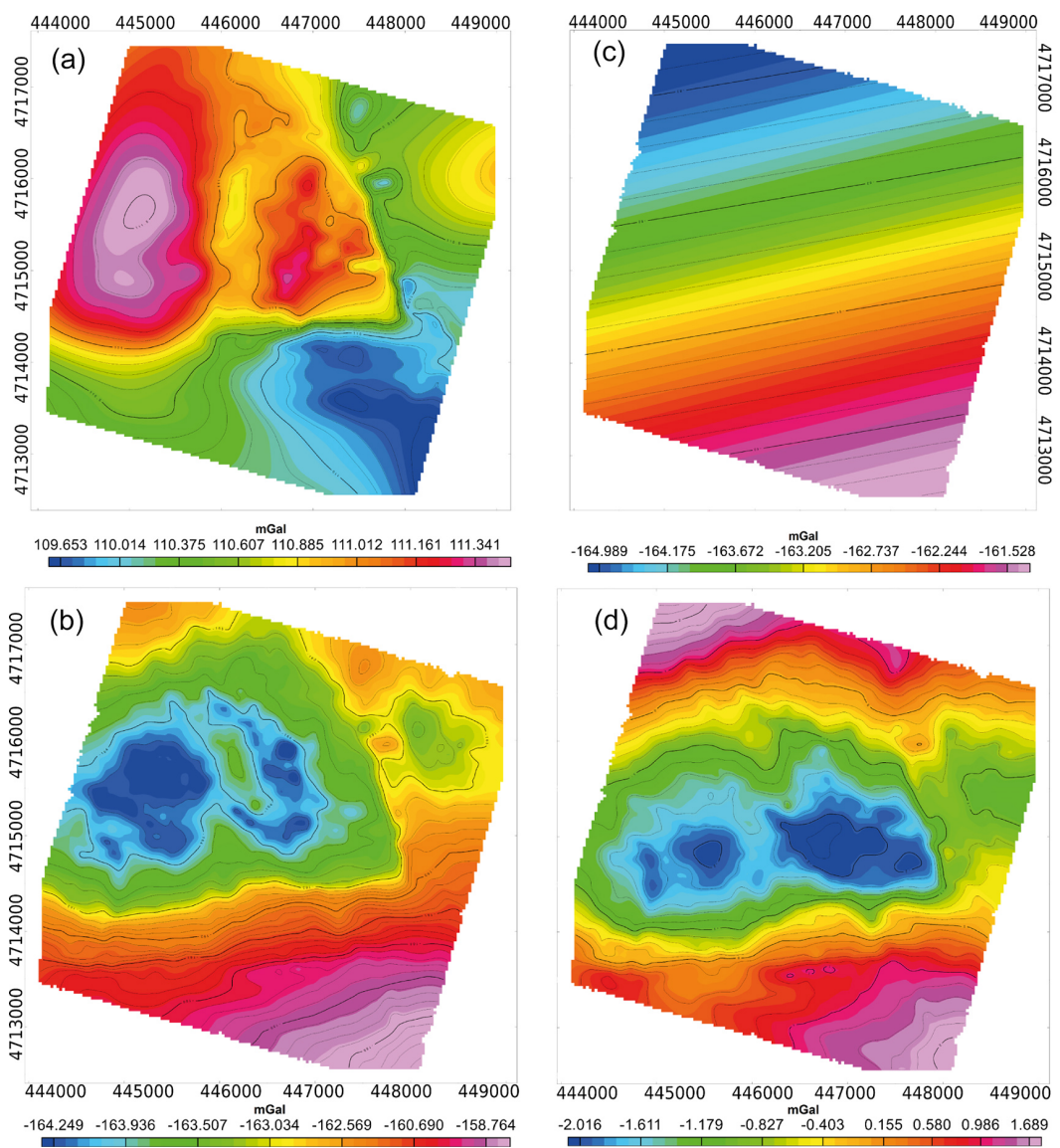

Figure 7. (a) Gravity response of the sedimentary sequence as imaged by Alcalde et al. (2014) and by the 2-D models presented in Fig. 5a and c, (b) regional component of the BA in Fig. 3, (c) gravity residual anomaly resulting from subtracting the map in (a) to the BA map in Fig. 3 and (d) final anomaly grid resulting from subtracting the map in (b) to that in (c). This grid will be the one used for inversion procedure.

ment and the sedimentary succession. While the south fault affects all the sedimentary packages, the east fault seems to be fossilized by the late Cretaceous sediments. The structural configuration of the profile shows a dome-like structure with a thick layer (up to $2000 \mathrm{~m}$ ) of Keuper evaporites. The Jurassic succession is affected by a minor fault that affects the lower Cretaceous as well.

Model 2 has an approximate E-W direction and crosses the east fault (Fig. 5c). The vertical offset of the east fault is around $400 \mathrm{~m}$ and has a $45^{\circ}$ dip. The basement in the western sector shows a progressive uplift towards the $\mathrm{E}$. The dome-like structure is recognized in this model as well as in Model 1 and is characterized by a growth of the Keuper evaporites thickness, forming a gentle fold on the overlaying Jurassic layers.

The processing workflow applied to the BA data to perform the inversion of basement topography has led to a series of maps presented in Fig. 7. Figure 7a represents the gravity response of the sedimentary succession interpreted by Alcalde et al. (2014). The forward calculation includes the Cenozoic down to an internal boundary within the Keuper rocks. Gravity minima are found to the SE of the study area and describe an irregular shape in the SE corner. These minima are in accordance with the location of a deep basement as deduced by the gravimetric models, allowing the existence a thicker Keuper layer. The maximum is located to the $\mathrm{W}$ and has a round shape. Another relative maximum can be found in the centre of the study area, coinciding with the deepest point of the basement in the 2-D gravimetric models. Figure $7 \mathrm{~b}$ presents the calculated long-wavelength filter, representing the regional, and shows a gentle negative gradient towards the NW. The values have a range of less than $3 \mathrm{mGal}$. Given the reduced dimensions of the survey area, it is difficult to discern the depth of the source we are filtering out. In any case, we believe that the signal is related to density variations within the upper crust and below the top 

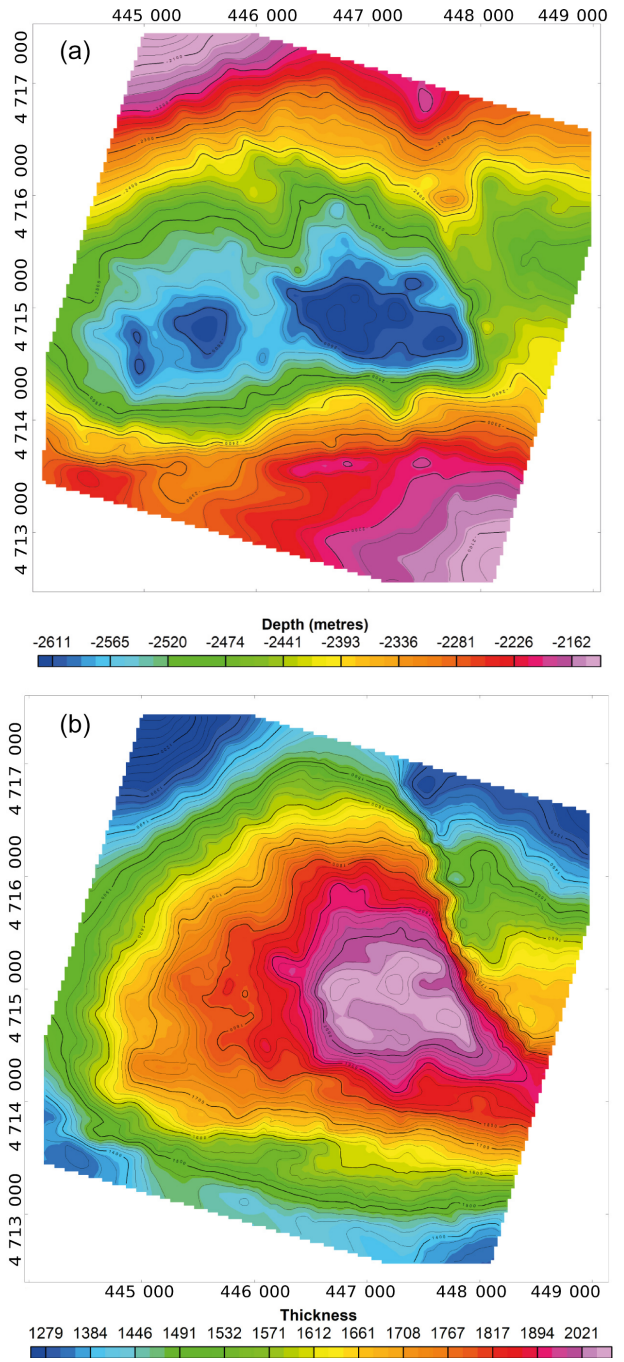

Figure 8. (a) Basement topography derived from the inversion of the residual gravity data shown in Fig. 7d, and (b) thickness map of the Triassic Keuper evaporites after comparing the basement topography and the bottom of the sedimentary sequence.

of the basement, and may be either compositional (a lithological gradient) or structural (a structure imposing a gravity gradient, e.g. low offset fault).

The resulting final grid used to perform the inversion of the gravity data is that obtained from subtracting the regional contribution in Fig. $7 \mathrm{~b}$ to the BA map without the sediment gravity signature (Fig. 7c). This approach represents the most accurate model that we could build to ensure the best outcome of the gravity inversion, and it is shown in Fig. 7d. The resulting final grid again shows an E-W minimum in the central part, reaching values of $-2.1 \mathrm{mGal}$. Maxima appear once more in the SE corner of the area and reach values above $1.4 \mathrm{mGal}$. A strong E-W gradient exists again in the southern part of the study area. This map allows us to undertake the inversion of the geometry of the boundary, given that anomaly, i.e. the top of the basement/base of the Keuper layer.

The inversion has been performed within the Geosoft platform, using a GM-SYS 3-D module. The goal of this procedure is to obtain the geometry of the basement since the densities of the intervening lithologies are well constrained by well data. The initial set-up consisted of a two-layer model, the upper one formed by Keuper salts and the bottom one by the basement. A mean density of $2520 \mathrm{~kg} \mathrm{~m}^{-3}$, which includes all the layers above the Keuper, even the ones located above sea level, was used as background density. The results of the inversion are shown in Fig. 8a and picture a deep basement ranging roughly from -2000 to $-2650 \mathrm{~m}$ below sea level, with a mean depth of $-2300 \mathrm{~m}$. Its geometry shows a pair of minima in the central-west area, bounded at the NW and SE by local maxima. The minima lay parallel to a welldefined gradient zone that has been identified in most of the gravity maps generated for this paper. This feature seems to represent one of the main structural elements of the area and, according to its position, is interpreted as the south fault (Alcalde et al., 2014, and Fig. 5a).

The geometry of the top of the basement allows us to calculate the thickness of the Triassic Keuper salts (Fig. 8b) by calculating the space between the top of the basement and the bottom of the anhydrites layer. Results show that the Triassic Keuper appears to have a mean thickness of $1660 \mathrm{~m}$ with a maximum of $2020 \mathrm{~m}$ around the centre-east of the area. This is in agreement with the data derived from exploration well Rojas NE-1, near Hontomín, where a total thickness of $1400 \mathrm{~m}$ was drilled (Carola et al., 2015). The borders of the study area appear to be the location where the Triassic Keuper is thinnest, with values of about $1200 \mathrm{~m}$. In general, the thickness of the layer is conditioned by the mobility of the salt and the migration pathways generated by the tectonic events.

Three cross sections (location in Fig. 3) presented in Fig. 6 were extracted from the results of the gravity inversion, which at the same time includes constraints from 3-D seismic. Two of the cross sections coincide with the two 2-D gravity models and show a relatively good correlation with them (Fig. 5a and c). In particular, cross section 1 running in a NE-SW direction has a good correlation with the 2-D Model 1 and shows a deep basement affected by the south and east faults as well as a thick Keuper layer overlaying the basement. The third profile runs in a NW-SE direction and accounts for the NW basement high presented in Fig. 8a.

Finally, a THD has been applied to the residual gravity anomaly obtained from the Hontomín area (Fig. 7d) and is presented in Fig. 9. Results of this process are relevant for identifying gradient zones and accordingly fault zones, and will be discussed in the next section. 


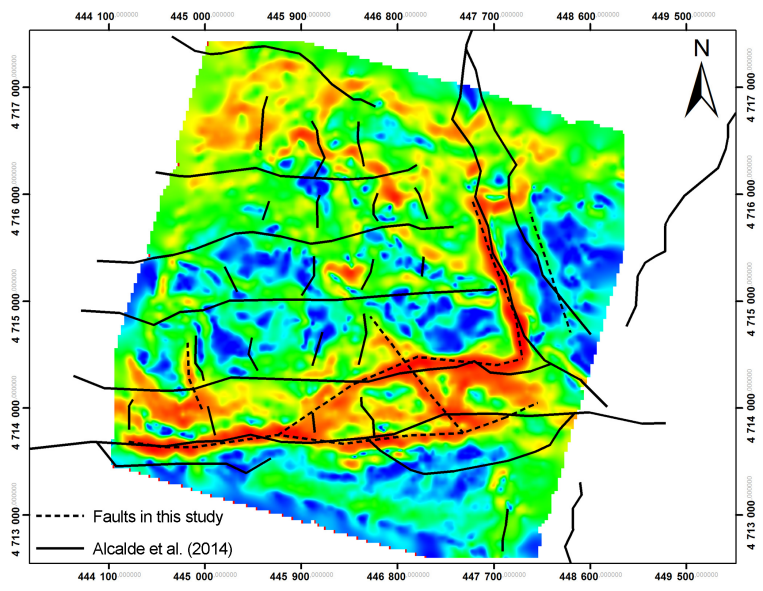

Figure 9. THD map of the gravity residual depicted in Fig. 7d with a comparison between the faults interpreted from this map and the gravity inversion (discontinuous line) and those interpreted by $\mathrm{Al}-$ calde et al. (2014) from 3-D seismics.

\section{Discussion}

The outcome of the analysis of the high-resolution BA map of the Hontomín area and its integration with the 3-D seismic results acquired over the same area (Alcalde et al., 2014) results in a coherent model of the structure of the dome that sheds some light about its evolution. Even though a good agreement between the gravity and seismic data exists regarding the topography of the basement, some issues remain unsolved in the NW sector and will be discussed further in Sect. 5.2.

\subsection{Structural setting of the Hontomín dome basement}

The Hontomín dome has been described as an extensional forced fold (Tavani et al., 2013) resulting from the extension and reactivation of Permo-Triassic normal faults affecting the basement. The presence of a detaching level represented by the Keuper Triassic salts produced the forced folding in the upper sedimentary cover by migration of these salts (Tavani et al., 2013; Carola et al., 2015). For the area of study, Carola et al. (2015) have suggested a thin-skinned configuration based on surface geology, well data and vintage seismic lines.

Here, we present a comprehensive model, from surface to basement, centred in the surroundings of the spot where the $\mathrm{CO}_{2}$ storage site is currently being developed. The new model suggests a local thick-skinned deformation style for the area with two major faults affecting the basement, namely the south and the east faults, already described by Alcalde et al. (2014). This model defines an area divided into three main blocks, south, centre-north-west and north-east.
The THD presented in Fig. 9 delineates high-gradient areas affecting the residual gravity data set of Fig. $7 d$. These zones are interpreted as faults (discontinuous lines in Fig. 9) and are compared with the ones described by Alcalde et al. (2014). Among these, one striking $\sim \mathrm{E}-\mathrm{W}$ stands out in the southern area and is interpreted as a major fault, coinciding with the south fault as defined by Alcalde et al. (2014). The gravity gradient of this fault is observed in most of the gravity maps produced in this paper, including the residual gravity map and derivatives shown in Fig. 4 as well as those in shown in Fig. 9, indicating that the south fault affects sediments and basement. Furthermore, the cross sections derived from the 3-D model (Fig. 6) show an offset in the basement of $150 \mathrm{~m}$ for the south fault. Another fault parallel to the south fault is shown in Fig. 5a, close to the thickest interval of Keuper evaporites, and features a normal offset of $200 \mathrm{~m}$ over the basement. These two faults combined create a downward displacement of the basement of about $350 \mathrm{~m}$. The south fault is thought to be a branch of the rightlateral Ubierna Fault affecting the basement and all the stratigraphic succession and conditioning the structural setting of the area. This fault has been affected by two deformation stages: a Late Jurassic-Early Cretaceous extensional stage (Tavani and Muñoz, 2012) and a later Cenozoic compression related with the formation of the Pyrenees. The kinematics and sedimentary history of this fault were interpreted by Alcalde et al. (2014). They suggest a flower-like structure associated with the strike-slip movement of the Ubierna faults. The Jurassic-Lower Cretaceous succession shows a thicker sedimentary record to the NW of the south fault, suggesting a normal displacement of the hanging wall during this period.

Another fault interpreted from the map in Fig. 9 is located to the NE, strikes NW-SE and is correlated with the east fault of Alcalde et al. (2014). This fault affects the basement and the sedimentary succession up to the Cenozoic packages, which are not affected by it. The fault has two minor associated faults (Fig. 9) that strike in the same direction but have less extension. The vertical motion of this fault was also described by Alcalde et al. (2014). Here, a downward displacement of the SW block during the Jurassic period has been assigned by the information extracted from the exploration wells. The 3-D model created after the inversion of the gravity data shows a SW dipping fault with a normal sense of motion and offsets of around $400 \mathrm{~m}$, which are comparable to the offset accumulated by the southern fault. The east fault, as interpreted in the seismic data set, is not as clear in the derivatives of the BA data (Fig. 4c and d), although it is visible and clear in the residual maps (Fig. 4b), in the basement depth maps (Fig. 8a) and in the THD performed over the final anomaly grid used for the inversion (Fig. 9). This might be due to the fact that it does not affect the entire sedimentary sequence. In general, the south and east faults seem to have been reactivated during the Jurassic-Lower Cretaceous extension, generating a sunken basement block. 


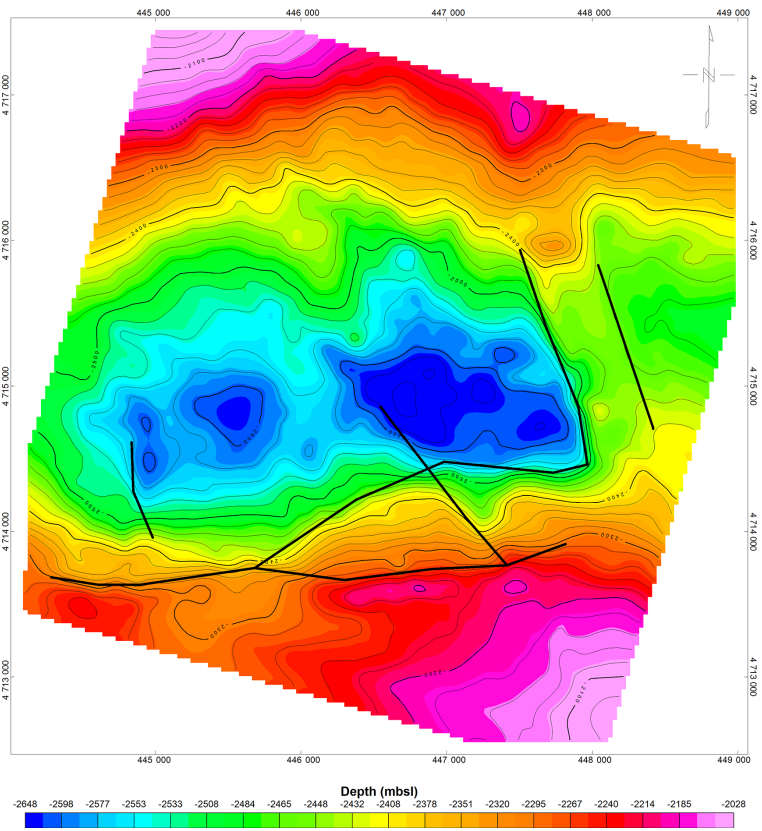

Figure 10. Faults interpreted from the THD of the residual gravity map and shown in Fig. 9, superimposed on the basement topography map.

Figure 9 also shows good agreement existing between the south and east faults as deduced from gravity and 3-D seismic data. Good correlation exists too between minor fractures associated with these faults, like an E-W fault located to the north of the south fault and interpreted from both data sets.

Finally, the two 2-D transects modelled from the Bouguer Anomaly map (Fig. 5a and c), both of which run over one or two of the Hontomín 1 and 2 boreholes, show a similar set of faults and the same reservoir-dome-like structure. However, these models cannot be compared to the seismic lines at depth since the seismic data do not reach the basement level.

The faults interpreted in the central sunken block by Alcalde et al. (2014) are not clearly recognizable in the THD map (Fig. 9), which shows an irregular anomaly pattern in the central domain. This could be due to either the confinement of faulting within the cover succession or to the minor offsets associated with these faults not generating strong enough gravity gradients to be recognized with this method.

\subsection{Structural setting of the sedimentary cover}

Another set of faults can be interpreted from the THD of the reduced BA map (Fig. 9). These strike NNW-SSE and have limited length. Even though they have a weak signature, they are similar to those interpreted from the seismic data striking
SE

NW

(a) Basement high

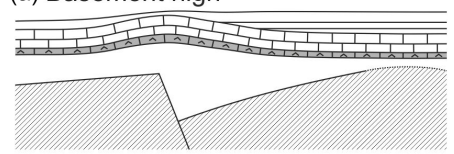

(b) Salt migration

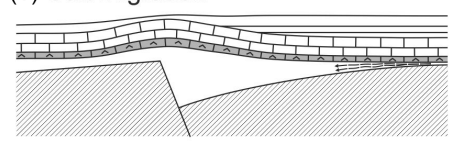

(c) Facies change

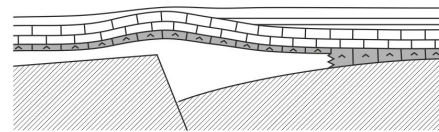

LEGEND

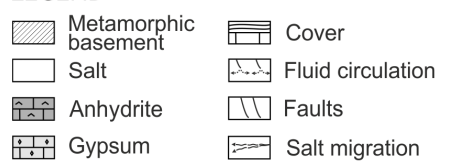

Figure 11. Schematic cross sections in a NW-SE direction, showing the different possibilities for explaining the discrepancy to the NW between the gravity model and that presented by Alcalde et al. (2014). (a) Basement high, (b) salt migration, (c) facies change from Keuper evaporites to anhydrites.

in an almost N-S direction (Alcalde et al., 2014), which were described as active during the Liassic period. However, there is a discrepancy regarding their area of influence, as the latter were interpreted to be associated with a possible Triassic extensional normal faulting affecting the basement, which triggered the movement of the Triassic evaporates. Furthermore, either they do not affect the basement topography (Figs. 8a, 9 and 10), except locally to the SW, or at least they do not produce a basement offset identifiable in the gravity data. This suggests that this set of faults may only affect the Jurassic and Triassic succession and that they can be associated with the movement of the Triassic evaporites towards the basement wall, causing the dome growth.

Despite the general good agreement between the basement model presented here and that presented by Alcalde et al. (2014), there are still some differences, especially concerning the NW sector. Here, the basement topography appears to be higher when deduced from gravity data than in the seismic model. Three hypotheses can be proposed to explain this discrepancy (Fig. 11). The first (Fig. 11a) is that the basement high deduced by the gravity study is real. This basement high could be explained as a rollover anticline generated by the listric geometry of the south fault. The remain- 


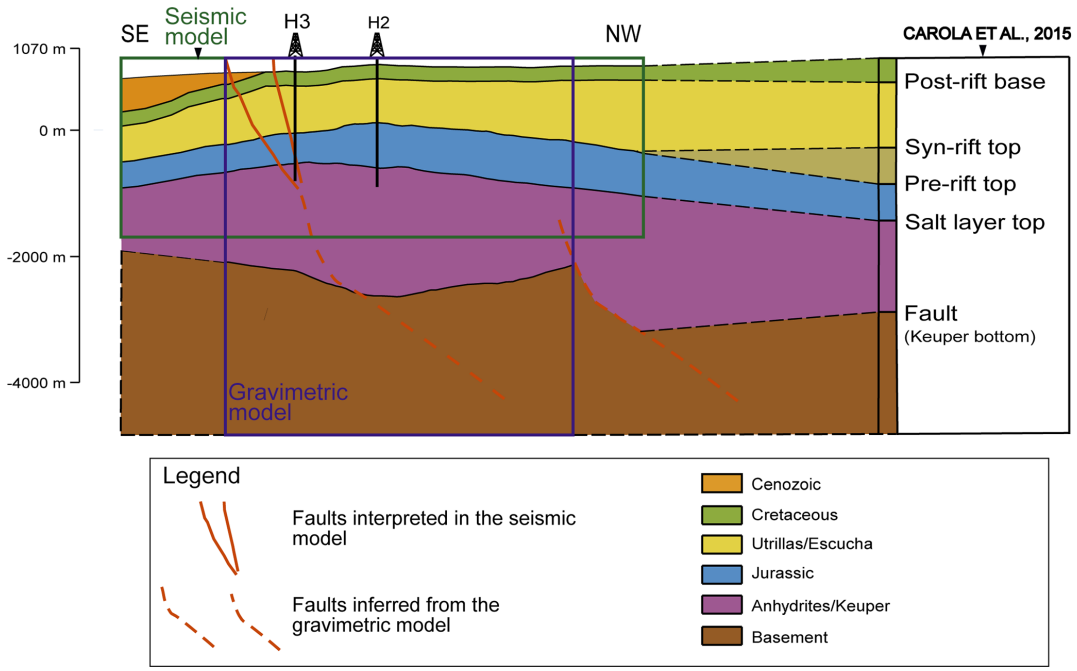

Figure 12. Correlation of the joint gravity and seismic model with that presented by Carola et al. (2015). Note the thickening of the salt layer to the NW. A new fault is proposed to accommodate the increased thickness. The location of the fault is speculative. The tilt of the hanging-wall is taken from the south fault.

ing hypotheses imply that the gravity high observed in the NW sector is not only produced by a basement high, but also by a complex organization of the stratigraphic succession. The second hypothesis (Fig. 11b) has a reduced Keuper thickness in this area, which would imply a general increase of the gravity signal. This could be explained as the result of the migration of the Keuper evaporites towards the dome and would imply a thickening of the Jurassic-Recent stratigraphic succession in this zone. Figure $11 \mathrm{c}$ shows a third possible scenario where the positive gravity anomaly is related to the occurrence of a dense stratigraphic unit, which could correspond to Triassic anhydrites laterally passing to the less dense Keuper evaporites of the dome domain. Nevertheless, we cannot rule out the possibility that this structure is related to the edge effects generated after filtering a regional component in such a small area.

The basement high $(2100 \mathrm{~m}$ b.s.l.) at the NW end of the gravimetric model also contrasts with the position of the basement top at $-2800 \mathrm{mb}$ b.s.l. $5 \mathrm{~km}$ to the north as interpreted by Carola et al. (2015) based on seismic data (Fig. 12). These authors propose a thin-skinned model detached at the top of the basement and associated with a large offset on top of a low angle footwall ramp. However, the staircase geometry of the basement top across the Hontomín structure (Fig. 12) is in our opinion in disagreement with this model, since the cover does not show a structural culmination associated with the NW basement high, which should be expected in a thin-skinned model. Besides, the monoclinal attitude of the Upper Cretaceous limestones on the southern border of the Hontomín structure above the south fault and the homogeneous uplift of this layer north of this point sug- gests that this feature is mainly associated with the inversion of the south fault and hence is a thick-skinned model. In this scenario, the basement step NW of the gravimetric model would be associated with a new normal fault (Fig. 12), which was not inverted during the compressive stage. The NW fault would be mainly responsible for the extensional forced folding occurring during the rifting stage as already proposed by Tavani et al. (2013).

At a regional scale, the thickness of the Triassic salt layer in the Plataforma Burgalesa is very inhomogeneous from north to south. Exploration wells have drilled different thicknesses, ranging from 2000 to just $300 \mathrm{~m}$ (Carola et al., 2015). This is also the case in the Hontomín area, where the average thickness of the Keuper evaporites is $1660 \mathrm{~m}$ with a maximum of $2020 \mathrm{~m}$ and a minimum of $1200 \mathrm{~m}$. This thickening generates a gravity low observed in the BA map, which appears somehow displaced from the south fault, as is also clearly pictured in the 2-D models and the cross sections derived from 3-D models (Figs. 5a, c, 6). These offsets of the gravity minima provide evidence of the mobilization of the evaporites towards the walls of the principal faults (south fault and the east fault) related to the migration pathways forced by the Cenozoic compressional stage (Tavani et al., 2013) but also to some extent to salt mobilization during the rifting stage as a consequence of the sedimentary load of the syn-rift succession on the hanging wall of the basement faults. 


\section{Conclusions}

We have built a consistent structural model for the Hontomín $\mathrm{CO}_{2}$ storage site from the surface down to the basement. The model relies on the integration of high-resolution 3-D gravity and seismic data. The microgravity analysis of the area has allowed us to further constrain its tectonic setting, basement geometry, faults relationships and Triassic salt thickness. The new model reveals a thick-skinned tectonic setting configured by three sets of faults, all of them correlatable with those identified by Alcalde et al. (2014). Two of them, namely the south fault and the east fault, striking ENE-WSW and NWSE respectively, clearly affect the basement. The south fault also affects the entire stratigraphic succession above it, while the east fault affects the basement and the sedimentary succession up to the Cenozoic sediments. We propose a halfgraben-like structure for the configuration of the south fault. Accordingly, a basement high located in the NW section of the area and not affected by any structure might suggest that the south fault has acted as a listric fault, configuring the basement topography in the NW sector. A third set of faults striking NNW-SSE has been identified. However, its gravity signature in the residual gravity map is not very conspicuous, suggesting that they may affect just the Triassic Keuper evaporites and the Jurassic succession above but not the basement. Accordingly, they have been interpreted to be the result of the movement of the salt towards the main faults. However, it is also possible that they affected the basement but produced small offsets, as previously suggested by the 3D seismic data. This paper demonstrates that the integration of high-resolution geophysical data sets is a magnificent tool for unravelling the structure of geologically complex areas.

Acknowledgements. We dedicate this paper to the memory of Andres Perez Estaún, who was a great and committed scientist, wonderful colleague and even better friend. The data sets in this work have been funded by Fundación Ciudad de la Energía (Spanish Government, www.ciuden.es) and by the European Union through the "European Energy Programme for Recovery" and the Compostilla OXYCFB300 project. Juan Alcalde is currently funded by NERC grant NE/M007251/1. Simon Campbell and Samuel Cheyney are acknowledged for thoughtful comments on gravity inversion. We thank Dr. Malehmir and an anonymous reviewer for their revisions and comments which have improved the manuscript.

Edited by: J. Alvarez-Marron

\section{References}

Alcalde, J., Martí, D., Juhlin, C., Malehmir, A., Sopher, D., Saura, E., Marzán, I., Ayarza, P., Calahorrano, A., Pérez-Estaún, A., and Carbonell, R.: 3-D reflection seismic imaging of the Hontomín structure in the Basque-Cantabrian Basin (Spain), Solid Earth, 4, 481-496, doi:10.5194/se-4-481-2013, 2013a.
Alcalde, J., Martí, D., Calahorrano, A., Marzán, I., Ayarza, P., Carbonell, R., Juhlin, C., and Pérez-Estaún, A.: Active seismic characterization experiments of the Hontomín research facility for geological storage of $\mathrm{CO}_{2}$, Spain, Int. J. Greenh. Gas Con., 19, 785-795, 2013b.

Alcalde, J., Marzán, I., Saura, E., Martí, D., Ayarza, P., Juhlin, C., Pérez-Estaún, A., and Carbonell, R.: 3-D geological characterization of the Hontomín $\mathrm{CO}_{2}$ storage site, Spain: Multidisciplinary approach from seismic, well-log and regional data, Tectonophysics, 627, 6-25, 2014.

Andrés, J.: Aplicación de la microgravimetría a la caracterización geológica del área de Hontomín (Burgos), MSc. Thesis, 2012.

Blakely, R. J.: Potential Theory in Gravity and Magnetic Applications, Cambridge University Press, Cambridge, 464 pp., 1995.

Blakely, R. J. Simpson, R. W.: Approximating edges of source bodies from magnetic or gravity anomalies, Geophysics, 51, 14941498, 1986.

Brown, R. N.: History of exploration and discovery of Morgan, Ramadan, and July oilfields, Gulf of Suez, Egypt, in: Facts and principles of world petroleum occurrence, edited by: Miall, A. D., Canadian Society of Petroleum Geologists Memoir, 6, 733-764, 1980.

Canal, J., Delgado, J., Falcón, I., Yang, Q., Juncosa, R., and Barrientos, V.: Injection of $\mathrm{CO}_{2}$-saturated water through a siliceous sandstone plug from the Hontomín test site (Spain): Experiment and modelling, Environ. Sci. Technol., 47, 159-167, 2013.

Carola, E., Muñoz, J. A., and Roca, E.: The transition from thickskinned to thin-skinned tectonics in the Basque-Cantabrian Pyrenees: the Burgalesa Platform and surroundings, Int. J. Earth Sci., 104, 2215-2239, doi:10.1007/s00531-015-1177-z, 2015.

Chappell, A. R. and Kusznir, N. J: Three-dimensional gravity inversion for Moho depth at rifted continental margins incorporating a lithosphere thermal gravity anomaly correction, Geophys. J. Int., 174, 1-13, 2008.

Contrucci, I., Matias, L., Moulin, M., Géli, L., Klingelhofer, F., Nouzé, H., Aslanian, D., Olivet, J.-L., Réhault, J.-P., and Sibuet, J.: Deep structure of the West African continental margin (Congo, Zaire, Angola) between $5^{\circ} \mathrm{S}$ and $8^{\circ} \mathrm{S}$, from reflection/refraction seismics and gravity data, Geophys. J. Int., 158, 529-553, 2004.

Døssing, A., Hansen, T. M., Olesen, A. V., Hopper, J. R., and Funck, T.: Gravity inversion predicts the nature of the Amundsen Basin and its continental borderlands near Greenland, Earth Planet. Sci. Lett., 408, 132-145, 2014

Elío, J., Nisi, B., Ortega, M. F., Mazadiego, L. F., Vaselli, O., and Grandia, F.: $\mathrm{CO}_{2}$ soil flux baseline at the Technological Development Plant for $\mathrm{CO}_{2}$ Injection at Hontomín (Burgos, Spain), Int. J. Greenh. Gas Con., 18, 224-236, 2013.

Engen, Ø., Frazer, L. N., Wessel, P., and Faleide, J. I.: Prediction of sediment thickness in the Norwegian-Greenland 28 Sea from gravity inversion, J. Geophys. Res., 111, B11403, doi:10.1029/2005JB003924, 2006.

European Union: Directive 2009/31/EC of the European Parliament and of the council of 23 April 2009 on the geological storage of carbon dioxide and amending Council Directive 85/337/EEC, European Parliament and Council Directives 2000/60/EC, 2001/80/EC, 2004/35/EC, 2006/12/EC, 2008/1/EC and Regulation (EC) No 1013/2006, 2009. 
Filina, I., Delebo, N., Mohapatra, G., Coble, C., Harris, G., Layman, J., Strickler, M., and Blangy, J.: Integration of seismic and gravity data - A case study from the western Gulf of Mexico, Interpretation, 3, 99-106, 2015.

García-Mondejar, J.: Plate reconstruction of the Bay of Biscay, Geology, 24, 635-638, 1996.

Hedin, P., Malehmir, A., Gee, D. G., Juhlin, C., and Dyrelius, D.: $3 \mathrm{D}$ interpretation by integrating seismic and potential field data in the vicinity of the proposed COSC-1 drill site, central Swedish Caledonides. Geological Society, London, Special Publications, 390, 301-319, 2014.

IEA Greenhouse Gas R\&D Programme (IEA GHG): CCS Site Characterisation Criteria, 2009/10, July 2009.

Jacobsen, B. H.: A case for upward continuation as a standard separation filter for potential-field maps, Geophysics, 52, 1138-1148, 1987.

Jacoby, W. and Smilde, P. L.: Gravity Interpretation - Fundamentals and Application of Gravity Inversion and Geological Interpretation, Springer, Heidelberg, 2009.

Laubscher, H. P.: Die Sudostecke des Rheingrabens-ein kinematisches und dynamisches problem, Eclogae Geol. Helv., 75, 101116, 1982.

Leveille, J. P., Larner, K., and Higgingbotham, J.: A problem workshop, The Leading Edge, 24, 1126-1132, 2005.

Manspeizer, W.: Chapter 3 - Triassic - Jurassic rifting and opening of the Atlantic: An overview, in: Developments in Geotectonics, edited by: Manspeizer, W., Elsevier, 22, 41-79, 1988.

Malehmir, A., Thunehed, H., and Tryggvason, A.: The Paleoproterozoic Kristineberg mining area, northern Sweden: Results from integrated 3D geophysical and geologic modeling, and implications for targeting ore deposits, Geophysics, 74, 9-22, 2009.

Nisi, B., Vaselli, O., Tassi, F., Elío, J., Delgado Huertas, A., Maadiego, L. P., and Ortega, M. F.: Hydrogeochemistry of surface and spring waters in the surroundings of the $\mathrm{CO}_{2}$ injection site at Hontomín-Huermeces (Burgos, Spain), Int. J. Greenh. Gas Con., 14, 151-168, 2013.

Parker, R. L.: The rapid calculation of potential anomalies, Geophys. J. Roy. Astr. S., 42, 315-334, 1972.

Permanyer, A., Márquez, G., and Gallego, J. R.: Compositional variability in oils and formation waters from the Ayoluengo and Hontomín fields (Burgos, Spain), Implications for assessing biodegradation and reservoir compartmentalization, Organ. Geochem., 54, 125-139, 2013.

Prado Pérez, J. A. R, Campos, C., Ruiz, M., Pelayo, F., Recreo, L., Lomba, A., Hurtado, S., Eguilior, L., and Pérez del Villar.: Almacenamiento geológico de $\mathrm{CO}_{2}$, Selección de formaciones favorables, Comunicación técnica, Congreso Nacional del Medio Ambiente, Cumbre del desarrollo Sostenible, Madrid, 2008.

Pujalte, V., Robles, S., García-Ramos, J. C., and Hernández, J. M.: El Malm-Barremniense no marinos de la Cordillera Cantábrica, in: Geología de Espana, edited by: Vera, J. A., SGE-IGME, Madrid, 288-291, 2004.

Oldenburg, D. W.: The inversion and interpretation of gravity anomalies, Geophysics, 39, 526-536, 1974.

Ogaya, X., Ledo, J., Queralt, P., Marcuello, Á., and Quintà, A.: First geoelectrical image of the subsurface of the Hontomín site (Spain) for $\mathrm{CO}_{2}$ geological storage: A magnetotelluric 2D characterization, Int. J. Greenh. Gas Con., 13, 168-179, 2013.
Ogaya, X., Queralt, P., Ledo, J., Marcuello, Á., and Jones, A. G.: Geoelectrical baseline model of the subsurface of the Hontomín site (Spain) for $\mathrm{CO}_{2}$ geological storage in a deep saline aquifer: a 3D magnetoteluric characterisation, Int. J. Greenh. Gas Con., 27, 120-138, 2014.

Quintá, A. and Tavani, S.: The foreland deformation in the south-western Basque-Cantabrian Belt (Spain), Tectonophysics, 576/577, 4-19, 2012.

Rousseau, J. H. L., Calandra, H., and de Hoop, M. V.: Three dimensional depth imaging with generalized screens: A salt body case study, Geophysics, 68, 1132-1139, 2003.

Rubio, F. M., Ayala, C., Gumiel, J. C., and Rey, C.: Caracterización mediante campo potencial y teledetección de la estructura geológica seleccionada para planta de desarrollo tecnológico de almacenamiento geológico de $\mathrm{CO}_{2}$ en Hontomín (Burgos), IGMEInstituto Geológico y Minero de España Technical Report, 182 pp., 2011.

Sava, P. and Biondi, B.: Wave-equation migration velocity analysis, II. Subsalt imaging examples, Geophys. Prosp., 52, 607-623, 2004.

Serrano, A. and Martínez del Olmo, W.: Tectónica salina en el Dominio Cántabro-Navarro: evolución, edad y origen de las estructuras salinas, in: Formaciones evaporíticas de la Cuenca del Ebro y cadenas periféricas, y de la zona de Levante, Nuevas Aportaciones y Guía de Superficie, edited by: Ortí, F. and Salvany, J. M., Empresa Nacional De Residuos Radiactivos S.A., ENRESAGPPG, Barcelona, 39-53, 1990.

Stadtler, C., Fichler, C., Hokstad, K., Myrlund, E. A., Wienecke, S., and Fotland, B.: Improved salt imaging in a basin context by high resolution potential field data?, Nordkapp Basin, Barents Sea, Geophys. Prospect., 62, 615-630, 2014.

Tavani, S. and Muñoz, J. A.: Mesozoic rifting in the BasqueCantabrian Basin (Spain): Inherited faults, transversal structures and stress perturbation, Terra Nova, 24, 70-76, 2012.

Tavani, S., Quintà, A., and Granado, P.: Cenozoic right-lateral wrench tectonics in the Western Pyrenees (Spain): The Ubierna Fault System, Tectonophysics, 509, 238-253, 2011.

Tavani, S., Carola, Granado, P., Quintà, A., and Muñoz, J. A.: Transpressive inversion of a Mesozoic extensional forced fold system with an intermediate décollement level in the Basque-Cantabrian Basin (Spain), Tectonics, 32, 146-158, 2013.

Ugalde, A., Villaseñor, A., Gaite, B., Casquero, S., Martí, D., Calahorrano, A., Marzán, I., Carbonell, R., and Estaún, A. P.: Passive seismic monitoring of an experimental $\mathrm{CO}_{2}$ geological storage site in Hontomín (Northern Spain), Seismol. Res. Lett., 84, 7584, 2013.

Vera, J. A.: Geología de España, SGE-IGME, Madrid, p. 890, 2004. Verduzco, B., Fairhead, J. D., Green, C. M., and MacKenzie, C.: New insights into magnetic derivatives for structural mapping, The Leading Edge, 23, 116-119, 2004.

Vilamajó, E., Queralt, P., Ledo, J., and Marcuello, A.: Feasibility of Monitoring the Hontomín (Burgos, Spain) $\mathrm{CO}_{2}$ Storage Site Using a Deep EM Source, Surv. Geophys., 34, 441-461, 2013.

Ziegler, P. A.: Evolution of the North Atlantic: An Overview, AAPG Memoir, 46, in: Extensional Tectonics and Stratigraphy of the North Atlantic Margins, edited by: Tankard, A. J. and Balkwill, H. R., American Association of Petroleum Geologists Canadian Geological Foundation, 111-129, 1988. 


\section{Bibliography}

Afonso, Juan Carlos, Giorgio Ranalli, and Manel Fernàndez (2005). "Thermal expansivity and elastic properties of the lithospheric mantle: results from mineral physics of composites". In: Physics of the Earth and Planetary Interiors 149.3, pp. 279 -306. ISSN: 0031-9201. DOI: https://doi .org/ 10.1016/j.pepi.2004.10.003. URL: http://www.sciencedirect.com/science/article/pii/ S0031920104003747.

Aki, Keiiti (1957). "Space and time spectra of stationary stochastic waves, with special reference to microtremors". In: Bulletin of the Earthquake Research Institute 35, pp. 415-456.

Alcock, James E. et al. (May 2009). "Use of thermal modeling to assess the tectono-metamorphic history of the Lugo and Sanabria gneiss domes, Northwest Iberia”. In: Bulletin de la Société Géologique de France 180.3, pp. 179-197. ISSN: 0037-9409. DOI: 10.2113/gssgfbull .180 .3 . 179. eprint: https : //pubs . geoscienceworld . org/bsgf/article-pdf/180/3/179/2967542/179 . pdf. URL: https://doi.org/10.2113/gssgfbull.180.3.179.

Andrés, J. et al. (2018). "Curie Point Depth of the Iberian Peninsula and Surrounding Margins. A Thermal and Tectonic Perspective of its Evolution". In: Journal of Geophysical Research: Solid Earth 123.3, pp. 2049-2068. DOI: 10.1002/2017jb014994.

Andrés, J. et al. (2020). "What can seismic noise tell us about the Alpine reactivation of the Iberian Massif? An example in the Iberian Central System". In: Solid Earth Discussions 2020, pp. 1-24. DOI: 10.5194/se-2020-94. URL: https://se . copernicus .org/preprints/se-2020-94/.

Andrés, Juvenal et al. (2019). "Lithospheric image of the Central Iberian Zone (Iberian Massif) using global-phase seismic interferometry". In: Solid Earth 10.6, pp. 1937-1950. DOI: 10.5194/se-101937-2019.

Andrés, J. et al. (2019). "Imaging the lithospheric structure of the Central Iberian Zone". In: EGU General Assembly. EGU General Assembly, Vienna, Austria, 7-12 April 2019.

Ayarza P.; Martínez Catalán, J. R.; Villalaín-J. J.; Alvarez Lobato F.; Durán-Oreja M.: \& Joven Romero P. (2016). "Age and origin of the Eastern Galicia Magnetic Anomaly (NW Spain): Constraints on the understanding of the Central-Iberian Arc". In: AGU Fall Meeting. AGU.

Ayarza, P. et al. (2004). "Geophysical constraints on the deep structure of a limited ocean-continent subduction zone at the North Iberian Margin". In: Tectonics 23.1. DOI: 10.1029/2002TC001487. eprint: https : / / agupubs . onlinelibrary . wiley . com/doi/pdf / 10 . 1029/2002TC001487. URL: https://agupubs . onlinelibrary.wiley.com/doi/abs/10.1029/2002TC001487.

Ayarza, P. et al. (2010). "A wide-angle upper mantle reflector in SW Iberia: Some constraints on its nature". In: Physics of the Earth and Planetary Interiors 181.3, pp. 88 -102. ISSN: 0031-9201. DOI: https : / / doi . org/10 . 1016/j . pepi . 2010.05 .004. URL: http://www . sciencedirect . com/ science/article/pii/S0031920110001032. 
Ayarza, P. et al. (2020). "Evolution of the Iberian Massif as deduced from its crustal thickness and geometry of a mid-crustal (Conrad) discontinuity". In: Solid Earth Discussions 2020, pp. 1-46. DOI: 10.5194/se-2020-158. URL: https://se. copernicus .org/preprints/se-2020-158/.

Ayarza, Puy and José R. Martínez Catalán (2007). "Potential field constraints on the deep structure of the Lugo gneiss dome (NW Spain)". In: Tectonophysics 439.1, pp. 67 -87. ISSN: 0040-1951. DOI: https://doi.org/10.1016/j.tecto.2007.03.007. URL: http://www . sciencedirect.com/ science/article/pii/S004019510700145X.

Ayarza, Puy et al. (1998). "Estudio Sísmico de la Corteza Ibérica Norte 3.3: A seismic image of the Variscan crust in the hinterland of the NW Iberian Massif". In: Tectonics 17.2, pp. 171-186. DOI: 10. 1029/97TC03411. eprint: https : //agupubs . onlinelibrary . wiley . com/doi/pdf/10 . 1029/ 97TC03411. URL: https://agupubs .onlinelibrary.wiley.com/doi/abs/10.1029/97TC03411.

Bakulin, Andrey and Rodney Calvert (2006). "The virtual source method: Theory and case study". In: GEOPHYSICS 71.4, SI139-SI150. DOI: 10.1190/1.2216190.

Balda, M.A.Diez, J.R.Martinez Catalan, and P.Ayarza Arribas (1995). "Syn-collisional extensional collapse parallel to the orogenic trend in a domain of steep tectonics: the Salamanca Detachment Zone (Central Iberian Zone, Spain)". In: Journal of Structural Geology 17.2, pp. 163 -182. ISSN: 0191-8141. DOI: https : / / doi . org/10 . 1016/0191-8141 (94 ) E0042-W. URL: http : / / wwW . sciencedirect.com/science/article/pii/0191814194E0042W.

Banda, E. et al. (Dec. 1981). "Crust and upper mantle structure of the central Iberian Meseta (Spain)". In: Geophysical Journal International 67.3, pp. 779-789. ISSN: 0956-540X. DOI: 10.1111/j.1365246X . 1981 . tb06954 . x. eprint: http : / / oup.prod . sis . lan/gji / article-pdf / 67 / 3 /779/ 1970020/67-3-779.pdf. URL: https://doi.org/10.1111/j.1365-246X.1981.tb06954.x.

Bansal, A. et al. (2016). "Curie Depth Estimation from Aeromagnetic for Fractal Distribution of Sources". In: Fractal Solutions for Understanding Complex Systems in Earth Sciences. Ed. by V. Dimri. ISBN: ISBN 978-3-319-24675-8. DOI: https ://doi.org/10.1007/978-3-319-24675-8.

Bansal, A.R. et al. (2013). "Depth to the bottom of magnetic sources (DBMS) from aeromagnetic data of Central India using modified centroid method for fractal distribution of sources". In: Tectonophysics 603, pp. 155 -161. ISSN: 0040-1951. DOI: https://doi.org/10.1016/j.tecto.2013.05. 024. URL: http://www.sciencedirect.com/science/article/pii/S0040195113003363.

Barbero, L. and C. Villaseca (2000). "Eclogite facies relicts in metabasites from the Sierra de Guadarrama (Spanish Central System): P-T estimations for the Hercynian evolution". In: Mineralogical Magazine 64, pp. 815-836.

Bea, F. (2004). "La naturaleza del magmatismo de la Zona Centroibérica: Consideraciones generales y ensayo de correlación". In: Geología de España. Ed. by J. Vera.

Bea, Fernando, Pilar Montero, and Tatiana Zinger (2003). "The Nature, Origin, and Thermal Influence of the Granite Source Layer of Central Iberia". In: The Journal of Geology 111.5, pp. 579-595. DOI: 10.1086/376767. eprint: https://doi.org/10.1086/376767. URL: https://doi.org/10.1086/ 376767.

Becker, G and B Knapmeyer-Endrun (Nov. 2017). "Crustal thickness across the Trans-European Suture Zone from ambient noise autocorrelations". In: Geophysical Journal International 212.2, 
pp. 1237-1254. ISSN: 0956-540X. DOI: 10.1093/gji/ggx485. eprint: https://academic.oup.com/ gji/article-pdf/212/2/1237/22373210/ggx485.pdf. URL: https : //doi .org/10.1093/gji/ ggx485.

Beltrando, Marco et al. (2014). "Recognizing remnants of magma-poor rifted margins in high-pressure orogenic belts: The Alpine case study". In: Earth-Science Reviews 131, pp. 88 -115. ISSN: 0012-8252. DOI: https://doi.org/10.1016/j.earscirev.2014.01.001. URL: http://www. sciencedirect. com/science/article/pii/S001282521400004X.

Bensen, G. D. et al. (2007). "Processing seismic ambient noise data to obtain reliable broad-band surface wave dispersion measurements". In: Geophysical Journal International 169.3, pp. 12391260. DOI: $10.1111 / \mathrm{j} .1365-246 \mathrm{x} .2007 .03374 . \mathrm{x}$.

Bhattacharyya, B. K. and Lei-Kuang Leu (1975). "Analysis of magnetic anomalies over Yellowstone National Park: Mapping of Curie point isothermal surface for geothermal reconnaissance". In: Journal of Geophysical Research (1896-1977) 80.32, pp. 4461-4465. DOI: 10.1029/JB080i032p04461. eprint: https : //agupubs . onlinelibrary.wiley.com/doi/pdf/10.1029/JB080i032p04461. URL: https://agupubs . onlinelibrary.wiley.com/doi/abs/10.1029/JB080i032p04461.

Blakely, Richard J. (1995). Potential Theory in Gravity and Magnetic Applications. Cambridge University Press. DOI: 10.1017/CB09780511549816.

Boillot, G. et al. (1980). "Ocean-continent boundary off the Iberian margin: A serpentinite diapir west of the Galicia Bank". In: Earth and Planetary Science Letters 48.1, pp. 23 -34. ISSN: 0012-821X. DOI: https : //doi .org/10 . 1016/0012-821X(80) 90166-1. URL: http: //www . sciencedirect . com/science/article/pii/0012821X80901661.

Bouligand, Claire, Jonathan M. G. Glen, and Richard J. Blakely (2009). "Mapping Curie temperature depth in the western United States with a fractal model for crustal magnetization". In: Journal of Geophysical Research: Solid Earth 114.B11. DOI: 10.1029/2009JB006494. eprint: https : // agupubs . onlinelibrary.wiley.com/doi/pdf/10.1029/2009JB006494. URL: https://agupubs . onlinelibrary.wiley.com/doi/abs/10.1029/2009JB006494.

Boyer, Timothy et al. (2005). "Objective analyses of annual, seasonal, and monthly temperature and salinity for the World Ocean on a 0.25̌̌ grid”. In: International Journal of Climatology 25.7, pp. 931945. DOI: 10.1002/joc.1173. eprint: https://rmets.onlinelibrary.wiley.com/doi/pdf/10. 1002/joc.1173. URL: https://rmets.onlinelibrary.wiley.com/doi/abs/10.1002/joc.1173.

Bruijne, C.H. de and P.A.M. Andriessen (2002). "Far field effects of Alpine plate tectonism in the Iberian microplate recorded by fault-related denudation in the Spanish Central System". In: Tectonophysics 349.1. Low Temperature Thermochronology: From Tectonics to Landscape Evolution, pp. 161 -184. ISSN: 0040-1951. DOI: https : //doi org/10 . 1016/S0040-1951(02) 00052-5. URL: http: //www.sciencedirect.com/science/article/pii/s0040195102000525.

Buffoni, Carolina et al. (2019). "Crustal structure beneath Tierra del Fuego, Argentina, inferred from seismic P-wave receiver functions and ambient noise autocorrelations". In: Tectonophysics 751, pp. 41-53. DOI: $10.1016 / \mathrm{j}$.tecto.2018.12.013.

Carballo, A. et al. (2015a). "From the North-Iberian Margin to the Alboran Basin: A lithosphere geotransect across the Iberian Plate". In: Tectonophysics 663. Special issue on Iberia geodynamics: An 
integrative approach from the Topo-Iberia framework, pp. 399 -418. ISSN: 0040-1951. DOI: https: //doi.org/10.1016/j.tecto.2015.07.009. URL: http://www.sciencedirect. com/science/ article/pii/S0040195115003765.

Carballo, A. et al. (2015b). "Thermal and petrophysical characterization of the lithospheric mantle along the northeastern Iberia geo-transect". In: Gondwana Research 27.4, pp. 1430 -1445. ISSN: 1342937X. DOI: https://doi .org/10.1016/j.gr.2013.12.012. URL: http://www sciencedirect . com/science/article/pii/S1342937X14000070.

Carbonell, Ramon (2004). "On the nature of mantle heterogeneities and discontinuities: evidence from a very dense wide-angle shot record". In: Tectonophysics 388.1. Continental Lithosphere. Papers presented at the 10th International Symposium on Deep Seismic Profiling of the Continents and their Margins, pp. 103 -117. ISSN: 0040-1951. DOI: https://doi.org/10.1016/j.tecto.2004.07.025. URL: http://www.sciencedirect.com/science/article/pii/S0040195104002495.

Carbonell, Ramon, Alan Levander, and Rainer Kind (2013). "The Mohorovii discontinuity beneath the continental crust: An overview of seismic constraints". In: Tectonophysics 609. Moho: 100 years after Andrija Mohorovicic, pp. 353 -376. ISSN: 0040-1951. DOI: https : // doi . org/10 . 1016/ j . tecto . 2013 .08 .037. URL: http : / / www . sciencedirect . com / science/article / pii / S0040195113005374.

Chertova, M. V. et al. (2014). "Underpinning tectonic reconstructions of the western Mediterranean region with dynamic slab evolution from 3-D numerical modeling". In: Journal of Geophysical Research: Solid Earth 119.7, pp. 5876-5902. DOI: 10 . 1002 / 2014JB011150. eprint: https : // agupubs.onlinelibrary.wiley.com/doi/pdf/10.1002/2014JB011150. URL: https://agupubs . onlinelibrary.wiley.com/doi/abs/10.1002/2014JB011150.

Christensen, Nikolas I. (1966). "Elasticity of ultrabasic rocks". In: Journal of Geophysical Research (1896-1977) 71.24, pp. 5921-5931. DOI: 10.1029/JZ071i024p05921. eprint: https://agupubs . onlinelibrary . wiley . com/doi/pdf / 10 . 1029 / JZ071i024p05921. URL: https : / / agupubs . onlinelibrary.wiley.com/doi/abs/10.1029/JZ071i024p05921.

Claerbout, Jon F. (1968). "SYNTHESIS OF A LAYERED MEDIUM FROM ITS ACOUSTIC TRANSMISSION RESPONSE". In: GEOPHYSICS 33.2, pp. 264-269. DOI: 10.1190/1.1439927. eprint: https://doi.org/10.1190/1.1439927. URL: https://doi.org/10.1190/1.1439927.

Cloetingh, S. et al. (2002). "Lithospheric folding in Iberia". In: Tectonics 21.5, pp. 5-1-5-26. DOI: 10 . 1029/2001TC901031. eprint: https : / / agupubs . onlinelibrary . wiley . com/doi / pdf / 10 . 1029/2001TC901031. URL: https : / / agupubs . onlinelibrary . wiley . com/doi/abs/10 . 1029/ 2001 TC901031.

Connard, G., R. Couch, and M. Gemperle (Mar. 1983). "Analysis of aeromagnetic measurements from the Cascade Range in central Oregon". In: Geophysics 48.3, pp. 376-390. ISSN: 0016-8033. DOI: 10.1190/1.1441476. eprint: https://pubs . geoscienceworld.org/geophysics/articlepdf/48/3/376/3162774/376.pdf. URL: https://doi.org/10.1190/1.1441476.

Davies, J. Huw (2013). "Global map of solid Earth surface heat flow". In: Geochemistry, Geophysics, Geosystems 14.10, pp. 4608-4622. DOI: 10.1002/ggge.20271. eprint: https://agupubs .onlinelibrary . 
wiley.com/doi/pdf/10.1002/ggge.20271. URL: https://agupubs.onlinelibrary.wiley.com/ doi/abs/10.1002/ggge. 20271.

de Vicente, G. and A. Muñoz-Martín (2013). "The Madrid Basin and the Central System: A tectonostratigraphic analysis from 2D seismic lines". In: Tectonophysics 602. TOPO-EUROPE III, pp. 259 -285. ISSN: 0040-1951. DOI: https : //doi .org/10 .1016/j . tecto. 2012 .04 .003. URL: http: //www.sciencedirect.com/science/article/pii/S0040195112001965.

de Vicente, G. et al. (2007). "Cenozoic thick-skinned deformation and topography evolution of the Spanish Central System". In: Global and Planetary Change 58.1. TOPO-EUROPE: the Geoscience of Coupled Deep Earth-Surface Processes, pp. 335 -381. ISSN: 0921-8181. DOI: https://doi.org/ 10.1016/j.gloplacha.2006.11.042. URL: http://www.sciencedirect.com/science/article/ pii/S0921818107000707.

de Vicente, G. et al. (2018). "The Spanish-Portuguese Central System: An Example of Intense Intraplate Deformation and Strain Partitioning". In: Tectonics 37.12, pp. 4444-4469. DOI: 10 . 1029 / 2018TC005204. eprint: https : / / agupubs . onlinelibrary . wiley . com / doi / pdf / 10 . 1029/2018TC005204. URL: https : / / agupubs . onlinelibrary . wiley . com/doi/abs / 10 . 1029 / $2018 \mathrm{TC} 005204$.

Dewey, J. F. et al. (1989). "Kinematics of the western Mediterranean". In: Geological Society, London, Special Publications 45.1, pp. 265-283. DOI: 10.1144/gsl.sp.1989.045.01.15.

Diaz, J., J. Gallart, and R. Carbonell (2016). "Moho topography beneath the Iberian-Western Mediterranean region mapped from controlled-source and natural seismicity surveys". In: Tectonophysics 692. SI:Crustal seismology, pp. 74 -85. ISSN: 0040-1951. DOI: https : // doi . org / 10 . 1016 / j . tecto . 2016 . 08 . 023. URL: http : / / www . sciencedirect . com / science / article / pii / S0040195116303602.

Díaz, J. et al. (1993). "A deep seismic sounding investigation of lithospheric heterogeneity and anisotropy beneath the Iberian Peninsula". In: Tectonophysics 221.1, pp. 35-51. DOI: 10.1016/ 0040-1951 (93) 90026-g.

Draganov, Deyan et al. (2009). "Reflection images from ambient seismic noise". In: GEOPHYSICS 74.5, A63-A67. DOI: 10.1190/1.3193529.

Duggen, S. et al. (Mar. 2009). "Flow of Canary mantle plume material through a subcontinental lithospheric corridor beneath Africa to the Mediterranean". In: Geology 37.3, pp. 283-286. ISSN: 0091-7613. DOI: 10 .1130/G25426A . 1. eprint: https : //pubs . geoscienceworld . org/geology/ article-pdf/37/3/283/3537249/i0091-7613-37-3-283.pdf. URL: https://doi.org/10.1130/ G25426A.1.

Díez Balda M. A., Vegas R. González Lodeiro F. (1990). "Central- Iberian Zone. Autochthonous Sequences". In: Pre-Mesozoic Geology of Iberia. Ed. by R. D. Dallmeyer and E. Martínez García. Berlin: Springer, pp. 172-188.

Ehsan, Siddique Akhtar et al. (2014). "Crustal deformation styles along the reprocessed deep seismic reflection transect of the Central Iberian Zone (Iberian Peninsula)". In: Tectonophysics 621, pp. 159 -174. ISSN: 0040-1951. DOI: https : / / doi .org/10 .1016/j . tecto . 2014 .02 .014. URL: http: //www.sciencedirect.com/science/article/pii/S0040195114001140. 
Ehsan, Siddique Akhtar et al. (2015). "Lithospheric velocity model across the Southern Central Iberian Zone (Variscan Iberian Massif): The ALCUDIA wide-angle seismic reflection transect". In: Tectonics 34.3, pp. 535-554. DOI: 10.1002/2014TC003661. eprint: https ://agupubs . onlinelibrary.wiley . com/doi/pdf/10.1002/2014TC003661. URL: https://agupubs . onlinelibrary.wiley . com/doi/ abs/10.1002/2014TC003661.

Etheve, Nathalie et al. (2016). "Extensional vs contractional Cenozoic deformation in Ibiza (Balearic Promontory, Spain): Integration in the West Mediterranean back-arc setting". In: Tectonophysics 682, pp. 35 -55. ISSN: 0040-1951. DOI: https://doi.org/10.1016/j . tecto.2016.05.037. URL: http://www.sciencedirect.com/science/article/pii/S0040195116301731.

Fernández, M. et al. (1998). "Heat flow, heat production, and lithospheric thermal regime in the Iberian Peninsula". In: Tectonophysics 291.1. Heat Flow and the Structure of the Lithosphere - IV, pp. 29 -53. ISSN: 0040-1951. DOI: https://doi .org/10.1016/S0040-1951 (98) 00029-8. URL: http://www.sciencedirect.com/science/article/pii/S0040195198000298.

Ferré, Eric C. et al. (2013). "The magnetism of mantle xenoliths and potential implications for subMoho magnetic sources". In: Geophysical Research Letters 40.1, pp. 105-110. DOI: 10 . 1029 / 2012GL054100. eprint: https : / / agupubs . onlinelibrary . wiley . com / doi / pdf / 10 . 1029 / 2012GL054100. URL: https ://agupubs . onlinelibrary . wiley . com/doi/abs/10 . 1029/2012GL054100.

Flecha, I. et al. (2009). "Seismic imaging and modelling of the lithosphere of SW-Iberia". In: Tectonophysics 472.1. Deep seismic profiling of the continents and their margins, pp. 148 -157. ISSN: 00401951. DOI: https://doi.org/10.1016/j.tecto.2008.05.033. URL: http://www. sciencedirect. com/science/article/pii/S0040195108002436.

Fletcher, K.M.U. et al. (2011). "Building a higher resolution magnetic database for Europe for resource evaluation". In: First Break 29.4, pp. 95-101.

Fores, B. et al. (2018). "Monitoring Saturation Changes with Ambient Seismic Noise and Gravimetry in a Karst Environment". In: Vadose Zone Journal 17.1, p. 170163. DOI: 10.2136/vzj2017.09.0163.

Franke, W. (Jan. 2000). "The mid-European segment of the Variscides: tectonostratigraphic units, terrane boundaries and plate tectonic evolution". In: Orogenic Processes: Quantification and Modelling in the Variscan Belt. Geological Society of London. ISBN: 9781862390737. DOI: 10.1144/GSL. SP. 2000.179.01.05. URL: https://doi.org/10.1144/GSL.SP. 2000.179.01.05.

Friend, P. F. (1996). Tertiary basins of Spain : the stratigraphic record of crustal kinematics. Cambridge England New York, NY, USA: University of Cambridge Press. ISBN: 9780521461719.

Fullea, J. et al. (2010). "The structure and evolution of the lithosphereasthenosphere boundary beneath the AtlanticMediterranean Transition Region". In: Lithos 120.1. The lithosphere/asthenosphere boundary: Nature, formation and evolution, pp. 74 -95. ISSN: 0024-4937. DOI: https://doi .org/ 10.1016/j . lithos . 2010.03.003. URL: http: //www . sciencedirect . com/science/article/ pii/S0024493710000782.

Gallart, Josep et al. (2015). "Iberia geodynamics: An integrative approach from the Topo-Iberia framework". In: Tectonophysics 663. Special issue on Iberia geodynamics: An integrative approach from the Topo-Iberia framework, pp. 1 -4. ISSN: 0040-1951. DOI: https://doi .org/10 . 1016/ 
j . tecto . 2015 . 09 .010. URL: http : / / wWw . sciencedirect . com / science / article / pii / S0040195115005107.

Gallastegui, Jorge, Javier A. Pulgar, and Josep Gallart (2016). "Alpine tectonic wedging and crustal delamination in the Cantabrian Mountains (NW Spain)". In: Solid Earth 7.4, pp. 1043-1057. DOI: $10.5194 / \mathrm{se}-7-1043-2016$.

Gibbons, Wes (2002). The geology of Spain. London: Geological Society. ISBN: 9781862391277.

Gómez-Ortiz, D. et al. (2005). "Crustal density structure in the Spanish Central System derived from gravity data analysis (Central Spain)". In: Tectonophysics 403.1-4, pp. 131-149. DOI: 10.1016/j . tecto.2005.04.006.

Gorbatov, A., E. Saygin, and B. L. N. Kennett (Dec. 2012). "Crustal properties from seismic station autocorrelograms". In: Geophysical Journal International 192.2, pp. 861-870. ISSN: 0956-540X. DOI: 10. 1093/gji /ggs064. eprint: https : / / academic . oup . com/gji /article-pdf / 192/2/861/ 5946880/ggs064.pdf. URL: https://doi.org/10.1093/gji/ggs064.

Green, C. M. et al. (1992). "The African magnetic mapping project". In: EAEG 54th Meeting and Technical Exhibition. Paris.

Guillot, Stéphane et al. (2015). "Tectonic significance of serpentinites". In: Tectonophysics 646, pp. 1 -19. ISSN: 0040-1951. DOI: https : / / doi org/10 . 1016/j . tecto . 2015 . 01 . 020. URL: http : //www.sciencedirect.com/science/article/pii/S0040195115000657.

Hales, A.L. (1969). "A seismic discontinuity in the lithosphere". In: Earth and Planetary Science Letters 7.1, pp. 44 -46. ISSN: 0012-821X. DOI: https://doi.org/10.1016/0012-821X (69)900090. URL: http://www.sciencedirect.com/science/article/pii/0012821X69900090.

Herrero-Bervera, Emilio et al. (2011). "Rock Magnetic Characterization Through an Intact Sequence of Oceanic Crust, IODP Hole 1256D". In: The Earth's Magnetic Interior. Ed. by Eduard Petrovský et al. Dordrecht: Springer Netherlands, pp. 153-168. ISBN: 978-94-007-0323-0. DOI: 10.1007/97894-007-0323-0_11. URL: https://doi.org/10.1007/978-94-007-0323-0_11.

Hijmans, Robert J. et al. (2005). "Very high resolution interpolated climate surfaces for global land areas". In: International Journal of Climatology 25.15, pp. 1965-1978. DOI: 10.1002/joc. 1276. eprint: https : //rmets. onlinelibrary . wiley.com/doi/pdf/10.1002/joc.1276. URL: https: //rmets.onlinelibrary.wiley.com/doi/abs/10.1002/joc.1276.

Jammes, Suzon et al. (2009). "Tectonosedimentary evolution related to extreme crustal thinning ahead of a propagating ocean: Example of the western Pyrenees". In: Tectonics 28.4. DOI: 10. 1029 / 2008TC002406. eprint: https : / / agupubs . onlinelibrary . wiley . com / doi / pdf / 10 . 1029/2008TC002406. URL: https : //agupubs . onlinelibrary . wiley . com/doi/abs/10 . 1029 / 2008 TC002406.

Julivert M., Fontboté J. M. Ribeiro A. Nabais-Conde L. E. (1972). Mapa Tectónico de la Península Ibérica y Baleares 1:100000. Map. IGME.

Julià, Jordi and Jorge Mejía (Jan. 2004). "Thickness and Vp/Vs Ratio Variation in the Iberian Crust". In: Geophysical Journal International 156.1, pp. 59-72. ISSN: 0956-540X. DOI: 10.1111/j.1365246X.2004.02127.x. eprint: https://academic.oup.com/gji/article-pdf/156/1/59/6040298/ 156-1-59.pdf. URL: https://doi.org/10.1111/j.1365-246X. 2004 .02127 .x. 
Kennett, B. L. N., E. R. Engdahl, and R. Buland (July 1995). "Constraints on seismic velocities in the Earth from traveltimes". In: Geophysical Journal International 122.1, pp. 108-124. ISSN: 0956-540X. DOI: $10.1111 / j .1365-246 X$.1995.tb03540.x. eprint: http://oup.prod.sis.lan/gji/articlepdf / 122 / 1 / 108/1543667 / 122-1-108 . pdf. URL: https : / / doi . org / 10 . $1111 / \mathrm{j}$. 1365246X.1995.tb03540.x.

Kennett, B. L. N., E. Saygin, and M. Salmon (2015). "Stacking autocorrelograms to map Moho depth with high spatial resolution in southeastern Australia”. In: Geophysical Research Letters 42.18, pp. 7490-7497. DOI: $10.1002 / 2015 g 1065345$.

Kennett, B.L.N. (2015). "Lithosphere-asthenosphere P-wave reflectivity across Australia". In: Earth and Planetary Science Letters 431, pp. 225-235. DOI: 10.1016/j.eps1.2015.09.039.

Laske G., Masters G. Ma Z. Pasyanos M. (2013). "Update on CRUST1.0 - A 1-degree Global Model of Earths Crust". In: EGU General Assembly. EGU.

Leprêtre, A. et al. (2013). "Multiphased tectonic evolution of the Central Algerian margin from combined wide-angle and reflection seismic data off Tipaza,Algeria". In: Journal of Geophysical Research: Solid Earth 118.8, pp. 3899-3916. DOI: 10 . 1002 / jgrb. 50318. eprint: https : // agupubs . onlinelibrary . wiley.com/doi/pdf/10.1002/jgrb.50318. URL: https : //agupubs . onlinelibrary.wiley.com/doi/abs/10.1002/jgrb.50318.

Levander A., Bezada M. J. Niu F. Humphreys-E. D. Palomeras I. Thurner-S. M. (2014). "Subductiondriven recycling of continental margin lithosphere". In: Nature 515.7526, pp. 253-256. DOI: https: //doi.org/10.1038/nature13878.

Li, Chun-Feng and Jian Wang (2016). "Variations in Moho and Curie depths and heat flow in Eastern and Southeastern Asia". In: Marine Geophysical Research 37.1, pp. 1-20. ISSN: 1573-0581. DOI: 10.1007/s11001-016-9265-4. URL: https://doi.org/10.1007/s11001-016-9265-4.

Li, Chun-Feng et al. (2013). "Thermal evolution of the North Atlantic lithosphere: New constraints from magnetic anomaly inversion with a fractal magnetization model". In: Geochemistry, Geophysics, Geosystems 14.12, pp. 5078-5105. DOI: 10.1002/2013GC004896. eprint: https://agupubs . onlinelibrary.wiley.com/doi/pdf/10.1002/2013GC004896. URL: https://agupubs.onlinelibrary . wiley.com/doi/abs/10.1002/2013GC004896.

Li C.F., Lu Y. Wang J. (2017). "A global reference model of Curie-point depths based on EMAG2". In: Scientific Reports 7. DOI: https://doi.org/10.1038/srep45129.

Mancilla, Flor de Lis and Jordi Diaz (2015). "High resolution Moho topography map beneath Iberia and Northern Morocco from receiver function analysis". In: Tectonophysics 663. Special issue on Iberia geodynamics: An integrative approach from the Topo-Iberia framework, pp. 203 -211. ISSN: 0040-1951. DOI: https : / / doi . org/10 . 1016/j . tecto . 2015 . 06 . 017. URL: http : //www . sciencedirect.com/science/article/pii/S0040195115003224.

Martínez Catalán, José R. (2011). "Are the oroclines of the Variscan belt related to late Variscan strikeslip tectonics?" In: Terra Nova 23.4, pp. 241-247. DOI: 10.1111/j.1365-3121.2011.01005.x.

- (2012). "The Central Iberian arc, an orocline centered in the Iberian Massif and some implications for the Variscan belt". In: International Journal of Earth Sciences 101.5, pp. 1299-1314. ISSN: 14373262. DOI: 10.1007/s00531-011-0715-6. URL: https://doi.org/10.1007/s00531-011-0715-6. 
Martínez Catalán, José R. et al. (2009). "A rootless suture and the loss of the roots of a mountain chain: The Variscan belt of NW Iberia". In: Comptes Rendus Geoscience 341.2. Mécanique de l'orogénie varisque : Une vision moderne de le recherche dans le domaine de l'orogénie, pp. 114 -126. ISSN: 1631-0713. DOI: https : // doi .org/10 . 1016/j . crte . 2008 .11 .004. URL: http: //www.sciencedirect.com/science/article/pii/S1631071308002691.

Martínez Catalán, José R. et al. (2014). "The late Variscan HT/LP metamorphic event in NW and Central Iberia: relationships to crustal thickening, extension, orocline development and crustal evolution". In: Geological Society, London, Special Publications 405.1, pp. 225-247. ISSN: 0305-8719. DOI: 10.1144/SP405.1. eprint: https://sp. lyellcollection.org/content/405/1/225 . full .pdf. URL: https://sp.lyellcollection.org/content/405/1/225.

Martínez Catalán, José R. et al. (2018). "Magnetic Anomalies in Extensional Detachments: The Xistral Tectonic Window of the Lugo Dome (NW Spain)". In: Tectonics 37.11, pp. 4261-4284. Dor: 10 . 1029/2017TC004887. eprint: https : / / agupubs . onlinelibrary . wiley . com/doi/pdf / 10 . 1029/2017TC004887. URL: https : / /agupubs . onlinelibrary . wiley · com/doi/abs/10 . 1029/ 2017 TC004887.

Martínez Poyatos, D. et al. (2012). "Imaging the crustal structure of the Central Iberian Zone (Variscan Belt): The ALCUDIA deep seismic reflection transect". In: Tectonics 31.3. DOI: 10 . 1029 / 2011TC002995. eprint: https : / / agupubs . onlinelibrary . wiley . com / doi / pdf / 10 . 1029/2011TC002995. URL: https : //agupubs . onlinelibrary . wiley · com/doi/abs/10 . 1029/ $2011 \mathrm{TC} 002995$.

Matte, P. (2001). "The Variscan collage and orogeny (480290 Ma) and the tectonic definition of the Armorica microplate: a review". In: Terra Nova 13.2, pp. 122-128. DOI: 10 . 1046/ j . 13653121 . 2001.00327.x. eprint: https://onlinelibrary.wiley.com/doi/pdf/10.1046/j . 13653121 . 2001 .00327 . x. URL: https : //onlinelibrary . wiley . com/doi/abs/10 . 1046/j . 1365$3121.2001 .00327 . \mathrm{x}$.

Maus, S. et al. (2009). "EMAG2: A 2arc min resolution Earth Magnetic Anomaly Grid compiled from satellite, airborne, and marine magnetic measurements". In: Geochemistry, Geophysics, Geosystems 10.8. DOI: 10 .1029/2009GC002471. eprint: https ://agupubs . onlinelibrary . wiley . com/doi/ pdf/10.1029/2009GC002471. URL: https://agupubs.onlinelibrary.wiley.com/doi/abs/10. 1029/2009GC002471.

Maus, Stefan and Vijay Dimri (Jan. 1996). "Depth estimation from the scaling power spectrum of potential fields?" In: Geophysical Journal International 124.1, pp. 113-120. ISSN: 0956-540X. DOI: 10.1111/j.1365-246X . 1996. tb06356 .x. eprint: http://oup.prod.sis .lan/gji/articlepdf / 124/1/113/6092559/124-1-113 . pdf. URL: https : / / doi . org/10 . 1111/j . 1365246X.1996.tb06356.x.

Maus, Stefan, Dan Gordon, and Derek Fairhead (Apr. 1997). "Curie-temperature depth estimation using a self-similar magnetization model". In: Geophysical Journal International 129.1, pp. 163-168. ISSN: 0956-540X. DOI: 10.1111/j.1365-246X.1997.tb00945.x. eprint: http://oup.prod.sis . lan/gji/article-pdf/129/1/163/6063739/129-1-163.pdf. URL: https://doi.org/10.1111/ j.1365-246X.1997.tb00945.x. 
Muñoz-Martín, A. et al. (2010). "Spectral analysis of the gravity and elevation along the western AfricaEurasia plate tectonic limit: Continental versus oceanic lithospheric folding signals". In: Tectonophysics 495.3, pp. 298 -314. ISSN: 0040-1951. DOI: https : // doi .org/10 . $1016 /$ j . tecto . 2010 . 09 .036. URL: http : / / wWw . sciencedirect . com / science/article / pii / S0040195110004087.

Nakata, Nori, Roel Snieder, and Michael Behm (2014). "Body-wave interferometry using regional earthquakes with multidimensional deconvolution after wavefield decomposition at free surface". In: Geophysical Journal International 199.2, pp. 1125-1137. DOI: 10.1093/gji/ggu316.

Nishitsuji, Yohei et al. (2016a). "Reflection imaging of aseismic zones of the Nazca slab by global-phase seismic interferometry". In: Interpretation 4.3, SJ1-SJ16. DOI: 10.1190/INT-2015-0225.1. eprint: https : //doi .org/10 .1190/INT-2015-0225 .1. URL: https : //doi .org/10 . 1190/INT-20150225.1.

Nishitsuji, Yohei et al. (2016b). "Reflection imaging of the Moon's interior using deep-moonquake seismic interferometry". In: Journal of Geophysical Research: Planets 121.4, pp. 695-713. DOI: 10 . 1002 / 2015JE004975. eprint: https : / / agupubs . onlinelibrary . wiley . com/doi / pdf / 10 . 1002/2015JE004975. URL: https : //agupubs . onlinelibrary . wiley . com/doi/abs/10 . 1002 / 2015JE004975.

Obermann, A. et al. (2014). "Seismic noise correlations to image structural and mechanical changes associated with theMw7.9 2008 Wenchuan earthquake". In: Journal of Geophysical Research: Solid Earth 119.4, pp. 3155-3168. DOI: 10.1002/2013jb010932.

Okubo, Y. et al. (1985). "Curie point depths of the Island of Kyushu and surrounding areas, Japan". In: GEOPHYSICS 50.3, pp. 481-494. DOI: 10.1190/1.1441926. URL: https://doi.org/10.1190/ 1.1441926 .

OReilly, W (1976). "Magnetic minerals in the crust of the Earth". In: Reports on Progress in Physics 39.9, pp. 857-908. DOI: 10.1088/0034-4885/39/9/002. URL: https://doi .org/10.1088\%2F0034$4885 \% 2 \mathrm{~F} 39 \% 2 \mathrm{~F} 9 \% 2 \mathrm{~F} 002$.

Oren, Can and Robert L. Nowack (2016). "Seismic body-wave interferometry using noise autocorrelations for crustal structure". In: Geophysical Journal International 208.1, pp. 321-332. DOI: 10.1093/gji/ggw394.

Osako, M., A. Yoneda, and E. Ito (2010). "Thermal diffusivity, thermal conductivity and heat capacity of serpentine (antigorite) under high pressure". In: Physics of the Earth and Planetary Interiors 183.1. Special Issue on Deep Slab and Mantle Dynamics, pp. 229 -233. ISSN: 0031-9201. DoI: https: //doi .org/10 . 1016/j .pepi . 2010.07 .005. URL: http://www . sciencedirect . com/science/ article/pii/S0031920110001470.

Palomeras, I. et al. (2009). "Nature of the lithosphere across the Variscan orogen of SW Iberia: Dense wide-angle seismic reflection data". In: Journal of Geophysical Research: Solid Earth 114.B2. DOI: 10 . 1029/2007JB005050. eprint: https : / / agupubs . onlinelibrary . wiley . com/doi / pdf / 10 . 1029/2007JB005050. URL: https : //agupubs . onlinelibrary . wiley . com/doi/abs/10 . 1029/ 2007 JB005050. 
Palomeras, I. et al. (2011). "Geophysical model of the lithosphere across the Variscan Belt of SWIberia: Multidisciplinary assessment". In: Tectonophysics 508.1. SEISMIX 2008, Active and passive plate margins and subduction zones, pp. 42 -51. ISSN: 0040-1951. DOI: https://doi . org/10. 1016/j . tecto . 2010 .07 .010. URL: http://www. sciencedirect.com/science/article/pii/ S0040195110002982.

Palomeras, I. et al. (2014). "Finite-frequency Rayleigh wave tomography of the western Mediterranean: Mapping its lithospheric structure". In: Geochemistry, Geophysics, Geosystems 15.1, pp. 140-160. DOI: 10 . 1002/2013GC004861. eprint: https : //agupubs . onlinelibrary . wiley . com/doi/pdf/ 10.1002/2013GC004861. URL: https://agupubs.onlinelibrary.wiley.com/doi/abs/10.1002/ 2013 GC004861.

Palomeras, I. et al. (2017). "Lithospheric structure of Iberia and Morocco using finite-frequency Rayleigh wave tomography from earthquakes and seismic ambient noise". In: Geochemistry, Geophysics, Geosystems 18.5, pp. 1824-1840. DOI: 10.1002/2016GC006657. eprint: https://agupubs . onlinelibrary .wiley.com/doi/pdf/10.1002/2016GC006657. URL: https://agupubs .onlinelibrary . wiley.com/doi/abs/10.1002/2016GC006657.

Pedrera, A. et al. (2016). "Serpentinization-driven extension in the Ronda mantle slab (Betic Cordillera, S. Spain)". In: Gondwana Research 37, pp. 205 -215. ISSN: 1342-937X. DOI: https://doi .org/ 10.1016/j.gr.2016.05.008. URL: http://www.sciencedirect.com/science/article/pii/ S1342937X16301034.

Pérez-Estaún, A. et al. (1994). "Crustal structure of the external variscides in northwest spain from deep seismic reflection profiling". In: Tectonophysics 232.1-4, pp. 91-118. DOI: 10 . 1016/00401951 (94) 90078-7.

Pous, J. et al. (2012). "Análisis de la estructura alpina de la corteza del centro de la Península Ibérica: Una sección Magneto-Telúrica a través del Sistema Central (Sierra de Gredos)". In: Geo-Temas 13, pp. 4-8.

Pulgar, J. A. et al. (1995). "The ESCIN-2 deep seismic reflection profile: a traverse across the Cantabrian Mountains and adjacent Duero basin". In: Revista Sociedad Geológica de España 8, pp. 383-394.

Pulgar, J.A. et al. (1996). "Seismic image of the Cantabrian Mountains in the western extension of the Pyrenees from integrated ESCIN reflection and refraction data". In: Tectonophysics 264.1-4, pp. 1-19. DOI: 10.1016/s0040-1951 (96)00114-x.

Pérez-Estaún, A., J.R. Martinez-Catalán, and F. Bastida (1991). "Crustal thickening and deformation sequence in the footwall to the suture of the Variscan belt of northwest Spain". In: Tectonophysics 191.3. Deformation and Plate Tectonics, pp. 243 -253. ISSN: 0040-1951. DOI: https://doi .org/ 10 . 1016/0040-1951 (91) 90060-6. URL: http://www . sciencedirect . com/science/article/ pii/0040195191900606.

Quintana, L., J.A. Pulgar, and J.L. Alonso (2015). "Displacement transfer from borders to interior of a plate: A crustal transect of Iberia". In: Tectonophysics 663. Special issue on Iberia geodynamics: An integrative approach from the Topo-Iberia framework, pp. 378 -398. ISSN: 0040-1951. DOI: https: 
//doi.org/10.1016/j.tecto.2015.08.046. URL: http://www . sciencedirect.com/science/ article/pii/S0040195115004813.

Ravat, D., P. Morgan, and A.R. Lowry (Aug. 2016). "Geotherms from the temperature-depthconstrained solutions of 1-D steady-state heat-flow equation". In: Geosphere 12.4, pp. 1187-1197. ISSN: 1553040X. DOI: 10 .1130/GES01235 . 1. eprint: https : //pubs . geoscienceworld . org/geosphere/ article-pdf/12/4/1187/3334863/1187.pdf. URL: https://doi.org/10.1130/GES01235.1.

Ravat, D. et al. (May 2007). "A study of spectral methods of estimating the depth to the bottom of magnetic sources from near-surface magnetic anomaly data". In: Geophysical Journal International 169.2, pp. 421-434. ISSN: 0956-540X. DOI: 10.1111/j.1365-246X . 2007 .03305 . x. eprint: http : // oup . prod. sis. lan/gji/article-pdf/169/2/421/5904574/169-2-421.pdf. URL: https : //doi.org/10.1111/j.1365-246X.2007.03305.x.

Reston, T.J. (2009). "The structure, evolution and symmetry of the magma-poor rifted margins of the North and Central Atlantic: A synthesis". In: Tectonophysics 468.1. Role of magmatism in continental lithosphere extension continental lithosphere extension, pp. 6 -27. ISSN: 0040-1951. DOI: https : //doi.org/10.1016/j.tecto.2008.09.002. URL: http://www. sciencedirect. com/ science/article/pii/S0040195108004216.

Romero, Paula and Martin Schimmel (2018). "Mapping the Basement of the Ebro Basin in Spain With Seismic Ambient Noise Autocorrelations". In: Journal of Geophysical Research: Solid Earth 123.6, pp. 5052-5067. DOI: 10.1029/2018JB015498. eprint: https : //agupubs . onlinelibrary . wiley.com/doi/pdf/10 . 1029/2018JB015498. URL: https : //agupubs . onlinelibrary . wiley . com/doi/abs/10.1029/2018JB015498.

Rosenbaum, Gideon, Gordon S. Lister, and Cécile Duboz (2002). "Relative motions of Africa, Iberia and Europe during Alpine orogeny". In: Tectonophysics 359.1, pp. 117 -129. ISSN: 0040-1951. DOI: https : //doi .org/10.1016/S0040-1951(02) 00442-0. URL: http://www . sciencedirect . com/ science/article/pii/S0040195102004420.

Ruigrok, Elmer and Kees Wapenaar (2012). "Global-phase seismic interferometry unveils P-wave reflectivity below the Himalayas and Tibet". In: Geophysical Research Letters 39.11. DOI: 10 . 1029 / 2012GL051672. eprint: https : / / agupubs . onlinelibrary . wiley . com / doi / pdf / 10 . 1029/2012GL051672. URL: https : //agupubs . onlinelibrary . wiley . com/doi/abs/10 . 1029/ 2012GL051672.

Salem, Ahmed et al. (2014). "Depth to Curie temperature across the central Red Sea from magnetic data using the de-fractal method". In: Tectonophysics 624-625. Crustal and mantle sources of magnetic anomalies, pp. 75 -86. ISSN: 0040-1951. DOI: https://doi.org/10.1016/j.tecto.2014.04. 027. URL: http://www.sciencedirect.com/science/article/pii/S004019511400208X.

Schimmel, M. and J. Gallart (2007). "Frequency-dependent phase coherence for noise suppression in seismic array data". In: Journal of Geophysical Research: Solid Earth 112.B4. DOI: 10. $1029 /$ 2006JB004680. eprint: https : / / agupubs . onlinelibrary . wiley . com / doi / pdf / 10 . 1029 / 2006JB004680. URL: https : //agupubs . onlinelibrary.wiley.com/doi/abs/10.1029/2006JB004680.

Schimmel, M., E. Stutzmann, and J. Gallart (2011). "Using instantaneous phase coherence for signal extraction from ambient noise data at a local to a global scale". In: Geophysical Journal International 
184.1, pp. 494-506. DOI: 10.1111/j.1365-246X.2010.04861.x. eprint: https://onlinelibrary. wiley . com/doi/pdf/10.1111/j.1365-246X . 2010.04861 x. URL: https : //onlinelibrary . wiley.com/doi/abs/10.1111/j.1365-246X.2010.04861.x.

Schimmel, M., E. Stutzmann, and S. Ventosa (2018). "Low-Frequency Ambient Noise Autocorrelations: Waveforms and Normal Modes". In: Seismological Research Letters 89.4, pp. 1488-1496. DOI: 10. $1785 / 0220180027$.

Schimmel, Martin (Oct. 1999). "Phase cross-correlations: Design, comparisons, and applications". In: Bulletin of the Seismological Society of America 89.5, pp. 1366-1378. ISSN: 0037-1106. eprint: https: //pubs.geoscienceworld.org/bssa/article-pdf/89/5/1366/2709877/BSSA0890051366.pdf.

Schimmel, Martin and Hanneke Paulssen (1997). "Noise reduction and detection of weak, coherent signals through phase-weighted stacks". In: Geophysical Journal International 130.2, pp. 497-505. DOI: $10.1111 / \mathrm{j} .1365-246 \mathrm{x} .1997 . \mathrm{tb} 05664 . \mathrm{x}$.

Schuster, G. T. et al. (2004). "Interferometric/daylight seismic imaging". In: Geophysical Journal International 157.2, pp. 838-852. DOI: 10.1111/j.1365-246x.2004.02251.x.

Sens-Schönfelder, C. and U. Wegler (2006). "Passive image interferometry and seasonal variations of seismic velocities at Merapi Volcano, Indonesia". In: Geophysical Research Letters 33.21. DOI: 10 . 1029/2006GL027797. eprint: https : / / agupubs . onlinelibrary . wiley . com/doi /pdf / 10 . 1029/2006GL027797. URL: https : / /agupubs . onlinelibrary . wiley . com/doi/abs/10 . 1029/ 2006 GL027797.

Simancas, J. F. et al. (2003). "Crustal structure of the transpressional Variscan orogen of SW Iberia: SW Iberia deep seismic reflection profile (IBERSEIS)". In: Tectonics 22.6. DOI: 10.1029/2002TC001479. eprint: https : / / agupubs . onlinelibrary . wiley . com/doi/pdf / 10 . 1029/2002TC001479. URL: https://agupubs. onlinelibrary.wiley.com/doi/abs/10.1029/2002TC001479.

Simancas, J. F. et al. (2013). "A seismic geotraverse across the Iberian Variscides: Orogenic shortening, collisional magmatism, and orocline development". In: Tectonics 32.3, pp. 417-432. DOI: 10.1002/ tect . 20035. eprint: https : / /agupubs . onlinelibrary . wiley . com/doi/pdf/10 . 1002/tect. 20035. URL: https://agupubs. onlinelibrary.wiley.com/doi/abs/10.1002/tect. 20035.

Snieder, Roel (2004). "Extracting the Green's function from the correlation of coda waves: A derivation based on stationary phase". In: Physical Review E 69.4. DOI: 10.1103/physreve.69.046610.

Snieder, Roel, Evert Slob, and Kees Wapenaar (2010). "Lagrangian Greens function extraction, with applications to potential fields, diffusion and acoustic waves". In: New Journal of Physics 12.6, p. 063013. DOI: 10 .1088/1367-2630/12/6/063013. URL: https://doi . org/10 . 1088\%2F1367$2630 \% 2 \mathrm{~F} 12 \% 2 \mathrm{~F} 6 \% 2 \mathrm{~F} 063013$.

Snieder, Roel and (2007). "Extracting the Greens function of attenuating heterogeneous acoustic media from uncorrelated waves". In: The Journal of the Acoustical Society of America 121.5, pp. 26372643. DOI: $10.1121 / 1.2713673$. URL: https://doi.org/10.1121/1.2713673.

Stockwell, R. G., L. Mansinha, and R. P. Lowe (1996). "Localization of the complex spectrum: the S transform". In: IEEE Transactions on Signal Processing 44.4, pp. 998-1001.

Suriñach, E. and R. Vegas (1988). "Lateral inhomogeneities of the Hercynian crust in central Spain". In: Physics of the Earth and Planetary Interiors 51.1, pp. 226 -234. ISSN: 0031-9201. DOI: https: 
//doi.org/10.1016/0031-9201(88)90049-0. URL: http://www.sciencedirect. com/science/ article/pii/0031920188900490.

Syracuse, Ellen M., Peter E. van Keken, and Geoffrey A. Abers (2010). "The global range of subduction zone thermal models". In: Physics of the Earth and Planetary Interiors 183.1. Special Issue on Deep Slab and Mantle Dynamics, pp. 73 -90. ISSN: 0031-9201. DoI: https://doi .org/10. 1016/j ·pepi . 2010 .02 .004. URL: http: //www . sciencedirect . com/science/article/pii/ S0031920110000300.

Tanaka, A, Y Okubo, and O Matsubayashi (1999). "Curie point depth based on spectrum analysis of the magnetic anomaly data in East and Southeast Asia". In: Tectonophysics 306.3, pp. 461 470. ISSN: 0040-1951. DOI: https : // doi .org/10 . 1016/S0040-1951 (99) 00072-4. URL: http : //www.sciencedirect.com/science/article/pii/S0040195199000724.

Taylor, George, Sebastian Rost, and Gregory Houseman (2016). "Crustal imaging across the North Anatolian Fault Zone from the autocorrelation of ambient seismic noise". In: Geophysical Research Letters 43.6, pp. 2502-2509. DOI: 10 . 1002/2016GL067715. eprint: https : / / agupubs . onlinelibrary.wiley.com/doi/pdf/10.1002/2016GL067715. URL: https://agupubs . onlinelibrary . wiley.com/doi/abs/10.1002/2016GL067715.

Teixell, A. et al. (2018). "Crustal structure and evolution of the Pyrenean-Cantabrian belt: A review and new interpretations from recent concepts and data". In: Tectonophysics 724-725, pp. 146 170. ISSN: 0040-1951. DOI: https : // doi .org/10 . 1016/j . tecto . 2018 . 01 . 009. URL: http : //www.sciencedirect.com/science/article/pii/S0040195118300209.

Teixell, Antonio et al. (2005). "Effects of mantle upwelling in a compressional setting: the Atlas Mountains of Morocco". In: Terra Nova 17.5, pp. 456-461. DOI: 10.1111/j . 1365-3121.2005. 00633.x. eprint: https : //onlinelibrary . wiley . com/doi/pdf/10 .1111/j . 1365-3121 . 2005. 00633 .x. URL: https : //onlinelibrary . wiley . com/doi/abs/10 .1111/j . 1365-3121 . 2005. 00633.x.

Thurner, Sally et al. (2014). "Ongoing lithospheric removal in the western Mediterranean: Evidence from Ps receiver functions and thermobarometry of Neogene basalts (PICASSO project)". In: Geochemistry, Geophysics, Geosystems 15.4, pp. 1113-1127. DOI: 10 . 1002 / 2013GC005124. eprint: https : //agupubs . onlinelibrary . wiley . com/doi/pdf /10 . 1002/2013GC005124. URL: https: //agupubs.onlinelibrary.wiley.com/doi/abs/10.1002/2013GC005124.

Tibuleac, Ileana M. and David von Seggern (Apr. 2012). "Crust-mantle boundary reflectors in Nevada from ambient seismic noise autocorrelations". In: Geophysical Journal International 189.1, pp. 493500. ISSN: 0956-540X. DOI: 10.1111/j.1365-246X . 2011.05336.x. eprint: https : //academic . oup.com/gji/article-pdf/189/1/493/6046199/189-1-493.pdf. URL: https://doi .org/10 . $1111 / \mathrm{j} .1365-246 \mathrm{X} .2011 .05336 . \mathrm{x}$.

Torne, Montserrat et al. (2015). "Crust and mantle lithospheric structure of the Iberian Peninsula deduced from potential field modeling and thermal analysis". In: Tectonophysics 663. Special issue on Iberia geodynamics: An integrative approach from the Topo-Iberia framework, pp. 419 -433. ISSN: 0040-1951. DOI: https : //doi .org/10 .1016/j . tecto . 2015.06 .003. URL: http: //wWw . sciencedirect.com/science/article/pii/S0040195115002954. 
Torné, M. et al. (1992). "Crustal and velocity structure of the Valencia trough (western Mediterranean), Part I. A combined refraction/ wide-angle reflection and near-vertical reflection study". In: Tectonophysics 203.1. Geology and Geophysics of the Valencia through Western Mediterranean, pp. 1 -20. ISSN: 0040-1951. DOI: https : // doi .org/10 . 1016/0040-1951 (92) 90212-0. URL: http://www.sciencedirect.com/science/article/pii/0040195192902120.

Tugend, J. et al. (2014). "Formation and deformation of hyperextended rift systems: Insights from rift domain mapping in the Bay of Biscay-Pyrenees". In: Tectonics 33.7, pp. 1239-1276. DoI: 10. 1002/2014TC003529. eprint: https : / / agupubs . onlinelibrary . wiley . com/doi / pdf / 10 . 1002/2014TC003529. URL: https : / / agupubs . onlinelibrary . wiley . com/doi/abs/10 . 1002/ $2014 \mathrm{TC} 003529$.

Van Wees, J.D. et al. (1998). "Temporal and spatial variations in tectonic subsidence in the Iberian Basin (eastern Spain): inferences from automated forward modelling of high-resolution stratigraphy (PermianMesozoic)". In: Tectonophysics 300.1, pp. 285 -310. ISSN: 0040-1951. DOI: https://doi. org/10 . 1016/S0040-1951 (98) 00244-3. URL: http : / / www . sciencedirect . com/science / article/pii/S0040195198002443.

Vergés, J. et al. (1995). "Eastern Pyrenees and related foreland basins: pre-, syn- and post-collisional crustal-scale cross-sections". In: Marine and Petroleum Geology 12.8, pp. 903-915. DOI: 10.1016/ 0264-8172 (95) 98854-x.

Vergés, Jaume and Manel Fernàndez (2012). "TethysAtlantic interaction along the IberiaAfrica plate boundary: The BeticRif orogenic system". In: Tectonophysics 579. Orogenic processes and structural heritage in Alpine-type mountain belts, pp. 144 -172. ISSN: 0040-1951. DOI: https://doi.org/10. 1016/j . tecto . 2012 .08 . 032. URL: http://www . sciencedirect . com/science/article/pii/ S0040195112005215.

Villaseca, C, L Barbero, and G Rogers (1998). "Crustal origin of Hercynian peraluminous granitic batholiths of Central Spain: petrological, geochemical and isotopic (Sr, Nd) constraints". In: Lithos 43.2, pp. 55 -79. ISSN: 0024-4937. DOI: https://doi .org/10.1016/S0024-4937 (98)00002-4. URL: http://www.sciencedirect.com/science/article/pii/S0024493798000024.

Villaseca C., Ruiz-Martínez V. C. Pérez-Soba-C (2017). "Magnetic susceptibility of Variscan granitetypes of the Spanish central system and the redox state of magma". In: Geologica Acta 15, pp. 379394.

Wang, Jian and Chun-Feng Li (2015). "Crustal magmatism and lithospheric geothermal state of western North America and their implications for a magnetic mantle". In: Tectonophysics 638, pp. 112 -125. ISSN: 0040-1951. DOI: https://doi.org/10.1016/j . tecto 2014.11 .002 . URL: http://www.sciencedirect.com/science/article/pii/S0040195114005800.

Wapenaar, Kees (2003). "Synthesis of an inhomogeneous medium from its acoustic transmission response". In: GEOPHYSICS 68.5, pp. 1756-1759. DOI: 10.1190/1.1620649. eprint: https://doi. org/10.1190/1.1620649. URL: https://doi.org/10.1190/1.1620649.

- (2004). "Retrieving the Elastodynamic Greens Function of an Arbitrary Inhomogeneous Medium by Cross Correlation". In: Physical Review Letters 93.25. DOI: 10.1103/physrevlett.93.254301. 
Wapenaar, Kees and Jacob Fokkema (2006). "Greens function representations for seismic interferometry". In: GEOPHYSICS 71.4, SI33-SI46. DOI: 10.1190/1.2213955. eprint: https://doi.org/ 10.1190/1.2213955. URL: https://doi.org/10.1190/1.2213955.

Wapenaar, Kees et al. (2010). "Tutorial on seismic interferometry: Part 1 - Basic principles and applications". In: GEOPHYSICS 75.5, 75A195-75A209. DOI: 10.1190/1.3457445.

Zeyen, Hermann et al. (2005). "Lithospheric structure under the western African-European plate boundary: A transect across the Atlas Mountains and the Gulf of Cadiz". In: Tectonics 24.2. DOI: 10 . 1029/2004TC001639. eprint: https : / / agupubs . onlinelibrary . wiley . com/doi / pdf / 10 . 1029/2004TC001639. URL: https : / /agupubs . onlinelibrary . wiley . com/doi/abs/10 . 1029/ $2004 \mathrm{TC} 001639$.

Ziegler, Peter (1990). Geological atlas of Western and Central Europe. City: Shell. ISBN: 9789066441255. 
